\title{
Taxonomy and Symbiosis in Associations of Physciaceae and Trebouxia
}

\author{
Dissertation \\ zur \\ Erlangung des Doktorgrades \\ der \\ Biologischen Fakultät der \\ Georg-August Universität \\ Göttingen
}

\author{
Vorgelegt \\ von \\ Gert W.F. Helms \\ aus \\ Tübingen
}

Göttingen 2003 
D7

1. Gutachter: Prof. Dr. T. Friedl

2. Gutachter: Prof. Dr. G. Rambold

Tag der Einreichung: 22. September 2003

Tag der mündlichen Prüfung: 6. November 2003 


\section{Contents}

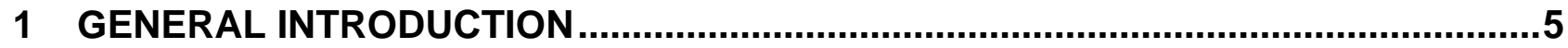

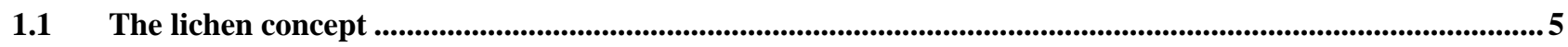

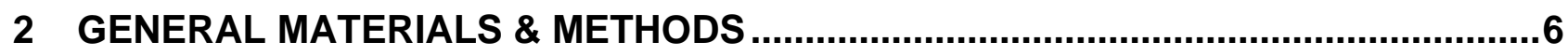

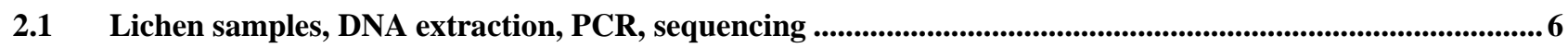

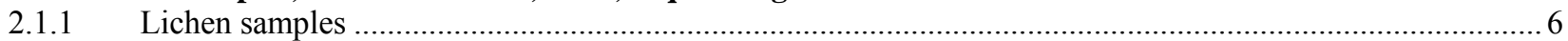

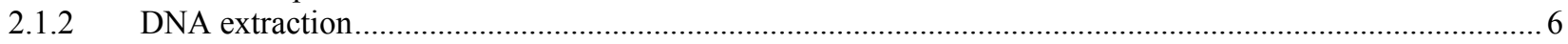

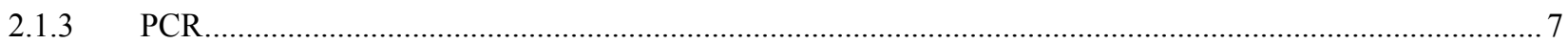

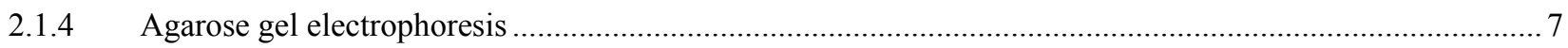

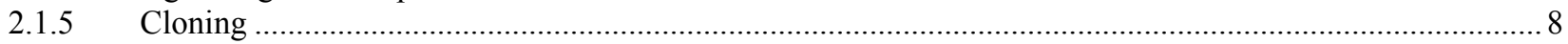

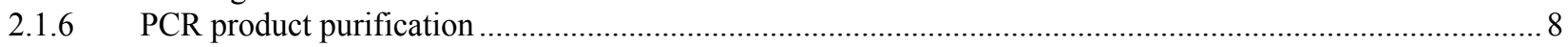

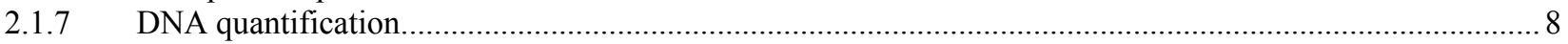

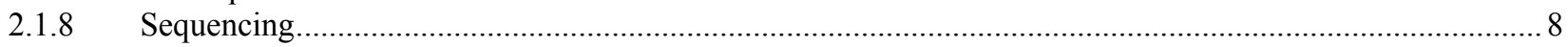

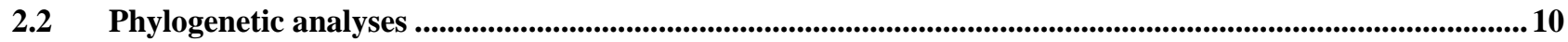

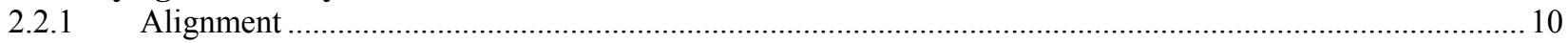

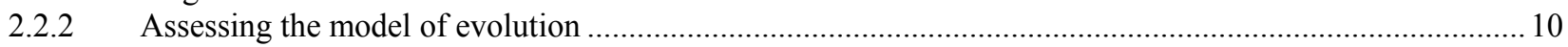

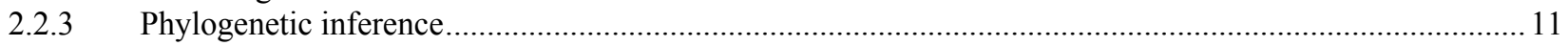

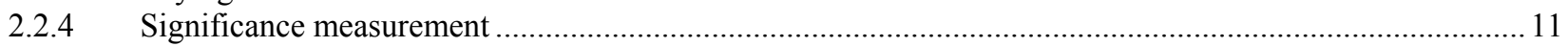

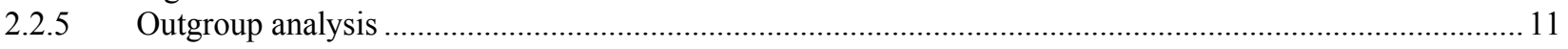

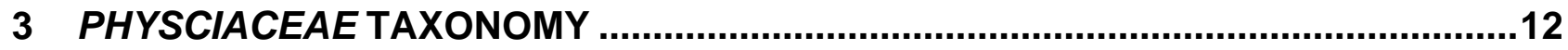

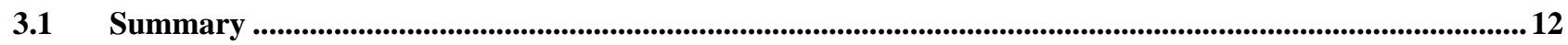

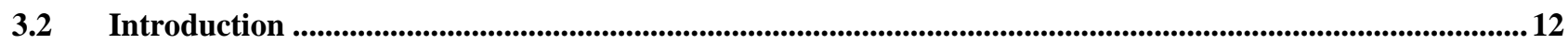

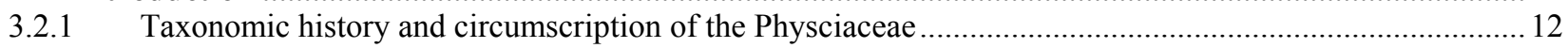

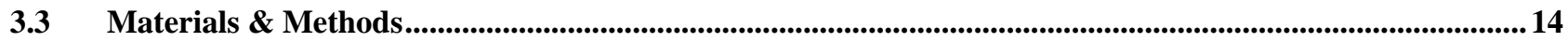

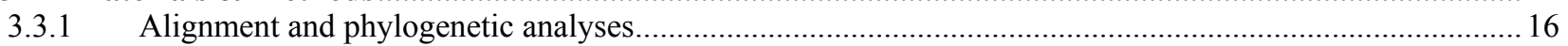

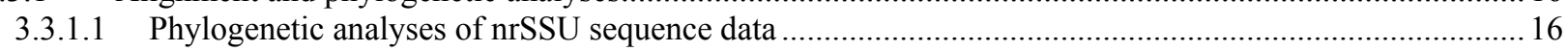

3.3.1.2 Phylogenetic analyses of nrITS sequence data ............................................................................. 18

3.3.2 Testing alternative tree topologies ………………........................................................................ 18

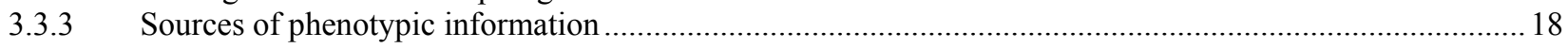

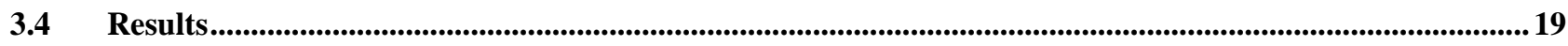

3.4.1 nrSSU analyses, phylogenetic positioning of Physciaceae and Caliciaceae within the Lecanorales ............ 19

3.4.1.1 A phylogenetic marker motive in the Physciaceae/Caliciaceae clade......................................................21

3.4.2 nrITS analyses, phylogentic structure within the Physciaceae................................................................. 21

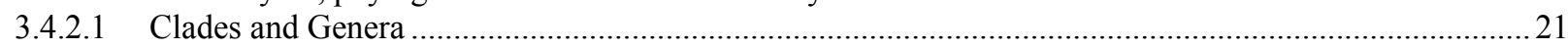

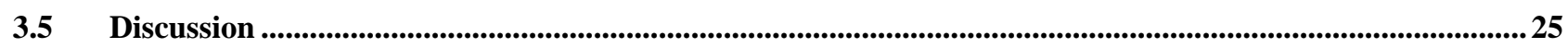

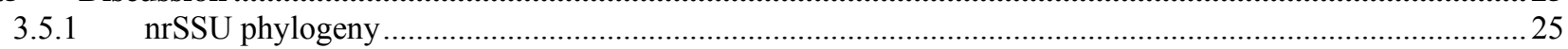

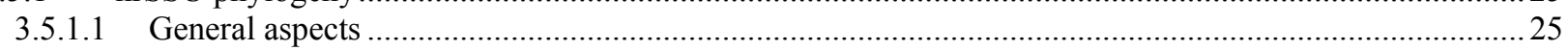

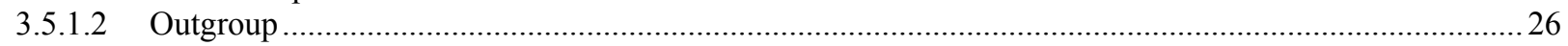

3.5.1.3 Monophyly of a clade uniting Caliciaceae and Physciaceae...............................................................26

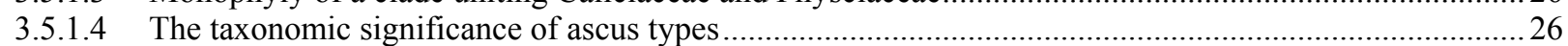

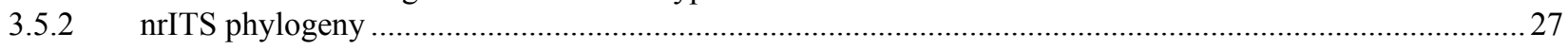

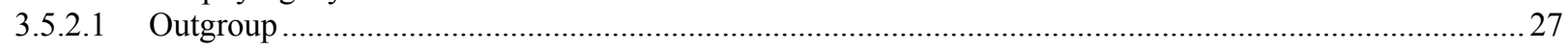

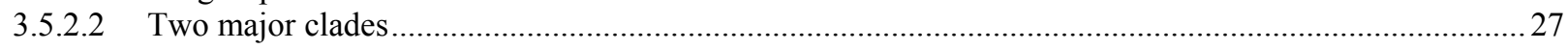

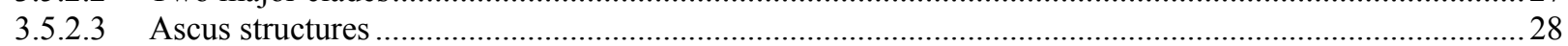




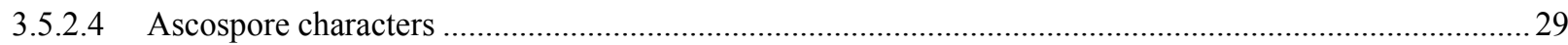

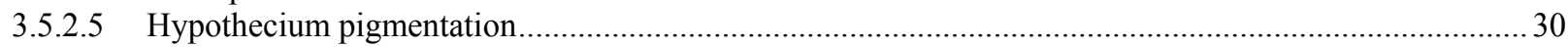

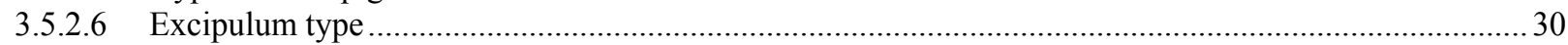

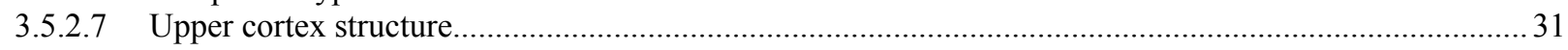

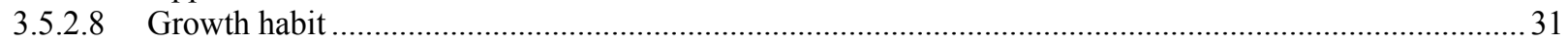

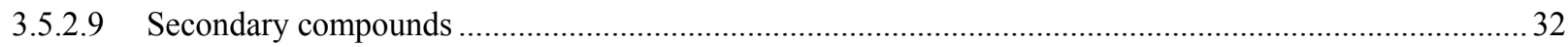

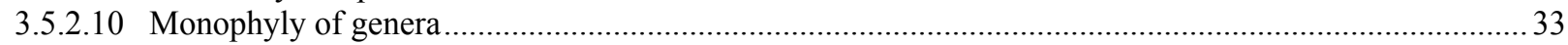

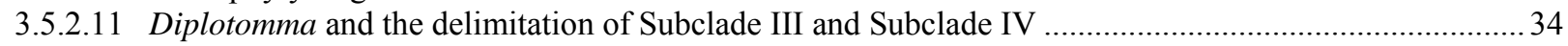

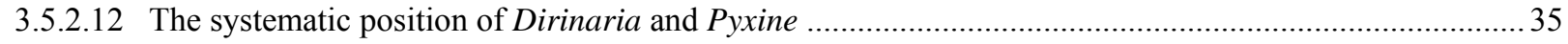

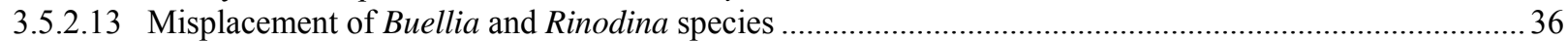

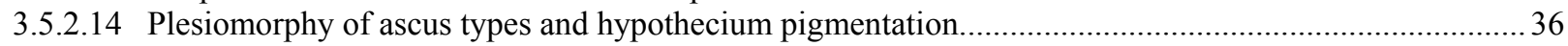

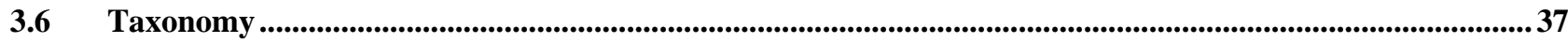

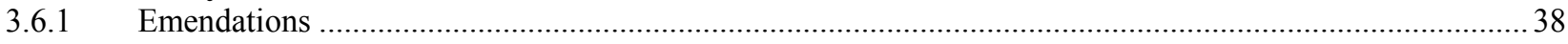

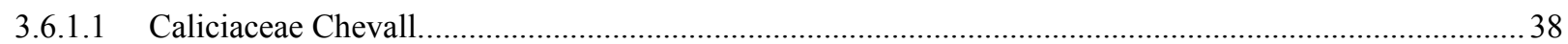

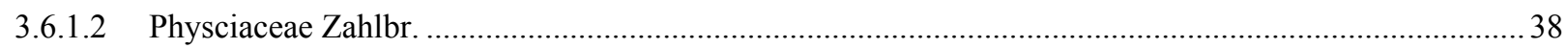

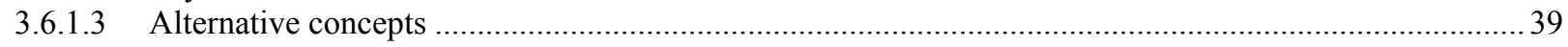

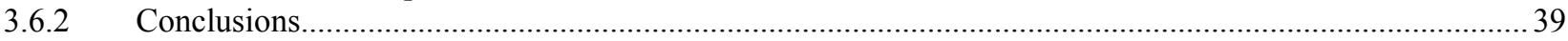

4 PHOTOBIONTS OF THE PHYSCIACEAE AND THE GENUS TREBOUXIA .............40

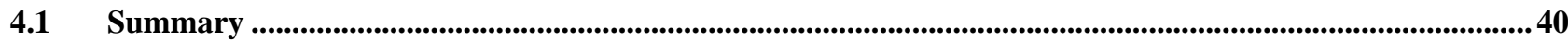

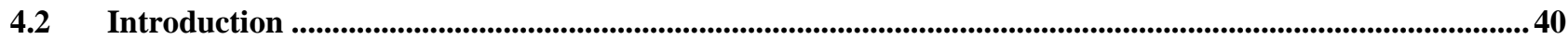

4.2.1 Taxonomy and circumscription of the genus Trebouxia Puymaly ........................................................40

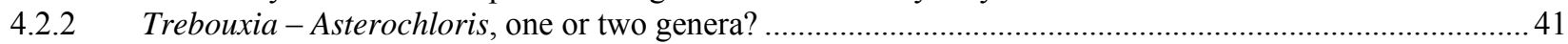

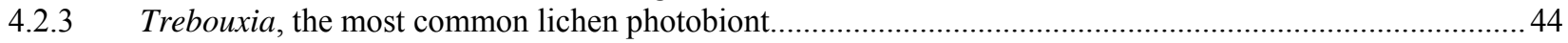

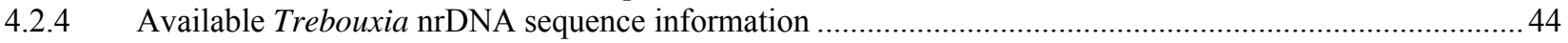

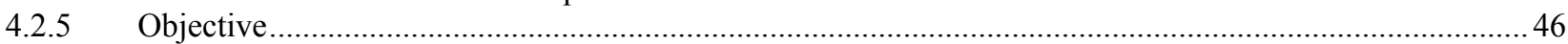

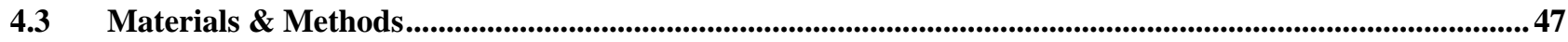

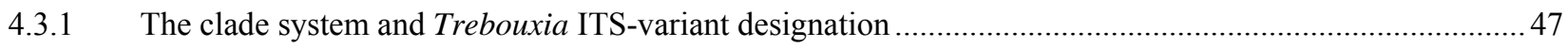

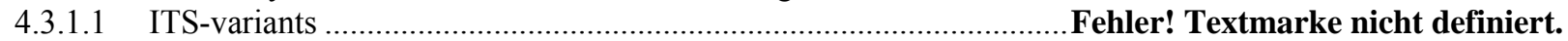

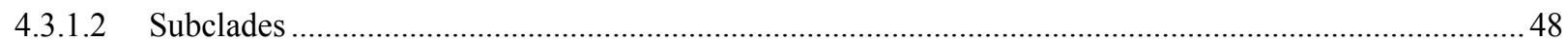

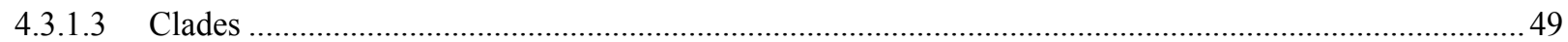

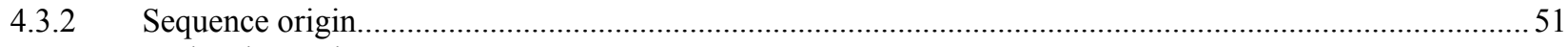

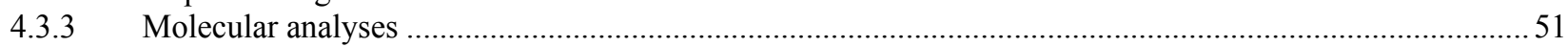

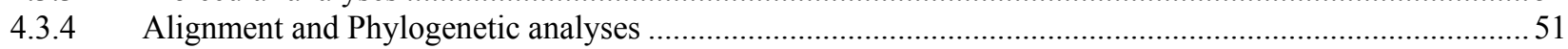

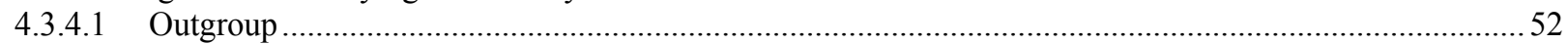

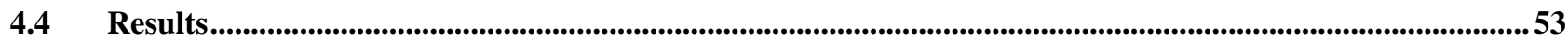

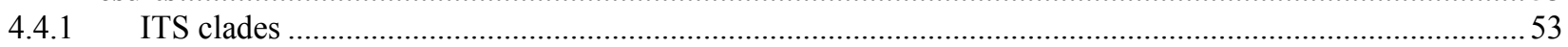

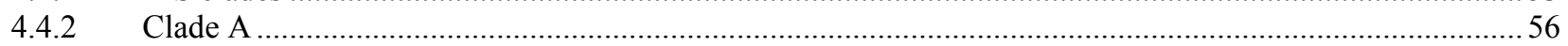

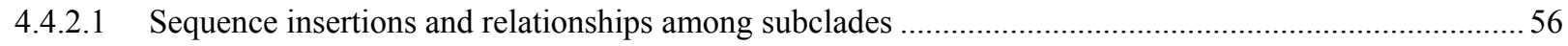

4.4.2.2 Authentic strains, new ITS-variants, subclade support, internal distances ......................................57

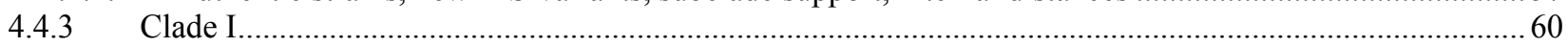

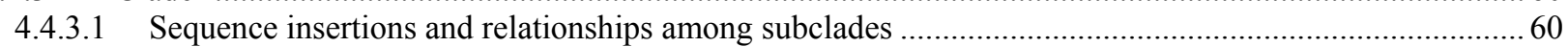

4.4.3.2 Authentic strains, new ITS-variants, subclade support, internal distances .......................................60

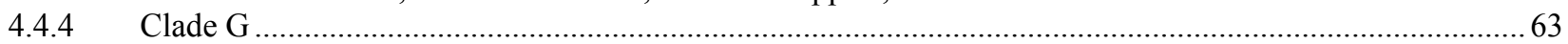

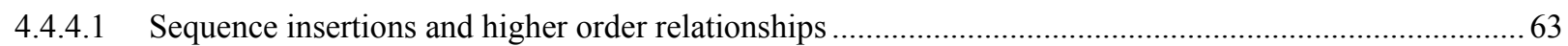

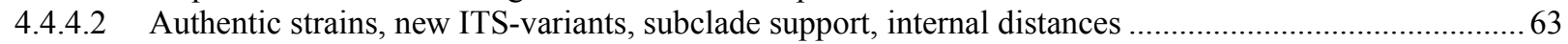

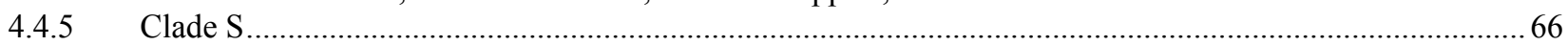

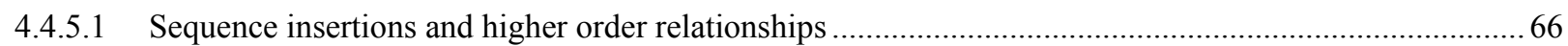

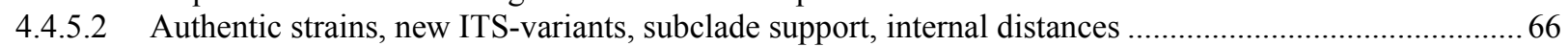




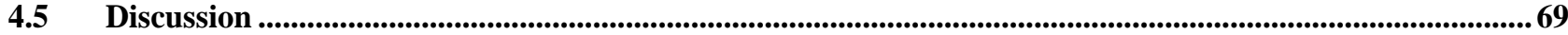

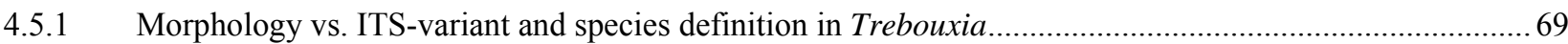

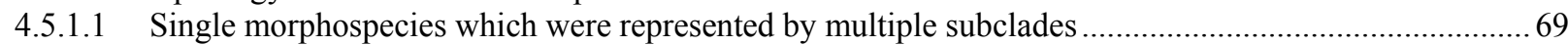

4.5.1.2 Multiple morphospecies which were represented by single subclades or even single ITS-variants ............ 69

4.5.1.3 Relationships among morphospecies which synonymy had been proposed .....................................69

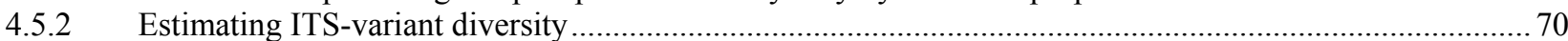

\section{ECOLOGICAL AND EVOLUTIONARY DEPENDENCE IN ASSOCIATIONS OF} PHYSCIACEAE AND TREBOUXIA .......................................................................

5.1 Summary

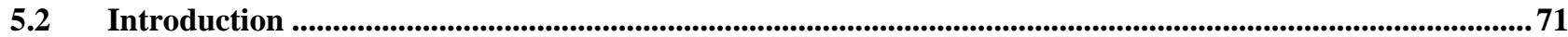

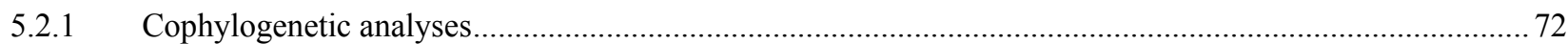

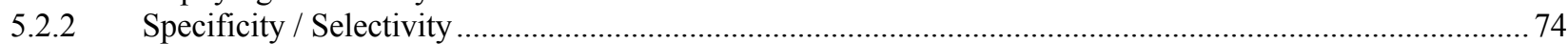

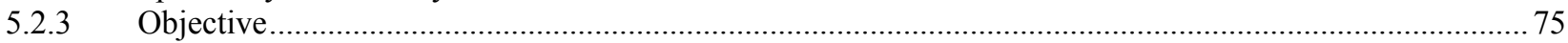

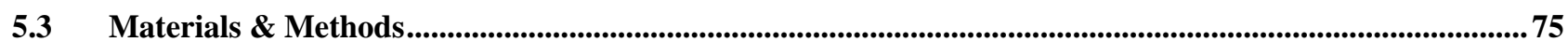

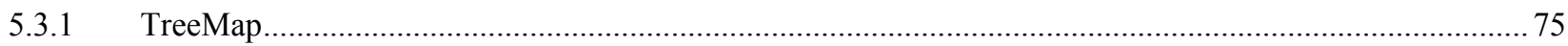

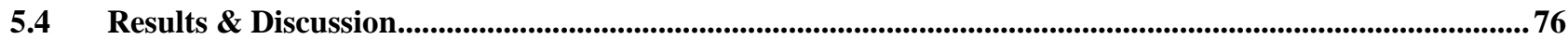

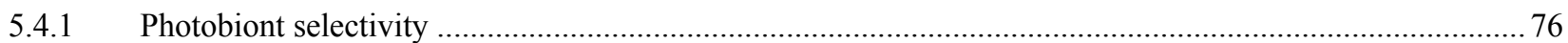

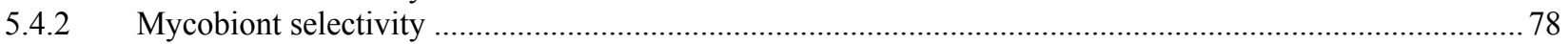

5.4.3 Photobiont heterogeneity in a single specimen, species, or genus of the Physciaceae ............................... 81

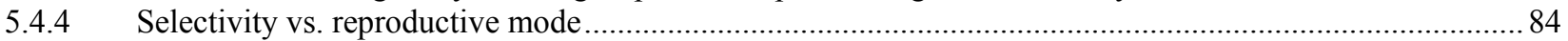

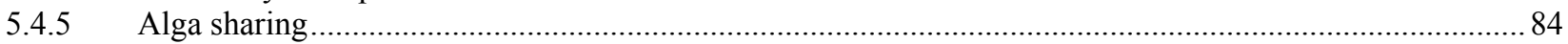

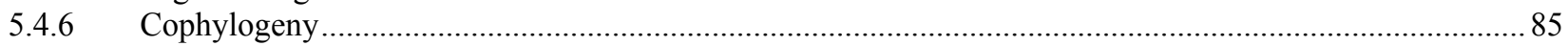

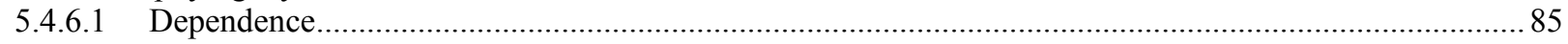

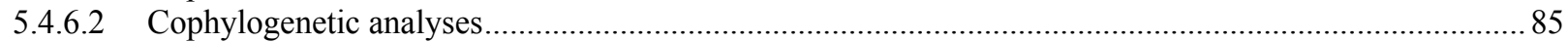

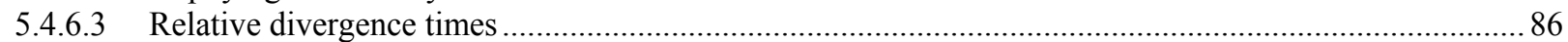

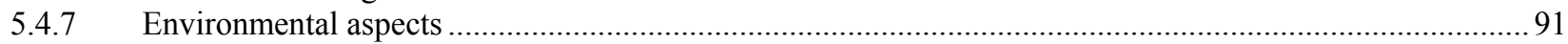

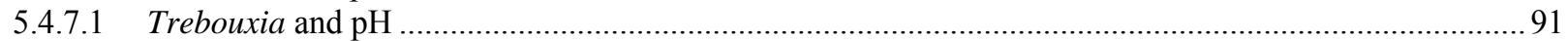

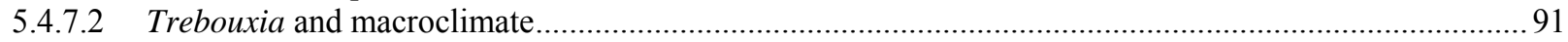

5.4.7.3 Correlating Trebouxia and Physciaceae phylogenies with environmental parameters .................................. 92

5.4.7.4 Photobionts and mycobionts may adapt independently to particular environments ................................92 92

5.4.7.5 Dual propagule formation, a strategy to colonize substrates that are devoid of compatible photobionts 94

5.4.7.6 Single Trebouxia ITS-variants might be ecologically differentiated ...................................................... 94

\section{SYMBIOSIS IN ASSOCIATIONS OF PHYSCIACEAE AND TREBOUXIA ...................97}

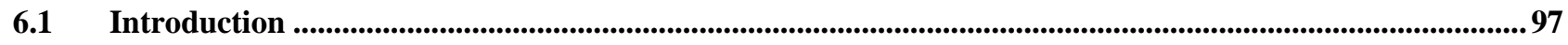

6.2 Systems of coevolving organisms are characterized by highly efficient mechanisms of isolation.................98

6.3 The Lichen symbiosis: Mutualism or Parasitism? ........................................................................................99

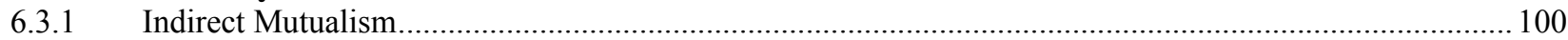

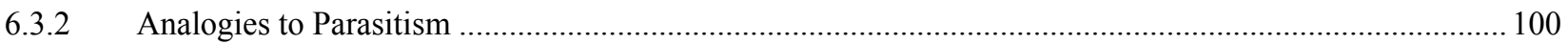

6.3.3 Certain aspects of lichen ecology appear as adaptations to nutrition deficient habitats.............................. 102

6.4 The significance of competition for lichen ecology and evolution........................................................................ 102

6.4.1: Flow diagram of hypothetical interactions between lichen bionts and subaerial algae .................................. 104 
7 INTRONS OF THE PHYSCIACEAE nrSSU

7.1 Summary

7.2 Introduction

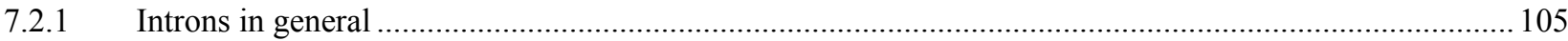

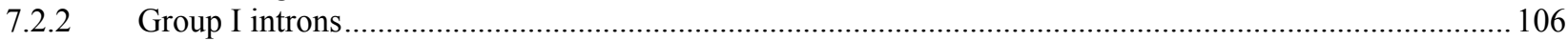

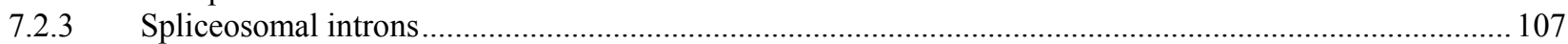

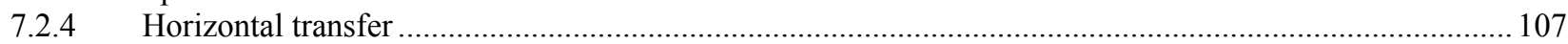

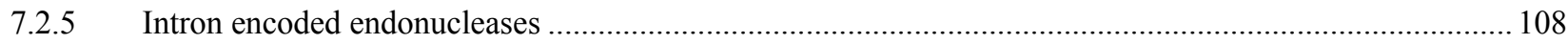

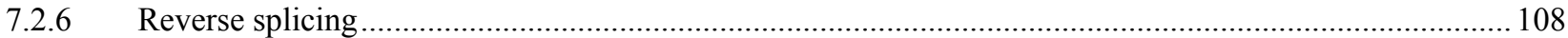

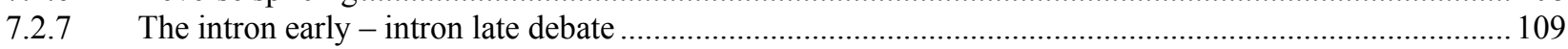

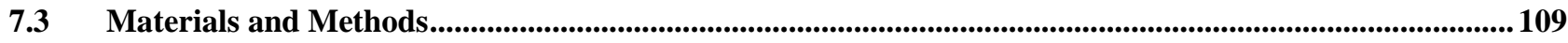

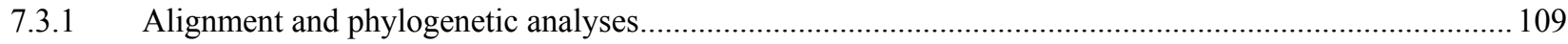

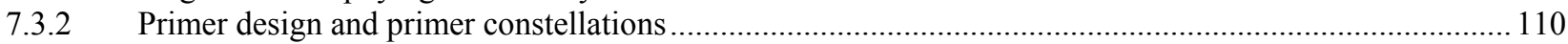

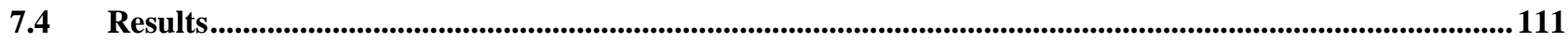

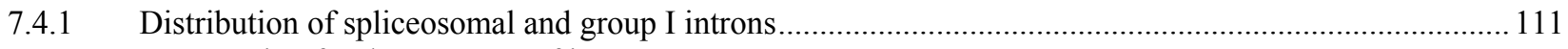

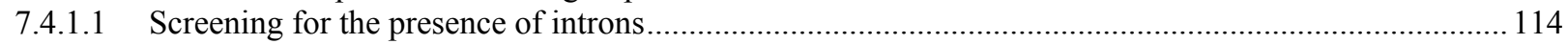

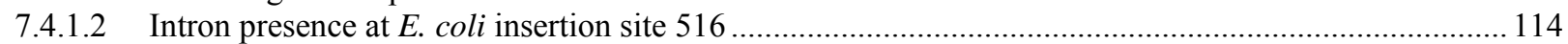

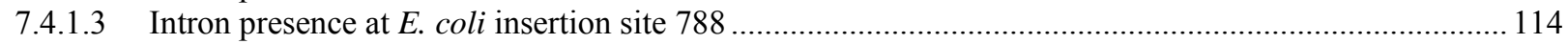

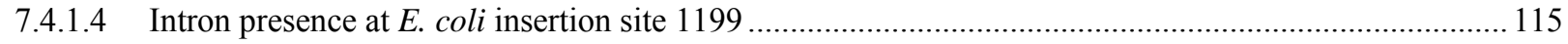

7.4.2 Comparing nrSSU intron genealogies with the nrITS phylogeny................................................... 117

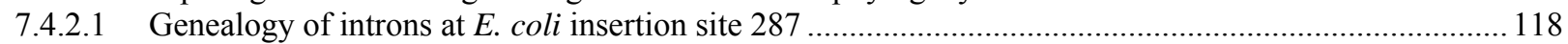

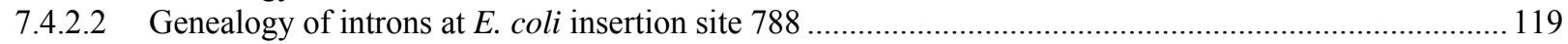

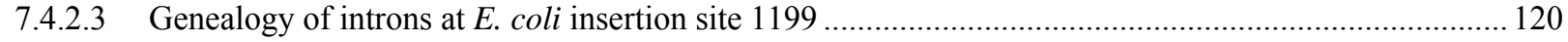

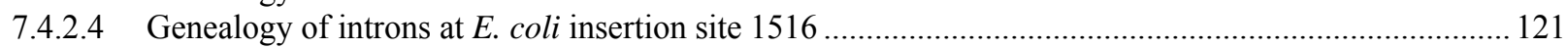

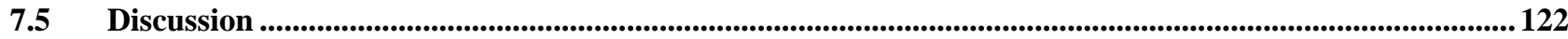

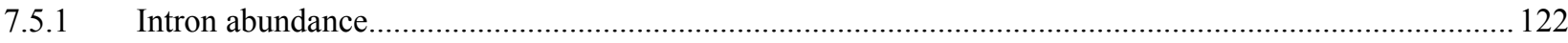

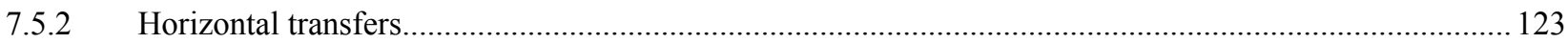

LITERATURE CITED ...........................................................................................125

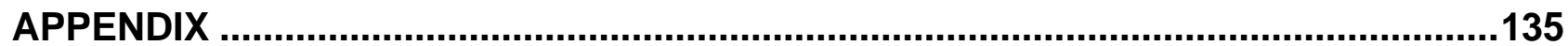

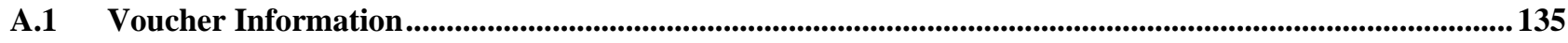

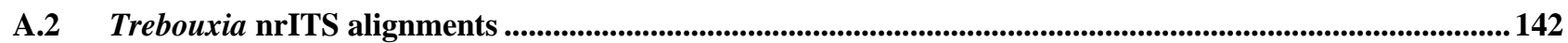

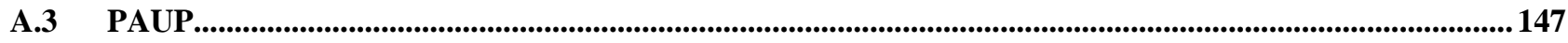

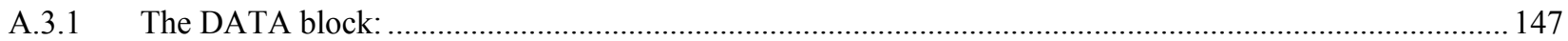

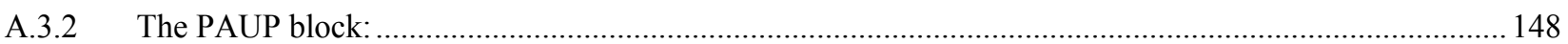

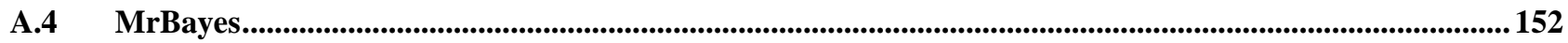

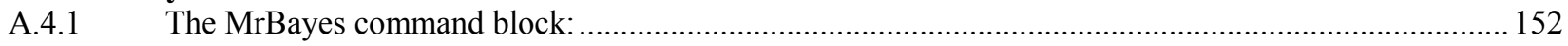

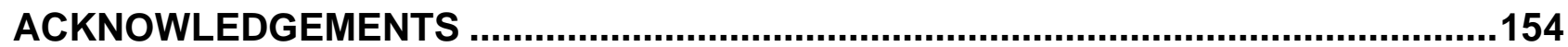

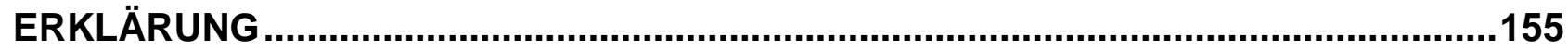

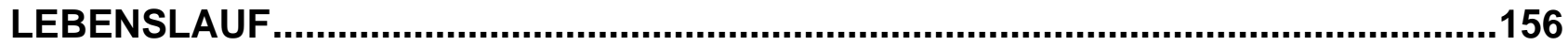




\section{General Introduction}

\subsection{The lichen concept}

The dualistic nature of lichens was first noticed by DeBary in 1866, who initially applied this concept to gelatinous lichens only. Shortly afterwards, in 1869, Schwendener generalized this concept to all lichens. In general, lichens exist as discrete thalli and are implicitly treated as individuals in many studies (e.g. Fahselt 1996), even though they may be a symbiotic entity involving three kingdoms (Nash III 1996). Recent investigations revealed that the integration of fungi and algae or cyanobacteria into symbiotic associations evolved multiple times independently, resulting in an exceptionally high diversity of life forms referred to as lichens (Gargas et al. 1995, Lutzoni et al. 2001). If referring to the ecological phenomenon, lichens are no more a systematic unit than are parasites, trees or water plants. Consequently, lichens as such cannot be used in phylogenetic classifications because they have no phylogeny (Tehler 1996). Today, most authors define lichens as an ecologically obligate long-lived consortium (or mutualism) of photoautotroph organisms and fungi, where the fungus forms a specific, symbiosis induced thallus (Jahns 1988, Ahmadjian 1993, Hawksworth 1994). Unfortunately, this definition conflicts with nomenclature. According to the international code of nomenclature (ICBN), lichen names refer exclusively to the mycobiont and not to a consortium (or mutualism) as which lichens are most commonly defined (ICBN, Greuter et al. 1999 paragraph 13.1d: "For nomenclatural purposes names given to lichens shall be considered as applying to their fungal component."). Taking the above lichen definition and the ICBN literally, there are no lichens with names. This discrepancy between lichen definition and nomenclature is not superficial. In numerous environmental studies, lichens were treated as a single entity, only reporting fungal names. However, photosynthesis rates were measured as one of the most sensitive parameters in "lichens" responding to environmental stress such as sulfur dioxide imission. Regularly, the identity of the photobiont was not reported in these studies (e.g. Beekley et al. 1981, Gaussla et al. 1996, Sanz et al. 1992). Interestingly, a number of studies show that numerous lichens are able to associate with a variety of different photobionts (Wang-Yang \& Ahmadjian 1972, Tschermak-Woess 1988, Friedl 1987, 1989b, Ahmadjian 1993, Beck 2002) and that different photobionts vary greatly in their physiological properties (Marti 1985, Palmqvist 1994).

Few authors offered alternative definitions of lichens, that were compatible with nomenclature. Ahmadjian (1959, 1995) described lichens as a form of "controlled parasitism" where the fungus parasitizes the photobiont. Correspondingly, Hawksworth and Honegger (1994) interpreted lichens as the symbiotic phenotype of nutritionally specialized fungi. Both views abandon the description of lichens as consortia but point to a specific taxon, the mycobiont. Following Hawksworth and Honegger (1994), here, lichens are 
defined as exhabitant fungi, which are obligatory and selectively associated with algae and/or cyanobacteria and develop a thallus.

Since all lichen definitions explicitly state the fungal dependence on a photobiont, it is obvious that determining a lichen's photobiont is inevitable for a complete description of the lichen symbiosis. Investigating photobiont identity and constancy (i.e. selectivity) in an abundant group of lichens is, therefore, an important aspect of this survey. However, photobiont identification is not the ultimate goal here but the basis for further analyses concerning symbiosis and coevolution in lichens. The Physciaceae were selected as a common and globally distributed family of lichenized ascomycetes, offering the opportunity to analyze the effects of environmental factors and distribution patterns. Further more, the Physciaceae appeared as a monophyletic group of lichens, facilitating cophylogenetic investigations.

\section{General Materials \& Methods}

\subsection{Lichen samples, DNA extraction, PCR, sequencing}

\subsubsection{Lichen samples}

Samples in this study were either collected recently or received on loan from the herbaria B (Berlin, Germany), GOET (Göttingen, Germany), GZU (Graz, Austria), M (München, Germany), UPS (Uppsala, Sweden), or the private herbarium of P. Dornes, Germany. Herbarium material was up to 13 years old. Most specimens were collected in Europe some in other continents (North and South America, Australia, India, SE-Asia, and Africa). Voucher information is given in the appendix A.1 (voucher information). In this study, 23 of the 27 genera as listed in Eriksson et al. (2003) could be analyzed. Species of the Physciacean genera Dermiscellum Hafellner, H. Mayrhofer \& Poelt, Gassicurtia Fée, Mischoblastia A. Massal., Redonia C.W. Dodge and the tropical buellioid genera recently erected by Marbach (2000) could not be included in this work, because no material suitable for PCR amplification was available.

\subsubsection{DNA extraction}

The material was checked for contaminant lichenicolous fungi under a dissecting microscope and small fragments of thalli or single apothecia were excised. Subsequently the excised tissue was transferred in a 1,5 $\mathrm{ml}$ reaction tube and placed on an aluminum block, which was pre-cooled in liquid nitrogen. After the tissue had cooled down it was ground with a pre-cooled micropestle fastened in a drilling machine. DNA was 
extracted from the pulverized tissue with either of the following kits: DNeasy Plant Mini Kit (Qiagen), Invisorb Spin Plant Kit (Invitek), Puregene Genomic DNA Purification Kit D-5000A (Gentra), Protocols and extraction buffers were as recommended by the manufacturers. After extraction, total lichen DNA was dissolved in 50 - $100 \mu \mathrm{l}$ TE buffer. When using the REDExtract-N-AMP Plant PCR Kit (Sigma) the kit's protokoll was modified as follows: The tissue was pulverized prior to incubation. After incubation in $70 \mu \mathrm{l}$ of buffer A (10 min at $95^{\circ} \mathrm{C}$ in an Eppendorf Thermomixer 5437 at ca. $\left.1000 \mathrm{rpm}\right)$, the solution was spun down and $50 \mu 1$ of the supernatant were transferred to a fresh tube and mixed with $50 \mu$ lof buffer B. $1-2 \mu 1$ of this mix were used as template in PCR assays as described below.

\subsubsection{PCR}

For the specific amplification of fungal and algal nrDNA, a set of biont specific 5'-PCR primers was used in combination with non-specific 3'-PCR primers (TABLE 2.1). PCR was performed with 1-2 $\mu 1$ of the dissolved total lichen DNA in a $50 \mu 1$ reaction volume containing a reaction mix of $0.2 \mathrm{mM}$ of each of the four dNTPs (dNTP-Mix, Hybaid-AGS), $2 \mathrm{mM} \mathrm{MgCl}_{2}, 4 \%$ DMSO, $0.2 \mu \mathrm{M}$ of each PCR primer, and 1 unit SilverStar Taq-polymerase with the supplier's buffer (Eurogentec). For PCR amplification three different thermo cyclers were used, a Biometra Personal Cycler, PTC-200 (Biozym), and Primus 96 (MWG-Biotech). All three had heating lids which were held at constant $110^{\circ} \mathrm{C}$. After an initial denaturing step at $95^{\circ} \mathrm{C}$ for 5 min, 33 cycles of denaturing at $94^{\circ} \mathrm{C}$ for $40 \mathrm{~s}$, annealing at $51{ }^{\circ} \mathrm{C}$ for $30 \mathrm{~s}$ with a time increment of $2 \mathrm{~s}$ per cycle, and extension at $72^{\circ} \mathrm{C}$ for $120 \mathrm{~s}$ with a time increment of $2 \mathrm{~s}$ per cycle, were performed and followed by final 6 cycles of $94^{\circ} \mathrm{C}$ for $40 \mathrm{~s}$ and $72^{\circ} \mathrm{C}$ for $2 \mathrm{~min}$.

\subsubsection{Agarose gel electrophoresis}

$3 \mu 1$ of the PCR products were mixed either with $2 \mu 16$ x Loading Dye $(0.09 \%$ bromophenol blue, $0.09 \%$ xylene cyanol FF, $60 \%$ glycerol and 60mM EDTA) and $2 \mu 11 \mathrm{M} \mathrm{NaCl}$ or with $2 \mu 1$ of GelStar dye $(0,2 \%$ (v/v) GelStar, $100 \mathrm{mM} \mathrm{NaCl}, 0,25 \%$ (w/v) bromophenol blue, 0,25\% (w/v) xylene cyanol, and 13\% (w/v) Ficoll). Subsequently samples were loaded onto a $1 \%$ agarose gel (agarose dissolved in $0.5 \mathrm{x}$ TBE buffer) and run in $0.5 \mathrm{x}$ TBE buffer at a voltage of ca. $50 \mathrm{~V} / \mathrm{cm} .0 .5 \mu \mathrm{g}$ of Lambda DNA, digested with EcoR I and Hind III was run as a fragment size marker. DNA which was loaded with the Loading Dye was stained with ethidium bromide after gel electrophoresis in an ethidium bromide bath containing $10 \mathrm{mg}$ ethidium bromide per 11 tap water. Gels were stained for $10 \mathrm{~min}$ and destained for $30 \mathrm{~min}$ in tap water. Samples loaded with GelStar dye did not need extra staining. Both stainings were visualized with UV light of $312 \mathrm{~nm}$ on a Transilluminator (Biotec-Fischer). Gels were photographed with a Phero-Cam (Biotec-Fischer) using the Image Acquisition software (Biotec-Fischer) and printed on a thermoprinter (Video Copy Processor, model P67E, Mitsubishi). 


\subsubsection{Cloning}

Multi-banded PCR products were cloned with the pGEM-T Vector-System I (Promega) following the manufacturer's protocol. Competent Escherichia coli cells, strain DH5 $\alpha$ were used and grown on LB medium with $100 \mathrm{mM}$ Ampicillin. Transformant colonies were PCR-screened with M13 primers (TABLE 2.1). PCR products of different length obtained through screening were purified and sequenced directly.

\subsubsection{PCR product purification}

Prior to sequencing, free primers, salts, and NTPs were removed from all PCR products by either an alcohol precipitation or with the High Pure PCR Product Purification Kit (Roche). When using the kit the manufacturers instructions were followed. Alcohol precipitations were carried out either with 2.5 volumes ethanol and 1 volume $1 \mathrm{M} \mathrm{NaCl}$ or 1 volume Isopropanol and 0,1 volume $3 \mathrm{M} \mathrm{NaAcetate}, \mathrm{pH} 5,5$; volumes refer to the volume of PCR product that was precipitated, (Sambrook et al. 1989). The precipitation solution was incubated at $-20^{\circ} \mathrm{C}$ over night and then spun down for $30 \mathrm{~min}$ at maximum speed in a table centrifuge $(>12000 \mathrm{rpm})$. The supernatant was discarded and three volumes of $70 \%$ ethanol were pipetted over the pellet. The assay was centrifuged again for $10 \mathrm{~min}$ at maximum speed and the supernatant discarded. The cleaned PCR products were resuspended in $60 \mu 1 \mathrm{TE}$ - buffer.

\subsubsection{DNA quantification}

DNA concentrations of the cleaned PCR products were determined photometrically with the Biophotometer (Eppendorf). $55 \mu \mathrm{l}$ of the cleaned PCR product were used in DNA quantification. Only when extinction exceeded 1.0, the cleaned PCR product was diluted 10 fold.

\subsubsection{Sequencing}

For sequencing reactions with only one sequencing primer, $100 \mathrm{ng} / \mathrm{kb}$ of the cleaned amplicon were used. For sequencing reactions with two opposing primers whose binding sites were less than $1 \mathrm{~kb}$ apart (LiCor, e.g. ITS sequencing), only $10 \mathrm{ng} / \mathrm{kb}$ were used. The amount of template was reduced here because of the amplification effect during cycle sequencing. Both strands of DNA were sequenced with a set of sequencing primers as listed in TABLE 2.1. For the ALF express II automated sequencer (Pharmacia), CY-5-labeled primers were used in combination with the Thermo Sequenase Sequencing Kit with 7-deaza-dGTP (Amersham) (chain-termination sequencing method with ddNTPs, Sanger et al. 1977). Sequencing reactions which were run on a LI-COR NEN Global IR $^{2}$ sequencer were prepared with IR-700 and IR-800 labeled primers and the same sequencing kit as above. The program for cycle sequencing with this kit started with an initial denaturing step at $95^{\circ} \mathrm{C}$ for $2 \mathrm{~min}$, followed by 22 cycles of denaturing at $94^{\circ} \mathrm{C}$ for $15 \mathrm{~s}$, annealing at 
$53^{\circ} \mathrm{C}$ for $25 \mathrm{~s}$, and extension at $72^{\circ} \mathrm{C}$ for $35 \mathrm{~s}$, and final 6 cycles of $94^{\circ} \mathrm{C}$ for $15 \mathrm{~s}$ and $72^{\circ} \mathrm{C}$ for $1 \mathrm{~min}$. The final 6 cycles without annealing step were run in order to incorporate ddNTPs in unterminated fragments. This reduced background noise in the electropherograms. Sequences obtained with the ALF sequencer were assembled with the ALF-software. Sequences obtained with the LiCor were assembled with AlignIR V1.2 software (LI-COR). The Big Dye Terminator V2.0 Cycle Sequencing Kit (ABI) was used when preparing sequencing reactions for the ABI 3100 automated sequencer. Here, unlabeled primers and labeled ddNTPs were used. When using the Big Dye Terminator V2.0 Cycle Sequencing Kit (ABI) a different cycle sequencing program was employed. Initially template DNA was denatured at $95^{\circ} \mathrm{C}$ for $2 \mathrm{~min}$, followed by 25 cycles of denaturing at $95^{\circ} \mathrm{C}$ for $15 \mathrm{~s}$, annealing at $53^{\circ} \mathrm{C}$ for $15 \mathrm{~s}$, and extension at $60^{\circ} \mathrm{C}$ for $4 \mathrm{~min}$. ABI sequences were also assembled with the AlignIR V1.2 software (LI-COR).

TABLE 2.1: PCR- and sequencing primers used in this study for amplifying and sequencing SSU and ITS nrDNAs. MY at the beginning of a primer name indicates that the primer is specific for fungal or ascomycete templates, PHY indicates specificity for Caliciacean/Physciacean templates, AL indicates specificity for green algae, SEQ denotes an unspecific primer that was used for sequencing, $\mathrm{F}$ at the end of a primer name indicates the forward direction, and $\mathrm{R}$ the reverse direction. Primers lacking these signatures were designed by other authors. 1800 R, ITS 2 N, ITS 4, LR1850, LR3 are unspecific reverse primers, ITS $3 \mathrm{~N}$ is an unspecific forward primer. ITS4, LR1850, and LR3 were used as reverse primers for PCR amplification. Primers 1800 F, 1800 R, ITS 2 N, ITS 3 N, and ITS 4 were used for sequencing. Primer binding sites in the nrSSU refer to X. elegans, AF088254. Sequence positions of the green algal specific primers (AL 1500aF, AL 1500bF, AL 1700F) are compared to the nrSSU of T. asymmetrica SAG 48.88 (Z21553). M13F and M13 R were plasmid specific primers that were used for amplifying cloned PCR products. Primers below the M13 primers were used for testing intron presence and absence.

\begin{tabular}{|c|c|c|c|}
\hline Primer Name & Primer Sequence $5^{\prime} \rightarrow 3^{\prime}$ & Primer binding site & source \\
\hline MY $60 \mathrm{~F}$ & CGCAA TGTCT AAGTA TAAGC AA & $51-72$ & Helms et al. 2003 \\
\hline MY $800 \mathrm{~F}$ & CGGAA TAATA GAATA GGACG TG & $799-820$ & Helms et al. 2003 \\
\hline MY $1200 \mathrm{~F}$ & CGCAA CACGG GGAAA CTC & $1190-1207$ & Helms et al. 2003 \\
\hline MY $1300 \mathrm{~F}$ & GAGTG ATTTG TCTGC TTAAT TG & $1295-1316$ & Helms et al. 2003 \\
\hline MY $1700 \mathrm{~F}$ & GCGGT CATTT AGAGG AASTA A & $1736-1756$ & Helms et al. 2003 \\
\hline MY $1200 \mathrm{R}$ & CGCGG ACCTG GTGAG TTTC & $1203-1219$ & Helms et al. 2003 \\
\hline MY $1300 \mathrm{R}$ & CGCAA TTAAG CAGAC AAATC AC & $1297-1318$ & Helms et al. 2003 \\
\hline PHY $1200 \mathrm{~F}$ & AACTC ACCAG GTCCA GATTT G & $1203-1223$ & Helms et al. 2003 \\
\hline PHY 1200A R & GCCAT GCACC ACCAM CTTTG A & $1259-1279$ & Helms et al. 2003 \\
\hline PHY 1200B R & СТСTC AATCT GTCAA TCСTT ATCA & $1222-1245$ & Helms et al. 2003 \\
\hline ITS 4 & TCCTC CGCTT ATTGA TATGC & LSU & White et al. 1990 \\
\hline LR1850 & CCTCA CGGTA CTTGT TC & LSU & Friedl 1996 \\
\hline LR3 & CCGTG TTTCA AGACG GG & LSU & Friedl \& Rokitta 1997 \\
\hline SEQ $80 \mathrm{~F}$ & GTGAA ACTGC GAATG GC & $81-97$ & Helms et al. 2003 \\
\hline SEQ $322 \mathrm{~F}$ & CTACC ACATC CAAGG AAG & $403-420$ & Helms et al. 2003 \\
\hline SEQ $500 \mathrm{~F}$ & AATTG GAGGG CAAGT CTG & $542-559$ & Helms et al. 2003 \\
\hline SEQ $800 \mathrm{~F}$ & GAATA GGACG TGTGG TTCTA & $809-828$ & Helms et al. 2003 \\
\hline SEQ $1050 \mathrm{~F}$ & CATAA ACTAT GCCGA CTAG & $1022-1040$ & Helms et al. 2003 \\
\hline SEQ $1200 \mathrm{~F}$ & GGATT GACAG ATTGA GAGC & $1228-1246$ & Helms et al. 2003 \\
\hline SEQ $1300 \mathrm{~F}$ & TGCGA TAACG AACGA GAC & $1315-1332$ & Helms et al. 2003 \\
\hline SEQ $1700 \mathrm{~F}$ & CCTAG TAAGC GCAAG TCA & $1582-1599$ & Helms et al. 2003 \\
\hline $1800 \mathrm{~F}$ & ACCTG CGGAA GGATC ATT & $1784-1801$ & Friedl 1996 \\
\hline ITS $3 \mathrm{~N}$ & GATGA AGAAC GCAGC GA & 5.8S nrDNA & Beck et al. 1998 \\
\hline SEQ $322 \mathrm{R}$ & CTTCC TTGGA TGTGG TAG & $403-420$ & Helms et al. 2003 \\
\hline SEQ $600 \mathrm{R}$ & ATACG CTATT GGAGC TGG & $581-598$ & Helms et al. 2003 \\
\hline SEQ $1050 \mathrm{R}$ & CTAGT CGGCA TAGTT TATG & $1022-1040$ & Helms et al. 2003 \\
\hline SEQ $1200 \mathrm{R}$ & TTTCC CCGTG TTGAG TC & $1188-1204$ & Helms et al. 2003 \\
\hline
\end{tabular}




\begin{tabular}{llll} 
SEQ 1300 R & AACTA AGAAC GGCCA TGC & $1273-1290$ & Helms et al. 2003 \\
SEQ 1750 R & CATTC AATCG GTAGT AGCG & $1646-1664$ & Helms et al. 2003 \\
$1800 \mathrm{R}$ & CAATG ATCCT TCCGC AGGT & $1784-1802$ & Friedl 1996 \\
ITS $2 \mathrm{~N}$ & TGCCT GCGTT CTTCA TC & $5.8 \mathrm{~S}$ nrDNA & Beck et al. 1998 \\
AL 1500AF & GCGCG CTACA CTGAT GC & $1464-1480$ & Helms et al. 2001 \\
AL 1500BF & GATGC ATTCA ACGAG CCTA & $1476-1494$ & Helms et al. 2001 \\
AL 1700F & CCCAC CTAGA GGAAG GAG & $1737-1754$ & Helms et al. 2001 \\
M13 Forward (-21) & TGTAA AACGA CGGCC AGT & plasmid & MWG \\
M13 Reverse (-29) & CAGGA AACAG CTATG ACC & plasmid & MWG \\
$1199-5$ IF & GGCCG ATTCG GTGGC GMGC & group I intron & Helms et al. 2003 \\
$1199-3 I R$ & GCCCA UCAUT TTGUA TGCG & group I intron & Helms et al. 2003 \\
$1199-5 E F$ & GGTGC ATGGC CGTTC TTA & $1270-1287$ & Helms et al. 2003 \\
$516-5$ IF & AGGUT TCCGG UWCGG GGAA & group I intron & Helms et al. 2003 \\
$516-3 I R$ & GGCGG GATTA GCACG TACC & group I intron & Helms et al. 2003 \\
$516-3 E R$ & CCCTA TTAAT CATTA CGGCG & $848-867$ & Helms et al. 2003 \\
$788-5 I F$ & GAGCG CAGTC UACAG ACTG & group I intron & Helms et al. 2003 \\
$788-3 E R$ & GGTGG TGCCC TTCCG TC & $1146-1162$ & Helms et al. 2003 \\
SR7R & TTAAA AAGCT CGTAG TTGAC & $615-635$ & R. Vilgalys web site* \\
SR11R & GGAGC CTGAG AAACG GCTAC & $387-406$ & Spatafora et al. 1995 \\
$5.8 S$ & CGCTG CGTTC TTCAT CG & $5.8 S$ nrDNA & Vilgalys and Hester, 1990 \\
\hline
\end{tabular}

* Department of Biology, Duke University; http://www.biology.duke.edu/fungi/mycolab.

\subsection{Phylogenetic analyses}

\subsubsection{Alignment}

After sequence assemblage and proof reading, sequences were automatically aligned with ClustalW (Thompson et al. 1994) and subsequently manually refined using the sequence editor BioEdit (Hall 1999). Prior to phylogenetic analyses ambiguously aligned positions were excluded and the resulting alignment exported as Nexus file using BioEdit. "N" characters were defined as missing data and indels as gaps in the FORMAT command of the exported Nexus file. This Nexus file was used in the Program ModelTest (Posada and Crandall 1998), in the Program PAUP (Swofford 2000), and in MrBayes (version 3b4, Huelsenbeck \& Ronquist 2001).

\subsubsection{Assessing the model of evolution}

Prior to ML analyses a model of sequence evolution that fit the data best was selected using the Akaike Information Criterion (AIC, Akaike 1974) as implemented in the program ModelTest (Version 3.06, Posada \& Crandall 1998). 


\subsubsection{Phylogenetic inference}

To exploit the breadth of available phylogenetic methods, "simple" methods such as the neighbor joining method (NJ) with the Jukes-Cantor model of evolution (Jukes \& Cantor 1969) were employed as well as more sophisticated methods such as maximum parsimony (MP), weighted maximum parsimony (wMP), and maximum likelihood (ML) as implemented in PAUP* V4.0b10 (Swofford 2000). In ML analyses the model of evolution estimated with ModelTest was employed (see appendix A.3, PAUP). As an alternative likelihood based approach, Bayesian analyses (BA) of phylogeny using Markov Chain Monte Carlo methods as implemented in the program MrBayes (versions 2.01 and 3.01b, and 3.0b4, Huelsenbeck \& Ronquist 2001) were conducted. The command block is shown in the appendix A.4 (MrBayes) including further annotations.

\subsubsection{Significance measurement}

Reliability of the phylograms obtained in NJ-, MP- and wMP analyses was assessed using bootstrap analyses. Usually 1000 replicates were analyzed. The command file in which each analysis is specified is given in the appendix A.3 (PAUP) including further annotations. Reliability values for ML based phylogenies were obtained in Bayesian analyses. This method estimates posterior probabilities for each node. Posterior probabilities are a measurement for branch reliability like bootstrap values but behave differently (Alfaro et al. 2003). While values above $80 \%$ are considered significant support in bootstrap analyses, 0.95 is the limit above which posterior probability obtained in Bayesian analyses indicate phylogenetic significance (Larget \& Simon 1999).

\subsubsection{Outgroup analysis}

To select appropriate outgroups, phylogenies were analyzed that comprized potential sistertaxa to the ingroup of interest. Short branch taxa that were closely related to, but not included in the ingroup, were tested for suitability with the RASA test (Lyons-Weiler et al. 1996) as implemented in the alignment editor Align (Hepperle 2000). The criterion for appropriateness of a putative outgroup was an increase of the $t_{\text {RASA }}$ value compared to the unrooted ingroup. In addition, the outgroup should not appear as an extraneous element to the ingroup in an unrooted RASA plot (Lyons-Weiler et al. 1998). 


\section{Physciaceae Taxonomy*}

\subsection{Summary}

The monophyletic origin of the ascomycete family Physciaceae, its position within the Lecanorales, and the phylogenetic structure within the family were investigated using nuclear rDNA sequence analyses. The common origin of the Caliciaceae and Physciaceae as previously shown (Wedin et al. 2000) was confirmed. Further it could be shown that the Caliciaceae are nested within the Physciaceae. A unique region in loop 37 of the nrSSU rRNA secondary structure model was identified, which distinguishes the Physciaceae/ Caliciaceae from other Lecanoralean families. Furthermore, the nrSSU sequence data did not support a particular relationship with any other Lecanoralean family. Analyses of nrITS sequences revealed a bifurcation of the Physciaceae/Caliciaceae clade, which was found to be congruent with the distribution of certain morphological characters. The congruence with the ITS phylogeny demonstrated the phylogenetic significance of ascus type, hypothecium pigmentation, ascospore characters and excipulum type. Finestructure details of ascospores and the structure of excipula were found to be important for the recognition of convergences in these traits. Other previously used characters, i.e. growth habit, certain ascospore types or structure of the upper cortex, were found to be of multiple origins within the Physciaceae. All monophyletic lineages of non-crustose growth habit exhibit uniform ascospore types, indicating a higher evolutionary age of ascospore types than foliose growth habit. The taxonomic segregation of the Physciaceae into the Physciaceae and Caliciaceae is proposed here.

* Most of this chapter is identical with the publication "Phylogenetic Relationships of the Physciaceae inferred from rDNA sequence data and selected phenotypic Characters" by G.Helms, T. Friedl, and G. Rambold. 2003. Mycologia 95(6) in press. Taxonomic consequences were based on discussions with coauthor G. Rambold.

\subsection{Introduction}

\subsubsection{Taxonomic history and circumscription of the Physciaceae}

The family Physciaceae Zahlbr. (1898), in its currently accepted circumscription, comprises 27 genera of lichenized ascomycetes of various growth forms (Eriksson et al. 2003), i.e. crustose, foliose and fruticose lichens. Zahlbruckner placed these taxa into two separate families, the Buelliaceae Zahlbr. (1907) and the Physciaceae Zahlbr. (1898). Poelt (1973) unified both families into the Physciaceae, and this concept essentially has remained unchanged until now. However, Poelt kept Dermatiscum Nyl. in a separate family and placed it together with the Physciaceae, Candelariaceae Hakul. and Teloschistaceae Zahlbr. in the 
suborder Buelliineae. Henssen and Jahns (1974) established the suborder Physciineae with the Physciaceae as the only family, essentially comprising the same genera as in the Physciaceae of Poelt, however, they included Dermatiscum as well. Hafellner et al. (1979) published a survey on the Physciaceae, adding the genus Dermiscellum Hafellner, H. Mayrhofer \& Poelt to the family. Rambold \& Triebel (1992) regarded asci with an amyloid tholus enclosing a less amyloid axial body as a diagnostic feature for determining suborders and thus placed the Physciaceae in the suborder Lecanorineae. This view is kept until now, as documented in the most recent 'Outline of Ascomycota' (Eriksson et al. 2003). Molecular support for a common origin of the Physciaceae and the Caliciaceae, was first presented by Wedin et al. (2000), who included two Physciacean genera of different growth forms and four genera of the Caliciaceae in their survey. This finding was unexpected since the Caliciaceae were considered to belong to a different order of Ascomycetes, the Caliciales. Relationships of the Physciaceae to other ascomycete families were previously only considered within the Lecanorales, e.g. to the Lecanoraceae, to the Teloschistaceae and to the Candelariaceae.

The current circumscription of the Physciaceae is based on ascus and ascospore types. Asci of the Lecanora-

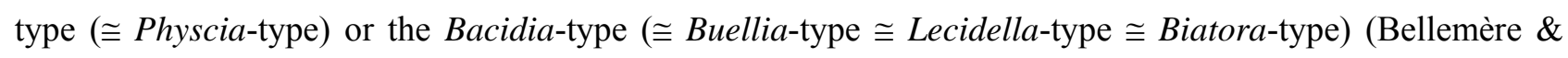
Letrouit-Galinou 1981, 1987; Hafellner 1984) and pigmented, septate, thick-walled ascospores, categorized into 20 types (Mayrhofer 1982, 1984, but see Matzer \& Mayrhofer 1996), are the essential character states for the recognition of this family.

Before the unification of the families Buelliaceae and Physciaceae by Poelt (1973), these two were distinguished by growth habit, which demonstrates the importance given to this character in the past. The Buelliaceae comprised crustose taxa, while foliose taxa were assigned to the Physciaceae. In addition, the excipulum type was regarded as an important trait and used to separate the genera Buellia and Rinodina (Zahlbruckner 1926), which constituted the Buelliaceae. Species of Rinodina develop an apothecial margin with algal cells (thalline excipulum), but they are absent in proper excipula of Buellia species. When not employing growth form as primary phylogenetic trait (e.g., Poelt 1973), the delimitation of Rinodina becomes uncertain. In addition, the remarkable diversity in ascospore types described in this genus (Mayrhofer 1982, 1984, Matzer \& Mayrhofer 1996) might suggest that Rinodina in its current circumscription is not a monophyletic genus. In fact, nrITS studies revealed that Rinodina in its actual concept represents a paraphyletic assemblage comprising the closest relatives of most foliose genera of the Physciaceae (Grube \& Arup 2001). Both genera, Buellia and Rinodina, remained large and diverse assemblages even after the segregation of the genera Phaeorrhiza, Rinodinella, Mobergia, Hafellia, Amandinea, Diploicia and Diplotomma s. str., and were subject of recent investigations (e.g. Nordin 2000, Grube \& Arup 2001). 
In this study, nrSSU and/or nrITS sequence data of 23 of the 27 genera as listed in Eriksson et al. (2003) could be determined and proved to be particular useful for the understanding of phylogenetic relationships among these genera as well as for testing the phylogenetic significance of various morphological characters.

\subsection{Materials \& Methods}

Most of the Physciaceae sequence data obtained in this survey were published in Bhattacharya et al. 2002 and Helms et al. 2003. Accession numbers are given in TABLE 3.1.

TABLE 3.1: Accession numbers of Physciaceae specimens, which were published in Helms et al. 2003. Herbaria: B (Berlin, Germany), GOET (Göttingen, Germany), GZU (Graz, Austria), M (München, Germany), UPS (Uppsala, Sweden), or the private herbarium of P. Dornes, Germany.

\begin{tabular}{|c|c|c|}
\hline Species & GenBank & Collector / voucher number/ herbarium \\
\hline Amandinea punctata (Hoffm.) Coppins \& Scheid. & $\begin{array}{l}\text { ITS: AF540492 } \\
\text { SSU: AJ549800 }\end{array}$ & H. Mayrhofer 13.931 \& B. Litterski (GZU) \\
\hline A. cacuminum (Th. Fr.) H. Mayrhofer \& Sheard & ITS: AJ421693 & H. Mayrhofer 13.706 (GZU) \\
\hline Anaptychia ciliaris (L.) Körb. & ITS: AF540493 & T. Friedl 94/8 (GOET) \\
\hline A. runcinata (With.) J. R. Laundon & $\begin{array}{l}\text { ITS: AJ421249 } \\
\text { SSU: AJ421692 }\end{array}$ & G. Rambold $6162 \&$ D. Triebel (M) \\
\hline A. ulotrichoides (Vain.) Vain & ITS: AF540494 & B. Litterski 4994 (GZU) \\
\hline Australiaena streimannii Matzer, H. Mayrhofer \& Elix & ITS: AF540495 & H. Sipman 42136 (B) \\
\hline Buellia aethalea (Ach.) Th. Fr. & $\begin{array}{l}\text { ITS: AF540496 } \\
\text { SSU: AJ549801 }\end{array}$ & A. Nordin 3256 (UPS) \\
\hline B. capitis-regum W. A. Weber & ITS: AF540497 & T.H. Nash 33113 (UPS) \\
\hline B. elegans Poelt & $\begin{array}{l}\text { ITS: AJ421415 } \\
\text { SSU: AJ421680 }\end{array}$ & $\begin{array}{l}\text { U. Trinkaus 439, J. Prügger \& H. Mayrhofer } \\
\text { (GZU) }\end{array}$ \\
\hline B. geophila (Flörke ex Sommerf.) Lynge & ITS: AF540499 & A. Nordin 4429 (UPS) \\
\hline B. georgei Trinkaus, H. Mayrhofer \& Elix & $\begin{array}{l}\text { ITS: AJ421416 } \\
\text { SSU: AJ421681 }\end{array}$ & U. Trinkaus 356a (GZU ) \\
\hline B. griseovirens (Turner \& Borrer ex Sm.) Almb. & ITS: AF540500 & A. Nordin 4734 (UPS) \\
\hline B. muriformis A. Nordin \& Tønsberg & ITS: AF540501 & A. Nordin 5336a (UPS) \\
\hline B. ocellata (Flot.) Körb. & ITS: AF540502 & A. Nordin 4284 (UPS) \\
\hline B. penichra (Tuck.) Hasse & ITS: AF540503 & A. Nordin 5322 (UPS) \\
\hline B. submuriformis Aptroot \& Diederich & ITS: AF540504 & L. Tibell 21897 (UPS) \\
\hline B. triphragmioides Anzi & ITS: AF540505 & A. Nordin 4425 (UPS) \\
\hline B. triseptata A. Nordin & ITS: AF540506 & A. Nordin 5229 (UPS) \\
\hline B. zoharyi Galun & ITS: AJ421418 & U. Trinkaus 356a \& M. Grube (GZU) \\
\hline Dermatiscum thunbergii (Ach.) Nyl. & ITS: AF540507 & H. Sipman 19.908 (B) \\
\hline Dimelaena oreina (Ach.) Norman & ITS: AJ421417 & H. Mayrhofer 13.970 \& E. Sterner (GZU) \\
\hline Diploicia canescens (Dickson) A. Massal & $\begin{array}{l}\text { ITS: AJ421992 } \\
\text { SSU: AJ421684 }\end{array}$ & G. Rambold 6188 \& D. Triebel (M) \\
\hline Diplotomma alboatrum (Hoffm.) Flot. & ITS: AF540508 & A. Nordin 4961 (UPS) \\
\hline & SSU: AJ549802 & A. Nordin 4961 (UPS) \\
\hline & ITS: AJ549959 & A. Nordin 5055 (UPS) \\
\hline & ITS: AJ549958 & B. Benfield 04973 (UPS) \\
\hline D. epipolium (Ach.) Arnold & ITS: AF540509 & H. Mayrhofer 13.933 \& B. Litterski, (GZU) \\
\hline D. lutosum A.Massal. & ITS: AF540510 & A. Nordin 4449 (UPS) \\
\hline D. venustum (Körb.) Körb. & ITS: AF540511 & A. Nordin 3180 (UPS) \\
\hline Dirinaria applanata (Fée) D. D. Awasthi & ITS: AF540512 & H. Sipman 46067 (B) \\
\hline D. confluens (Fr.) D. D. Awasthi & ITS: AF540513 & H. Sipman 13009 (B) \\
\hline D. picta (Sw.) Clem. \& Shear & ITS: AF540514 & H. Sipman 45628 (B) \\
\hline Hafellia dissa (Stirt.) H. Mayrhofer \& Sheard & ITS: AF540515 & A. Nordin 4632 (UPS) \\
\hline
\end{tabular}


H. disciformis (Fr.) Marbach \& H. Mayrhofer Heterodermia albicans (Pers.) Swinscow \& Krog

H. boryi (Fée) K. P. Singh \& S. R. Singh

H. comosa (Eschw.) Follm. \& Redon

H. diademata (Taylor) D. D. Awasthi

H. flabellata (Fée) D.D. Awasthi

H. leucomela (L.) Poelt

H. lutescens (Kurok.) Follm.

Hyperphyscia adglutinata (Flörke) H. Mayrhofer \& Poelt

Phaeophyscia endophoenicea (Harm.) Moberg

P. orbicularis (Neck.) Moberg

Physcia adscendens (Fr.) H. Olivier

P. aipolia (Ehrh. ex Humb.) Fürnr.

P. alba (Fée) Müll. Arg.

P. atrostriata Moberg

P. caesia (Hoffm.) Fürnr.

P. dimidiata (Arnold) Nyl.

P. erumpens Moberg

$P$. integrata Nyl.

P. krogiae Moberg

P. millegrana Degel.

P. semipinnata (J.F. Gmel.) Moberg

P. sorediosa (Vain.) Lynge

P. stellaris (L.) Nyl.

P. tenella (Scop.) DC.

P. tribacia (Ach.) Nyl.

P. undulata Moberg

Physconia distorta (With.) J.R.Laundon

P. enteroxantha (Nyl.) Poelt

P. grisea (Lam.) Poelt

P. perisidiosa (Erichsen) Moberg

P. venusta (Ach.) Poelt

Pyxine cocoes (Sw.) Nyl.

P. farinosa Kashiw.

P. petricola Nyl.

P. sorediata (Ach.) Mont.

Rinodina atrocinerea (Hook.) Körb.

R. gennarii Bagl.

R. lecanorina (A. Massal.) A. Massal.

$R$. luridescens

R. milvina (Wahlenb.) Th. Fr.

R. nimisii Giralt \& H. Mayrhofer

R. obnascens (Nyl.) Oliv.

R. oleae Bagl.

R. olivaceobrunnea Dodge \& Baker

R. oxydata (A. Massal.) A. Massal.

R. pyrina (Ach.) Arnold

R. sophodes (Ach.) A. Massal.

R. tunicata H. Mayrhofer \& Poelt

R. zwackhiana (Kremp.) Körb.

Rinodinella controversa (A. Massal.) H. Mayrhofer \&

Poelt

Santessonia sorediata Sérus. \& Wessels

Tornabea scutellifera (With.) J.R. Laundon
ITS: AF540498

ITS: AF540516

ITS: AJ421419

ITS: AF540517

ITS: AF540518

ITS: AF540519

ITS: AF540520

ITS: AJ544180

ITS: AF540521

SSU: AJ549803

ITS: AF540527

ITS: AF540528

SSU: AJ549804, AJ549805

ITS: AJ421414

ITS: AJ421420

ITS: AJ544181

ITS: AF540529

ITS: AF540530

ITS: AF540531

ITS: AF540532

ITS: AF540533

ITS: AF540534

ITS: AF540535

ITS: AF540536

ITS: AF540537

ITS: AJ421421

SSU: AJ421688

ITS: AF540538

ITS: AF540539

ITS: AJ544182

SSU: AJ549806

ITS: AF540522

ITS: AF540523

ITS: AF540524

ITS: AJ421422

SSU: AJ421689

ITS: AF540526

ITS: AF540540

ITS: AF540541

SSU: AJ549807

ITS: AF540542

ITS: AF540543

ITS: AF540544

ITS: AJ544187

SSU: AJ549808

ITS: AF540545

ITS: AJ544183

ITS: AF540546

ITS: AJ544184

ITS: AJ544185

ITS: AJ544186

ITS: AF540547

ITS: AF540548

SSU: AJ506971

ITS: AF540549

ITS: AF540550

ITS: AF540551

ITS: AF540552

ITS: AJ421423

SSU: AJ421691

ITS: AF540553

SSU: AJ549809

ITS: AF540554

SSU: AJ549810
P. Johansson 5 (UPS)

R. Welz 894 (B)

M. Düsing 8.111199 (GOET)

K. Bach \& M. Kessler, J 92 (B)

K. Bach, M. Kessler \& Portugal 389 (B)

P.A. Bawingan 61 (B)

H. Sipman 44833 \& R. Welz (B)

H. Sipman 44716 \& R. Welz (B)

P. Dornes $411 b$ (Dornes)

P. Bilovitz \& H. Mayrhofer 1187 (GZU)

M. Schultz 9808.021 (Dornes)

P. Dornes 9806.005 (Dornes)

T. Friedl (GOET)

R. Welz 738 (B)

H. Sipman 39628 (B)

P. Dornes 9807.004 (Dornes)

H. Mayrhofer 13.932 \& B. Litterski, (GZU)

R. Welz 182 (B)

H. Sipman 44890 \& R. Welz (B)

H. Sipman 44672 \& R. Welz (B)

T. Friedl x80 (Dornes)

P. Dornes 133b (Dornes)

H. Sipman 44971a \& Bohnke (B)

P. Dornes 9604.006 (Dornes)

P. Dornes 45g (Dornes)

P. Dornes 504a (Dornes)

H. Sipman 46400 (B)

G. Helms \& V. Souza (GOET)

G. Helms, V. Souza, A. Espinosa (GOET)

P. Dornes $112 \mathrm{e}$ (Dornes)

T. Friedl 94/12 (GOET)

G. Helms \& P. Dornes 10.290900 (GOET)

H. Sipman 46259 (B)

H. Sipman 46068 (B)

B. Manara 767 (B)

U. Schwarz 5541 (B)

H. Mayrhofer 13.740 \& U. Arup (GZU)

H. Sipman 44435 (B)

H. Mayrhofer 13.120 (GZU)

H. Sipman 42835 \& T. Raus (B)

H. Mayrhofer 13.702 (GZU)

H. Sipman 42685 \& T. Raus (B)

H. Sipman 42477 \& T. Raus (B)

H. Sipman 42740a \& T. Raus (B)

J. Romeike 2.090300 (GOET)

H. Mayrhofer 13.930 \& B. Litterski (GZU)

P. Bilovitz 483 \& H. Mayrhofer (GZU)

P. Bilovitz 968 (GZU)

H. Mayrhofer 13.749 \& R. Ertl (GZU)

H. Mayrhofer 13.848 (GZU)

H. Mayrhofer 13.747 \& R. Ertl (GZU)

C. Kainz 275 (M)

P. Hein 5323 (B) 


\subsubsection{Alignment and phylogenetic analyses}

Available nrSSU and nrITS sequences of the Physciaceae and from various families of the Lecanorales used in the phylogenetic analyses were taken from GenBank (for nrSSU accession numbers see FIG. 3.1, for ITS accession numbers see TABLE 3.2). Sequences were initially aligned with ClustalW (Thompson et al. 1994) and subsequently the resulting alignment was manually refined with BioEdit (Hall 1999).

\subsubsection{Phylogenetic analyses of nrSSU sequence data}

Nearly full-length nrSSU sequences ( $\geq 1600 \mathrm{bp}$ ) only were included, constituting an alignment of 67 taxa. nrSSU sequences were aligned to the insertion-free nrSSU sequence AF088254 from Xanthoria elegans to detect and remove nrSSU introns. Positions that were conserved or comprised only one base change were excluded before phylogenetic analyses, as were ambiguously aligned positions. The resulting nrSSU data matrix then contained 293 variable positions of which 273 were parsimony-informative. A model of sequence evolution that fit this data set best was selected with the hierarchical likelihood ratio test (hLRT) under the Akaike information criterion (AIC) as implemented in the program ModelTest (Version 3.06, Posada et al. 1998). For the nrSSU data set, the 'TVM $+G$ ' model (Rodríguez et al. 1990) was selected and likelihood parameters (Lset) were set as follows: Base frequencies (Base) were $\mathrm{A}=0.2363, \mathrm{C}=0.2786$, $\mathrm{G}=0.1902 \mathrm{~T}=0.2950$, substitution types $(\mathrm{Nst})=6$ with substitution values (Rmat) $\mathrm{AC}=0.9678, \mathrm{AG}=2.6625$, $\mathrm{AT}=0.8204, \mathrm{CG}=0.3888, \mathrm{CT}=2.6625, \mathrm{GT}=1.0000$; the site-to-site rate heterogeneity was modeled as a gamma distribution (Yang 1994) with a shape parameter (shape) $\alpha=1.9369$, resolved with 4 rate classes. The proportion of invariable sites was set to zero (Pinvar $=0$ ). This model was employed in a maximumlikelihood search. Tree search was started with a neighbor-joining tree and subsequent heuristic search using the tree bisection-reconnection (TBR) branch-swapping algorithm. All other parameters were as the default settings of PAUP. Further, maximum-parsimony (MP) and distance analyses were conducted. In maximumparsimony analyses, the sites were weighted (rescaled consistency index [RC] over an interval of 1-1000; Bhattacharya \& Medlin 1995) and then used as input for bootstrap analyses (1000 replications). Introduced gaps were treated as fifth character state in the MP analyses. Heuristic search conditions were with starting trees built stepwise with 10 random additions of taxa, using the TBR algorithm. Best scoring trees were held at each step. For distance analyses, the neighbor-joining method (NJ; Saitou and Nei 1987) and the Jukes Cantor model was used. Bootstrap analyses were conducted with 1000 replicates. This simple model was employed as a methodical counterbalance to the more complex models and to test the robustness of the analyses. 
TABLE 3.2: Previously published nrITS sequences from the Physciaceae included in this study.

\begin{tabular}{|c|c|}
\hline Species & GenBank \\
\hline Anaptychia bryorum Poelt & AF250781 \\
\hline Buellia asterella Poelt \& M. Sulzer & AF250785 \\
\hline Buellia dijiana Trinkaus & AF250788 \\
\hline B. erubescens Arnold & AF250786 \\
\hline B. frigida Darb. & AF276068 \\
\hline B. lindingeri Erichsen & AF250789 \\
\hline B. schaereri De Not. & AF250791 \\
\hline Diplotomma rivas-martinezii Barr. et Crespo & AF101286 \\
\hline Heterodermia speciosa (Wulfen) Trevis. & AF224360 \\
\hline Lecidea lapicida (Ach.) Ach. & AF332119 \\
\hline Mobergia calculiformis (W.A. Weber) H. Mayrhofer \& Sheard & AF224359 \\
\hline Phaeophyscia ciliata (Hoffm.) Moberg & AF224457 \\
\hline P. constipata (Norrl. \& Nyl.) Moberg & AF224374 \\
\hline P. endococcina (Körb.) Moberg & AF224444 \\
\hline P. nigricans (Flörke) Moberg & AF224375 \\
\hline P. sciastra (Ach.) Moberg & AF224357 \\
\hline Phaeorrhiza nimbosa (Fr.) H. Mayrhofer \& Poelt & AF224363 \\
\hline P. sareptana (Tomin) H. Mayrhofer \& Poelt & AF250801 \\
\hline Physcia albinea (Ach.) Nyl. & AF224433 \\
\hline P. biziana (A. Massal.) Zahlbr. & AF224417 \\
\hline P. dubia (Hoffm.) Lettau & AF224413 \\
\hline P. leptalea (Ach.) DC. (= P. semipinnata) & AF224429 \\
\hline P. magnussonii Frey & AF224376 \\
\hline P. phaea (Tuck.) J.W. Thomson & AF224378 \\
\hline Physciella chloantha (Ach.) Essl. & AF250797 \\
\hline Physconia detersa (Nyl.) Poelt & AF224372 \\
\hline P. muscigena (Ach.) Poelt & AF224369 \\
\hline Rinodina bischoffii (Hepp) A. Massal. & AF250807 \\
\hline R. confragosa & AF250808 \\
\hline R. interpolata (Stirt.) Sheard. & AF250809 \\
\hline R. mniaraea (Ach.) Körb. & AF250811 \\
\hline R. plana H. Magn. & AF250812 \\
\hline R. turfacea (Wahlenb.) Körb. & AF224362 \\
\hline Rinodinella dubyanoides (Hepp) H. Mayrhofer \& Poelt & AF250815 \\
\hline
\end{tabular}

For obtaining likelihood-based branch support values, Bayesian analysis and Markov chain Monte Carlo tree search algorithms as implemented in MrBayes, version 3.01b (Huelsenbeck \& Ronquist 2001) were employed. A six parameter model of evolution was specified, the exact parameter values being estimated during tree search. The rate variation of nucleotide substitution was modeled by a gamma distribution approximated by six rate categories. One million generations were calculated of which every 100th was saved. Four differently heated chains were run, corresponding to the default setting of MrBayes 3.01b. The first 2000 saved trees were discarded before constructing a majority rule consensus tree from the remaining 8000 trees. Branch lengths were averaged across all of the 8000 trees from which the consensus was calculated. Branch supports of the consensus tree, referred to as posterior probabilities, correspond to the fraction of the 8000 trees that contained the supported nodes and were regarded as significant when exceeding 0.95 (Larget \& Simon 1999). 


\subsubsection{Phylogenetic analyses of nrITS sequence data}

Two data sets of ITS sequences were analyzed. A data set reduced in taxa was constructed in order to maintain a numerical balance of species among the different genera and this contained 50 Physciaceae taxa (FIG. 3.2). The second extended data set included all 116 Physciaceae taxa examined in this study (FIG. 3.3). As in the nrSSU data set, strongly conserved and ambiguous positions were removed. After exclusion of constant and ambiguously aligned sites, the extended ITS data set contained 203 positions of which 195 were parsimony-informative. The 'SYM $+G$ ' model (Zharkikh 1994) was selected using ModelTest with Lset parameters Base $=$ equal; $\mathrm{Nst}=6$; Rmat $=(2.1951,3.9535,2.3711,1.3580,9.5189,1.0000)$; Rates $=$ gamma; Shape $=1.4215 ;$ Ncat $=4$; Pinvar $=0$. For the reduced ITS data set the same alignment positions as in the extended data set were analyzed. Again, the 'SYM $+\mathrm{G}$ ' model was selected with Lset parameters Base $=$ equal; Nst = 6; Rmat $=(3.0820,4.8120,3.3231$, 2.0149, 11.9643, 1.0000); Rates $=$ gamma; Shape $=1.5530$; Ncat $=4$; Pinvar $=0$. ITS phylogenies were inferred with the methods as for the nrSSU sequence data. Alternative tree topologies for the ITS phylogeny corresponding to hypotheses as suggested by phenotypic characters were examined. For this purpose the ML phylogeny of the reduced data set (as shown in FIG. 3.2) was manipulated manually in TreeView (v. 1.5.3, Page 1996) and tested with the approximately unbiased test and the Kishino-Hasegawa test (Kishino \& Hasegawa 1989) as implemented in CONSEL (v. 0.1f, Shimodaira \& Hasegawa 2001). Both tests carried out in CONSEL were based on the ML criterion, while the KH-test based on the MP criterion was calculated in PAUP.

\subsubsection{Testing alternative tree topologies}

Alternative phylogenies as suggested by phenotypic character combinations were manipulated manually in TreeView (v. 1.5.3, Page 1996) and tested with the approximately unbiased test and the Kishino-Hasegawa test (Kishino \& Hasegawa 1989) as implemented in CONSEL (v. 0.1f, Shimodaira \& Hasegawa 2001). Both tests carried out in CONSEL were based on the ML criterion, while the KH-test based on the MP criterion was calculated in PAUP. Simple sequence divergences as calculated for Trebouxia ITS-variants, were calculated as p-distances with the program MEGA2 (Kumar et al. 2001). In these analyses ambiguously aligned positions were not excluded since the focus here was on the distances between closely related taxa. Positions including gaps in these pairwise comparisons were ignored.

\subsubsection{Sources of phenotypic information}

To identify morphological characters that correlated with the ITS phylogeny, the obtained topologies were compared with phenotypic data summarized in Nordin \& Mattsson (2001), Scheidegger et al. (2001) and citations therein. Further, Purvis et al. (1992), and the genera data set of LIAS (Rambold \& Triebel, 19962002) were consulted. Descriptive data of species were taken from Awasthi (1975), Esslinger (1986), Giralt 
(2001), Hale \& Vobis (1978), Kalb (1987), Kashiwadani (1975), Matzer et al. (1997), Mayrhofer (1984), Mayrhofer, Sheard \& Matzer (1992), Moberg (1977, 1987), Moberg \& Nash, (1999), Moberg \& Purvis (1997), Nimis \& Tretiach (1997), Nordin (2000), Scheidegger (1993), Sérusiaux \& Wessels (1984), Scheidegger (1993), Sheard (1992), Swinscow \& Krog (1976, 1988). Assignment of taxonomic categories mostly followed the nomenclature as given in Myconet (Eriksson et al. 2003), except when otherwise noted.

\subsection{Results}

\subsection{1 nrSSU analyses, phylogenetic positioning of Physciaceae and Caliciaceae within the Lecanorales}

Phylogenetic analyses of nrSSU sequences placed the studied members of the Physciaceae together with species of the Caliciaceae (Cyphelium inquinans, Texosporium sancti-jacobi, and Thelomma mammosum and others as already shown in Wedin et al. (2000) in a well supported monophyletic clade within the Lecanorales (FIG. 3.1). Support for the common origin of the two families was highly significant in Bayesian, maximum-parsimony (MP), and distance (NJ) analyses (1.00, 99\%, 93\% respectively). The branching pattern at the base of the Lecanorales was ambiguously resolved. Depending on taxa selection, inclusion/exclusion of alignment positions and the method of phylogenetic inference, the tree topologies at the base of the Lecanorales differed significantly. Monophyly of the Lecanorales was however consistently supported in all analyses (FIG. 3.1).

Apart from the Caliciaceae-Physciaceae clade, the families Parmeliaceae and Sphaerophoraceae, and the Cladoniaceae-Stereocaulaceae clade were well supported. Support for most other families of the Lecanorales (e.g., the Teloschistaceae) was insignificant. There were no more than 216 parsimony-informative positions in the nrSSU alignment for the Lecanoralean clade. Within the Caliciaceae-Physciaceae clade, the resolution of many relationships was ambiguous. Among the sequences from this clade, 193 sites were variable, of which 98 were parsimony-informative.

The common origin of Buellia georgei, B. elegans, Amandinea punctata, Santessonia sorediata, Buellia aethalea (which represent Subclade IV, see below) with a clade representing the Caliciaceae was resolved with all methods applied and received significant supported in Bayesian analysis, but only moderate or low bootstrap support in MP and NJ analyses (FIG. 3.1). Diploicia, Diplotomma, Dirinaria and Pyxine formed another well supported clade (which represents Subclade III, see below) and formed a sister group to the former two lineages (FIG. 3.1). Monophyly of Physcia spp. with Rinodina gennarii, Physconia with Anaptychia, and Hyperphyscia with Rinodina oxydata was highly supported. However, the relationships among these lineages and further Physciacean taxa were ambiguous in the nrSSU phylogeny (FIG. 3.1). 


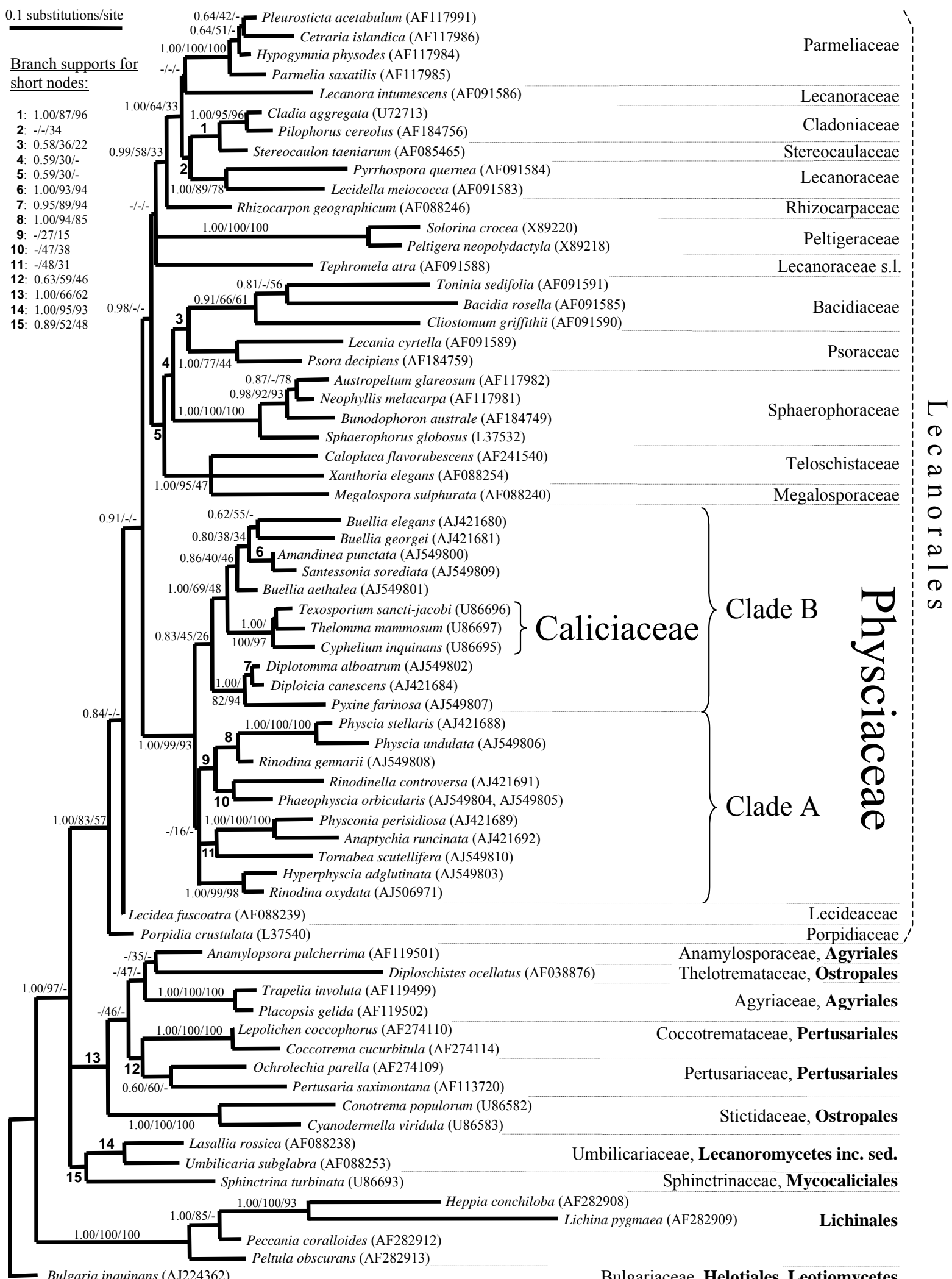

FIG. 3.1: nrSSU phylogeny of selected Lecanorales. Taxonomic assignments as given in Eriksson et al. 2003). Maximum-likelihood phylogram obtained under the 'TVM + G' model (see text). Significance values obtained through Bayesian analysis as well as from bootstrap tests using maximum-parsimony and neighbor-joining (Jukes-Cantor model) are shown in this respective order. Single missing support values indicate that the respective branch was not resolved with the respective method. Nodes without support values did not receive significant support in either analysis. 


\subsubsection{A phylogenetic marker motive in the Physciaceae/Caliciaceae clade}

Consistent separation of the Caliciaceae-Physciaceae clade from other members of the Lecanorales was based on only 12 positions (TABLE 3.3). Two adjacent complementary 4-base stretches (pos. 1220-1223 and 1260-1263 of the reference sequence AF088254 from Xanthoria elegans) were found to be unique for the Caliciaceae-Physciaceae (TABLE 3.3). They form the base of hairpin loop 37 in the secondary structure model of the eukaryotic nrSSU of Wuyts et al. (2002). These sequence stretches were used to construct PCR primers specific for Caliciaceae and Physciaceae (Phy 1200 F, Phy 1200a R and Phy 1200b R; TABLE 1.1) to discriminate against all other fungal families, e.g. common contaminant lichenicolous fungi growing on Physciacean specimens. In addition, these primers were especially helpful for crustose taxa that grew in contact with other crustose lichens of different taxonomic groups.

TABLE 3.3: Unique positions in the nrSSU which delimit the Physciaceae and Caliciaceae from other Lecanorales. Exceptional deviations in brackets. The Xanthoria elegans nrSSU (AF088254) was used as reference sequence.

\begin{tabular}{lll}
\hline \hline Position in X. elegans nrSSU & $\begin{array}{l}\text { Physciaceae, } \\
\text { Caliciaceae }\end{array}$ & Other Lecanorales \\
\hline 146 & A & C (A) \\
148 & C & T (C) \\
650 & T (A) & A (G,T) \\
971 & G (T) & T \\
$1220-1223$ & TTTG & CACA (CANN) \\
$1260-1263$ & CAAA & TGTG (NNTG) \\
\hline
\end{tabular}

\subsection{2 nrITS analyses, phylogentic structure within the Physciaceae}

\subsubsection{Clades and Genera}

In the nrITS phylogeny the monophyly of lineages found in the nrSSU analyses could be confirmed and further refined. Members of the Physciaceae were clearly separated into two major clades, A and B, and each of these clades was further divided into two subclades (subclades I through IV, FIG. 3.2, 2.3). Monophyly of both major clades was well resolved, as was the monophyly of three of the four subclades. Relationships within the subclades, however, were ambiguous in most cases. Because no ITS sequences for Caliciacean taxa were available, the relationship of the Caliciaceae to putative relatives in the Physciaceae could not be tested further. Subclade I (FIG. 3.2) consisted of the genera Heterodermia, Mobergia, Physcia, Tornabea, and Rinodina p.p. Several other species of Rinodina, Buellia lindingeri, and members of the genera Anaptychia, Hyperphyscia, Phaeophyscia, Phaeorrhiza, Physconia, and Rinodinella formed Subclade II. Subclade III comprised the genera Diploicia, Diplotomma, Dirinaria, and Pyxine. With the exception of B. 
lindingeri, the polyphyletic genus Buellia was found to be restricted to Subclade IV, which also included the genera Amandinea, Australiaena, Dermatiscum, Dimelaena, Hafellia, and Santessonia. Monophyletic origin for this subclade was consistently low in the various analyses (Bayesian: 76\%, NJ: 17\%, MP: 18\%).

To examine the monophyly of certain Physciacean genera, additional taxa not represented in FIG. 3.2 were included in the nrITS analyses (TABLES I, III, FIG. 3.3). With this enlarged data set, the monophyly of the genera Physcia, Physconia, Heterodermia, Dirinaria, and Pyxine could be supported and the grouping of Physciella chloantha with Phaeophyscia was well resolved (Subclade II, FIG. 3.3). Anaptychia was found to be potentially polyphyletic. A. runcinata and A. bryorum were placed together with Physconia spp. in one lineage, but A. ciliaris and A. ulotrichoides were distinct from it (Subclade II, FIG 3). The genera Buellia and Rinodina were clearly polyphyletic in the nrITS analyses. 


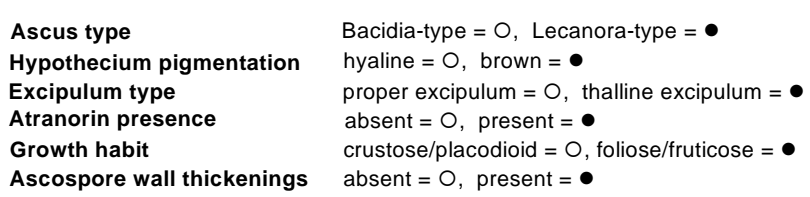

Bacidia-type $=0$, Lecanora-type $=\bullet$

hyaline $=0$, brown $=\bullet$

proper excipulum $=0$, thalline excipulum $=\bullet$

absent $=0$, present $=\bullet$

crustose $/$ placodioid $=0$, foliose $/$ fruticose $=\bullet$

absent $=O$, present $=\bullet$

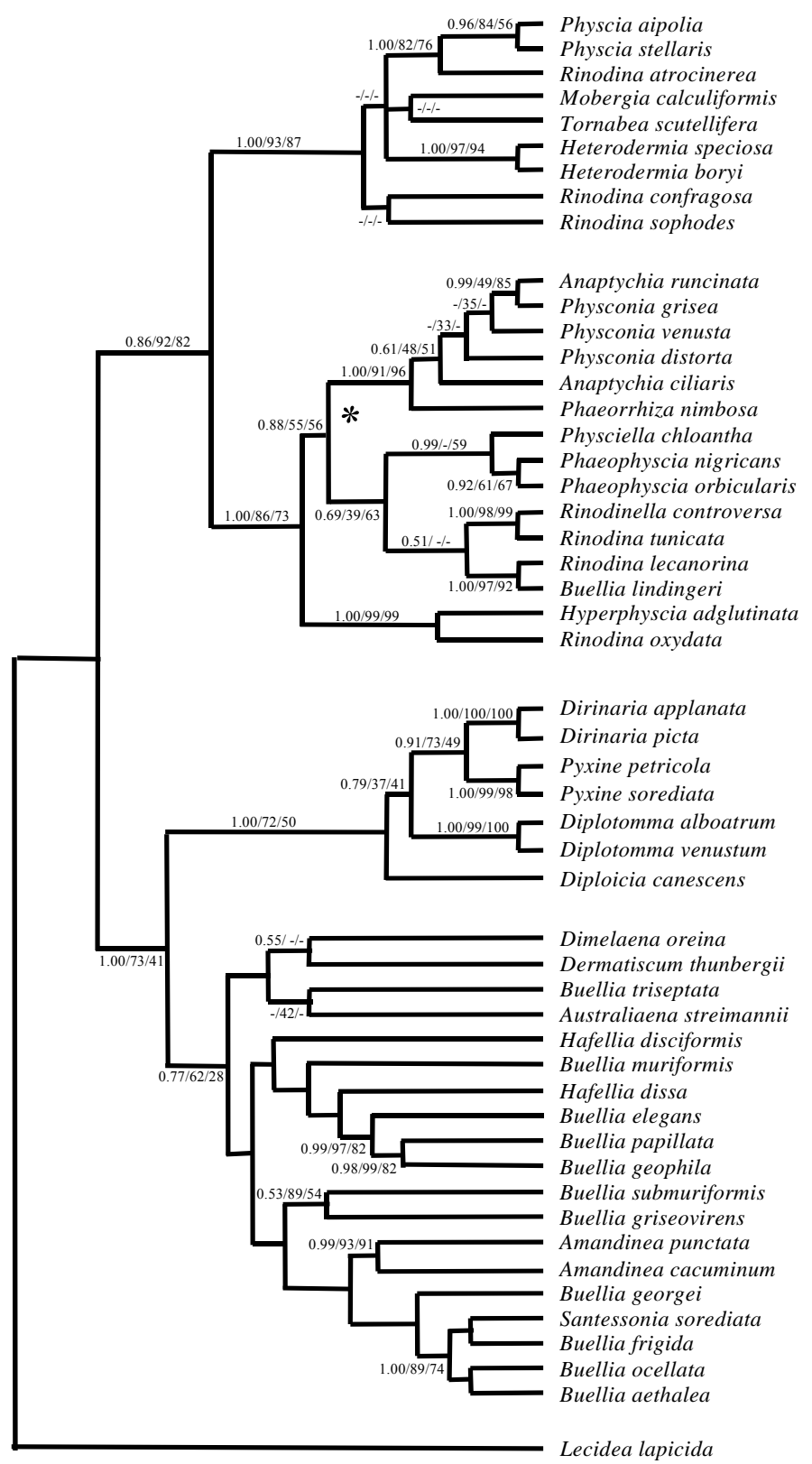

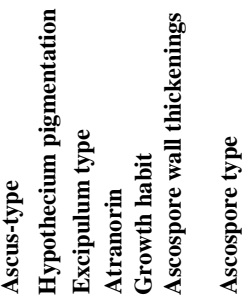

- • • P Physcia-type

- $\bullet \bullet \bullet$ Physcia -type

- $\circ \circ \bullet$ Physcia -type

- $\bullet \circ \bullet$ Physcia-type

- - asexual

- $\circ$ - • Polyblastidium-type

- $\circ$ - $\circ$ Physcia-type

- $\circ \circ \circ \cdot$ Milvina-type

- $\circ \circ \bullet$ Physconia-type

- $\circ \circ \bullet \bullet$ Physconia-type

- $\circ$ - - Physconia-type

- 0 - - Physconia-type

- $\circ \circ \bullet$ - Physconia-type

- $\circ \circ \circ$ Beltraminia -type

- $\circ \circ$ - Physcia-type

- $\circ \bullet \bullet$ Physcia-type

- $\circ \circ \bullet \bullet$ Physcia-type

- $\circ \circ \circ \quad \circ$ Rinodinella-type

- $\circ \circ \circ$ - Tunicata-type

- $\circ \circ \circ \bullet$ Bicincta-type

- 0 0 0 ० 0 Physcia-type

- 0 - Physcia-type

- $\bullet$ - $\bullet$ Mischoblastia-type

- • - Dirinaria-type

- $\bullet$ Dirinaria-type

- $\circ \circ \bullet$ Dirinaria-type

- $\circ \bullet \bullet$ Dirinaria-type

- $\circ \circ \circ \circ$ Diplotomma-type

- $\circ \circ \circ \circ$ triseptate

- $\circ \bullet$ - Dirinaria-type

$\circ$ - $\bigcirc \circ$ Beltraminia-type

- $\circ$ - Beltraminia-type

- 0 ○ 0 o triseteptate

- 0 o 0 ○ variable

- $\circ \circ$ - B Beltraminia-type

- 0 - 0 o muriform

- 0 - - Callispora-type

- $\circ \circ \circ$ Beltraminia-type

- $\circ$ - o Beltraminia -type

- $\circ \circ \circ \circ$ triseteptate

- 0 o muriform

- $\circ$ - o Diplotomma-type

- $\circ \circ \circ \circ$ Beltraminia-type

- 0 - $\bigcirc$ Beltraminia-type

- $\circ \circ \circ$ Beltraminia -type

- - asexual

- $\circ$ o Beltraminia -type

- $\circ \circ \circ$ B Beltraminia -type

- $\circ \circ \circ$ Beltraminia -type
- $\circ \circ \bullet$ Physconia-type
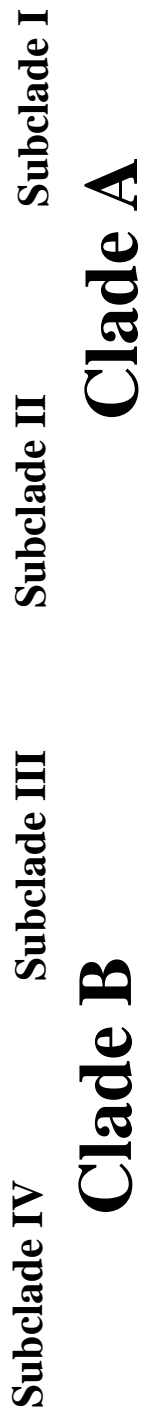

FIG. 3.2: nrITS phylogeny of selected Physciaceae. Maximum-likelihood cladogram obtained under the 'SYM + G' model (see text). Significance values obtained through Bayesian analysis as well as from bootstrap tests using maximum-parsimony and neighbor-joining (Jukes-Cantor model) are shown in this respective order. Single missing support values indicate that the respective branch was not resolved with the respective method. Nodes without support values did not receive significant support in either analysis. Support values (posterior probabilities) obtained in Bayesian analyses are regarded as significant when exceeding 0.95. Note: The type species of Santessonia, S. namibensis Hale \& Vobis has a Bacidia-type ascus, a pigmented hypothecium, Beltraminia-type ascospores, and a lecideine apothecium (Hafellner at al. 1979). The lineage marked with an asterisk (*) was tested for alternative topologies as shown in TABLE 3.6. 


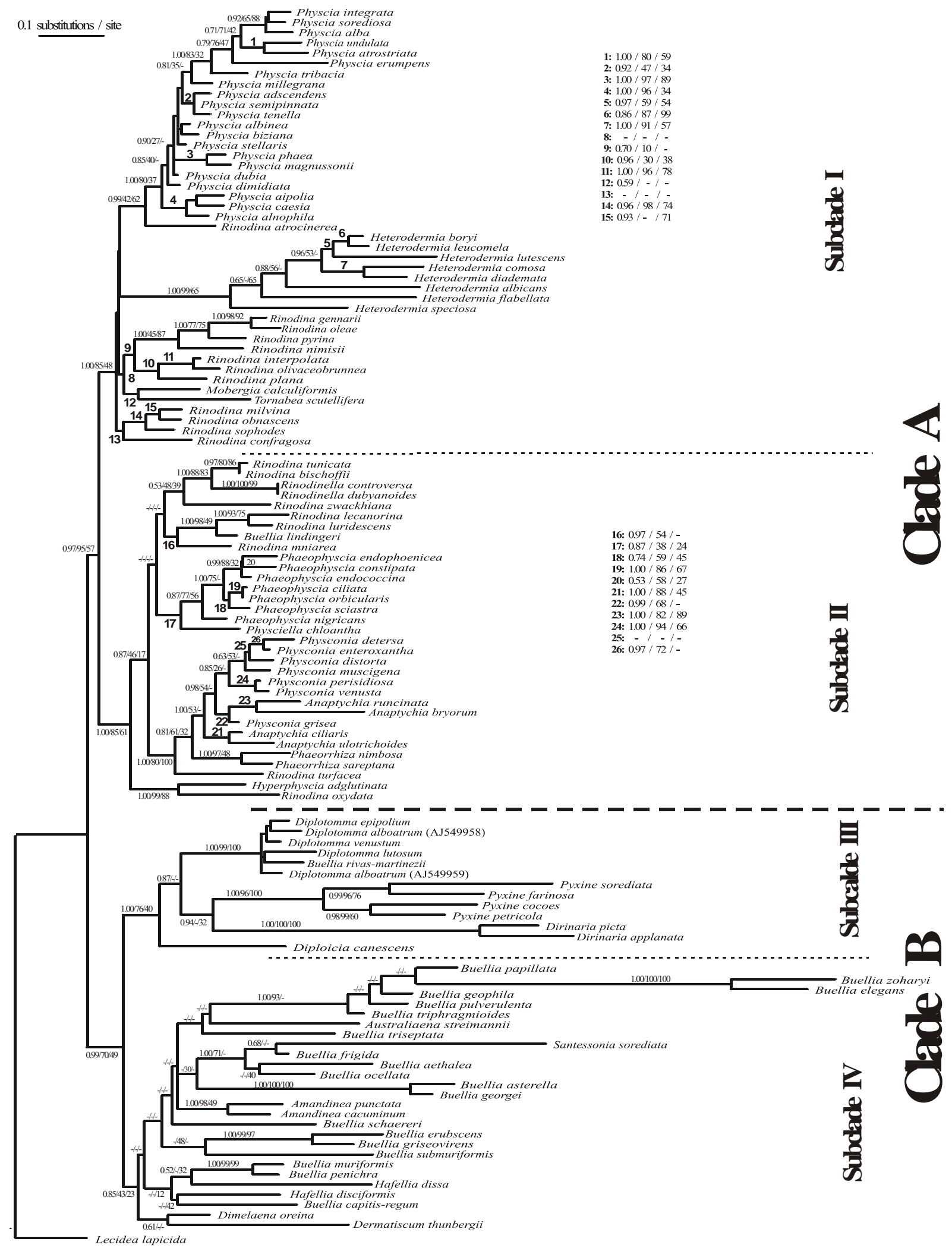

FIG. 3.3: nrITS phylogeny of all Physciaceae species investigated. Maximum-likelihood phylogram obtained under the 'SYM + G' model (see text). Significance values obtained through Bayesian analysis as well as from bootstrap tests using maximum-parsimony and neighbor-joining (Jukes-Cantor model) are shown in this respective order. Single missing support values indicate that the respective branch was not resolved with the respective method. Nodes without support values did not receive significant support in either analysis. Support values (posterior probabilities) obtained in Bayesian analyses are regarded as significant when exceeding 0.95 . 


\subsection{Discussion}

Analysis of nrSSU sequence data revealed the Physciaceae to be paraphyletic with the Caliciaceae. Together, these two families formed a well supported monophyletic clade within the Lecanorales as has already been shown by Wedin et al. (2000). The addition of a broad sample of taxa representing the phenotypic variety of the Physciaceae in the present study revealed a particular lineage (Subclade IV) within the Physciaceae that most likely forms the sister group with the Caliciaceae. The analysis of nrITS sequences from 23 of the 27 Physciacean genera showed the Physciaceae to consist of two major clades. Ascus characters and hypothecium pigmentation were found to corroborate the delimitation of the two clades. A general correlation of ascospore and excipulum characters with these clades could be revealed but a considerable degree of homoplasy was detected in these traits. The presence of secondary compounds derived from the acetate-polymalonate pathway such as atranorin or norstictic acid seemed to delimit the foliose genera of Subclades I and II. Characters such as growth habit and structure of the upper cortex did not correlate with clade or subclade delimitations but were shown to be indicative at genus level.

\subsection{1 nrSSU phylogeny}

\subsubsection{General aspects}

The proportion of parsimony-informative positions within the Lecanoralean nrSSU alignment was comparatively small. Further, a large proportion of these positions appeared to be quite variable and resulted in a high content of homoplasy, especially when distantly related taxa were compared. In addition, the number of informative positions supporting a single node in a cladogram was in a similar magnitude as that of presumable sequence errors or point mutations that were not deleted by selection. An unfavorable relation of phylogenetic signal and "background noise" (nucleotide substitutions which do not reflect relatedness of taxa) as well as the large number of uninformative sites might obscure bootstrap analyses, the most widespread method for evaluating reliability of phylogenetic reconstructions (Zharkikh and Li 1992, Hillis and Bull 1993). The effect may be clearly seen in recently published Euascomycete nrSSU phylogenies in which basal nodes are all without support (Stenroos et al. 1998, Wedin et al. 2000, Lutzoni et al. 2001). In contrast to bootstrap analyses that ignore a considerable fraction of alignment positions for each bootstrap replicate, Bayesian analysis makes use of all alignment positions during the process of significance measurement. Among other reasons, this increases the support particularly of basal branches. Further, this method revealed phylogenies that corresponded well to maximum likelihood analyses, but needed much less computing time. Therefore, this method of phylogenetic analysis was preferred over all other methods of phylogenetic reconstruction. 


\subsubsection{Outgroup}

In addition to taxon sampling, the choice of the outgroup might significantly influence tree topologies. This might explain apparent differences among the Lecanorales phylogeny shown here and phylogenies of other authors (e.g. Lutzoni et al. 2001, Stenroos et al. 1998, Wedin et al. 2000). These authors used taxa outside the Euascomycetes as outgroups, such as Saccharomyces cerevisiae or even more distantly related taxa. However, the focus of this study was to clarify the position of the Physciaceae within the Lecanorales and therefore, S. cerevisiae was suspected to be too distantly related to the taxa under consideration and might have resulted in a too high degree of homoplasy. Hence, Bulgaria inquinans (Helotiales) was chosen as outgroup for the Lecanoralean phylogeny.

\subsubsection{Monophyly of a clade uniting Caliciaceae and Physciaceae}

Despite the lack of significant support for basal nodes in the Lecanoralean phylogeny, the CaliciaceaePhysciaceae clade was highly supported and could be unambiguously recognized by two adjacent complementary 4-base stretches forming the base of hairpin loop 37 of the nrSSU (Wuyts et al. 2002). The uniqueness of these positions is assumed to originate from an ancient reciprocal strand exchange as can be deduced from the high similarity of the corresponding regions in other Lecanoralean taxa (TABLE 3.3). In addition to the monophyly of the Caliciaceae-Physciaceae clade, an affiliation of the Caliciaceae to a particular lineage within the Physciaceae is indicated by the nrSSU phylogeny. When compared to the ITS phylogeny, the Physciacean taxa closest related to the Caliciaceae are members of Subclade IV (FIG. 3.2). Both are connected by the presence of a true excipulum, Beltraminia-type ascospores and similar ascospore ontogeny and ornamentation, characters which are considered to be important phylogenetic traits in this lichen group (Nordin 2000, Wedin et al. 2000).

\subsubsection{The taxonomic significance of ascus types}

According to Hafellner (1984) the coherence of the Caliciaceae-Physciaceae clade might be questioned because different ascus types or subtypes are observed in this clade: the prototunicate ascus in the Caliciaceae, the Bacidia-type ascus in Buellia and allied genera, and the Lecanora-type ascus found in the taxa of Clade A. However, the latter two ascus types were shown to be variable (Ekman 1996, Thell et al. 1995) and might closely resemble each other at certain ontogenetic stages. Therefore, it is assumed that both ascus types are related. The prototunicate ascus of the Caliciaceae, in fact, is not interpreted as an ascus type of its own but rather a reduction of an ancient non-prototunicate ascus type, as proposed by Wedin et al. (2000). Compared to other ascus types within the Lecanorales that are well distinguished by amyloid structures such as tubes or caps (Porpidia-type, respectively Lecidea-type), the occurrence of different but structurally related ascus types is not regarded as a contradiction to the monophyly of the Caliciaceae- 
Physciaceae clade. All three ascus types found in species of the Caliciaceae-Physciaceae clade are also found in families included in the sister clade of the Caliciaceae-Physciaceae clade (FIG. 3.1), which corroborates the sistergroup relationship between these two clades. Further, it could be suspected that the CaliciaceaePhysciaceae clade might be more closely related to other Lecanoralean families with the same ascus types than to families with different ascus types. Potential relationships of the Caliciaceae-Physciaceae to other Lecanoralean families then would be to the Lecanoraceae, Parmeliaceae, Candelariaceae (with Lecanoratype asci) or Bacidiaceae and Ramalinaceae (both with Bacidia-type asci). A closer relationship of the Caliciaceae-Physciaceae clade to any of these Lecanoralean families than to families with different ascus types could neither be validated nor rejected on the basis of the presented Lecanoralean nrSSU phylogeny.

\subsection{2 nrITS phylogeny}

\subsubsection{Outgroup}

To root Physciaceae ITS phylogenies, various taxa already have been used as outgroup (Grube et al. 2001, Lohtander et al. 2000). As seen in the nrSSU phylogeny (FIG. 3.1), the genus Lecidea appeared as the taxon closest to the root of the Physciaceae. When using Lecidea lapicida (AF 282124) as outgroup, the $t_{\text {RASA }}$ test statistic increased considerably. This effect was consistent, regardless of the portion of ambiguous positions removed from the alignment prior to phylogenetic inference. In addition, Lecidea lapicida did not appear as an extraneous element in an unrooted RASA plot.

\subsubsection{Two major clades}

The distinction of two major clades in the nrITS phylogeny is congruent with the distribution of certain morphological character states (FIG. 3.2, TABLE 3.4). The distribution of the ascus type, hymenium pigmentation, excipulum type and various ascospore types turned out to significantly correlate to the clades of the nrITS phylogeny. However, no character could be detected that was absolutely free of homoplasy. Taxa that exhibit deviations from the typical character states of their assigned subclade are listed in TABLE 3.5. Taxa of Clade A typically are characterized by the Lecanora-type ascus, an unpigmented hypothecium, a thalline excipulum, and ascospores with wall thickenings or Rinodinella-type ascospores. Pluriseptate ascospores were the exception in this clade. Members of Clade B typically have Bacidia-type asci, a pigmented hypothecium, a proper excipulum, and usually ascospores without distinctive wall thickenings or Dirinaria-type ascospores. Pluriseptate ascospores are more frequent in Clade B than in Clade A and might have evolved several times here (Nordin 2000). 


\subsubsection{Ascus structures}

After ascus structures were accepted as major phylogenetic traits in ascomycetes (Chadefaud et al. 1963, 1968), ascus types were described in detail for lichens by Bellemère \& Letrouit-Galinou $(1981,1987)$ and Hafellner (1984) and used to delimit families of lichenized ascomycetes (e.g., Hafellner 1984). With respect to the Physciaceae, ascus structures and types were already discussed by Rambold et al. (1994). The present study revealed the ascus type as one of the most constant phylogenetic traits in the Physciaceae, corroborating the subdivision of this family as seen in the ITS phylogeny. This coincides with a survey in the Pezizaceae (Pezizomycetes), where ascus types also correlated well with nrDNA phylogenies (Hansen et al. 2001), supporting the phylogenetic significance of this trait. The only critical genus in this study is Australiaena, which inserts in Subclade IV but develops a Lecanora-type ascus. Further, a couple of Rinodina species develop a Bacidia-type ascus (TABLE 3.5). Interestingly these Rinodina species exhibit additional character states that assign them to Clade B (Giralt 2001). Therefore, these taxa are not considered exceptions but in need of a revision. All Buellia-like genera established by Marbach (2000) are described with Bacidia-type asci, which indicates their relationship to taxa included in Clade B as described here. In other lichen families, the taxonomic significance of ascus structures and types have been controversially discussed due to the observation of ascus-type variation within families or even genera that were homogenous with respect to other morphological characters (Lumbsch et al. 2001, Hafellner 1984, Rambold et al. 1998a). In Buellia oidalea and B. oidaliella, both with extremely large spores, an axial body is expressed that closely resembles that of the Lecanora-type ascus (Nordin 2000). However, in most of the investigated Physciaceae, ascus type did not seem to correlate with ascospore size (data not shown) as observed in the Bacidiaceae (Ekman 1996).

TABLE 3.4: Typical character state distribution among clade A and B. Exceptions from these clade - character state assignments are listed in TABLE 3.5. For further discussion see text.

\begin{tabular}{|c|c|c|}
\hline & Clade A & Clade B \\
\hline Ascus type & Lecanora-type ascus & $\begin{array}{l}\text { Bacidia-type ascus or } \\
\text { prototunicate ascus (Caliciaceae } \\
\text { Chevall.) }\end{array}$ \\
\hline Hypothecium pigmentation & hyaline hypothecium & pigmented hypothecium \\
\hline $\begin{array}{l}\text { Ascospores wall } \\
\text { thickenings }\end{array}$ & $\begin{array}{l}\text { with distinct wall thickenings } \\
\text { or of Rinodinella-type }\end{array}$ & $\begin{array}{l}\text { ascospores without distinct wall } \\
\text { thickenings or of Dirinaria-type }\end{array}$ \\
\hline Excipula types & $\begin{array}{l}\text { Species usually with thalline } \\
\text { excipula }\end{array}$ & $\begin{array}{l}\text { Species usually with proper } \\
\text { excipula }\end{array}$ \\
\hline $\begin{array}{l}\text { Occurrence of pluriseptate } \\
\text { Ascospores }\end{array}$ & quite rare & more common, polyphyletic \\
\hline
\end{tabular}


TABLE 3.5: Taxa that were recognized to develop character states which deviate from the typical character state of their subclade as depicted in TABLE 3.4.

\begin{tabular}{|c|c|c|c|c|}
\hline Deviating taxon & $\begin{array}{c}\text { Subclade } \\
\text { to which the } \\
\text { deviating taxon } \\
\text { is assigned to } \\
\end{array}$ & $\begin{array}{l}\text { Conflicting } \\
\text { character }\end{array}$ & $\begin{array}{l}\text { Deviating } \\
\text { character } \\
\text { state }\end{array}$ & $\begin{array}{l}\text { Typical character } \\
\text { state of the subclade to } \\
\text { which the deviating } \\
\text { taxon is assigned to }\end{array}$ \\
\hline "Buellia" lindingeri & II & Excipulum type & proper & thalline \\
\hline Phaeorrhiza nimbosa & II & Ascospore wall thickenings & absent & present \\
\hline Rinodina luridescens & II & Hypothecium pigmentation & present & absent \\
\hline R. oxydata & II & Atranorin presence & present & absent \\
\hline Dirinaria spp. & III & Excipulum type & thalline & proper \\
\hline Amandinea cacuminum & IV & Excipulum type & thalline & proper \\
\hline Australiaena streimannii & IV & $\begin{array}{l}\text { Ascus type } \\
\text { Ascospore wall thickenings }\end{array}$ & $\begin{array}{l}\text { Lecanora } \\
\text { present }\end{array}$ & $\begin{array}{l}\text {-type Bacidia-type } \\
\text { absent }\end{array}$ \\
\hline Buellia ocellata & IV & Excipulum type & thalline & proper \\
\hline Dermatiscum thunbergii & IV & Excipulum type & thalline & proper \\
\hline Dimelaena oreina & IV & $\begin{array}{l}\text { Hypothecium pigmentation } \\
\text { Excipulum type }\end{array}$ & $\begin{array}{l}\text { hyaline } \\
\text { thalline }\end{array}$ & $\begin{array}{l}\text { pigmented } \\
\text { proper }\end{array}$ \\
\hline Hafellia spp. & IV & Ascospore wall thickenings & present & absent \\
\hline
\end{tabular}

\subsubsection{Ascospore characters}

Ascospore characters also delimited clades A and B from each other. In contrast to members of Clade B, taxa of Clade A usually develop ascospores with distinct wall thickenings, designated to about 16 different types (Mayrhofer 1982, 1984, Nordin 1997, but see Matzer and Mayrhofer 1996). Rinodinella takes an exceptional position in this aspect, because it develops ascospores with unusually thin ascospore walls without any thickenings (Rinodinella-type). Physcia-, Pachysporaria-, and Polyblastidium-types occur together within well separated genera (e.g. Physcia, Phaeophyscia, and Heterodermia, Mayrhofer 1982) and regularly form intermediates even within single species (e.g. Swinscow \& Krog 1988). They are therefore considered as belonging to one major type in this study. This ascospore type is found in five lineages of Clade A, i.e. Heterodermia, Physcia and Rinodina atrocinerea, Mobergia, and Rinodina confragosa (Subclade I), as well as in Buellia lindingeri, Phaeophyscia (including Physciella), and Hyperphyscia (Subclade II). Also the Physconia-ascospore type appears homoplasious. This ascospore type might have developed in Subclade II in the assumed common ancestor of Anaptychia and Physconia, and in Subclade I in Tornabea. Phaeorrhiza might be an exception, because it develops the Beltraminia ascospore type, which otherwise is typical for Clade B. However, Mayrhofer \& Poelt (1978) described occasional thickenings of the ascospore. In Clade B, ascospores with wall thickenings evolved only in few cases (TABLE 3.5). Most common are the Buellia- and the Beltraminia-ascospore type and pluriseptate ascospores that do not exhibit distinct wall thickenings. Beltraminia- and Buellia-ascospore types, originally delimited by the presence/absence of a torus (Mayrhofer 1984), were not distinguished in this study, following Matzer \& Mayrhofer (1996). The Beltraminiaascospore type differs from the Rinodinella-type in that its ascospore walls are uniformly thickened. In the 
assumed common ancestor of Diploicia, Pyxine, and Dirinaria the Dirinaria ascospore type with wall thickenings and Type-B ontogeny evolved. This spore type is also found in a group of Rinodina species in Clade A (FIG. 3.3), represented by the species $R$. gennarii, $R$. olea, and $R$. nimisii. Notably, R. pyrina clustered within these species and develops Physconia-type ascospores. Further Rinodina species with type B ascospore ontogeny are known (Giralt 2001, Scheidegger 2001), which phylogenetic position was not investigated. Marbach (2000) described Cratiria Marbach, Fluctua (Malme in J. Steiner) Marbach and Sculptolumina Marbach with pronounced ascospore wall thickenings. As mentioned above, major phylogenetic traits denote these three genera as members of Clade B. Considering their tropical origin, an affiliation to Subclade III might be suspected. Triseptate, submuriform (Diplotomma-type) or muriform ascospores seem to have evolved several times (Nordin 2000). Especially in the genus Diplotomma, the number of septa seems to be a rather variable trait.

\subsubsection{Hypothecium pigmentation}

Hypothecium pigmentation turned out to be a highly conserved phylogenetic trait and proved to be of similar phylogenetic significance as ascus type. Exceptions were recognized in few species of the genera Dimelaena and Rinodina (Giralt 2001, Sheard 1974, Mayrhofer et al. 1996). Notably, in Dimelaena oreina, generally described to have a hyaline hypothecium, Hafellner et al. (1979) mention specimens with dark hypothecium. In addition, the closest relative of the genus Dimelaena treated in this study, Dermatiscum thunbergii, retained the hypothecial pigmentation. All genera described by Marbach (2000) have a pigmented hypothecium, again strongly suggesting their relatedness to taxa of Clade B.

\subsubsection{Excipulum type}

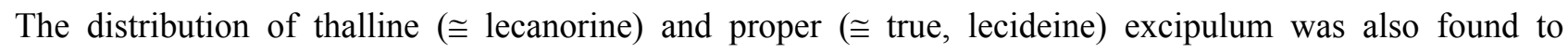
correspond to the bipartition of the Physciaceae. However, more exceptions were found in this trait than in the previously discussed characters. In Clade A, which taxa are usually characterized by a thalline excipulum, Buellia lindingeri exhibits a proper excipulum. In addition, Phaeorrhiza sareptana (Tomin) H. Mayrhofer \& Poelt, not included in this study (but see Grube \& Arup 2001), develops a lecideine excipulum. For Rinodina species with lecideine excipulum and taxa assigned to Clade B with thalline excipulum, see TABLE 3.5. All genera described by Marbach (2000) exhibit true excipula. Excipulum type may be a less conservative character than the presence of hypothecium pigmentation and, therefore, the genera Buellia and Rinodina may be more readily distinguished by this latter trait. In addition, hypothecium pigmentation is a character easy to recognize and apparently almost as well conserved as ascus type. 


\subsubsection{Upper cortex structure}

Upper cortex structure turned out to be quite variable and is not indicative for the relatedness of genera, as was initially implied by the former taxonomies, e.g. uniting species of the genera Anaptychia and Heterodermia or Physcia and Physconia (Zahlbruckner 1926). Poelt (1965) realized the insignificance of this trait and published a more refined system, which, in its coarse outline, has remained unchanged. The different structures of the upper cortex (elongated hyphae forming a prosoplectenchymatic cortex versus more or less isodiametric hyphae forming a paraplectenchymatic cortex) do not correlate with the delimitation of clades or subclades. In Clade A, both subclades contain both forms of upper cortex. In Subclade I, Physcia is characterized by a paraplectenchymatic cortex, in Subclade II, Physconia, Phaeophyscia and Hyperphyscia develop this cortex type. A prosoplectenchymatous upper cortex is found in Heterodermia and Tornabea (Subclade I) as well as in Anaptychia (Subclade II). The genera Anaptychia and Physconia are separated by this character but intermix in phenotypic as well as genotypic surveys, as published in Nordin et al. (2001) and Lohtander et al. (2000). A closer look also reveals that there is still some variability within each cortex type. For instance, Moberg (1977) distinguished Physconia grisea from all other Physconia species, partly due to a different cortex structure. This points to a high intrageneric variability, which eventually might enable the reversal of this character state. Therefore, a separation of $A$. runcinata from Physconia, based on this character, might not depict natural relationships. Besides these two genera, variation in the upper cortex structure seems to follow genus delimitations well.

\subsubsection{Growth habit}

The foliose growth habit seems to have evolved five times in Clade A. Hyperphyscia, Heterodermia, Physcia and Phaeophyscia appear as independent lineages, being separated by crustose Rinodina species. Anaptychia and Physconia form a single foliose lineage, signaling a closer relationship between these two genera than revealed for the other foliose genera in this clade. This assumption is further confirmed by the common ascospore type developed in both genera. The fruticose thallus of Tornabea, often regarded as closely related to Anaptychia (Mayrhofer 1982, Nordin \& Mattsson 2001), probably evolved independently. Therefore, the fruticose thallus does not represent an enhancement of a foliose growth habit, but a developmental line of its own (Poelt 1965). In Clade B more highly organized growth forms evolved at least three times: Once in Santessonia (fruticose); once in Dermatiscum (umbilicate); and once leading to the related genera Dirinaria and Pyxine (foliose). Also here, both genera are characterized by a common ascospore type. In addition, the umbilicate genus Dermiscellum is believed to belong to this clade. Multiple origins of non-crustose growth forms were postulated by Frey (1963) and Poelt (1965). Poelt assumed Rinodina and Buellia species as the closest relatives of each of these foliose/fruticose lineages. After asserting the evolutionary independence of these lineages with molecular data, it became evident that major ascospore types have remained constant during the radiation of these higher organized lineages, resulting in a remarkable uniformity of ascospore 
types in non-crustose lineages. This might suggest that the evolution of major ascospore types predates the origin of these foliose genera. Therefore, different major ascospore types (no intermediates or intraspecific transitions observed between these major ascospore types) might be considered as indicative for the delimitation of genera.

\subsubsection{Secondary compounds}

Secondary compounds derived from the acetate-polymalonate pathway delimit the foliose taxa of Subclade I from those of Subclade II (Nordin \& Mattsson 2001, Scheidegger et al. 2001). Foliose taxa of Subclade I are characterized by the presence of secondary compounds, such as atranorin or norstictic acid, synthesized via the acetate-polymalonate pathway, while taxa of Subclade II lack such substances. Contradicting statements concerning Anaptychia ciliaris were found. Whereas Kurokawa (1973) (followed by Hafellner et al. (1979) and Nordin \& Mattsson (2001)) found minor amounts of atranorin in this species, Scheidegger et al. (2001) noted the absence of this substance. Rinodina oxydata was the only species found in Subclade II that synthesizes atranorin. Two lineages of Rinodina species in Subclade I, annotated with branch support numbers 9 and 14 in FIG. 3.3, lack secondary compounds. Also in Tornabea scutellifera no secondary compounds were found. In addition, Tornabea scutellifera develops ascospores of the Physconia-type, which is typical for the Phaeorrhiza/Anaptychia/Physconia cluster in Subclade II. In order to evaluate these contradicting affiliations of phenotypic traits on one side and ITS sequence data on the other, the phylogenetic positions of $R$. sophodes and T. scutellifera were tested with the approximately unbiased test and the Kishino-Hasegawa test. Various constrains were set as shown in TABLE 3.6 A-I. Under ML as well as MP settings, all tested alternative topologies were rejected at the $5 \%$ significance level. 
TABLE 3.6: Tests of alternative topologies for the Anaptychia/Phaeorrhiza/Physconia lineage (Subclade II, marked with an asterisk in FIG. 3.2) when a closer relationship of Rinodina sophodes and Tornabea scutellifera (both members of Subclade I) with this lineage is assumed as it may be suspected from phenotypic data (A-I). In addition, a close relationship of Anaptychia runcinata to A. ciliaris was tested (J, K). The ML topology in FIG. 3.2 was used as the $\mathrm{H}_{0}$ topology and had a length of 1175 parsimonious steps. Manipulated taxa are shown in bold face. P-values below $5 \%$ were regarded as significant to reject the alternative topology. P: P-value of the respective tests, au: approximately unbiased test (CONSEL), ML: KH-test under the ML criterion (CONSEL), MP: KH-test under the MP criterion (PAUP). P. nim. = Phaeorrhiza nimbosa, A. cil. = Anaptychia ciliaris, $P$. dis. = Physconia distorta, $P$. ven. $=$ Physconia venusta, $P$. gris. $=$ Physconia grisea, A. run. $=$ Anaptychia runcinata

Original topology:

(P. nim. (A. ciliaris (P. dis. (P. ven. ( P. gris., A. runcinata)))))

Alternative topologies:

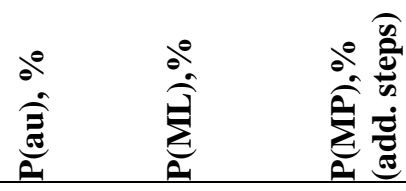

\begin{tabular}{|c|c|c|c|c|}
\hline A & (R. sophodes (T. scutellifera (P. nim. (A. cil. (P. dis. (P. ven. ( P. gris., A. run.))))))) & 0.0003 & 0.006 & $0.0037(20)$ \\
\hline$B$ & (R. sophodes (P. nim. (T. scutellifera (A. cil. (P. dis. (P. ven. ( P. gris., A. run.))))))) & $<0.0001$ & 0.003 & $0.0008(25)$ \\
\hline & (P. nim. (R. sophodes (T. scutellifera (A. cil. (P. dis. (P. ven. ( P. gris., A. run.))))))) & 0.001 & 0.0004 & $<0.0001(30)$ \\
\hline & (P. nim. (R. sophodes, T. scutellifera), (A. cil. (P. dis. (P. ven. ( P. gris., A. run.))))) & 0.0002 & $<0.0001$ & $0.0002(19)$ \\
\hline & (R. sophodes, T. scutellifera), (P. nim. (A. cil. (P. dis. (P. ven. ( P. gris., A. run.))))) & $<0.0001$ & 0.002 & $0.0016(15)$ \\
\hline & $($ R. sophodes (P. nim. (A. cil. (P. dis. (P. ven. ( P. gris., A. run. $))))))$ & 0.002 & 0.004 & $0.0043(11)$ \\
\hline & (P. nim. (R. sophodes (A. cil. (P. dis. (P. ven. ( P. gris., A. run.)))))) & $<0.0001$ & 0.0002 & $0.0001(19)$ \\
\hline & (T. scutellifera (P. nim. (A. cil. (P. dis. (P. ven. ( P. gris., A. run.)))))) & 0.019 & 0.012 & $0.0160(11)$ \\
\hline & (P. nim. (T. scutellifera (A. cil. (P. dis. (P. ven. ( P. gris., A. run.)))))) & 0.006 & 0.006 & $0.0015(16)$ \\
\hline & $(P$. nim. (A. ciliaris (A. runcinata (P. dis. (P. ven., P. gris., A. run.))))) & 0.053 & 0.054 & 0.1026 \\
\hline & (P. nim. (A. ciliaris, A. runcinata), (P. dis. (P. ven., P. gris. $))))$ & 0.019 & 0.033 & 0.0957 (5) \\
\hline
\end{tabular}

\subsubsection{Monophyly of genera}

To ensure unbiased taxon sampling, only a selection of the available ITS sequences of Physciacean species were included in the phylogenetic analyses shown in FIG. 3.2. Additional taxa were analyzed separately and used to further test the monophyletic origins of Physciacean genera (FIG. 3.3). When sequences from additional species of Physcia were included, the genus was still resolved as a well delimited clade. Rinodina atrocinerea was always most closely related to Physcia spp. When additional species of Heterodermia were included, their single origin was strongly supported. The common origin of Anaptychia runcinata and A. bryorum with Physconia spp. was consistently supported, thus showing paraphyly of both genera. A. ciliaris and A. ulotrichoides, formed a sister group to the clade comprising all Physconia species as well as A. runcinata and A. bryorum (FIG. 3.3). Paraphyly of Anaptychia was already shown in the molecular approaches by Lohtander et al. (2000), Grube \& Arup (2001) and a morphological survey by Nordin \& Mattsson (2001). A. runcinata shares adnate lobe tips, a lower cortex and hairs on the upper cortex with Physconia spp. and deviates in these characteristics from A. ciliaris (Nordin \& Mattsson 2001). In contrast, 
Anaptychia species share, by definition, the same upper cortex structure. Further, Helms et al. (2001) reported photobiont ITS-variants from A. ciliaris and A. runcinata that were closely related to each other but distantly related to all the studied Physconia photobionts. Therefore, mycobiont selectivity towards particular photobionts might be another trait that supports a delimitation of Anaptychia from Physconia species. In a ML-based Kishino-Hasegawa test and the approximately unbiased test as implemented in CONSEL (Shimodaira \& Hasegawa 2001), the hypothesis that Anaptychia is either monophyletic or paraphyletic but basal to Physconia could not be rejected at the 5\% significance level (TABLE $3.6 \mathrm{~J}, \mathrm{~K}$ ). Therefore, uncertainty remains about the phylogenetic relationship between these two genera. The genus Rinodina (type species: $R$. sophodes) was found to be a polyphyletic assemblage, which confirms the findings of Grube \& Arup (2001). Species of Rinodina were found in at least six independent lineages of clade A. Further branches of Rinodina species might be found, because Rinodina is by far the largest genus in Clade A and therefore least well represented. In addition, none of the typically corticolous, lignicolous and blastidate Rinodina species were included in this study. Mayrhofer (1984) described 15 ascospore types in this genus demonstrating a high diversity when compared with the foliose genera. Hyperphyscia, Tornabea and Mobergia appear to be small and well-delimited genera in which monophyly seems likely but cannot be discussed here because they were represented by only one species in this study. Monophyly of Phaeorrhiza nimbosa and P. sareptana already was shown by Grube \& Arup (2001).

\subsubsection{Diplotomma and the delimitation of Subclade III and Subclade IV}

The delimitation of Subclade III and Subclade IV, based on phenotypic traits only, seems problematic. Diploicia, Dirinaria and Pyxine are delimited from all other investigated members of Clade B by their Dirinaria-type ascospores. However, Diplotomma s. str. has triseptate or Diplotomma-type (= submuriform) ascospores that also occur in Subclade IV. Species of Diplotomma s. str. are characterized by calcium oxalate in the thallus, often pruinose apothecia, and a thick perispore which distinguishes them from most of the taxa of Subclade IV (Nordin 2000). A pruina which consists of calcium oxalate is also found in other members of Subclade III which supports a closer relationship of these taxa. A close affiliation of Diplotomma species and Diploicia had been already shown by Molina et al. (2002), who suggested the unification of the two genera. However, both genera are well delimited by their ascospore-types as well as ITS sequences and were therefore confirmed as two distinct genera in this study. The conspecificity of species determined as Diplotomma epipolium and $D$. venustum could be confirmed here on the basis of ITS sequence comparisons. Both share a seven base pair deletion in the most variable part of ITS-1 compared to other Diplotomma species. Because of the high variability of this part of ITS-1 no unambiguous alignment with other Physciacean ITS sequences was possible and it could therefore not be used in phylogenetic analyses. This may have caused the poor resolution among the sequences from Diplotomma in FIG. 3.3. A separate analysis 
of the Diplotomma taxa (not shown), in which all positions could be included and Diploicia canescens was used as outgroup, revealed Diplotomma rivas-martinezii as sister taxon to $D$. venustum. $D$. lutosum and $D$. pharcidium formed one lineage, which phylogenetic position in relation to D. alboatrum was ambiguous. Specimens assigned to the latter species exhibited a quite variable ITS region. Up to $6 \%$ sequence divergence could be observed in this species (nine specimens analyzed, data not shown), while the largest substitution rate among all the included Diplotomma species was only $8 \%$. Even in this better resolved analysis, $D$. alboatrum was paraphyletic. Buellia pulverulenta (Anzi) Jatta was not supported as a member of the Diplotomma cluster (Subclade III) as it was assumed by Nordin \& Mattsson (2001), but was found to be closely related to Buellia geophila in the present study (FIG. 3.3, subclade IV). The taxa of Subclade IV appear as a rather diverse assemblage, with respect to morphological characters as well as nrITS sequence data. This particularly applies to the large genus Buellia even after the segregation of Amandinea, Australiaena, Dimelaena, Diplotomma, and Hafellia (FIG. 3.3). Although weakly supported, Dermatiscum and Dimelaena form a clade. This coincides with their thalline excipulum which is otherwise rare within Subclade IV. The common origin of these two genera is further corroborated by Nordin's (2001) cladogram in which both genera form a well-supported clade. Ascospore ontogeny and ornamentation are regarded as important phylogenetic traits in this clade (Nordin 2000, Wedin et al. 2000), but the phylogenetic relevance of these characters could not be tested further due to the poor resolution among the taxa included in this molecular approach. Compared to the known diversity of this group, the number of available ITS sequences is still low and addition of further taxa might strongly influence cladistic analyses.

\subsubsection{The systematic position of Dirinaria and Pyxine}

The clade affiliation of some taxa was unexpected, referring to older literature, or disagreed with trait assignment to certain subclades as described here. The closer relationship of the genera Dirinaria and Pyxine to Diplotomma (Clade B) than to taxa of Clade A was unexpected. In former taxonomic surveys (Awasthi 1975, Nordin \& Mattsson 2001, Scheidegger et al. 2001), Dirinaria and Pyxine were assumed to be related to the foliose genera Physcia or Heterodermia, or at least to be descendants of an ancestor related to Rinodina (Mayrhofer 1982). This was due to similarities in growth habit, excipulum type and the presence of ascospore wall thickenings, which were thought to indicate a close relationship to these taxa. In contrast, conflicting characters such as ascus type and hypothecium pigmentation were given less weight. However, a closer look at e.g. ascospore and excipulum types reveals differences in fine structure that question the synapomorphy of these traits. The lecanorine excipula of Clade A differ in their alga distribution from the lecanorine excipula of Dirinaria (Awasthi 1975). These fine structure differences gain taxonomic weight when correlated with the Physciacean ITS phylogeny. Here the Dirinaria excipulum and stages of the early Pyxinean excipulum development are interpreted as convergent autapomorphies in these genera, where Pyxine might represent a transitory state between Diploicia and Dirinaria. This interpretation also 
corroborates the finding of Dirinaria to be a fairly derived genus with species represented by long branches in ITS trees (FIG. 3.3). The interpretation of excipulum characteristics to be homoplastic is supported by further examples of lecanorine excipula within Clade B and lecideine excipula in Clade A as listed in TABLE 3.5 .

\subsubsection{Misplacement of Buellia and Rinodina species}

Buellia lindingeri (Clade A) and Amandinea (Rinodina) cacuminum (Clade B) were already recognized to exhibit character states leading to contradicting taxonomic assignments (Rambold et al. 1994). Here, ITS sequence data show their phylogenetic position distinct from other species of Rinodina and Buellia, respectively. The ITS phylogeny supports the phylogenetic significance of the morphological markers under discussion, favoring ascus over excipulum characteristics. In the case of Amandinea cacuminum (formerly Rinodina cacuminum), the according recombination was done (Mayrhofer \& Sheard 2002). Additional candidates still to be investigated in this respect are $R$. biloculata (Nyl.) Sheard, R. ericina (Nyl.) Giralt, $R$. insularis (Arnold) Hafellner, and R. kalbii Giralt \& Matzer. In these species, the excipulum and ascus types lead to differing assignments, and it would be of great interest to see whether the priority of traits as stated above also holds in these cases.

\subsubsection{Plesiomorphy of ascus types and hypothecium pigmentation}

To assess the plesiomorphy of the two phenotypic traits that appeared to be most highly conserved in the Physciaceae and Caliciaceae, ascus types and hypothecium pigmentation were compared with taxa of other families that were depicted as basal taxa to the Physciaceae-Caliciaceae clade in the nrSSU phylogeny. These were the genera Lecidea (Lecideaceae) and Porpidia (Porpidiaceae), standing closer to the root of the ingroup than any other investigated taxon. Neither Lecidea nor Porpidia develop asci of a type found in the Physciaceae-Caliciaceae. Asci of Lecidea are characterized by a $\mathrm{I}_{\text {Lugol }}+$ palely stainable tholus, and a $\mathrm{I}_{\text {Lugol }}{ }^{+}$ dark blue cap-like structure. Those of Porpidia develop a $\mathrm{I}_{\text {Lugol }}+$ palely stainable tholus, and a central $\mathrm{I}_{\text {Lugol }}+$ dark blue tube-like structure. Therefore, it is assumed, that the Lecanora -type asci of the Physciaceae found in clade A and the Bacidia-type and prototunicate asci of clade B (which includes the Caliciaceae) are apomorphies. They are most likely convergent, but not homologous to similar ascus types found in other Lecanoralean families. In addition, ascospores in Lecidea and Porpidia are quite different from those of the ingroup taxa. Both develop elliptic, unicellular, hyaline ascospores, Lecidea without, and Porpidia with a halonate perispore. Connections between outgroup and ingroup are seen in apothecial traits. Lecidea and Porpidia usually exhibit a pigmented hypothecium which, however, is hyaline in some of their species. Both genera develop true excipula. A true excipulum as well as a pigmented hypothecium coincide with clade B. Therefore, these character states are considered ancestral within the Physciaceae-Caliciaceae. Correspondingly, the thalline excipulum as well as an unpigmented hypothecium found throughout clade A 
appear as autapomorphies of this clade. Naturally, thalline excipula occurring in clade B are likewise apomorphic.

The different contents of homoplasy in different morphological traits as described here are paralleled by findings in the Pezizomycetes (Hansen et al. 2001). In this study, ascus types also turned out as phylogenetically highly conserved characters which defined monophyletic clades. Other characters such as ascospore ornamentation and excipulum structure exhibited a higher degree of variability. The different degrees of phylogenetic conservation in these traits from such distantly related groups as Pezizaceae and Physciaceae is conspicuous and may be interpreted as evidence for the general ranking of "phylogenetic reliability" of these characters.

\subsection{Taxonomy}

The delimitation of the clades A and B on molecular and phenotypic levels is interpreted as indicative at the family level. However, unexpected taxonomic consequences might arise for clade B because it comprises genera of the Caliciaceae, including the type species of the family, C. viride. The similarities of certain phenotypic traits between the Caliciaceae and the Physciacean genera of clade B such as a true excipulum, hypothecium pigmentation, ascospore ornamentation and chemistry as well as their close genetic proximity indicate a closer relation of these taxa than contemporary concepts depict (Tibell 1984, Wedin et al. 2000). However, the delimitation of clade A from taxa of clade B including the Caliciaceae seems well supported from the presented data. Therefore, the critical question of how Physciaceae and Caliciaceae are related can be restricted to the question of how taxa of clade B are related to the Caliciaceae s. str.. In a phylogenetic survey based on mtSSU and nrITS data, Wedin et al. (2002) showed four members of the Caliciaceae to be paraphyletic with taxa of Clade B. This is confirmed also in this study. However, the phylogenetic positions of those Caliciaceae presented in Wedin et al. (2002) receive little support and appear incongruent with the phylogeny obtained from nrSSU data as presented in this study. Therefore, the phylogenetic relationships between the Caliciaceae and Clade $\mathrm{B}$ remains uncertain.

Regarding the type species Calicium viride as the anchor for the positioning of the family, two alternative scenarios might be deduced from the present data: First, the Caliciaceae might form a sister group to Subclade IV and Subclade III might be the sister group to the previous two groups. Clade A being the sister taxon to all of the previous three groups. Second, the Caliciaceae might be nested within Subclade IV. Therefore, establishing a higher order taxon comprising the taxa of clade B necessarily would also include the Caliciaceae. For reasons of nomenclatorial priority, the establishment of such a taxon would imply the transfer of these taxa into the Caliciaceae. Wedin \& Grube (2002) proposed the conservation of the family 
name Physciaceae against the name Caliciaceae for the complete Physciaceae/ Caliciaceae clade. Although the authors appreciate this attempt, they rather suggest to document the apparent split in the Physciaceae/Caliciaceae clade nomenclatorically. In case a transfer of most Physciaceae species (Clade B comprises more species than Clade A) into the Caliciaceae would be very difficult for most lichenologists to adapt to, it is suggested to conserve the family name Buelliaceae against Caliciaceae for all taxa in Clade B (including the Caliciaceae) and maintain the Physciaceae in a narrower circumscription. However, a "nomen conservandum" is not proposed here and the strict rules of nomenclature are followed.

\subsubsection{Emendations}

A phenotypic delimitation of the resulting families of the Physciaceae, represented by the taxa of clade A, and Caliciaceae (including the taxa of clade B) could be based on a combination of three characters, of which at least two indicate the correct affiliation. Only Australiaena might still be problematic under this concept, since it has asci that resemble the Lecanora-type ascus and exhibits fairly variable ascospores that occasionally develop ascospore wall thickenings. All other taxa fit the delimitation as given below. The ascospores for both families constantly being pigmented, septate and, with the exception of Rinodinella, thick-walled (see also TABLE 3.4).

\subsubsection{Caliciaceae Chevall. (1826) emend. G. Helms, G. Rambold \& T. Friedl}

Asci of Bacidia-type or prototunicate; hypothecium pigmented; ascospores without distinct wall thickenings. (Species usually with proper excipula, exceptional taxa: see TABLE 3.5.)

\subsubsection{Physciaceae Zahlbr. (1898) emend. G. Helms, G. Rambold \& T. Friedl}

Asci of Lecanora-type; hypothecium hyaline; ascospores with distinct wall thickenings or of Rinodinellatype. (Species usually with thalline excipula, exceptional taxa: see TABLE 3.5.)

The interrelations among the taxa of clade B, especially Subclade IV and Caliciaceae Pers. still await a more thorough exploration. A subsequent division of the newly emended Caliciaceae in families, corresponding to Subclades III, IV and the Caliciaceae in their former circumscription, might be appropriate, if further evidence could be found that supports this grouping. The critical taxon that prevents a clear delimitation of the two subclades is Diplotomma. ITS as well as nrSSU sequence data assign this genus to Subclade III, while it seems problematic to consistently delimit this genus from Subclade IV with phenotypic characters. Accordingly, groupings of taxa assigned to Diplotomma based on nrITS data (this study) and phenotypic traits (Nordin 2000) exhibit incongruencies. 


\subsubsection{Alternative concepts}

A segregation of the Caliciaceae in their new circumscription into three families, as outlined above would form an alternative concept. For Subclades III and IV existing family names could be adopted such as Pyxinaceae (E.M. Fries) Stitzenberger (1862) and Buelliaceae Zahlbr. (1907) respectively. Provided further investigation do not unravel the taxa with prototunicate asci as a polyphyletic assemblage, the Caliciacean concept could be re-established in the actual circumscription. In case the Caliciaceae and Subclade IV intermix, taxa of both groups could be designated to the Caliciaceae, resulting in a tripartite family concept with Physciaceae, Pyxinaceae and Caliciaceae. In all these scenarios, the new concept of the Physciaceae as proposed above would persist.

\subsubsection{Conclusions}

The Physciaceae are a highly diverse family of lichenized ascomycetes that have experienced detailed taxonomic refinement in the recent past. The nrDNA sequence data support most of the modern genus concepts that were all based on traditional phenotypic characters. It is anticipated that the critical combination of both methods will lead to a better understanding of character and taxa evolution. Although most genera of the Physciaceae were included in this survey, the phylogenetic position of numerous taxa still awaits further investigation.

In order to simplify the presentation and discussion in the following chapters, the distinction between Physciaceae and Caliciaceae as proposed here is not maintained. In the subsequent chapters all species of these two families that were analyzed in this study are denoted as Physciaceae in concordance with traditional usage of this name as well as Wedin \& Grube (2002). 


\section{Photobionts of the Physciaceae* and the genus Trebouxia}

\subsection{Summary}

The genetic diversity of Physciacean photobionts, based on nrITS sequencing, has been investigated in this study. A much larger genetic diversity was observed than had been known from cultured strains. This diversity was structured utilizing phylogenetic analyses, comparisons with authentic strains, as well as mycobiont selection behavior. Three systematic categories were employed to represent Trebouxia taxa. ITS sequences that differed in less than $2 \%$ of their nucleotide positions and were monophyletic in phylogenetic analyses (Neighbor-Joining, Jukes-Cantor model of evolution) were assigned to particular ITS-variants. Monophyletic groups of ITS-variants with p-distances usually less than $6 \%$ were summarized into subclades. Subclades are supposed to refer to the taxonomic level of species. Approximately twice as many subclades were differentiated in the Physciaceae than were represented by authentic strains. Almost all Trebouxia strains known from other lichen families were also found in the Physciaceae. However, representatives of Clade S were found only exceptionally. According to their relatedness, subclades were summarized in clades following the clade concept of Friedl et al. (2000). This clade concept divides the genus Trebouxia s. str. into four major clades that receive significant support for monophyly in phylogenetic analyses except for clade S. Compiling the data that were published before this study, it seems evident that Trebouxia s.l. is a non-natural taxon which comprises two well separated lineages, Asterochloris and Trebouxia s.str., which need to be considered as two distinct genera. Both lineages vary greatly in their phylogenetic diversity. The diversity of ITS sequences of all known Asterochloris species corresponds to the diversity of just one subclade of Trebouxia s.str.

\subsection{Introduction}

\subsubsection{Taxonomy and circumscription of the genus Trebouxia Puymaly}

Famintzin \& Boranetzky (1867) and Schwendener (1869) were the first who published specific descriptions and illustrations of coccal green algae resembling Trebouxia and named them "Cystococcus humicola Nägeli". This latter species had been described from humid soil (Nägeli 1849) and was later considered as a species of Chlorococcum (Gärtner 1985b). Puymaly (1924) suggested to use the name Trebouxia arboricola Puymaly instead of Cystococcus humicola for all algae isolated from Xanthoria parietina. For this new genus Puymaly adopted a diagnosis that had been already given by Treboux (Treboux 1912). Today members of the genus Trebouxia are described as coccoid green algae that may form autospore packages in 
the form of tetrades or larger cell complexes. Cell shape is spherical to elliptic. The cell walls are thin, only occasionally unilaterally thickened, without a gelatinous sheath. Chloroplasts in adult cells assume a central position and develop lobed or crenulate edges. Chloroplasts have one or multiple pyrenoids that are either naked or, in few species, enclosed by a starch sheath. Starch is usually deposited as starch grains in the chloroplast stroma. The nucleus is always positioned excentrically in a pronounced indention of the chloroplast. Only asexual reproduction is known via autospore formation or naked, two flagellated zoospores with a stigma (Ettl \& Gärtner 1995).

\subsubsection{Trebouxia - Asterochloris, one or two genera?}

Morphological and especially genetic data suggest that the genus Trebouxia is a paraphyletic assemblage (Archibald 1975, Hildreth \& Ahmadjian 1981, Tschermak-Woess 1989, Friedl \& Zeltner 1994, Friedl \& Rokitta 1997). On the basis of different types of immobile reproductive cells (spores), a segregation of the genus into Trebouxia Puymaly and Pseudotrebouxia Archibald was first proposed by Archibald in 1975. Gärtner (1985) and Tschermak-Woess (1989) also recognized differences in the formation of non-motile reproductive cells, but rejected Archibald's concept. Gärtner (1985a,b) interpreted all differences in nonmotile reproductive cells as a suppression of zoospore formation at different ontogenetic stages and therefore rejected the division of the genus. In contrast, Tschermak-Woess (1989) assumed only one type of nonmotile reproductive cells to originate from ontogenetic suppression (aplanospores) while she supposed the other type (autospores) to be a phylogenetically fixed mode of spore development. Therefore, she splitted Trebouxia into two subgenera, Trebouxia and Eleutherococcus. Eleutherococcus sensu Tschermak-Woess includes all species which do not develop autospores. Although referring to the same characteristics, her grouping was not congruent with that of Archibald. Friedl (1993) also recognized differences in autospore formation and distinguished two cell cycles A and B, resulting in groupings rather similar to TschermakWoess' subgenera. However, Friedl assigned T. flava and T. usneae to cell cycle B, corresponding to the "Eleutherococcus-group" sensu Tschermak-Woess (TABLE 4.1). Furthermore, he rejected the split of Trebouxia based on this trait because of its variability even within one strain and its dependence on culture conditions. With the exceptions of $T$. gelatinosa and $T$. anticipata, which were regarded as synonymous species by Friedl (1989b), all taxa included in Trebouxia subgenus Eleutherococcus by Tschermak-Woess were found to be identical in more than $93 \%$ of their nrITS sequence positions in a recent study by PierceyNormore \& DePriest (2001). These authors also included the photobiont of Anzina carneonivea (Anzi) Scheid. (formerly Varicellaria carneonivea (Anzi) Erichs.). From this lichen species the green algal genus Asterochloris was originally isolated and described (Tschermak-Woess 1980) with the species A. phycobiontica. Sequence comparison revealed that the Anzina photobiont was very closely related to the Eleutherococcus species of Tschermak-Woess (Tschermak-Woess 1989, Piercey-Normore \& DePriest 2001). The affiliation of Asterochloris phycobiontica with the species of Eleutherococcus had been also 
recognized by Tschermak-Woess (1989) from phenotypic characters. Accordingly, she transferred Asterochloris phycobiontica to Trebouxia subgenus Eleutherococcus and suggested, however, the reestablishment of Asterochloris if the taxa lacking autospores should be given genus rank (TschermakWoess 1989). All Trebouxia species found to resemble Asterochloris phycobiontica can be distinguished from the remaining Trebouxia species in five traits: A uniform and shorter nrITS region which strongly deviates from those of the remaining Trebouxia species. Friedl \& Zeltner (1994) and Friedl \& Rokitta (1997) inferred from nrSSU and nrLSU sequence data that Trebouxia (Asterochloris) magna was more closely related to Myrmecia biatorellae Tschermak-Woess \& Plessl than to Trebouxia s.str.. In contrast to Trebouxia s. str., the pyrenoid matrix in the Asterochloris/Eleutherococcus species is hard to distinguish from the chloroplast stroma or the pyrenoid has an irregular shape (Friedl 1989a, b). Further, the chloroplasts of species resembling Asterochloris may flatten and assume a parietal position prior to cell division as well as in zoo- and aplanospores, while chloroplasts of Trebouxia species remain lobed and at a more central position during division (Ahmadjian 1960, 1970, Hildreth \& Ahmadjian 1981, Gärtner 1985b, Friedl \& Gärtner 1988). Also the different chloroplast types of the Trebouxia s. str. and "Asterochloris" species are mutually exclusive (Friedl 1989b). Interestingly, the delimitation of Asterochloris and Trebouxia s. str. is accurately reflected by the photobiont selection behavior of Cladonia cristatella Tuck. in resynthesis experiments reported by Ahmadjian \& Jacobs (1981). In these experiments, C. cristatella formed squamules with all algal strains of the "Asterochloris-group" but parasitized and killed all other Trebouxia strains tested (TABLE 3.1). Rambold et al. (1998) assumed that all Asterochloris-like Trebouxia species would be the only compatible photobionts for the majority of the Cladoniaceae. This assumption was supported by PierceyNormore \& DePriest (2001). Compiling these findings, a delimitation of Trebouxia s.1. in Trebouxia (s.str.) and Asterochloris as noted in TABLE 4.1 is supported by these five independent traits which are considered strong evidence supporting the concept of two genera. Therefore, the genus Trebouxia is understood here in the strict sense, excluding the species which are assigned to Asterochloris here. 
TABLE 4.1: Traits that separate Trebouxia and Asterochloris. Clade and subclade affiliation as presented in this study; pyrenoid type follows Friedl (1989a); chloroplast type follows Friedl (1989b); Chloroplast shape and position prior to division follows Ahmadjian (1960, 1970), Hildreth \& Ahmadjian (1981), Gärtner (1985b), Friedl \& Gärtner (1988): c = central and lobate, $\mathrm{p}=$ parietal and flattened; autospore presence as in Tschermak-Woess (1989), cell cycle A and B follows Friedl (1993); Compatibility with Cladonia cristatella follows Ahmadjian \& Jakobs (1981). +: autospore present / compatible with C. cristatella, -: autospore absent / incompatible with C. cristatella, *: results published by Piercey-Normore \& DePriest (2001), n.a.: not analyzed.

\begin{tabular}{|c|c|c|c|c|c|c|c|}
\hline & 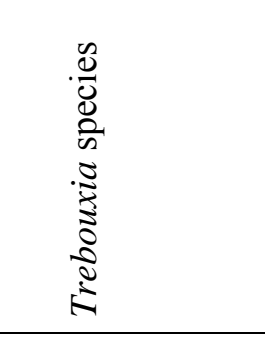 & 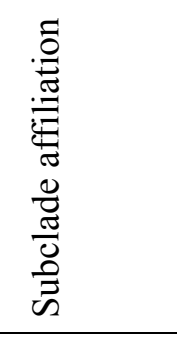 & 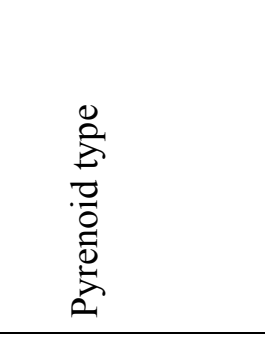 & 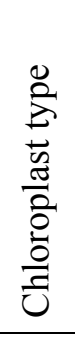 & 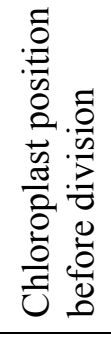 & 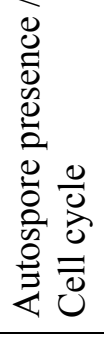 & 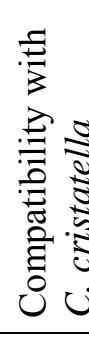 \\
\hline \multirow{19}{*}{ 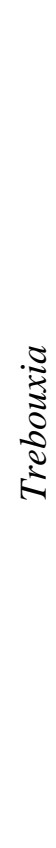 } & T. decolorans & A1 & arboricola-type & 4 & $\mathrm{c}$ & $+/ \mathrm{A}$ & - \\
\hline & T. arboricola & A2 & arboricola-type & 3 & $\mathrm{c}$ & $+/ \mathrm{A}$ & n.a. \\
\hline & T. aggregata & A2 & arboricola-type & 3 & $\mathrm{c}$ & $+/ \mathrm{A}$ & - \\
\hline & T. crenulata & A2 & arboricola-type & 4 & $\mathrm{c}$ & $+/ \mathrm{A}$ & - \\
\hline & T. jamesii & A4 & impressa-type & 2 & $\mathrm{c}$ & $+/ \mathrm{A}$ & - \\
\hline & T. asymmetrica & A7 & gigantea- type & 6 & $\mathrm{c}$ & $+/ \mathrm{A}$ & n.a. \\
\hline & T. showmanii & A8 & gigantea- type & 6 & $\mathrm{c}$ & $+/ \mathrm{A}$ & - \\
\hline & T. gigantea & A9 & gigantea- type & 6 & $\mathrm{c}$ & $+/ \mathrm{A}$ & - \\
\hline & T. incrustata & A10 & gigantea- type & 6 & $\mathrm{c}$ & $+/ \mathrm{A}$ & n.a. \\
\hline & T. flava & I1 & impressa-type & 1 & $\mathrm{c}$ & $+/ \mathrm{B}$ & n.a. \\
\hline & T. impressa & I1 & impressa-type & 1 & $\mathrm{c}$ & $+/ \mathrm{A}$ & - \\
\hline & T. potteri & I1 & impressa-type & 5 & $\mathrm{c}$ & $+/ \mathrm{A}$ & - \\
\hline & T. gelatinosa & I2 & gelatinosa-type & 7 & $\mathrm{c}$ & $-/ \mathrm{B}$ & - \\
\hline & T. anticipata & I2 & gelatinosa-type & 7 & $\mathrm{c}$ & $-/ \mathrm{B}$ & - \\
\hline & T. usneae & G1 & corticola-type & 8 & $\mathrm{c}$ & $+/ \mathrm{B}$ & - \\
\hline & T. corticola & G1 & corticola-type & 9 & $\mathrm{c}$ & $+/ \mathrm{A}$ & - \\
\hline & T. galapagensis & G2 & corticola-type & 9 & $\mathrm{c}$ & $+/ \mathrm{A}$ & - \\
\hline & T. higginsiae & G2 & corticola-type & 9 & $\mathrm{c}$ & $+/ \mathrm{A}$ & - \\
\hline & T. simplex & $\mathrm{S} 3$ & impressa-type & 2 & $\mathrm{c}$ & $+/ \mathrm{A}$ & n.a. \\
\hline \multirow{7}{*}{ 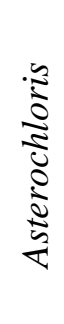 } & T. irregularis & Clade I* & irregularis-type & 10 & $\mathrm{p}$ & $-/ \mathrm{B}$ & n.a. \\
\hline & T. glomerata & Clade I* & irregularis-type & 10 & $\mathrm{p}$ & $-/ \mathrm{B}$ & + \\
\hline & T. pyriformis & Clade I* & irregularis-type & 10 & $\mathrm{p}$ & $-/ \mathrm{B}$ & + \\
\hline & T. italiana & n.a. & irregularis-type & 10 & $\mathrm{p}$ & ?/B & + \\
\hline & T. excentrica & Clade II* & irregularis-type & 11 & $\mathrm{p}$ & $-/ \mathrm{B}$ & + \\
\hline & T. magna & Clade II* & magna-type & 12 & $\mathrm{p}$ & ?/B & + \\
\hline & T. erici & Clade II* & erici-type & 10 & $\mathrm{p}$ & $-/ \mathrm{B}$ & + \\
\hline
\end{tabular}




\subsubsection{Trebouxia, the most common lichen photobiont}

The described diversity of lichen photobionts lags far behind that of lichen mycobionts. The percentage of lichen species in which the associated photobiont genus is reported is only about $2 \%$ of the total number of described lichen species (Tschermak-Woess 1988). Tschermak-Woess listed about 100 species of lichen photobionts which represented about 40 genera. Due to the uncertain taxonomy of many of these photobionts, these numbers were considered as approximations only. Ahmadjian (1993) estimates that only 25 genera were typical lichen photobionts. Members of the green alga genus Trebouxia Puymaly (Trebouxiophyceae) are considered to be the most common lichen photobionts. These authors estimated that more than $50 \%$ of all lichen species are associated with Trebouxia species. Outside the lichen thallus, in the aposymbiotic state, Trebouxia was reported only rarely (Famintzin \& Baranietzky 1867, Tschermak-Woess 1978, 1988, Bubrick et al. 1984, Ahmadjian 1988, Garty \& Delarea 1988, Mukhtar et al. 1994) leading to the assumption that it might not maintain stable, free-living populations (Ahmadjian 1987). The reasons for the comparable scarcity of knowledge about photobiont diversity are manifold. In taxonomic studies on lichens, it is common practice to study primarily herbarium material, which in many cases does not permit photobiont identification even at the genus level. In addition, photobionts in the lichenized state are often modified compared to the cultures used for species descriptions. Therefore, lichen photobionts must be cultivated for weeks in order to allow them to develop their typical morphology (Tschermak-Woess 1988). Isolating photobionts from lichen thalli is not always successful, but always time consuming and labor intensive. Even when photobionts could be isolated and grown in culture successfully, due to differences in culturing methods and the scarcity of microscopic characters, identification often remains ambiguous (Ahmadjian 1982).

\subsubsection{Available Trebouxia nrDNA sequence information}

With the advent of molecular methods, an alternative approach for photobiont identification became available. Using algal specific primers, a genetic marker of the photobiont could be amplified from crude lichen DNA extracts, without the need of photobiont cultivation. The PCR product could then be sequenced and the obtained sequence compared to the sequences of authentic strains (TABLE 4.2). nrITS sequencing has proven a powerful method in assessing phylogenetic diversity within the genus Trebouxia (see authors listed in TABLE 4.3). Accuracy of taxon determination improved and herbarium material up to several years old could be used for photobiont identification (Bhattacharya et al. 1996, Helms et al. 2001).

Still, only few reports of Physciaceae photobionts are available. All known photobionts observed in the Physciaceae were consistently assigned to Trebouxia. Three authentic strains were originally isolated from members of the Physciaceae, T. impressa (UTEX 892, UTEX 893), T. higginsiae (UTEX 2232), and T. 
potteri (UTEX 900, TABLE 4.3). In later surveys, nrITS sequences of these authentic strains were obtained. Beck et al. (1998), Dahlkild et al. (2001), and Helms et al. (2001) investigated Physciacean photobionts with molecular methods (TABLE 4.3). They added 56 further Trebouxia nrITS sequences of Physciacean photobionts from 21 Physciacean species which represent 9 genera. In all instances, only members of the genus Trebouxia were found.

TABLE 4.2: Authentic strains and the accession numbers of their nrITS sequences to which the sequences obtained in this survey could be compared. TF: sequences obtained by Thomas Friedl.

\begin{tabular}{|c|c|c|}
\hline Trebouxia species & culture number & $\begin{array}{l}\text { nrITS sequence } \\
\text { Accession number }\end{array}$ \\
\hline Trebouxia aggregata & UTEX 180 & TF, unpublished \\
\hline Trebouxia angustilobata & M-97.027B3 & AF128271 \\
\hline Trebouxia anticipata & UTEX 903 & $\mathrm{TF}$, unpublished \\
\hline Trebouxia arboricola & SAG 219-1a & Z68705 \\
\hline Trebouxia asymmetrica & SAG 4888 & AJ249565 \\
\hline Trebouxia corticola & UTEX 909 & AJ249566 \\
\hline Trebouxia crenulata & CCAP $219 / 2$ & $\mathrm{TF}$, unpublished \\
\hline Trebouxia decolorans & UTEX 901 & $\mathrm{TF}$, unpublished \\
\hline Trebouxia erici & $\begin{array}{l}\text { UTEX 910, } \\
\text { UTEX 911, } \\
\text { UTEX } 912\end{array}$ & $\begin{array}{l}\text { AF345439, } \\
\text { AF345440, } \\
\text { AF345441 }\end{array}$ \\
\hline Trebouxia excentrica & UTEX 1714 & AF345433 \\
\hline Trebouxia flava & UTEX 181 & AF242467 \\
\hline Trebouxia galapagensis & UTEX 2230 & AJ249567 \\
\hline Trebouxia gelatinosa & UTEX 905 & Z68698 \\
\hline Trebouxia gigantea & UTEX 2231 & AF242468 \\
\hline Trebouxia glomerata & $\begin{array}{l}\text { UTEX } 895, \\
\text { UTEX } 896, \\
\text { UTEX } 897\end{array}$ & $\begin{array}{l}\text { AF345382, } \\
\text { AF345404, } \\
\text { AF345405 }\end{array}$ \\
\hline Trebouxia higginsiae & UTEX 2232 & AJ249574 \\
\hline Trebouxia impressa & $\begin{array}{l}\text { UTEX 892, } \\
\text { UTEX } 893\end{array}$ & $\begin{array}{l}\text { AF345891, } \\
\text { AF345890 }\end{array}$ \\
\hline Trebouxia incrustata & UTEX 784 & AJ293795 \\
\hline Trebouxia irregularis & UTEX 2236 & $\mathrm{AF} 345411$ \\
\hline Trebouxia jamesii & UTEX 2233 & $\mathrm{TF}$, unpublished \\
\hline Trebouxia magna & UTEX 67 & AF345423 \\
\hline Trebouxia potteri & UTEX 900 & AF242469 \\
\hline Trebouxia pyriformis & $\begin{array}{l}\text { UTEX 1712, } \\
\text { UTEX } 1713\end{array}$ & $\begin{array}{l}\text { AF345406, } \\
\text { AF345407 }\end{array}$ \\
\hline Trebouxia showmanii & UTEX 2234 & AF242470 \\
\hline Trebouxia simplex & TW-1A2 & $\mathrm{TF}$, unpublished \\
\hline Trebouxia usneae & UTEX 2235 & AJ249573 \\
\hline
\end{tabular}


TABLE 4.3: Sources of Trebouxia nrITS sequences other than this study. UTEX strain numbers indicate authentic strains which were isolated from Physciaceae.

\begin{tabular}{llll}
\hline \hline Author & Lichen & \# of sequences & Photobiont \\
\hline Beck 1999 & Non-Physciaceae & 2 & Trebouxia spp. \\
Beck et al. 1998 & Physciaceae & 3 & Trebouxia spp. \\
& Non-Physciaceae & 3 & Trebouxia spp. \\
Bhattacharya et al. 1996 & Non-Physciaceae & 9 & Trebouxia spp. \\
Dahlkild et al. 2001 & Physciaceae & 25 & Trebouxia spp. \\
Friedl et al. 2000 & Buellia straminea & 1 & T. higginsiae (UTEX 2232) \\
& Non-Physciaceae & 15 & Trebouxia spp. \\
Kroken et al. 2000 & Physconia distorta & 1 & T. flava (UTEX 181) \\
& Non-Physciaceae & 14 & Trebouxia spp. \\
Piercey-Normore \& & Physcia stellaris & 2 & T. impressa (UTEX 892, 893) \\
DePriest 2001 & Non-Physciaceae & 12 & Trebouxia spp. \\
student labs 2000 / 2001 & Physciaceae & 23 & Trebouxia spp. \\
& Non-Physciaceae & 29 & Trebouxia spp. \\
Helms et al. 2001 & Physciaceae & 24 & Trebouxia spp. \\
Helms et al. subm. & Non-Physciaceae & 11 & Trebouxia spp. \\
Romeike et al. 2002 & Non-Physciaceae & 22 & Trebouxia spp. \\
\hline
\end{tabular}

\subsubsection{Objective}

The objective in this chapter is to describe Trebouxia nrITS diversity within the Physciaceae and to structure this diversity in a hierarchical system that represents phylogenetic and ecological contiguities among the included taxa. In order to structure the diversity of nrITS-variants (see below), four types of information were examined: Monophyly, genetic distances, sequence insertions and mycobiont selection behavior. Phylogenetic relationships among Trebouxia nrITS-variants as well as monophyly of lineages was assessed in phylogenetic analyses. Genetic distances of nrITS sequences among authentic and secondary strains were determined in order to approximate distance values that may suggest conspecificity or distinctness on species level. Insertions in the nrITS region were used as delimiters between lineages. Also, the apparent discrimination of certain mycobionts between phylogenetically distinct groups of Trebouxia nrITS-variants was considered when delimiting groups of nrITS-variants that were suspected to represent species. 


\subsection{Materials \& Methods}

\subsubsection{The clade system and Trebouxia ITS-variant designation}

Trebouxia nrITS sequencing revealed a much greater diversity in Trebouxia, than had been previously described (see below). A clade system was used to describe the phylogenetic hierarchy of the Trebouxia ITSvariants, as inferred by phylogenetic analyses of nrITS sequences. The lowest taxonomic rank was represented by ITS-variants. Monophyletic groups of closely related ITS-variants were united into subclades and monophyletic groups of subclades were combined to clades.

Clades are noted with an upper case letter, subclades by Arabic numbers and ITS-variants by a lower case letter (e.g. A2a). The clade that includes T. arboricola (authentic strain SAG 219-1a) was designated clade A, the clade including T. impressa (authentic strain UTEX 893) clade I, the clade with T. galapagensis (authentic strain UTEX 2230) clade G and the clade with T. simplex (authentic strain TW-1A2) clade S.

\subsubsection{ITS-variants}

An ITS-variant denoted a Trebouxia strain with a particular ITS sequence. In order to avoid an artificial inflation of the number of distinguished ITS-variants, due to sequencing errors or differential PCR amplification of within genome heterogeneities, a sequence variability of $2 \%$ within particular ITS-variants was admitted. In addition, particular ITS-variants had to be monophyletic in a neighbor-joining analysis employing the Jukes-Cantor model. As a consequence of the variability within ITS-variants, a number of ITS-variants comprized "short branch taxa" and "long branch taxa". Where "long branch taxa" of the different ITS-variants were separated by more than $2 \%$ substitutions, "short branch taxa" of the same ITSvariants could be separated by less than $2 \%$ nucleotide substitutions (FIG. 4.1). Here, long branch taxa of monophyletic clusters of ITS sequences were used to delimit ITS-variants. As a consequence short branch taxa of distinct ITS-variants could be separated by less than $2 \%$ nucleotide substitutions. This situation, however, occurred only in subclade I1, where a large number of very closely related taxa was sampled. 


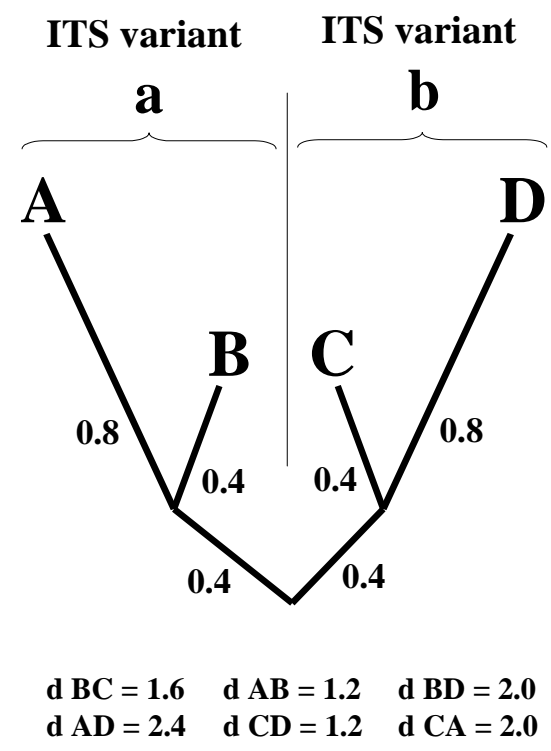

\begin{abstract}
FIG. 4.1: As a consequence of the admission of intra-ITS variant variability ( $\mathrm{p}$-distances $<2 \%$ ), conflicts between monophyly of ITS variants and the $2 \%$ limit of ITS variants variability occurred. Sequences B and C belong to different lineages but exhibit less than $2 \%$ sequence variability. In these instances, monophyly as revealed by a neighbor-joining analysis (using Jukes-Cantor model) was given priority above genetic distances in ITS variant assignment. Therefore, B and $\mathrm{C}$ were assigned to different ITS variants. Numbers on branches: $\mathrm{p}$-distances (\%), $d=p$-distances $(\%)$.
\end{abstract}

\title{
4.3.1.2 Subclades
}

The level above ITS-variants was represented by "subclades". This level was supposed to correspond to the taxonomic level of species. However, nrITS sequence data alone were not considered to provide sufficient information for a species definition (Grube \& Kroken 2000, Taylor et al. 2000). Therefore, in addition to the monophyly criterion and p-distances as used for ITS-variant delimitation, mycobiont selection behavior was regarded as an important delimiter of subclades.

Ahmadjian \& Jacobs (1981), demonstrated the usefulness of mycobiont selectivity in photobiont systematics in resynthesis experiments. The range of photobionts compatible with Cladonia cristatella and the delimitation of Asterochloris were found to be congruent (TABLE 4.1). According to Ahmadjian (1993) and Hawksworth \& Honegger (1994) lichens can be interpreted as algal parasites. Eichler (1941a, b, 1948) proposed the hypothesis that parasites' taxonomies reflect their hosts' taxonomies (Fahrenholz's rule). This hypothesis has been followed in numerous instances (e.g. Mitter \& Brooks 1983). Although it is now clear that Fahrenholz's rule is anything less than universal, it is generally accepted that most parasites are quite host specific (Mitter \& Brooks 1983). Accordingly, mycobionts that appeared to discriminate between sister groups of ITS-variants were regarded as important indicators for the delimitation of subclades (TABLE 5.1, chapter 5). The applicability of this method could be shown in numerous instances where genetic delimitation was congruent with selection behavior of particular mycobionts (see chapter 5). Therefore, where p-distances did not allow an obvious delimitation of subclades, mycobiont selection behavior was used for subclade assignment (e.g. subclades A1, A7 and I4). 
In order to approximate p-distances that suggest a delimitation of subclades, p-distances between the most closely related but morphologically clearly distinct species were determined. Genetic distances between $T$. asymmetrica SAG 48.88 and all other authentic strains of clade A (T. arboricola SAG219-1a, T. jamesii UTEX 2233, T. incrustata UTEX 784, T. gigantea UTEX 2231, and T. showmanii UTEX 2234) ranged between $6 \%$ and $8 \%$ (FIG. 4.4), p-distances between T. impressa UTEX 893 and T. gelatinosa UTEX 905 were $11 \%$ (FIG. 4.6), p-distances between T. simplex TW-1A2 and T. angustilobata AB97.027B3 were $8 \%$ (FIG. 4.6). However, mutation rates apparently varied among clades (FIG. 4.2; for clade delimitation see below). Average genetic distances in clade A were only $8 \%$ while in clades I and G $12 \%$ and $17 \%$ were observed respectively (FIG. 4.2). This observation questioned the applicability of a fixed distance value across all clades to specify maximal boundaries for the inclusion of ITS-variants into single subclades. In general, a $6 \%$ threshold appeared appropriate for the delimitation of subclades, i.e. the inclusion of ITSvariants into one subclade. For example, in the most frequently sampled subclade I1 (113 sequences determined) maximal p-distances were $5 \%$ or less. However, this threshold was not considered mandatory. When mycobiont selection behavior suggested a larger range of photobionts to be ecologically linked, larger p-distances within subclades were admitted (e.g. subclade I4 when considering Heterodermia leucomela including the conspecific $H$. boryi). When particular ITS-variants were found only once, and information about mycobiont selection behavior and potential intermediate sequences was not accessible, the $6 \%$ threshold was relaxed to up to $10 \%$. This conservative strategy of subclade delimitation was adopted, in order to avoid an artificial inflation of taxa. Although uncertainty may remain about the degree of mycobiont's selectivity as well as the taxonomic significance of p-distances, it is believed that including both types of information into a concept of subclade delimitation results in a more natural and ecologically meaningful subclade concept than relying on one of both only. Both aspects are strongly dependent on taxon sampling and subclade delimitation might therefore change in future, when additional information becomes available.

\subsubsection{Clades}

The highest level in this Trebouxia system was represented by clades. Also clades had to be monophyletic and previously published delimitations were adopted. According to Friedl et al. (2000), four clades were delimited, A, I, G, and S. Clade I includes clades 2 and 3 of Helms et al. (2001), which resulted in a more even range of genetic variability among clades. 
TABLE 4.4: List of Trebouxia nrITS sequences that were obtained in this study and those obtained from GenBank and student labs supervised by the author and numbers of available Trebouxia ITS-variants that originate from Physciacean specimens and non-Physciacean specimens. Note: Numbers of ITS-variants reported from Physciaceae and nonPhysciaceae are not additive, since single ITS-variants were found in both groups.

\begin{tabular}{|c|c|c|c|c|c|c|}
\hline $\begin{array}{l}\text { Clade / } \\
\text { subclade }\end{array}$ & $\begin{array}{l}\text { number of } \\
\text { sequences }\end{array}$ & $\begin{array}{l}\text { number of } \\
\text { sequences } \\
\text { determined in } \\
\text { this study }\end{array}$ & $\begin{array}{l}\text { number of } \\
\text { sequences } \\
\text { from } \\
\text { other sources }\end{array}$ & $\begin{array}{l}\text { number of } \\
\text { ITS-variants }\end{array}$ & $\begin{array}{l}\text { number of } \\
\text { Trebouxia } \\
\text { ITS-variants } \\
\text { found in the } \\
\text { Physciaceae }\end{array}$ & $\begin{array}{l}\text { \# of Trebouxia } \\
\text { ITS-variants also } \\
\text { found in non- } \\
\text { Physciaceae } \\
\text { lichens }\end{array}$ \\
\hline A1 & 27 & 9 & 18 & 5 & 5 & 2 \\
\hline $\mathrm{A} 2$ & 7 & 6 & 1 & 4 & 4 & 1 \\
\hline A3 & 2 & 2 & - & 2 & 2 & - \\
\hline A4 & 14 & 8 & 6 & 2 & 2 & 1 \\
\hline A5 & 7 & 6 & 1 & 2 & 2 & - \\
\hline A6 & 3 & 2 & 1 & 1 & 1 & 1 \\
\hline A7 & 11 & 8 & 3 & 4 & 4 & 1 \\
\hline A 8 & 1 & - & 1 & 1 & - & 1 \\
\hline A9 & 5 & 4 & 1 & 1 & 1 & 1 \\
\hline A 10 & 5 & 4 & 1 & 1 & 1 & 1 \\
\hline A11 & 7 & 3 & 4 & 1 & 1 & - \\
\hline SUM & 89 & 52 & 37 & 23 & 22 & 9 \\
\hline I1 & 113 & 61 & 52 & 21 & 21 & 5 \\
\hline I2 & 8 & 3 & 5 & 4 & 2 & 3 \\
\hline I3 & 7 & 5 & 2 & 2 & 2 & 1 \\
\hline I4 & 15 & 15 & - & 10 & 10 & - \\
\hline I5 & 1 & 1 & - & 1 & 1 & - \\
\hline \multirow{2}{*}{$\begin{array}{ll}16 & \\
& \text { SUM } \\
\end{array}$} & 2 & - & 2 & 1 & - & 1 \\
\hline & 146 & 85 & 61 & 39 & 36 & 10 \\
\hline G1 & 1 & - & 1 & 1 & - & 1 \\
\hline $\mathrm{G} 2$ & 1 & - & 1 & 1 & 1 & - \\
\hline G3 & 7 & 7 & - & 6 & 6 & - \\
\hline G4 & 5 & 5 & - & 3 & 3 & - \\
\hline G5 & 2 & 1 & 1 & 2 & 1 & 1 \\
\hline G6 & 2 & 1 & 1 & 2 & 1 & 1 \\
\hline G7 & 2 & 2 & - & 2 & 2 & - \\
\hline G8 & 1 & 1 & - & 1 & 1 & - \\
\hline G9 & 7 & 7 & - & 1 & 1 & - \\
\hline G10 & 2 & 1 & 1 & 2 & 1 & 1 \\
\hline SUM & 30 & 25 & 5 & 21 & 17 & 4 \\
\hline $\mathrm{S} 1$ & 31 & - & 31 & 6 & - & 6 \\
\hline $\mathrm{S} 2$ & 6 & - & 6 & 1 & - & 2 \\
\hline S3 & 7 & - & 7 & 2 & - & 2 \\
\hline \multirow{2}{*}{ S4 } & 1 & 1 & - & 1 & 1 & - \\
\hline & 45 & 1 & 44 & 11 & 1 & 10 \\
\hline 31 & 310 & 163 & 147 & 94 & 76 & 33 \\
\hline
\end{tabular}




\subsubsection{Sequence origin}

Photobiont nrITS sequence data were obtained from 154 Physciacean samples, representing 82 Physciacean species and 19 of the 27 currently accepted genera (Eriksson 2001). Physciaceae samples included in this survey had been collected worldwide and are therefore considered to be representative of the overall photobiont diversity in the Physciaceae. From these 154 Physciaceae samples 163 algal sequences were obtained. An additional 62 Physciacean photobiont nrITS sequences were available from GenBank or obtained in student labs, which were supervised by the author (TABLE 4.3, 4.4). Together this makes a total of 225 photobiont nrITS sequences now available from the Physciaceae. Eighty-five more Trebouxia sequences from non-Physciacean taxa were available from GenBank or obtained in student labs (TABLE 4.3, 4.4) resulting in a total of 310 compiled Trebouxia nrITS sequences.

\subsubsection{Molecular analyses}

All algal sequences were obtained from fresh material or air dried lichen samples, i.e. herbarium material up to 13 years old (appendix A.1, voucher information). The nrITS region was amplified with green alga specific forward primers that annealed at the 3'-half of the nrSSU and universal reverse primers that annealed at the $5^{\prime}$-end of the nrLSU (TABLE 2.1). Sequence determination and phylogenetic analyses were conducted as described in chapter 2. Additional Trebouxia nrITS sequence data were obtained from GenBank (TABLE 4.3).

\subsubsection{Alignment and Phylogenetic analyses}

Trebouxia nrITS sequences were analyzed with respect to their proportion of nucleotide substitution in pairwise comparisons (P-distances $\cong \%$ sequence divergence) as well as their phylogenetic relationships employing complex models of evolution. Five data sets were constructed. Data set 1 comprised one representative of every subclade of all four clades. Data sets 2 - 5 comprised only sequences of single clades, namely clades A, I, G, and S. In these four data sets one representative of every ITS-variant was included with the exception of subclade I1. Twenty-one ITS-variants were distinguished in this subclade, which could not all be included due to the incompleteness of some sequences. P-distances as shown in FIGS. 4.2, 4.4, 4.6, 4.8, and 4.10 were calculated from full length sequences with the program MEGA2 (Kumar et al. 2001).

Prior to phylogenetic analyses, completely conserved regions as well as ambiguously aligned regions were removed from the alignments. Dataset 1 then contained 185 variable positions of which 177 were parsimonyinformative. A model of sequence evolution that fit the data best was selected using the Akaike Information Criterion (AIC, Akaike 1974) as implemented in the program ModelTest. The 'TVM + G' model (Rodríguez et al. 1990) was selected and likelihood parameters (Lset) were set as follows: base frequencies (Base) were 
$\mathrm{A}=0.2223, \mathrm{C}=0.2413, \mathrm{G}=0.2429, \mathrm{~T}=0.2936$, substitution types $(\mathrm{Nst})=6$ with substitution values (Rmat) $\mathrm{AC}=1.8634, \mathrm{AG}=4.8886, \mathrm{AT}=2.9014, \mathrm{CG}=0.7090, \mathrm{CT}=4.8886, \mathrm{GT}=1$; the site-to-site rate heterogeneity was modeled as a gamma distribution (Yang 1994) with a shape parameter (shape) $=7.0076$. The gamma distribution was approximated by four categories of equal weight. The proportion of invariable sites was set to zero $($ Pinvar $=0)$.

For Clade A also the 'TVM $+\mathrm{G}$ ' model was selected with parameters Base $\mathrm{A}=0.2039, \mathrm{C}=0.2884, \mathrm{G}=$ $0.2368, \mathrm{~T}=0.2708 ; \mathrm{Nst}=6$; Rmat $\mathrm{AC}=1.5148, \mathrm{AG}=6.3122 ; \mathrm{AT}=2.7461 ; \mathrm{CG}=0.4788, \mathrm{CT}=6.3122$, $\mathrm{GT}=1.0000 ;$ shape $=6.9705$ with four rate categories of equal weight, Pinvar $=0$.

For Clade I the 'TVM $+\mathrm{G}$ ' was chosen with parameters Base $\mathrm{A}=0.2328, \mathrm{C}=0.2378, \mathrm{G}=0.2194, \mathrm{~T}=$ 0.3100; Nst =6; Rmat $\mathrm{AC}=0.9085, \mathrm{AG}=3.9485 ; \mathrm{AT}=1.7886 ; \mathrm{CG}=0.4203, \mathrm{CT}=3.9485, \mathrm{GT}=1.0000$; shape $=3.7180$ with four rate categories of equal weight, Pinvar $=0$.

For Clade $\mathrm{G}$ the $\mathrm{TVM}+\mathrm{G}$ ' was chosen with parameters Base $\mathrm{A}=0.2073, \mathrm{C}=0.2857, \mathrm{G}=0.2420, \mathrm{~T}=$ 0.2650; Nst =6; Rmat $\mathrm{AC}=1.4322, \mathrm{AG}=4.1838 ; \mathrm{AT}=2.3898 ; \mathrm{CG}=0.6995, \mathrm{CT}=4.1838, \mathrm{GT}=1.0000$; shape $=4.6379$ with four rate categories of equal weight, Pinvar $=0$.

For Clade $\mathrm{S}$ the 'TVMef' was chosen with parameters Base $=$ equal; Nst $=6$; Rmat $\mathrm{AC}=0.8504, \mathrm{AG}=$ 3.4197; $\mathrm{AT}=1.5299 ; \mathrm{CG}=0.0501, \mathrm{CT}=3.4197, \mathrm{GT}=1.0000$; equal rates, Pinvar $=0$.

\subsubsection{Outgroup}

In concordance with Piercey-Normore \& DePriest (2001) nrITS sequences of Asterochloris species were not found readily alignable with Trebouxia sequences and therefore, Asterochloris appears not appropriate to use as outgroup. No other taxa are known that could serve as outgroups. For the phylogenetic analyses of dataset 1 no suitable outgroup was available and therefore this phylogeny is unrooted (FIG. 4.3). For the separate analyses of Clades A, G, and I, the ITS-variant S3a (AJ249571) was employed as an outgroup (FIGS. 4.5, 4.7, 4.9, and 4.11). This sequence appeared as a short branch taxon in ML phylogenies and significantly increased the $t_{\text {RASA }}$ test statistic when used as an outgroup without behaving as an outlier taxon in a RASA plot (Lyons-Weiler 1997, Hepperle 2000). For Clade S, sequences of T. impressa (AF345890) and T. arboricola (Z68705) were used as outgroup. 


\subsection{Results}

\subsubsection{ITS clades}

The only photobiont genus detected in the Physciaceae was Trebouxia. This was concluded from the similarity of Physciacean photobiont ITS sequences with sequences of authentic Trebouxia strains. Also in phylogenetic analyses new ITS-variants inserted among known Trebouxia sequences and no unusual long branches were detected that would suggest the presence of another algal genus among Physciacean photobionts (FIG. 4.3). The compiled 310 nrITS sequences represented 94 distinct Trebouxia ITS-variants which were grouped into 31 subclades and four clades A, I, G, and S. The monophyletic origins of clades A, I, and G were well supported. However, there was no significant support for the monophyly of clade S (FIG. 4.3). Since genetic distances among members of clade $S$ were smaller than to any other member of Trebouxia, the phylogenetic distinctness of this clade could be assumed.

Genetic distances within the four clades were quite different. Clades A and S comprised maximal distances of $11 \%$ and average distances of $8 \%$ and $10 \%$ respectively (FIG. 4.2). Clades I comprised maximal distances of $18 \%$ and an average distance of $12 \%$ (FIG. 4.2). The largest distance values were observed in clade G. Average distances among subclades were $17 \%$ and the maximum distance observed in clade $\mathrm{G}$ was $27 \%$. These distances correspond to distances among clades A, I, and S. Almost all representatives of clade G were obtained from tropical samples and therefore the distinctness of this clade was also supported from an ecological point of view. However, except for subclade I4 all other representatives of clades A, I, and S originated from non-tropical climates. This may raise the suspicion that clade $\mathrm{G}$ forms a tropical counterpart to the other Trebouxia clades. It might be appropriate to assign clade rank to those lineages that comprise subclades G1 - G6, G7 - G9, and subclade G10. A split of clade G into additional clades, however, was omitted, since too little information besides nrITS sequence data were available to justify the establishment of further clades. 


\section{P-distances (\%) among clades and subclades}

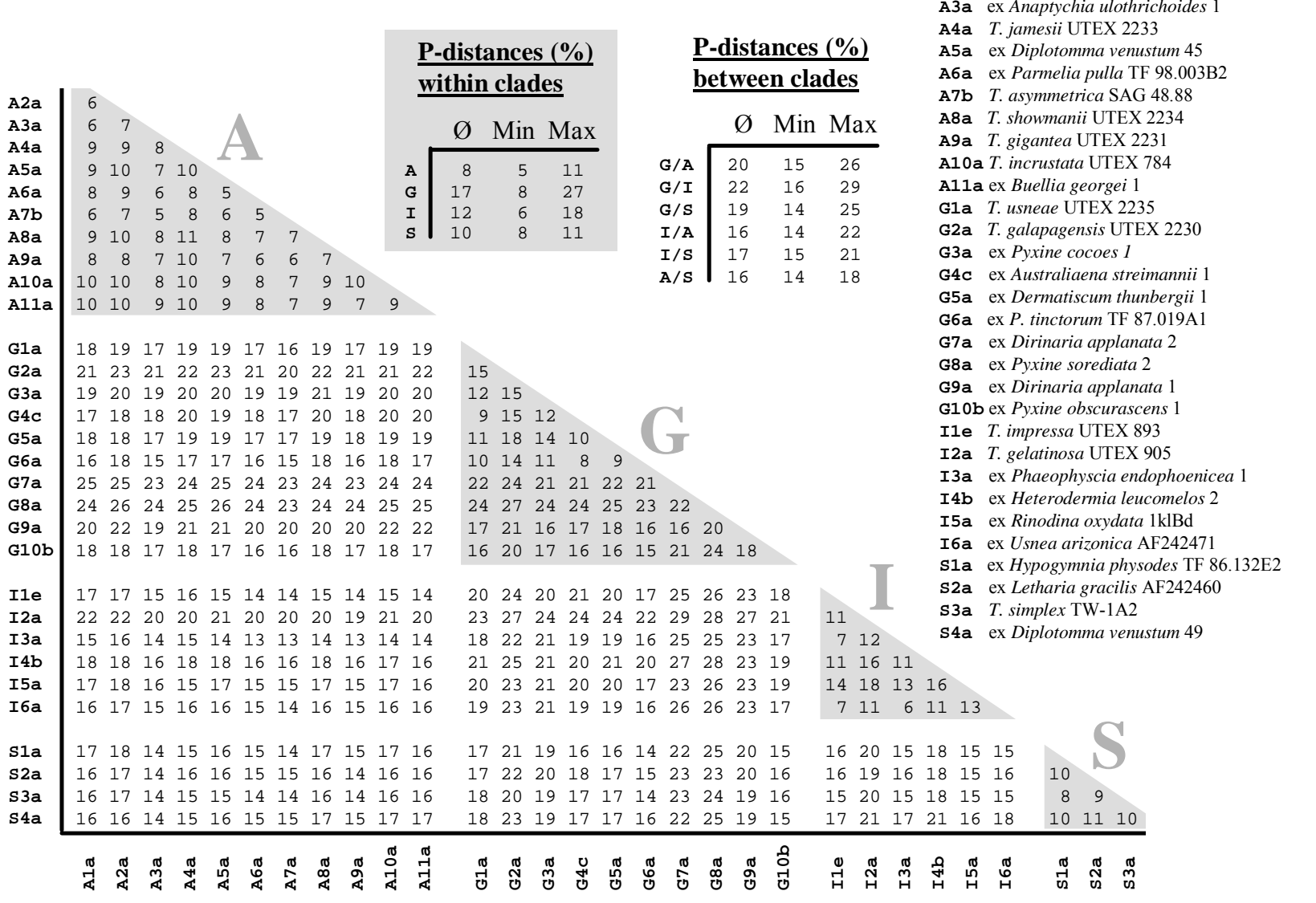

FIG. 4.2: P-distances between clades and subclades. Distance values within clades are shaded. Means, maxima and minima of P-distances between and within clades are shown in the two inserted tables. T.: Trebouxia, P.: Parmelia. 


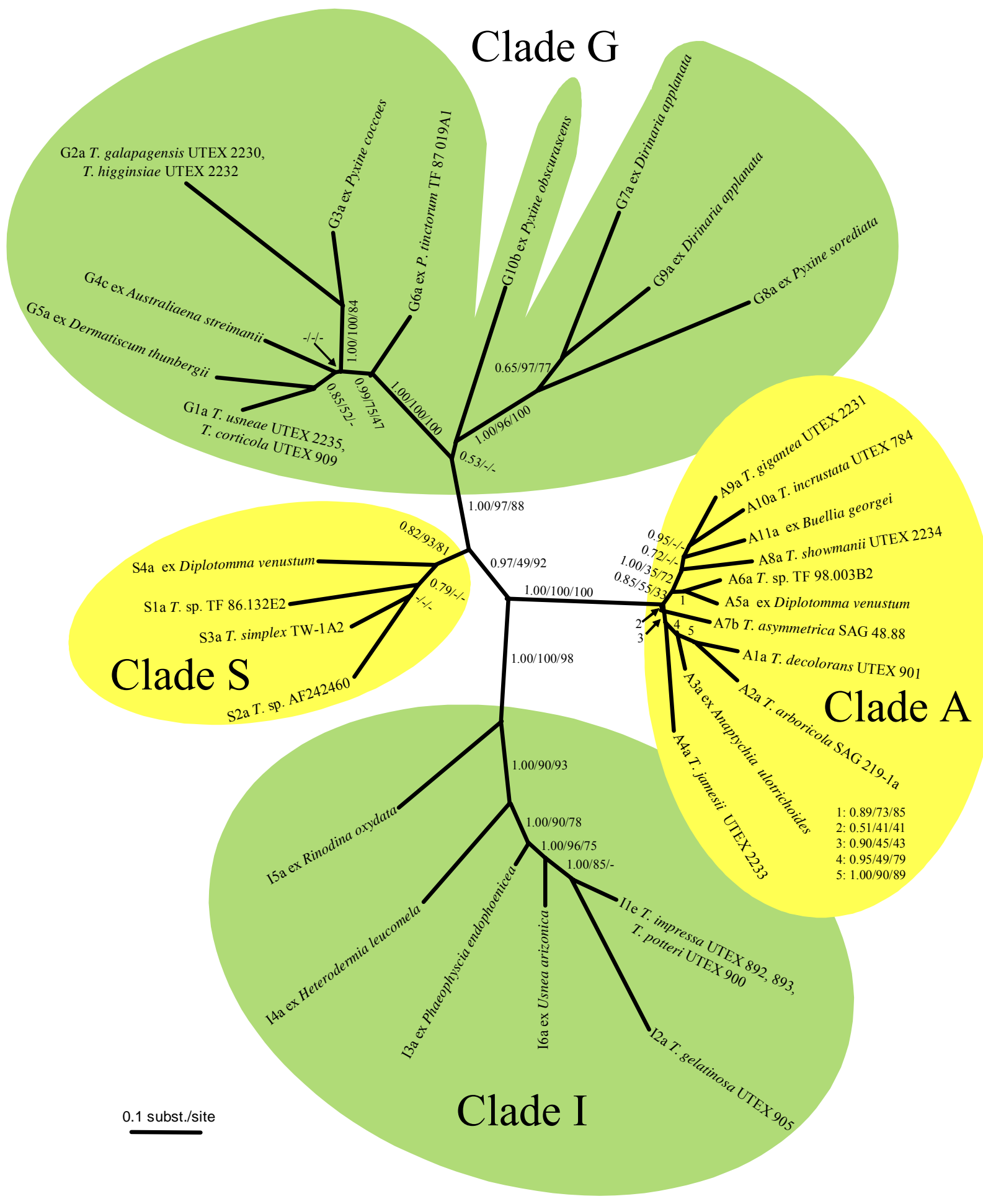

FIG. 4.3: Unrooted maximum likelihood phylogeny of Trebouxia clades and subclades. Branch supports obtained through Bayesian analysis (1 000000 generations, first support value), weighted maximum-parsimony analyses (1000 replicates, second support value), and neighbor-joining analyses, employing the Jukes-Cantor model of evolution (1000 replicates, third support value). 


\subsubsection{Clade A}

Clade A comprises eleven subclades A1 - A11 and 23 ITS-variants (FIG. 4.5). All ITS-variants except A8a (T. showmanii UTEX 2234) were found in the Physciaceae analyzed in this study (TABLE 4.4, FIGS. 4.4, 4.5). Although more subclades are differentiated in clade A than in the other clades, the average genetic distances within this clade are smaller than in the other clades. The average nucleotide substitution rate among subclades was $8 \%$ (FIG. 4.2). The largest P-distance within a subclade of clade A was observed in subclade A1 with $8 \%$. Substitution rates within the other subclades were below $4 \%$ (FIGS. 4.2, 4.4). Relationships among the subclades of clade A are not well resolved in several instances. Some subclades or groups of subclades received significant support in bootstrap and Bayesian analyses or were characterized by unique sequence insertions. These characteristic insertions, however, could not be included in the phylogenetic analyses.

\subsubsection{Sequence insertions and relationships among subclades}

As a reference sequence for numbering the positions of sequence insertions and deletions, the sequence of $T$. arboricola SAG 219-1a, (accession number Z68705, ITS-variant A2a) was chosen. The numbering of sequence positions starts with the first position of the ITS-1 region. All ITS-variants of clade A are characterized by the lack of an AG rich stretch of $4-9$ bp in the ITS 1 region after positions 59 (appendix A.2, FIG. A.1). The single origin of subclade A1 and A2 was consistently supported in phylogenetic analyses as well as by an insertion which both subclades had in common. This insertion resided in the ITS-2 region, position 577 - 588 (appendix A.2, FIG. A.2). Subclade A2 was delimited from A1 by an additional insertion in the ITS 1 region (positions 146 - 177). Notably this insertion plus flanking positions was absent in ITSvariant A2c (appendix A.2, FIG. A.3). Among all distinguished subclades, subclades A1 and A2 were separated by the least p-distances (6\% - 9\%, FIG. 4.4). Such p-distances were occasionally found within single subclades, e.g. A1 and I4. However, an additional insertion only present in subclade A2 as well as different substrate preferences and an apparent discrimination between the two subclades by certain mycobionts (e.g. Anaptychia ciliaris, see chapter 5) were considered sufficient evidence to justify the delimitation of both subclades. Together with subclades A3 and A4 both subclades formed a consistently supported lineage. Subclades A9, (T. gigantea, A9a), A10 (T. incrustata, A10a) and the new ITS-variant A11a formed one lineage that was characterized by the presence of an insertion of $85-87$ bp length at position 494 in the ITS-2 region (appendix A.2, FIG. A.4). However, their common origin was not significantly supported in bootstrap and Bayesian analyses. These three subclades were found to form a lineage together with $T$. showmanii (A8), which, received significant support in Bayesian analysis. Notably, T. showmanii was devoid of the sequence insertion that characterized subclades A9-A11. All other relationships among subclades of clade A appeared ambiguous. 


\subsubsection{Authentic strains, new ITS-variants, subclade support, internal distances}

Subclade A1 contains the authentic strain of T. decolorans UTEX 901 (ITS-variant A1a). Four more ITSvariants were found in this subclade, which are not represented as cultures. The common origin of these five ITS-variants is well supported in phylogenetic analyses. Notably the maximal p-distances observed in this subclade is already in the range of p-distances found between subclades, e.g. distances between A7 and most other subclades of clade A. However, Anaptychia ciliaris was found associated with ITS-variants A1a and A1e only, and the phylogenetic delimitation of A1b from these two former ITS-variants was uncertain, because of which the whole group of ITS-variants was included into one subclade. However, the uniformity of this subclade might remain uncertain.

Subclade A2 contains the authentic strain and type species of Trebouxia, T. arboricola SAG 219-1a (ITSvariant A2a). This strain is synonymous with the authentic strain of T. aggregata UTEX 180, as revealed by the identity of both's nrITS sequences. One further authentic strain belongs to this subclade, $T$. crenulata CCAP 219/2, which represents ITS-variant A2c. Further two new ITS-variants were found to be closely related to these authentic strains (max. p-distance 3\%). All four ITS-variants formed a highly supported subclade. Subclades A1 and A2 are the most closely related subclades in this study. The delimitation of both was recognized by different insertions in the ITS sequence as well as an apparent discrimination between the two subclades by e.g. Anaptychia ciliaris and Xanthoria parietina. Both lichens were exclusively associated with members of subclade A1.

The authentic strain of $T$. jamesii (UTEX 2233) represents ITS-variant A4a. Only one further ITS-variant in this subclade was detected, A4b. Both ITS-variants were separated by $3 \%$ nucleotide substitutions.

Two new ITS-variants were found that were closely related to T. asymmetrica (A7b). A common origin of these three ITS-variants was consistently found with different phylogenetic methods, but not significantly supported. However, all three genotaxa appeared to be the preferred photobionts of the closely related mycobionts Buellia elegans and B. zoharyi that were not found with other photobionts than these three ITSvariants. This was regarded as an indication for the unity of these ITS-variants into one subclade. Maximal pdistances were $4 \%$ in this subclade.

Subclades A8, A9, and A10 comprised only one ITS-variant each and were represented by the authentic strains of T. showmanii (UTEX 2234), T. gigantea (UTEX 2231), and T. incrustata (UTEX 784) respectively. All three subclades were separated by $7 \%$ to $10 \%$ nucleotide substitutions. 
The genetic distances of the new ITS-variant A11a to A10 and A9 were similar to the distance between A9 and A10. Therefore, the new ITS-variant was given subclade rank.

Subclades A3 and A6 were represented by one ITS-variant only and subclades A4 and A5 by two. All four subclades were well separated from each other and from subclades that included authentic strains and were therefore considered to be distinct.

\section{P-distances (\%) among ITS-variants of clade A}

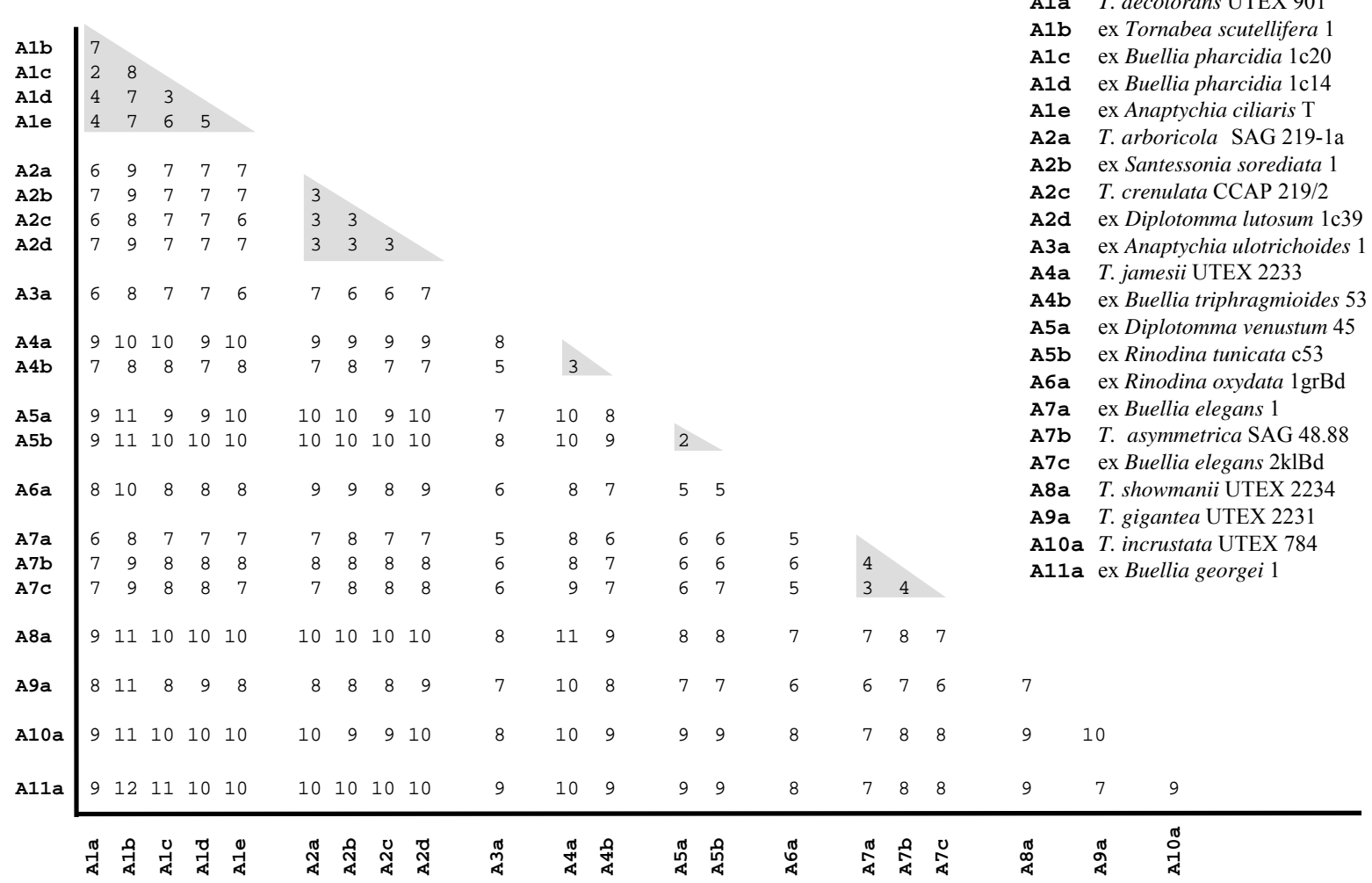

FIG. 4.4: P-distances among subclades and ITS-variants of clade A. P-distances within subclades are shaded. 


\section{Phylogeny of Clade A}

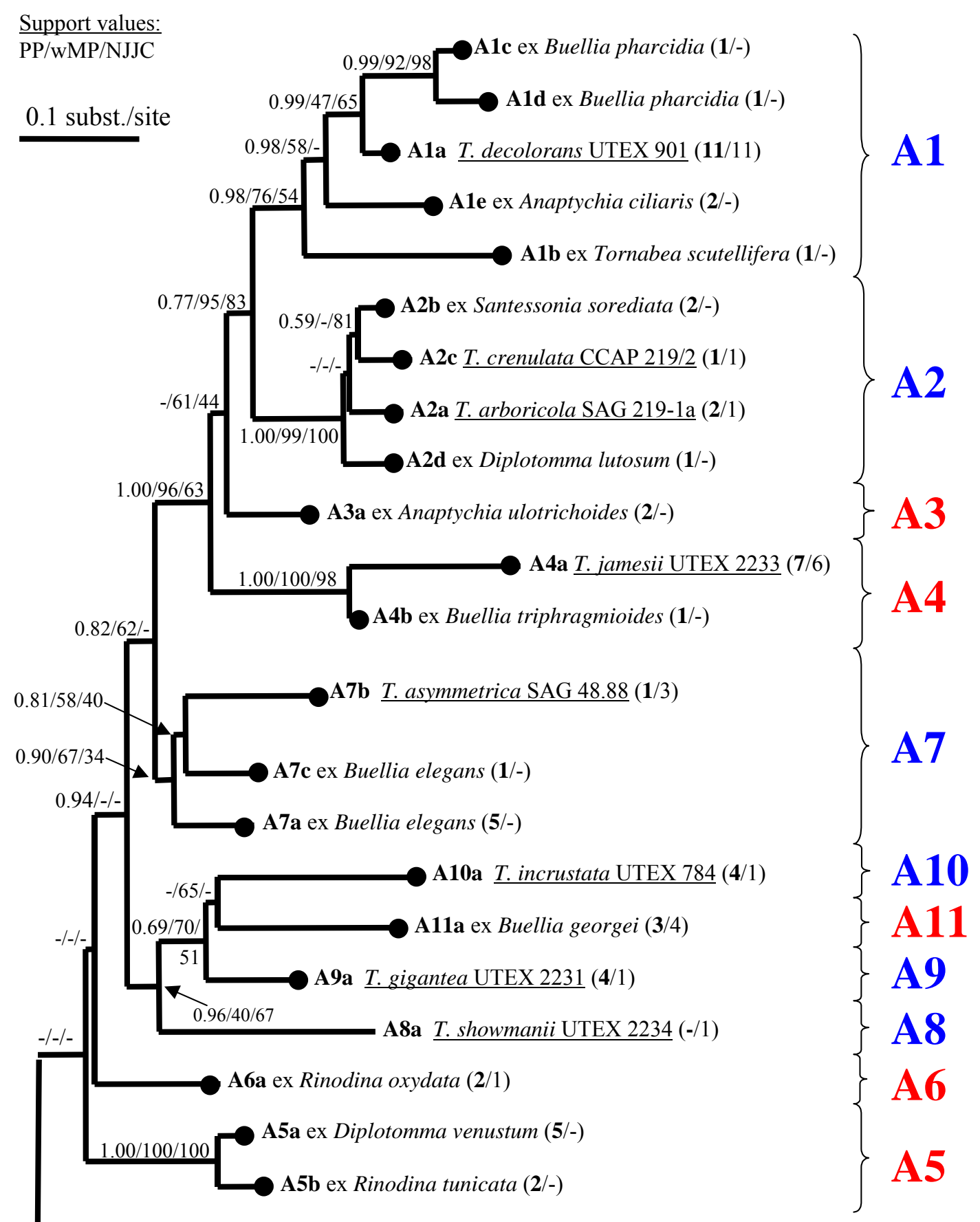

S3a T. simplex TW-1A2

FIG. 4.5: Maximum Likelihood (ML) phylogeny of clade A. Branch supports obtained through Bayesian analysis (PP, 200000 generations) and bootstrap analyses under the Maximum Parsimony (MP) criterion (500 replicates) and the Neighbor Joining method (NJJC, 1000 replicates). ITS-variants found in the Physciaceae are marked with a dot at the terminal nodes and ITS-variants obtained from cultures are underlined. Lichen names indicate the species from which the represented Trebouxia ITS-variant was obtained. Numbers in parentheses indicate the number of Physciaceae specimens (first number, bold) as well as the number of non-Physciacean specimens (second number) in which the respective ITS-variants were found. Blue subclade labels indicate subclades that include cultured strains, red labels indicate subclades from which no cultures are available. The same representative taxa as in FIG. 4.4 were used in this figure. 


\subsubsection{Clade I}

Clade I comprised six subclades, I1 - I6, which represented 39 ITS-variants (TABLE 4.4, FIGS. 4.6, 4.7). Only subclade I6 with one ITS-variant and ITS-variants I2a and I2c were not found in the Physciaceae. Average P-distances between subclades of clade I were $12 \%$ (FIG. 4.3). Subclade I1 comprised many more specimens (113 specimens) than any other subclade. Twenty-one ITS-variants were distinguished within subclade I1 and all were recovered from the Physciaceae.

\subsubsection{Sequence insertions and relationships among subclades}

Subclade I 2 is characterized by a long sequence insertion at the $5^{\prime}$ - end of the ITS 1 region. The position of this insertion cannot be unambiguously identified since its flanking regions are not alignable with other taxa of this clade. This insertion consists of a variable number of repeats. The repeated motif is 34 to $40 \mathrm{bp}$ long and repeated three (I2b, c), four (I2d) or five (I2a) times (appendix A.2, FIG. A.5). Except for subclade I5, all other taxa of clade I have a run of four to six adenosines corresponding to positions 540 to 544 of $T$. impressa UTEX 893 (appendix A.2, FIG. A.6).

Phylogenetic relationships among subclades are comparably well resolved in this clade. Only the position of subclade I6 changed in different analyses with respect to its relation to subclades I1 and I2 (FIGS. 4.3, 4.7) and received no significant support in the analyses illustrated in FIG. 4.7. Subclades I1, I2, and I6 formed a sistergroup to subclade I 3 and these four were sister to subclade I4. The very base of this clade is represented by ITS-variant I5a.

\subsubsection{Authentic strains, new ITS-variants, subclade support, internal distances}

Subclade I1 included the authentic strains T. impressa (UTEX 892 and UTEX 893), T. potteri (UTEX 900), and T. flava (UTEX 181). Both strains of T. impressa and T. potteri revealed almost identical ITS sequences and could be assigned to ITS-variant I1 e. T. flava represented ITS-variant I1f. Further, ITS-variants I1d and I1g were observed in strains M-96.012A2 and M-96.026D4 respectively. The remaining ITS-variants of subclade I1 could not be assigned to cultured strains. The maximum distance observed in this subclade was $5 \%$. Because of the high number of samples and the small genetic distances in this subclade, a few ITSvariants were distinguished that differed in less than $2 \%$ of their sequence positions (FIG. 4.1). Monophyly of subclade I1 was highly significant.

Subclade I2 includes the authentic strains T. gelatinosa UTEX 905 and T. anticipata UTEX 903 as well as strain TF 86.108B2. All three represent distinct ITS-variants (FIG. 4.6). One more ITS-variants was detected 
that could not be assigned to cultured strains. These four ITS-variants were separated by p-distances of $4 \%$ or less and together formed a highly supported monophylum.

Subclade I4 did not include any cultured Trebouxia strains and was represented by nine new ITS-variants. These exhibited a notable sequence heterogeneity with a maximum substitution rate of $9 \%$ (FIGS. 4.6, 4.7) and still formed a highly supported monophylum. This subclade was not further divided into more subclades because Heterodermia leucomela was found to be associated with the two lineages within this subclade (FIG. 4.7). Subclades I3, I5, and I6 formed separate lineages and deviated significantly in their ITS sequences from authentic strains but were only represented by one or two ITS-variants.

\section{P-distances (\%) among ITS-variants of clade I}

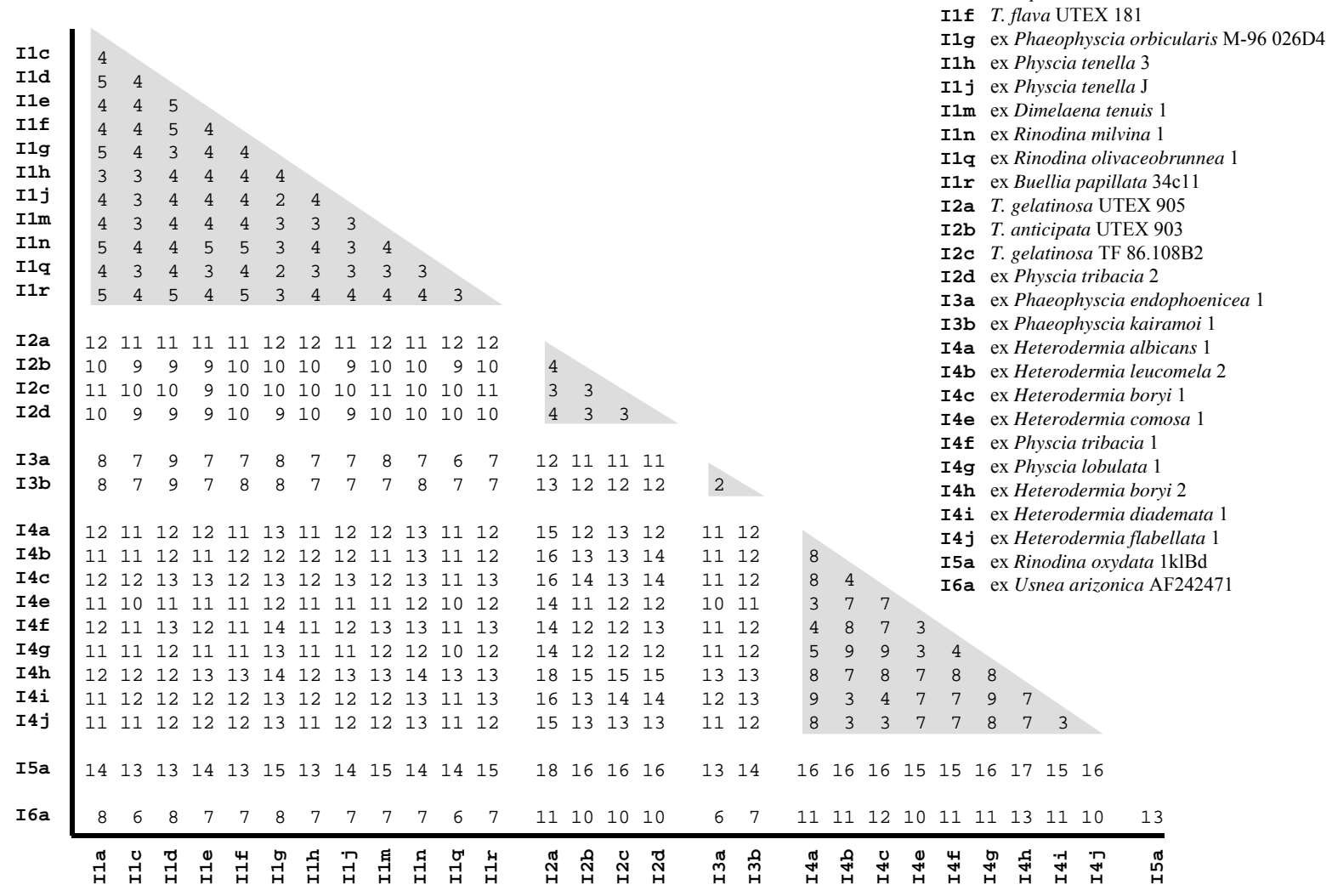

FIG. 4.6: P-distances among subclades and ITS-variants of clade I. P-distances within subclades are shaded. Not all ITS-variants of subclade I1 which were distinguished could be included in this figure. 


\section{Phylogeny of Clade I}

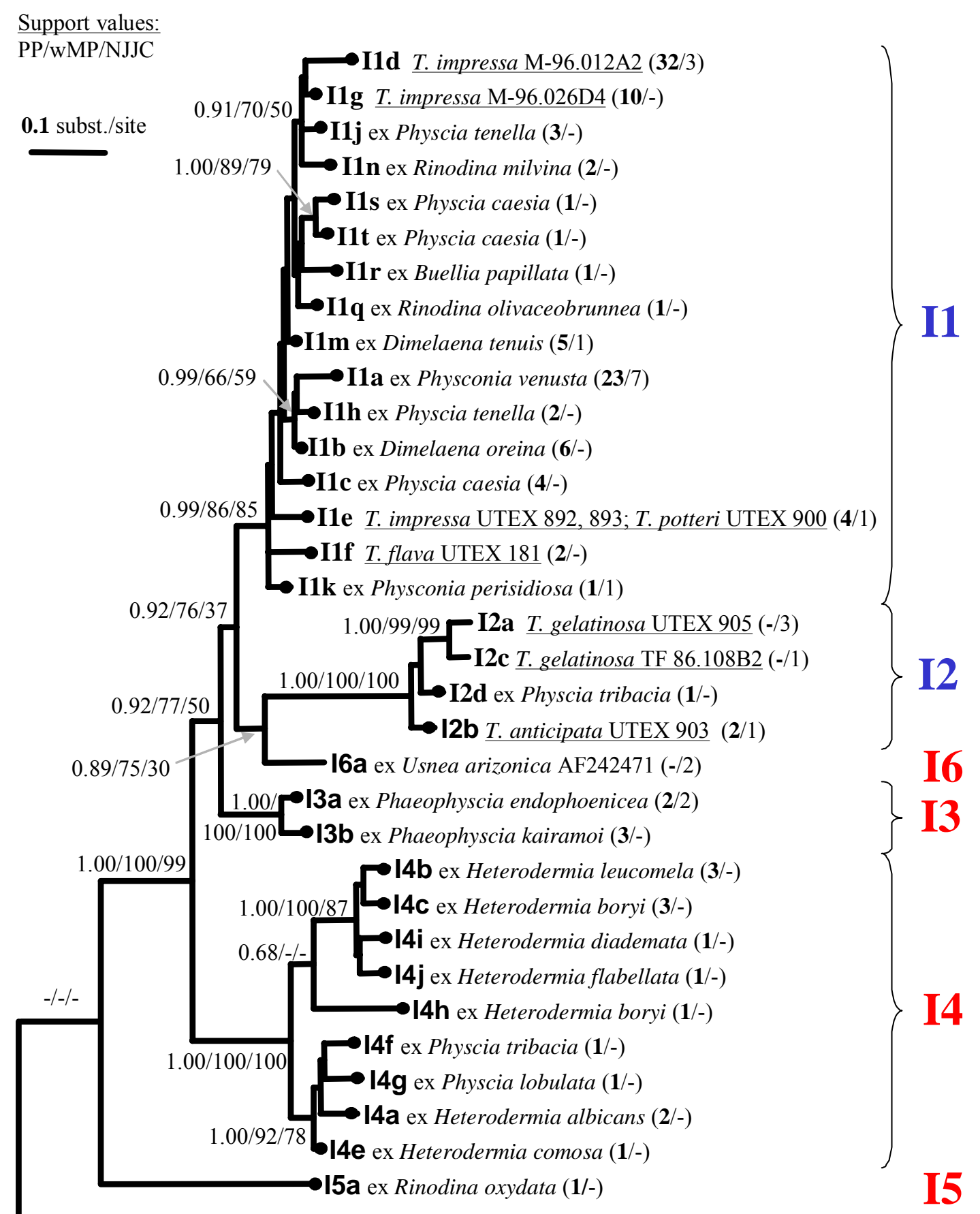

S3a T. simplex TW-1A2

FIG. 4.7: Maximum Likelihood (ML) phylogeny of clade I. Branch supports obtained through Bayesian analysis (PP, 200000 generations) and bootstrap analyses under the Maximum Parsimony (MP) criterion (500 replicates) and the Neighbor Joining method (NJJC, 1000 replicates). ITS-variants found in the Physciaceae are marked with a dot at the terminal nodes and ITS-variants obtained from cultures are underlined. Lichen names indicate the species from which the represented Trebouxia ITS-variant was obtained. Numbers in parentheses indicate the number of Physciaceae specimens (first number, bold) as well as the number of non-Physciacean specimens (second number) in which the respective ITS-variants were found. Blue subclade labels indicate subclades that include cultured strains, red labels indicate subclades from which no cultures are available. The same representative taxa were used in this figure as in FIG. 4.6. 


\subsubsection{Clade G}

This clade revealed considerably larger genetic distances than the other clades and only 25 photobionts belonging into this clade could be analyzed. Therefore, clade $\mathrm{G}$ was probably the least well represented clade and any structuring has to be considered preliminary. Ten subclades were distinguished in clade $\mathrm{G}$ comprising 17 ITS-variants (TABLE 4.4, FIGS. 8, 9). Average genetic distances within clade G were $17 \%$ which was similar to or even larger than the genetic distances between the clades A, I, and S. These latter three clades are separated by average P-distances of $16 \%$ - $17 \%$ (FIGS. 4.2, 4.8).

\subsubsection{Sequence insertions and higher order relationships}

Clade $\mathrm{G}$ can be structured into three major lineages. One of them is represented by only one subclade, G10. Subclades G7, G8, and G9 revealed a highly supported common origin. The third lineage comprised subclades G1-G6. Within this last lineage subclades G2 and G3 formed a highly supported monophylum, while the relationships of the other subclades remained ambiguous. Despite the large genetic distances that separated the three major lineages within clade $G$, these three lineages were not delimited in distinct clades, since further evidence for their distinctness was not available. Distinct habitat preferences could not be observed and either of the three lineages shared mycobiont genera (e.g. Dirinaria, Physcia, and Pyxine) with at least one of the other lineages. Furthermore, all representatives of this clade were of tropical origin and thereby ecological distinct from all other Trebouxia subclades, except for subclade I4. None of the subclades of clade $\mathrm{G}$ was characterized by particular insertions or deletions.

\subsubsection{Authentic strains, new ITS-variants, subclade support, internal distances}

Only two of the ten subclades in this clade include authentic strains. Subclade G1 is represented by $T$. corticola (UTEX 909) and T. usneae (UTEX 2235). Subclade G2 by T. galapagensis (UTEX 2230) and T. higginsiae (UTEX 2232). Each group of authentic strains represents one ITS-variant only. Neither of these ITS-variants was recovered from Physciaceae in this study. However, T. higginsiae (UTEX 2232) was originally isolated from Buellia straminea (Hildreth \& Ahmadjian 1981). Also subclades G5, G8, and G9 were represented by only one ITS variant. Subclades G3, G4, G6, and G7 consisted of multiple ITS-variants and revealed only comparably small genetic distances (FIG. 4.8). Subclade G10 comprised an ITS p-distance of $10 \%$ but since each of the two ITS-variants was represented by only one specimen a separation into two subclades appeared premature. Monophyly of each of these subclades was consistently supported (FIG. 4.9). 


\section{P-distances (\%) among ITS-variants of clade G}

\section{sources of Trebouxia ITS variants}

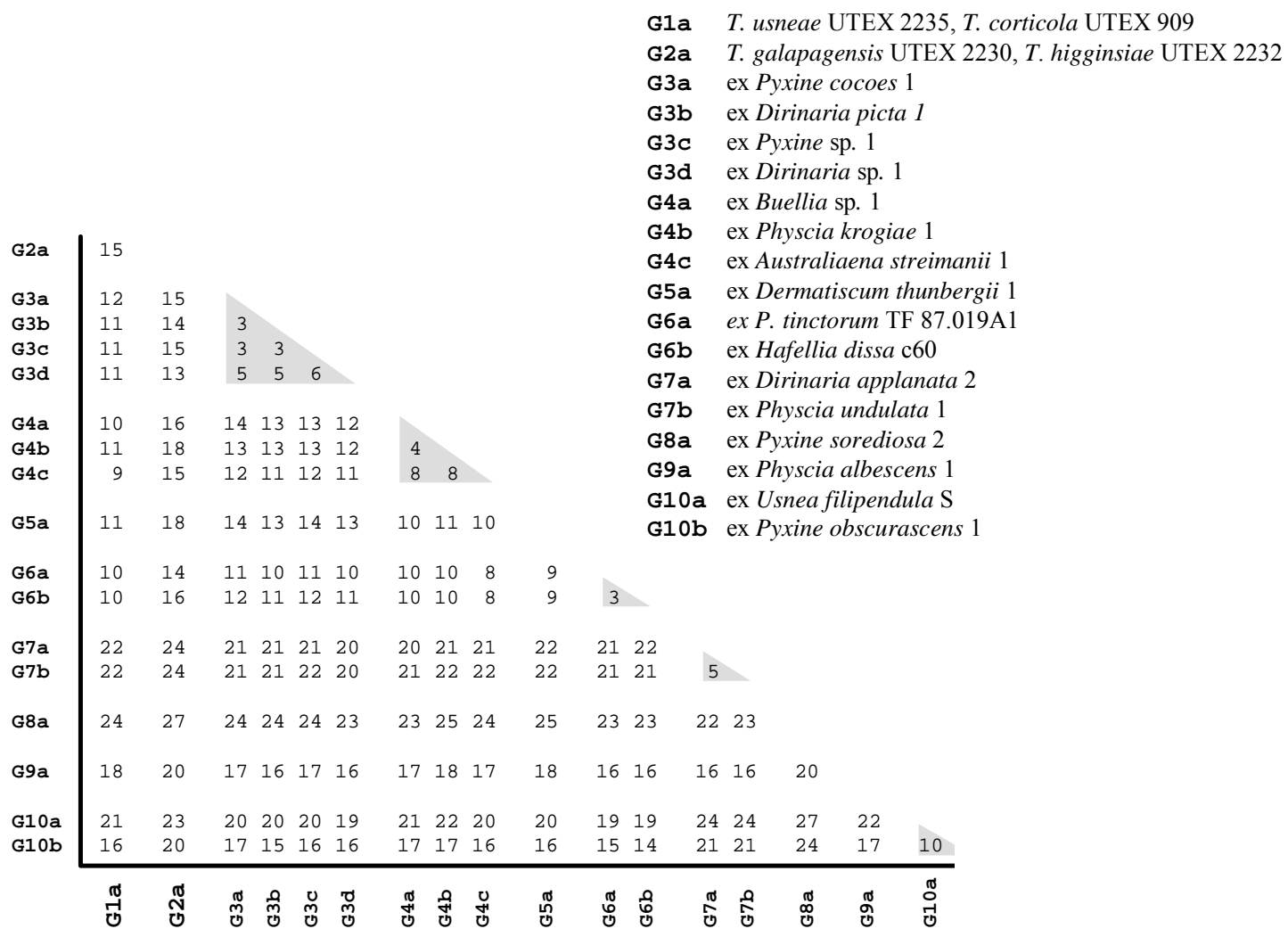

FIG. 4.8: P-distances among subclades and ITS-variants of clade G. P-distances within subclades are shaded. 


\section{$\underline{\text { ML Phylogeny of Clade G }}$}

Support values:

$\mathrm{PP} / \mathrm{wMP} / \mathrm{NJJC}$

\section{1 subst./site}

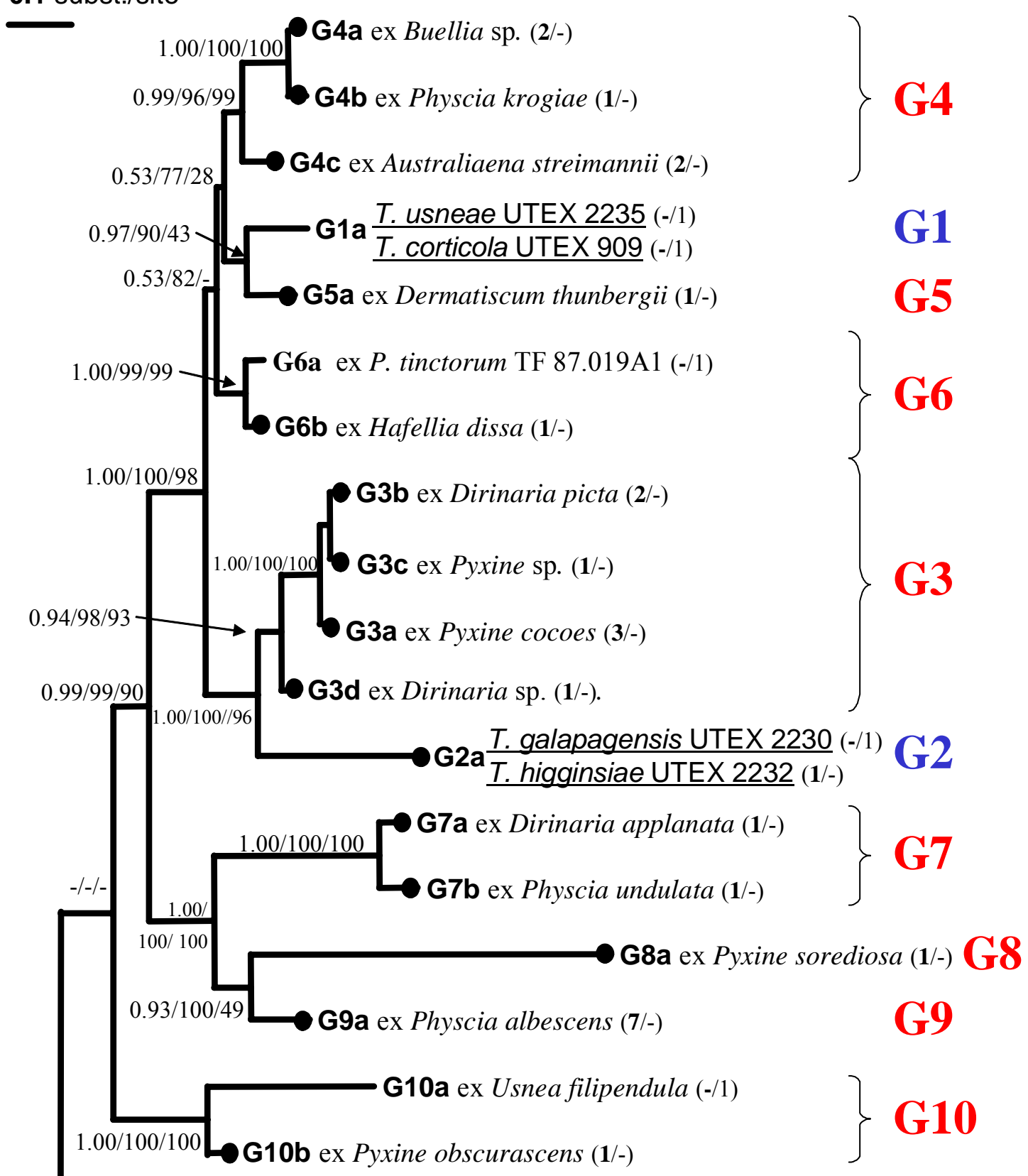

S3a T. simplex TW-1A2

FIG. 4.9: Maximum Likelihood (ML) phylogeny of clade G. Branch supports obtained through Bayesian analysis (PP, 200000 generations) and bootstrap analyses under the Maximum Parsimony (MP) criterion (500 replicates) and the Neighbor Joining method (NJJC, 1000 replicates). ITS-variants found in the Physciaceae are marked with a dot at the terminal nodes and ITS-variants obtained from cultures are underlined. Lichen names indicate the species from which the represented Trebouxia ITS-variant was obtained. Numbers in parentheses indicate the number of Physciaceae specimens (first number, bold) as well as the number of non-Physciacean specimens (second number) in which the respective ITS-variants were found. Blue subclade labels indicate subclades that include cultured strains, red labels indicate subclades from which no cultures are available. The same representative taxa were used in this figure as in FIG. 4.8. 


\subsubsection{Clade S}

This clade comprises four subclades and 11 ITS-variants (TABLE 4.4). Genetic distances within this clade are similar to distances within clade A, in which at least 6 morphospecies were described (FIG. 4.2). Nucleotide substitutions between subclades exhibit an average rate of $11 \%$ (FIG. 4.2). Representatives of Clade S were found only in three specimen of the Caliciaceae as defined in chapter 3. ITS-variant S1b was found in Amandinea petermannii, an Antarctic species. This ITS-variant is common on heavy metal rich substrates (Beck 2002) and was the most common photobiont in Antarctic Umbilicaria species (Romeike et al. 2002). ITS-variant S3b was found in a specimen of Cyphelium tigillare growing on Betula bark, an acid substrate not settled by any of the other Physciaceae species investigated in this study. ITS-variant S4a was found once in a sample of Diplotomma venustum, which was collected from calcareous rock. This sample was unusual in two respects: First, three other specimens of $D$. venustum were associated with ITS-variant A5a, i.e. appeared quite selective. Second, all other members of clade S apparently prefer acid substrates. A contamination from other specimens appeared improbable, since ITS-variant S4a was detected only once in this particular specimen. Therefore, the significance of ITS-variant S4a is considered uncertain.

\subsubsection{Sequence insertions and higher order relationships}

A closer relation between clades $\mathrm{G}$ and $\mathrm{S}$ is supported by similarities in a highly variable domain of the ITS 2 region (positions 468 - 482 of T. arboricola SAG 219-1a; appendix A.2, FIG. A.7). All members of clade S as well as subclades G1- G4, G6, and G10 have an insertion in common that is absent in all other Trebouxia subclades. This may support a single origin of clades $\mathrm{S}$ and $\mathrm{G}$, if two independent losses of this insertion in clade $\mathrm{G}$ were assumed, once in subclade G5 and once in the common ancestor of subclades G7 - G9.

\subsubsection{Authentic strains, new ITS-variants, subclade support, internal distances}

There has been some confusion about the taxonomic placement of the authentic strains $T$. jamesii UTEX 2233 and T. simplex TW-1A2. These two strains were believed to be conspecific (Friedl 1989b), but were found to belong to different clades, A and S, based on ITS sequence analyses (Beck 2002). Before the ITS sequence of T. simplex TW-1A2 was available, Trebouxia strains of clade S were misidentified as T. jamesii and ITS sequences obtained from these strains were accordingly published as T. jamesii (Bhattacharya et al. 1996). Sequence data of morphologically unknown Trebouxia taxa have subsequently been published (subclade S2, Kroken \& Taylor 2000) and assigned to T. jamesii, based on sequence comparison with these misclassified GenBank entries. The genetic distances suggest that those taxa that have been published in Bhattacharya et al. (1996) and Kroken \& Taylor (2000) might also not belong to T. simplex TW-1A2, but to other species. Those sequences published in Bhattacharya et al. (1996) exhibit great similarity to $T$. angustilobata (AB 97.027B3), while those published by Kroken \& Taylor (2000) eventually represent a new 
undescribed species. This suspicion is supported by the uncertainty of its phylogenetic position. Depending on taxon sampling, outgroup, and inclusion/exclusion of ambiguously aligned positions, subclade S2 sometimes becomes the sistertaxon to a lineage that comprises clade G and subclades S1, S3 and S4. Therefore, uncertainty remains about the monophyly of clade $S$ and the phylogenetic relationships among its subclades. A more extensive discussion about this clade is given in Beck (2002) and Helms et al. (submitted). Subclade S1 included more ITS-variants than the other three subclades of clade S and also the greatest p-distances. The authentic strain which represents this subclade deviated in $5-7 \%$ from the other members of subclade S1, while distances among those other ITS-variants were often considerably smaller (2 - 6 \%, FIG. 4.10). Beck (2002) distinguished four morphospecies in subclade S1. P-Distances among ITSvariants of subclades S2 and S3 were only $2 \%$.

\section{P-distances (\%) among ITS-variants of clade S}

\section{sources of Trebouxia ITS-varaints}

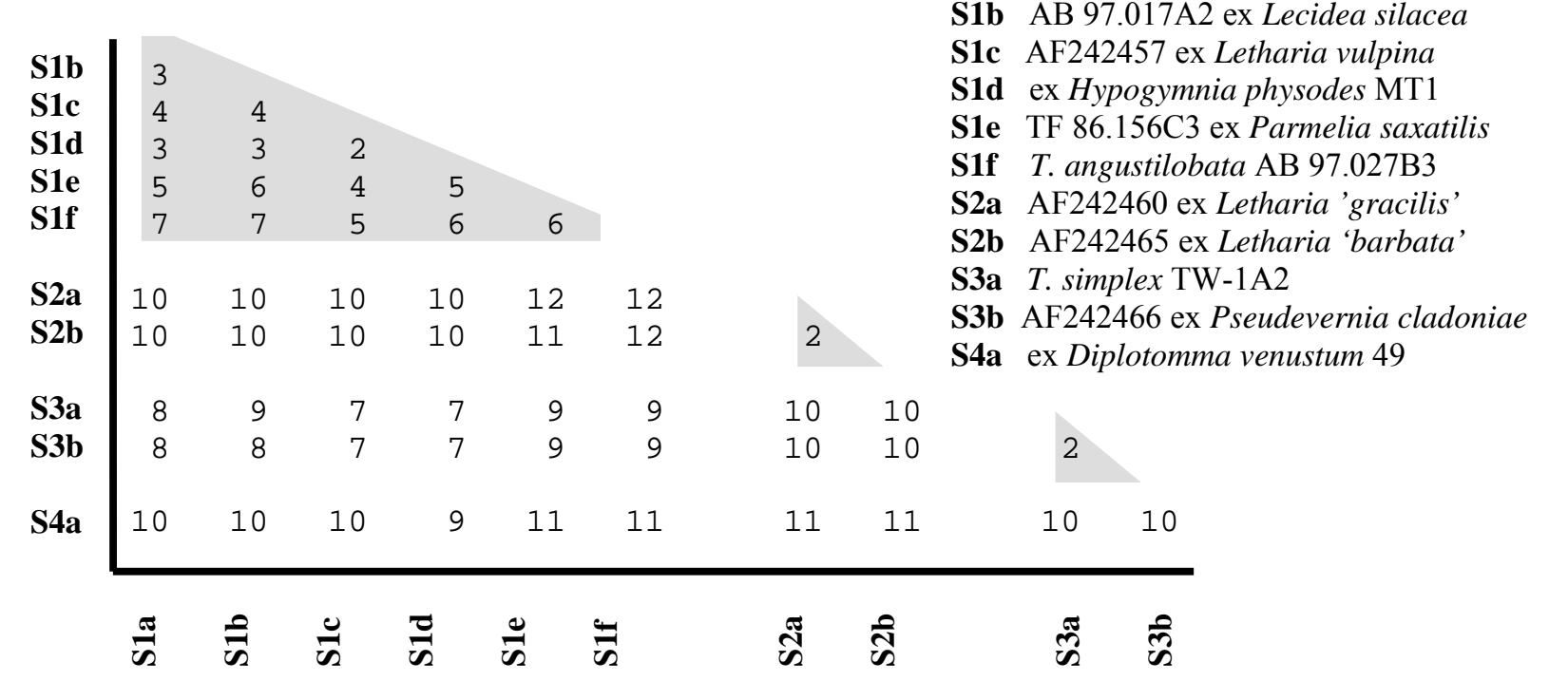

FIG. 4.10: P-distances among subclades and ITS-variants of clade S. P-distances within subclades are shaded. 


\section{Phylogeny of Clade S}

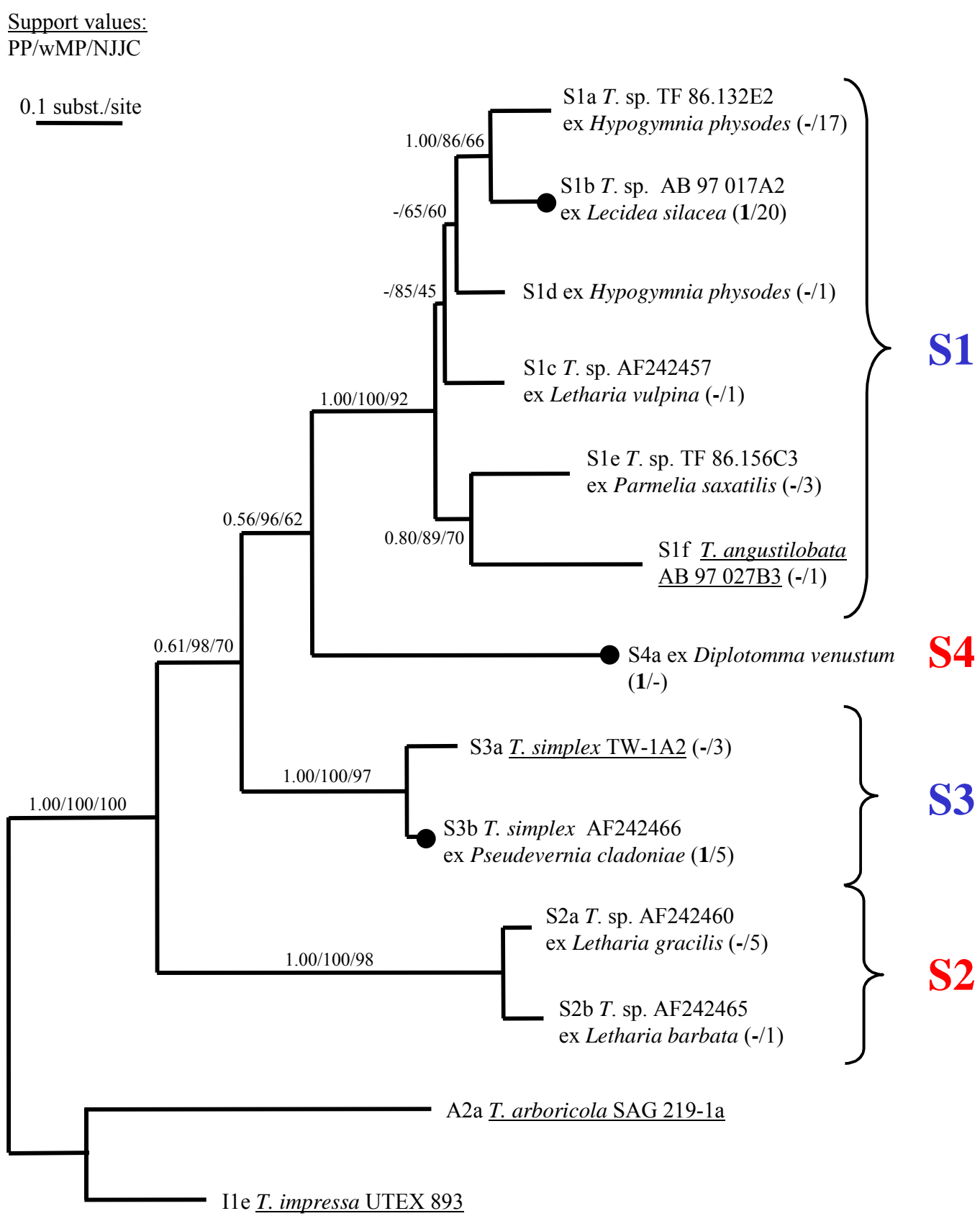

FIG. 4.11: Maximum Likelihood (ML) phylogeny of clade S. Branch supports obtained through Bayesian analysis (PP, 100000 generations) and bootstrap analyses under the Maximum Parsimony (MP) criterion (500 replicates) and the Neighbor Joining method (NJJC, 1000 replicates). ITS-variants found in the Physciaceae are marked with a dot at the terminal nodes and ITS-variants obtained from cultures are underlined. Lichen names indicate the species from which the represented Trebouxia ITS-variant was obtained. Numbers in parentheses indicate the number of Physciaceae specimens (first number, bold) as well as the number of non-Physciacean specimens (second number) in which the respective ITS-variants were found. Blue subclade labels indicate subclades that include cultured strains, red labels indicate subclades from which no cultures are available. The same representative taxa were used in this figure as in FIG. 4.10 . 


\subsection{Discussion}

\subsubsection{Morphology vs. ITS-variant and species definition in Trebouxia}

When analyzing ITS sequences from Trebouxia cultures which had been used in previous morphological studies (e.g. Ahmadjian \& Jakobs 1981, Archibald 1975, Friedl 1989b, Gärtner 1985, Hildreth \& Ahmadjian 1981) some inconsistencies between ITS sequence data and morphospecies delimitation became apparent. In some cases, a single morphospecies was represented by multiple subclades, while in other cases different morphospecies were found to represent the same ITS variant.

\subsubsection{Single morphospecies which were represented by multiple subclades}

The three subclades S1, S2, and S3 have been assigned to T. jamesii UTEX 2233 what later turned out to be a misclassification (see above). Beck (2002) described four new species within subclade S1, $T$. angustilobata, T. australis, T. brindabellae, and T. suecica, based on morphology. Also based on morphology, strain TF 87.019A1 had been assigned to T. usneae UTEX 2235 (Bhattacharya et al. 1996) but deviated in $10 \%$ of the sequence positions from this authentic strain and also was paraphyletic with it (FIG. 4.9).

\subsubsection{Multiple morphospecies which were represented by single subclades or even single ITS- variants}

Most authentic strains were observed in clade A. Three authentic strains represented subclade A2, T. arboricola SAG 219-1a, T. aggregata UTEX 180, and T. crenulata CCAP 219/2. T. arboricola SAG 2191a, T. aggregata UTEX 180 had identical nrITS sequences, while T. crenulata CCAP 219/2 deviated in only $3 \%$ of the sequence positions from the other two. The authentic strain T. impressa UTEX 893 was found to be identical with T. impressa UTEX 892/893 and T. potteri UTEX 900 and most probably conspecific with T. flava UTEX 181 as inferred from ITS p-distances (4\%, FIGS. 4.6, 4.7). The authentic strains of $T$. gelatinosa UTEX 905 and T. anticipata were members of the same subclade and deviated in $4 \%$ of their nrITS sequence positions. Hence, their conspecificity was assumed.

\subsubsection{Relationships among morphospecies which synonymy had been proposed}

T. gigantea (UTEX 2231), T. incrustata (UTEX 784) and T. showmanii (UTEX 2234), whose synonymy was proposed by Friedl (1989b), are represented by distinct ITS-variants that are separated by p-distances as large as those between other species of clade A (e.g. distances among T. asymmetrica SAG 48.88, T. jamesii UTEX 2233, and T. arboricola SAG 219-1a; FIG. 4.4). Further, T. showmanii is delimited from the two other 
authentic strains by the lack of a characteristic insertion as shown in the appendix A.2, FIG. A.3. Therefore, it is suggested to maintain these taxa as distinct species. Accordingly, they were given subclade rank in this survey. Friedl (1989b) suggested the synonymy of T. corticola (UTEX 909) with T. galapagensis (UTEX 2230) and T. higginsiae (UTEX 2232). However, T. corticola turned out not to be closely related to either of the latter two, but was characterized by an ITS sequence almost identical to that of T. usneae (UTEX 2235) (FIGS. 4.8, 4.9). The synonymization of $T$. galapagensis and $T$. higginsiae, however, was confirmed by ITS sequences that only differed in 10 positions yielding a p-distance of $1.5 \%$ and therefore were united in a single ITS variant. T. simplex TW-1A2 and T. jamesii UTEX 2233 were synonymized by Friedl (1989b) and turned out to belong to even separate clades, S and A respectively (Beck 2002).

The present data strongly suggest that the current morphospecies concepts are not suitable to accurately represent the genetic diversity within Trebouxia. Although ITS sequence data alone were not considered to be sufficient to characterize species (Grube \& Kroken 2000, Taylor et al. 2000), it seems that ITS sequence data are quite reliable for species identification.

In Trebouxia, ITS sequences are seen to provide a better taxonomic resolution than phenotypic traits, due to the low degree of morphological differentiation (Helms et al. 2001). Therefore, ITS sequence identity with authentic strains is considered as evidence for conspecificity here, even though this approach does not hold in other taxonomic groups (e.g. Physciaceae). Substitution rates in the ITS region of up to $8 \%$, were observed in subclade A1, and might not necessarily mean that compared taxa belong to different morphospecies (FIG. 4.4). Differences of only 6-7 \%, however, were found to separate distinct morphospecies (e.g. T. arboricola SAG 219-1a, T. jamesii UTEX 2233, and T. asymmetrica SAG 48.88; FIG. 4.4). Therefore, additional characters, such as morphology, ecology and mycobiont compatibility need to be analyzed in order to arrive at an ecologically meaningful species concept in Trebouxia.

\subsubsection{Estimating ITS-variant diversity}

The 310 Trebouxia ITS sequences included in this study were quite unevenly distributed among the distinguished subclades. This was due to sample choice, which was strongly biased towards a certain group of lichens, the Physciaceae, and within this group, the most common species of the genera Physcia and Physconia were over-represented. Therefore, it can be expected that numerous further ITS-variants and subclades will be discovered when lichen habitats not well represented in this study are investigated. 


\section{Ecological and Evolutionary Dependence in Associations of

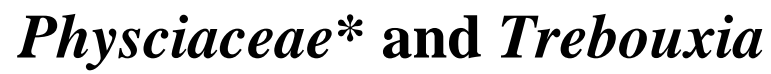

\subsection{Summary}

In this study, the ecological and evolutionary dependence of Physciacean mycobionts on their photobionts was investigated. Most species of which multiple specimens were analyzed were found to associate with photobionts of one Trebouxia subclade only (for subclade definition see section 4.3.1.2). Sexual and asexual reproductive modes were not found to correlate with a low or high degree of selectivity. Notably, crustose species often had low degrees of selectivity and foliose species were usually highly selective. Further, sexual species often were associated with ITS-variants that were different from those found in closely related asexual species. This suggests that alga sharing is not a common mode of photobiont acquisition in apotheciate species. The high degree of selectivity which was found in most Physciaceae species contrasted to the apparent lack of selectivity in the photobionts. Therefore, in analogy to parasitic systems, photobionts were denoted as host organisms and mycobionts as associates. According to an apparent dependence of most mycobionts on particular photobionts, correlated phylogenies could be suspected in the associated taxa (Fahrenholz' Rule, Mitter \& Brooks 1983). However, the analyses showed that associated taxa do not share a common evolutionary history. Furthermore, the correlation of selected environmental factors with both bionts' phylogenies was analyzed. These analyses revealed that the photobiont phylogeny is much closer correlated with the investigated environmental parameters than the mycobiont phylogeny. This suggests that photobionts and mycobionts adapt independently to particular environments. This as well as the phenomenon of resource partitioning are thought to explain the incongruent habitat ranges of associated bionts.

\subsection{Introduction}

Recent investigations have revealed that the integration of fungi and algae or cyanobacteria into a symbiotic association evolved multiple times independently, resulting in an exceptionally high diversity of life forms referred to as lichens (Gargas et al. 1995, Lutzoni et al. 2001). Typical lichen characters such as growth habit, formation of apothecia, and secondary metabolite production are only expressed by the lichenized mycobiont, not in the aposymbiotic stage as observed in culture experiments (Ahmadjian 1993). The high degree of organismic integration necessary for the expression of such complex characters was interpreted as evidence for a prolonged coadaptation (Ahmadjian 1987, Hawksworth 1988) which might have led to a reciprocal dependence between the associated bionts. A reciprocal dependence could be suspected to promote a coupling of the speciation process in the associated organisms. However, several observations

* "Physciaceae" also includes the analyzed species denoted as Caliciaceae in chapter 3. 
were made that contradict the hypothesis of cophylogeny in associated taxa. Various authors (e.g. WangYang et al. 1972, Friedl 1989b, Ahmadjian 1993) found mycobiont species associated with different photobiont species and vice versa, rejecting the hypothesis of mutual exclusiveness in lichen biont associations. These reports of a low degree of selectivity particularly call into question the hypothesis of cophylogeny.

As already mentioned in chapter four, the traditional impracticality of unambiguous recognition of the most common lichen photobionts constituted the major problem that has prevented profound investigations in coevolution as well as any other interaction between lichen bionts. Although lichens are commonly regarded as the most prominent example of symbiosis, investigation on lichen symbiosis has remained quite limited when compared to other symbiotic systems such as those of mycorrhiza and vascular plants, Rhizobium and legumes and many others (Janzen 1985). With the advent of molecular biology, it became possible to rapidly and reliably determine lichen photobionts (Beck et al. 1998, Beck 1999, 2002, Kroken \& Taylor 2000, Dahlkild et al. 2001, Helms et al. 2001, Romeike et al. 2002). By doing so, lichens were made accessible to the theories developed in the field of interspecific interactions. This molecular survey attempts to overcome the traditional obstacles of photobiont identification and apply methods of cophylogenetic analyses to the lichen symbiosis.

\subsubsection{Cophylogenetic analyses}

Cophylogenetic analyses focus on the question whether the biological dependence of an "associate" on its "host" is strong enough that speciation events in the "host" induce speciation in the associate (Page and Charlston (1998) used the terms "host" and "associate" for associations considered under the aspect of dependence). Such associations could be of quite different nature. They might be represented by introns evolving within particular exons, single genes which evolve inside host species, species evolving in dependence on other species (e.g. the classical host - parasite system), or it could be species evolving within a particular biogeographic history (the subject of biogeography, Rosen 1978). Repeated joint "speciation" would result in congruent phylogenies, which can be detected in comparative phylogenetic analyses. In such coevolutionary studies, a set of terms is employed that are outlined here. The term "coevolution" generally describes the process of reciprocal evolutionary change in interacting species (Thompson 1982). Today, however, this term is used on two levels. First, as coadaptation which is a process below the species level referring to the adaptation of particular properties of the associated organisms. Coadaptation is a common phenomenon and often does not result in cospeciation. Second, "coevolution" is understood above the species level, describing the phenomenon of repeated cospeciation and then termed cophylogeny or cocladogenesis. Cospeciation is the event of joint speciation of two or more lineages that are ecologically associated. Parallel cladogenesis describes congruent speciation patterns but does not necessarily imply 
reciprocal adaptation and thus might be used for taxa that are not associated but share congruent phylogenies, e.g. because of a common "habitat history" (Paterson \& Banks 2001, Page 2003). A distinction was made between cospeciation / cophylogeny and host-tracking. In instances in which host speciation results in reproductive islation also in the associated parasites, due to e.g. spatial separation, the separated parasite populations might speciate due to genetic drift rather than because of adapting to changed properties of the hosts. In such instances the term host tracking was suggested to be more appropriate than cospeciation (Thompson 1982). However, it might be impossible to distinguish between bilateral and unilateral impact on speciation in historical associations.

In the course of cophylogeny, six fundamental events are differentiated of which five can lead to incongruent phylogenies (FIG. 5.1). Therefore, incongruent phylogenies alone are not sufficient evidence to reject the hypothesis of coevolution (Paterson \& Banks 2001, Page 2003).

\section{Cospeciation}

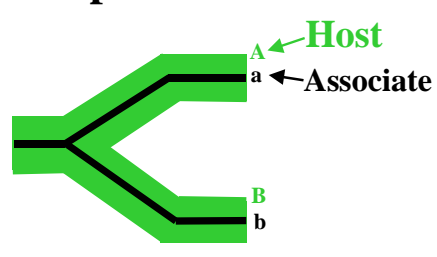

\section{Sorting events}

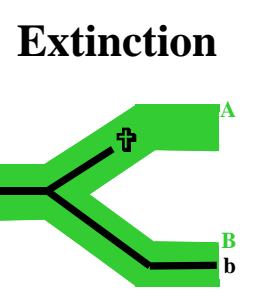

Missing the boat

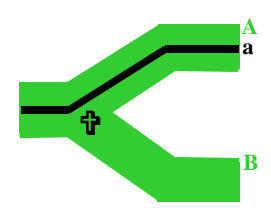

Host switch

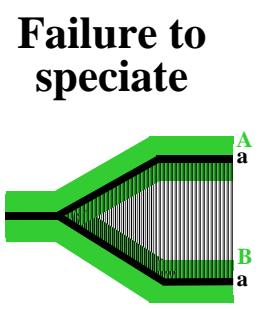

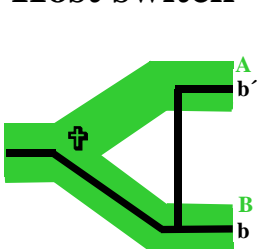

FIG. 5.1: Associates (inner line) evolving in dependence on their hosts (enclosing line). Six cophylogenetic events are distinguished, of which five may cause incongruent phylogenies in associated taxa (Page 2003). 


\subsubsection{Specificity / Selectivity}

Considering the degree of specialization of an organism towards a symbiotically associated taxon, the terms "selectivity" and "specificity" are distinguished. Galun \& Bubrick (1984) defined specificity as a mutual exclusiveness of biont combination, while selectivity points to a less strict combination of taxa where at least one of the bionts can associate with more than one partner species. In the general context of symbiosis, Smith \& Douglas (1987) did not restrict the term specificity to a mutual exclusiveness of biont combination, but defined this term as a variable characteristic. Qualifiers such as low or high were used with reference to the taxonomic range of acceptable partners. Honegger (1996) combines both views to describe a cephalodiate lichen to be highly selective for each of its photobionts (green alga and cyanobacterium) but non-specific in terms of the taxonomic range of these photobionts. Beck et al. (2002) uses the term specificity as an invariable descriptor of an entire symbiosis (which then has to be mutually exclusive) while selectivity is used when describing biont compatibility of single taxa (much in the sense of Galun \& Bubrick 1984).

Mutual exclusiveness of associated taxa appears as an exceptional situation in nature (Thompson 1982). If ever observed the expression "mutually exclusive" is considered sufficient. Also the terminological distinction made by Honegger (1996) is not considered relevant in the context of this study. Therefore, the terms specificity and selectivity might be used synonymously, applied to single taxa only and qualified appropriately with terms such as high, low or directly by the range of the observed partners. In order to avoid conflict with current opinions, only the term selectivity is used here, as the least common denominator and also with respect to the still uncertain species concepts in Trebouxia (see chapter 4).

When a symbiotic organism specializes on a particular species or a group of more or less closely related species, the organism is said to be specific or selective. Both terms imply an ability to distinguish between compatible and incompatible symbionts. What is less explicit is that the selecting organism does also depend on the accessibility of its compatible symbiont(s). It is therefore emphasized here that the term "selectivity" not only signals the ability to distinguish between different symbionts, but that it rather expresses an ecological dependence on the availability of compatible partners. 


\subsubsection{Objective}

In this study, the degree and variability of selectivity in Physciaceae mycobionts was analyzed. These issues were addressed by sampling multiple specimens of one species from as remote locations as possible. Furthermore, it was examined if sexual (with ascospores) and asexual (without ascospores, usually sorediate) reproduction mode affects the degree of selectivity. To investigate the evolutionary dependence of the associated organisms on each other, phylogenies of mycobionts and photobionts were compared. Here it was investigated if both phylogenies displayed congruent branching patterns and if speciation in one biont triggered a speciation event in the associated biont. These analyses allowed the assessment of how selectivity, i.e. ecological dependence, translated into evolutionary dependence. Furthermore, environmental factors, such as substrate $\mathrm{pH}$, and macroclimate were correlated with the both bionts' phylogenies. With this comparison, the relative importance of these two factors on the bionts' evolution was addressed and used to evaluate the occurrence of free-living Trebouxia populations.

\subsection{Materials \& Methods}

Data production and phylogenetic analyses of both biont groups followed the procedure as described in the two previous chapters. Taxon sampling of the Physciaceae in this chapter is restricted, however, to lichens of which both bionts were sequenced. The photobiont phylogeny consists of 31 Trebouxia subclades and the Physciaceae phylogeny consists of 77 Physciacean taxa and Lecidea lapicida as outgroup. Each photobiont subclade and each mycobiont species was represented by only one sequence. Mycobiont species that were associated with representatives of multiple photobiont subclades were treated as multiple associations.

\subsubsection{TreeMap}

Cophylogenetic patterns in myco- and photobiont phylogenies were analyzed using the program TreeMap (Page 1995). With this program, the number of cospeciation events, duplications, host switches, and sorting events was estimated. An exact search was conducted which allowed up to 5 host switches. Randomization tests with the proportional-to-distinguishable search algorithm and 1000 random trees for host, 4000 random trees for parasite, and 5000 random trees of host and parasite simultaneously were conducted to estimate the number of cospeciation events that could be expected by chance alone. More randomizations were calculated for the mycobiont phylogeny than for the photobiont phylogeny because of the higher number of taxa included. 


\subsection{Results \& Discussion}

\subsubsection{Photobiont selectivity}

None of the Trebouxia ITS-variants or subclades which were repeatedly found appeared to be restricted to just one mycobiont species or a group of closely related species only. In most cases particular, algal ITSvariants were found in distantly related mycobiont genera (FIG. 5.2, TABLE 5.1). For example, Trebouxia ITS-variant A1a was not only lichenized with phylogenetically distant Physciaceae species, but also with representatives of other lichen families. Within the Physciaceae, ITS-variant Ala was found in Anaptychia ciliaris, Diplotomma alboatrum, and Rinodina pyrina. Also Pleurosticta acetabulum (Parmeliaceae; Friedl 1989b, Friedl et al. 2000), Lecidella elaeochroma (Lecanoraceae, Beck et al. 1998), and Xanthoria parietina (Teloschistaceae; Beck et al. 1998) were shown to be selective for this ITS variant. A similar range of compatible mycobionts might be expected for most other photobiont ITS-variants. Since this work was restricted to the Physciaceae, knowledge about the diversity of mycobionts that are compatible with one particular photobiont ITS-variant is quite speculative. Notably, most photobionts of clades A or I that were associated with non-Physciaceae taxa were also found in the Physciaceae (TABLE 5. 2). Therefore, in general, photobionts did not appear to be adapted to particular mycobiont lineages or families.

TABLE 5.1: Diversity of photobionts in sorediate and asorediate Physciaceae. Only species of which three or more specimens were investigated are shown. Species marked with "*" include five specimens of Dahlkild et al. (2001), "\$" one specimen from Piercey-Normore \& DePriest (2001), "§" one specimen from Beck et al.(1998), "\&" one specimen from Kroken and Taylor (2000). Heterodermia leucomela includes two samples of the conspecific H. boryi. \#: number of lichen specimens examined.

\begin{tabular}{|c|c|c|c|}
\hline Lichen species & $\#$ & $\begin{array}{l}\text { Trebouxia } \\
\text { ITS variant }\end{array}$ & origin \\
\hline \multicolumn{4}{|l|}{ asorediate } \\
\hline Anaptychia ciliaris * & 8 & Ala, e & Germany, Spain, Sweden \\
\hline Anaptychia runcinata & 4 & $\mathrm{~A} 4 \mathrm{a}$ & Italy, Scotland, Spain \\
\hline Buellia elegans & 3 & $\mathrm{~A} 7 \mathrm{a}, \mathrm{b}, \mathrm{c}$ & Austria, Tibet, USA \\
\hline Dimelaena oreina & 4 & $\mathrm{Ilb}, \mathrm{g}$ & Austria, Spain, USA \\
\hline Diplotomma alboatrum & 4 & $\mathrm{~A} 1 \mathrm{a}, \mathrm{A} 2 \mathrm{a}, \mathrm{A} 3 \mathrm{a}$ & Arizona, Norway, Sweden \\
\hline Diplotomma venustum & 4 & $\mathrm{~A} 5 \mathrm{a}, \mathrm{S} 4 \mathrm{a}$ & Arizona, Crete, Hungary, Sweden \\
\hline Physcia aipolia & 3 & Ila, e & Germany, Spain \\
\hline Physcia semipinnata & 3 & $\mathrm{I} 1 \mathrm{a}, \mathrm{I} 1 \mathrm{~m}, \mathrm{I} 2 \mathrm{~b}$ & Spain \\
\hline Physcia stellaris*, \$ & 8 & Ila, c, e, h, v & Germany, Spain, USA \\
\hline \multicolumn{4}{|l|}{ sorediate } \\
\hline Heterodermia leucomela & 6 & $\mathrm{I} 4 \mathrm{a}, \mathrm{b}, \mathrm{c}$ & Bolivia, Canary Islands, El Salvador, Tanzania, Venezuela \\
\hline Phaeophyscia orbicularis $*, \S$ & 8 & Ila, b, g & Finland, Germany, Spain, Sweden \\
\hline Physcia adscendens $\oint$ & 7 & Ila, d & Germany, Spain \\
\hline Physcia caesia * & 9 & $\begin{array}{l}\text { Ilc, g, j, n, s, } \\
\text { t, u }\end{array}$ & $\begin{array}{l}\text { Antarctic, Finland, Germany, Mexico, Siberia, Spain, } \\
\text { Sweden }\end{array}$ \\
\hline Physcia tenella * & 12 & Ila, d, g, h, j & Finland, Germany, Spain, Sweden \\
\hline Physcia tribacia & 2 & $\mathrm{I} 2 \mathrm{~d}, \mathrm{I} 4 \mathrm{a}$ & Germany, Spain \\
\hline Physconia distorta *, \& & 10 & Ila, d, f, g & Finland, Germany, Netherlands, Spain, Sweden \\
\hline Physconia enteroxantha & 3 & Ila, c, d & Spain, Germany \\
\hline Physconia grisea & 8 & I1a, d & Austria, Germany, Italy, Spain \\
\hline
\end{tabular}


Table 5.2: Trebouxia subclades and their compatible mycobionts. Only samples are shown of which photobiont ITS sequences had been analyzed. Data from non-Physciacean mycobionts were compiled from references given in TABLE 4.3 (p. 47). Physciaceae species are in bold.

\section{Trebouxia compatible lichen species subclade}

A1 Amandinea cacuminum, Anaptychia ciliaris, Buellia georgei, B. pharcidia, Diplotomma alboatrum, Lecidella elaeochroma, Pleurosticta acetabulum, Punctelia subrudecta, Rinodina pyrina, R. sophodes, Tornabea scutellifera, Xanthoria parietina

A2 Buellia aeruginosa, B. frigida, Diplotomma alboatrum, D. lutosum, Santessonia sorediata

A3 Anaptychia ulotrichoides, Diplotomma alboatrum

A4 Amandinea punctata, Anaptychia runcinata, Buellia pulverulenta, B. triphragmioides, Evernia prunastri, Ramalina farinacea, $R$. pollinaria

A5 Buellia elegans, Diplotomma venustum, Rinodina tunicata, Rinodinella controversa

A6 Parmelia pulla, Rinodina atrocinerea, R. oxydata

A7 Buellia elegans, B. zoharyi, Diploschistes albescens, D. diacapsis, Hafellia dissa

A8 Lecanora hageni

A9 Caloplaca cerina, Diplotomma venustum, Rinodina tunicata, R. zwackhiana, Rinodinella controversa

A10 Amandinea punctata, A. cacuminum, Lecanora dispersa, Rinodina atrocinerea, R. oxydata

A11 Buellia georgei, B. sequax, Rinodina atrocinerea

I1 Buellia papillata, B. pulverulenta, Dimelaena oreina, D. tenuis, Hyperphyscia adglutinata, Melanelia exasperatula, M. glabra, Parmelina carporrhizans, P. tiliacea, Phaeophyscia orbicularis, Phaeorrhiza nimbosa, Phaeorrhiza sareptana, Physcia adscendens, $P$. aipolia, $P$. caesia, $P$. dimidiata, $P$. semipinnata, P. stellaris, P. tenella, Physconia distorta, P. enteroxantha, P. grisea, P. muscigena, P. perisidiosa, $\boldsymbol{P}$. venusta, Rinodina capensis, $R$. lecanorina, $\boldsymbol{R}$. milvina, $R$. olivaceobrunnea, Umbilicaria kappenii, Usnea cf filipendula

I2 Flavoparmelia caperata, F. subrudecta, Physcia millegrana, P. semipinnata, P. tribacia

I3 Buellia disciformis, B. triphragmioides, Phaeophyscia endophoenicea, P. kairamoi

I4 Heterodermia albicans, $H$. barbifera, $H$. boryi, $H$. comosa, H. diademata, H. flabellata, H. leucomela, Physcia lobulata, P. tribacia

I5 Rinodina oxydata

I6 Cetrelia olivetorum, Usnea arizonica

G1 Usnea filipendula

G2 Buellia straminea, Ramalina sp.

G3 Dirinaria picta, Pyxine cocoes, $P$. farinosa

G4 Australiaena streimannii, Buellia sp., Physcia krogiae, Rinodina sp.

G5 Dermatiscum thunbergii

G6 Hafellia dissa, Parmelia tinctorum

G7 Dirinaria applanata, Physcia undulata

G8 Pyxine sorediata

G9 Dirinaria applanata, Physcia alba, P. atrostriata, P. erumpens, P. integrata, P. sorediosa

G10 Pyxine obscurascens, Usnea filipendula

S1 Amandinea petermannii, Bryoria fuscescens, Hypogymnia physodes, H. tubulosa, Lecidea lapicida, L. silacea, Letharia vulpina, Parmelia exasperatula, P. saxatilis, Parmeliopsis ambigua, Pseudevernia furfuracea, Umbilicaria antarctica, U. kappenii

S2 Letharia vulpina 'barbata', Letharia vulpina 'gracilis', Letharia vulpina 'lucida', Letharia vulpina 'lupina', Letharia vulpina 'rugosa'

S3 Cyphelium tigillare, Imshaugia placordia, Lecanora conizaeoides, Pseudevernia cladoniae, P. consocians 


\subsubsection{Mycobiont selectivity}

In a survey on mycobiont selectivity in lichens of the Physcietum adscendentis, Beck et al. (1998) observed four photobiont species. Six mycobiont species of this community were apparently selective for particular photobionts, since in each of the species only a particular photobiont was found. This selection behaviour was also found in lichen societies growing on heavy metal rich substrates (Beck 2002) as well as in cyanolichens (Paulsrud 2001). Assuming that a diversity of photobionts is characteristic for most lichen habitats, repeated recovery of the same photobiont in a particular lichen species which was collected at remote stands, can be interpreted as evidence for a mycobiont inherent selection mechanism. Also in this study, most Physciaceae species which were collected multiple times, were found to be associated with very closely related Trebouxia ITS-variants only (TABLE 5.1, TABLE 5.3). In many cases, these closely related ITSvariants that were lichenized by particular mycobiont species formed distinct lineages, which were rather distinct from all other ITS-variants. Such clusters of closely related ITS-variants were denoted as "subclades" (see chapter 4). No species of the Physciaceae could be revealed that appeared to discriminate among the ITS-variants of one subclade. Therefore, Trebouxia subclades were chosen as the operational unit for analyzing cophylogenetic events. 
TABLE 5.3: Physciaceae species from which the photobiont identity was determined in this study and their compatible Trebouxia ITS-variants.

\begin{tabular}{lcl}
\hline \hline Lichen species & $\begin{array}{l}\text { \# of lichen } \\
\text { samples }\end{array}$ & $\begin{array}{l}\text { Trebouxia ITS } \\
\text { variant }\end{array}$ \\
\hline Amandinea punctata & 2 & A4a, A10a \\
Ama. cacuminum & 1 & A10a, A1a \\
Anaptychia ciliaris & 3 & A1a \\
Ana. runcinata & 4 & A4a \\
Ana. ulotrichoides & 1 & A3a \\
Australiaena streimannii & 2 & G4a \\
Buellia aeruginosa & 1 & A2a \\
Bul. disciformis & 1 & I3b \\
Bul. elegans & 3 & A7b, A7a \\
Bul. frigida & 1 & A2c \\
Bul. georgei & 1 & A11a \\
Bul. papillata & 1 & I1r \\
Bul. pharcidia & 1 & A1c, $\mathrm{d}$ \\
Bul. pulverulenta & 1 & A4a, I1d \\
Bul. sequax & 1 & A11a \\
Bul. triphragmioides & 1 & A4b, I3b \\
Bul. zoharyi & 2 & A7b, c \\
Dermatiscum thunbergii & 1 & G5a \\
Dimelaena oreina & 4 & I1b, I1g \\
Dim. tenuis & 1 & I1m \\
Diploicia canescens & 1 & G4a \\
Diplotomma alboatrum & 4 & A1a, A2a, A3a \\
Dip. epipolium & 1 & A9a \\
Dip. lutosum & 1 & A2d \\
Dip. venustum & 4 & A5a, S4a \\
Dirinaria applanata & 2 & G9c, G7 \\
Dir. picta & 1 & G3b \\
Hafellia dissa & 1 & A7a, G6b \\
Heterodermia albicans & 1 & I4a \\
Het. barbifera & 1 & I4b \\
Het. boryi & 2 & I4c, I4h \\
Het. comosa & 1 & I4a \\
Het. diademata & 1 & I4b \\
Het. flabellata & 1 & I4b \\
Het. leucomela & 4 & I4a, I4b \\
Hyperphyscia adglutinata & 1 & I1d \\
Phaeophyscia endophoenicea & 2 & I3a \\
Pha. kairamoi & 1 & I3b \\
Pha. orbicularis & 2 & I1a, I1b \\
Phaeorrhiza nimbosa & 1 & I1j \\
Phr. sareptana & 1 & I1g \\
\hline
\end{tabular}

\begin{tabular}{lcl}
\hline \hline Lichen species & $\begin{array}{c}\text { \# of lichen } \\
\text { samples }\end{array}$ & Trebouxia ITS \\
& variant \\
\hline Physcia adscendens & 6 & I1a, I1d \\
Pia. aipolia & 3 & I1e, I1a \\
Pia. alba & 1 & G9a \\
Pia. atrostriata & 1 & G9b \\
Pia. caesia & 4 & I1c, I1s, I1t \\
Pia. dimidiata & 1 & I1a \\
Pia. erumpens & 1 & G9a \\
Pia. integrata & 2 & G9a, G9b \\
Pia. krogiae & 1 & G4b \\
Pia. lobulata & 1 & I4a \\
Pia. millegrana & 1 & I2b \\
Pia. semipinnata & 3 & I1a, I1m, I2b \\
Pia. sorediosa & 1 & G9a \\
Pia. stellaris & 7 & I1a, I1c, I1e, I1h, \\
& & I1v \\
Pia. tenella & 7 & I1d, I1j, I1h, I1a \\
Pia. tribacia & 2 & I2d, I4a \\
Pia. undulata & 1 & G7b \\
Physconia distorta & 4 & I1a, I1d \\
Pco. enteroxantha & 3 & I1a, I1c, I1d \\
Pco. grisea & 8 & I1a, I1d \\
Pco. muscigena & 1 & I1u \\
Pco. perisidiosa & 2 & I1d, I1k \\
Pco. venusta & 1 & I1a \\
Pyxine cocoes & 2 & G3a \\
Pyx. farinosa & 1 & G3b \\
Pyx. obscurascens & 1 & G10b \\
Pyx. sorediata & 1 & G8a \\
Rinodina atrocinerea & 1 & A6a, A10a, A11a \\
Rin. capensis & 1 & I1g \\
Rin. lecanorina & 1 & I1g, I1p \\
Rin. milvina & 1 & I1n \\
Rin. olivaceobrunnea & 1 & I1g \\
Rin. oxydata & 1 & A10a, A6a, I5a \\
Rin. pyrina & 1 & A1a \\
Rin. sophodes & 1 & A1a \\
Rin. tunicata & 1 & A5b, A9a \\
Rin. zwackhiana & 1 & A9a \\
Rinodinella controversa & 1 & A5a A9a \\
Santessonia sorediata & 1 & A2b \\
Tornabea scutellifera & 1 & A1b \\
\hline & & \\
\hline
\end{tabular}




\section{Trebouxia ITS phylogeny}

Physciaceae ITS phylogeny

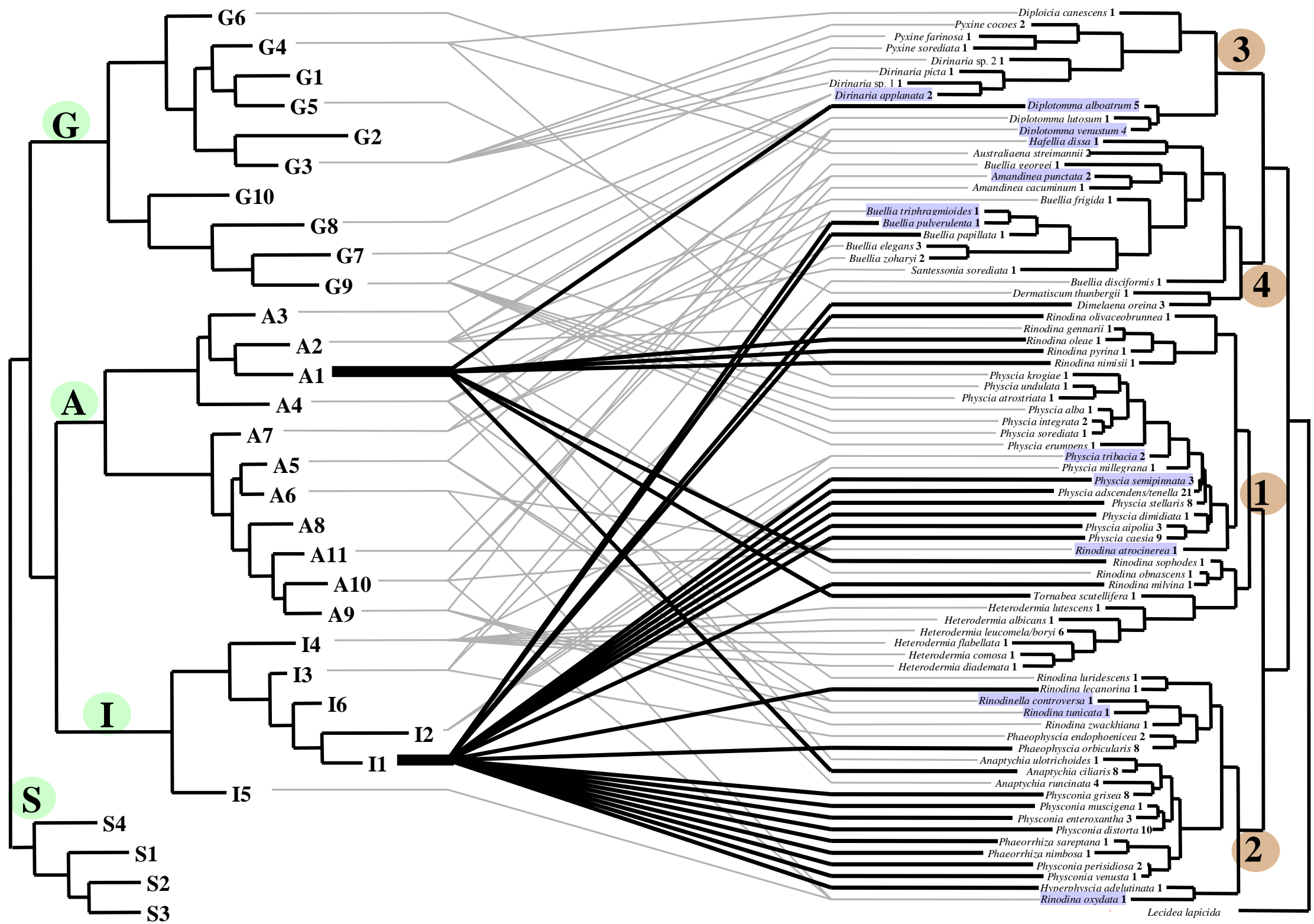

FIG. 5.2: Phylogenetic breadth of mycobionts that are associated with single Trebouxia subclades. Trebouxia ITS subclades A1 and I1 were most frequently observed and associations are

highlighted with bold lines. Numbers following the Physciaceae names indicate the number of specimens analyzed in the respective species.

Trebouxia clades are highlighted in green, Physciaceae subclades in brown color. Physciaceae species that were found with multiple Trebouxia subclades are highlighted in blue. 


\subsubsection{Photobiont heterogeneity in a single specimen, species, or genus of the Physciaceae}

The range of compatible algae found in a single specimen, species or genus of the Physciaceae varied considerably. Some foliose genera seemed to be restricted to a single Trebouxia ITS subclade, while in other cases, single thalli of some crustose species contained up to three distantly related Trebouxia ITS-variants (TABLES 5.3 and 5.4). On average, a higher percentage of crustose specimens was found to be lichenized with different Trebouxia subclades than foliose specimens. This might be partly explained by the sampling method. Due to the thinness of many crustose thalli, a larger area of the thallus, including several apothecia, was used for DNA extraction. In foliose species, only single apothecia or lobe tips were used, thus sampling only minute parts of the whole thallus. Since intrathalline photobiont heterogeneity was not the primary focus of this study, a systematic investigation cannot be presented here. Therefore, it might be suspected that photobiont heterogeneities were not detected in every instance in foliose specimens. Notably, Paulsrud (2001) investigated the aspect of intrathalline photobiont heterogeneity in the genera Peltigera and Nephroma. In single thalli of these cyanolichens he detected only single strains of Nostoc. This might support the suspicion that in most foliose specimens of the Physciaceae only one Trebouxia ITS-variant had been present. However, exceptions were found in Physcia caesia and Santessonia sorediata (TABLE 5.4). In single thalli of each of these two species, two closely related but distinct Trebouxia ITS-variants were found. This contrasts to the photobiont heterogeneity found in many crustose thalli, where photobionts of different subclades or even different clades were detected (TABLE 5.4). In a single specimen of Buellia pulverulenta photobionts of subclades A4 and I1 were detected, in a single thallus of B. triphragmioides subclades A4 and I3, in Hafellia dissa subclades A7 and G6, in Rinodina atrocinerea subclades A6, A10 and A11, in Rinodina oxydata subclades A6, A10 and I5, and in Rinodinella controversa subclades A5 and A9 (TABLE 5.4). Since only single specimens were analyzed of each of these species it cannot be evaluated here, if multiple photobiont subclades are typical in these species or not. A couple of crustose species appeared to have a similar degree of selectivity than foliose taxa. Buellia elegans and B. zoharyi appeared selective for subclade A7. Specimens of Diplotomma venustum collected in Greece, Hungary, and Sweden were associated with ITS-variant A5a. In a fourth specimen from Arizona an ITS-variant of subclade S4 was found. This observation appeared atypical in two respects. First, an alga of this clade is not considered the typical photobiont of Diplotomma, and second members of Trebouxia clade S appear to prefer acid substrates, while the Diplotomma specimen from which Trebouxia subclade S4 was obtained grew on limestone.

The pattern of intrathalline photobiont heterogeneity correlated with growth habit rather than with phylogeny. Probably crustose forms which grow along the substrate surface have a higher chance to overgrow and incorporate new Trebouxia ITS-variants than foliose taxa. Foliose taxa elevate themselves above the substrate and are delimited by a cortex. This might prevent the incorporation of new photobionts after thallus establishment, even for compatible photobionts. 
TABLE 5.4: Physciaceae species in which single specimens were found to be associated with multiple Trebouxia subclades. A2b': This ITS-variant deviated in less than $2 \%$ of its sequence positions from A2b (see chapter 4 ) but was distinct by an insertion in its nrSSU.

\begin{tabular}{ll}
\hline \hline Lichen species & $\begin{array}{l}\text { Trebouxia ITS- } \\
\text { variants }\end{array}$ \\
\hline$\underline{\text { crustose }}$ & \\
Amandinea cacuminum & A10a, A1a \\
Buellia pharcidia & A1c,d \\
Buellia pulverulenta & A4a, I1d \\
Buellia triphragmioides & A4b, I3b \\
Hafellia dissa & A7a, G6b \\
Rinodina atrocinerea & A6a, A10a, A11a \\
Rinodina lecanorina & I1g, I1p \\
Rinodina oxydata & A10a, A6a, I5a \\
Rinodina tunicata & A5b, A9a \\
Rinodinella controversa & A5a, A9a \\
& \\
foliose / fruticose & \\
Physcia caesia (PiaCae2) & I1s, I1t \\
Santessonia sorediata & A2b, A2b' \\
\hline
\end{tabular}

Photobiont variation among different thalli might be at least as large as within a single thallus. Finding only one photobiont variant in a particular thallus, however, does not indicate that all thalli of one species are associated with just one particular photobiont. Therefore, photobionts of multiple specimens of the same species were investigated in a number of instances. Emphasis was put on the analysis of specimens from as remote of locations as possible, in order to maximize the probability that associations were established independently and also under deviating environmental conditions (TABLE 5.1). Diversity of collection sites was considered to be of higher significance with respect to assessing the degree of selectivity in single species than analyzing numerous specimens of adjacent localities. With this strategy, photobiont heterogeneity within species was observed in most cases where multiple specimens of the same species were analyzed. In most foliose species of the Physciaceae that were sampled multiple times, different Trebouxia ITS-variants were observed that belonged to only one ITS subclade. A particularly high degree of selectivity was found in Anaptychia runcinata. Four specimens of A. runcinata which were collected in Spain, Italy, and Scotland were found with ITS-variant A4a (T. jamesii) only. Locations in Italy and Scotland were on the immediate coast, while two adjacent locations in Spain were $20 \mathrm{~km}$ inland, one on a sun exposed rock, the other on a shaded mossy rock beneath an oak tree (see voucher information given in the appendix A.1). The large distances and environmental differences between these habitats in combination with a photobiont constancy on the level of ITS-variant might suggest an exceptionally high degree of mycobiont selectivity. However, this constancy might be alternatively explained by an exceptional low variability within subclade A4. Only one other ITS-variant in this subclade was detected only once in a specimen of Buellia 
pulverulenta (FIG. 4.5). However, also instances were observed, where single, foliose Physciaceae species were found to be associated with representatives of different subclades at different locations. Different thalli of Physcia semipinnata were associated with members of subclades I1 and I2, and different thalli of Physcia tribacia were found lichenized with members of subclades I2 and I4 (TABLE 5.3).

At the level of subclades, photobiont steadiness not only prevailed in most thalli or species analyzed, but was also observed in whole genera. Twenty-six specimens of the genus Physconia, representing six species, which were collected in Greenland, central Europe, Scandinavia, and Spain, were exclusively lichenized with representatives of subclade I1. Eleven specimens of the genus Heterodermia, representing seven species, which were collected in Bolivia, El Salvador, Venezuela, the Canary Islands, South Africa, Tanzania, and the Philippines, were exclusively lichenized with representatives of subclade I4. Further lineages of closely related Physciaceae species were found with representatives of the same subclade. For example, photobionts of Dimelaena oreina, and D. tenuis, as well as Phaeorrhiza nimbosa and P. sareptana were all found to be selective for subclade I1. In other genera such as Anaptychia and Phaeophyscia, different species were selective for different photobiont subclades of the same clade. Phaeophyscia orbicularis was associated with algae of subclade I1 while Phaeophyscia endophoenicea and P. kairamoi were found with photobionts of subclade I3. Physcia, certainly the largest and most heterogeneous foliose genus of the Physciaceae, was found associated with photobionts belonging to two different clades, I and G. This was paralleled by the geographic range of this genus, which is distributed over temperate as well as tropical climates. None of the other foliose genera is distributed over such a wide range of different climates. All European species of Physcia were associated with algae of subclade I1 or, as exceptions, photobionts of subclades I2 or I4. Tropical Physcia species did not contain algae of subclade I1 or I2. They were lichenized either with algae of subclade I4 or with subclades G4, G7, and G9.

In summary, the degree of selectivity is a quite variable trait in the Physciaceae. Most foliose species seem quite selective, while many crustose species seem to be compatible with a variety of Trebouxia lineages. Fourteen of the 18 species of which three or more specimens were analyzed were associated with algae of only one subclade (TABLE 5.1). In all 77 species analyzed, nine species were found that were associated with photobionts of different subclades of the same clade and four species were found to be associated with Trebouxia ITS-variants from different clades (FIG. 5.2). 


\subsubsection{Selectivity vs. reproductive mode}

Lichens that reproduce with ascospores need to find a new compatible photobiont every generation while sorediate species omit the separation from their photobiont (Bowler \& Rundel 1975, Law \& Lewis 1983). Therefore, a selective pressure could be assumed that promotes a lower degree of selectivity in asorediate species than in sorediate species. However, a morphology-based study on Parmeliaceae photobionts revealed evidence against this hypothesis (Friedl 1989). P. saxatilis (sorediate) was found to be associated with three distantly related Trebouxia species, T. arboricola, T. jamesii, and "Asterochloris" irregularis. Pleurosticta acetabulum (asorediate) was found to be associated with $T$. arboricola in all 19 samples that were investigated. Also in the Physciaceae, a higher selectivity in sorediate than asorediate species could not be shown (TABLE 5.1). Some species of sorediate lichens appeared homogeneous with respect to their photobiont ITS-variants in areas as large as central Europe. Only when sampling at distant localities alternative photobionts were detected. In sevev specimens of Physconia grisea that were collected in Germany, Austria, and Italy, only ITS-variant I1d was found. One specimen collected in Spain was associated with ITS-variant I1a. Since Physconia grisea reproduces predominantly with soredia, a clonal reproduction mode could have been suspected for the central European specimens. However, the mycobionts of these specimens with identical photobionts exhibited divergences in their ITS sequences of up to $2 \%$. This finding might be explained by a much faster mutation rate in the mycobiont than in the photobiont. An alternative explanation could be the occurrence of somatogamy or parasexuality in "mechanical hybrids", i.e. thalli that are composed of genetically distinct individuals (Jahns 1988). This reproduction mode in lichens was suspected by Fahselt (1995, 1996), based on isoenzyme analyses, and received support by the observation of anastomoses, migrating nuclei, and multinucleate hyphae in certain lichens by Honegger (1991, 1993).

\subsubsection{Alga sharing}

Ott (1987) or Ahmadjian (1993) introduced the hypothesis that germinating ascospores may lichenize photobiont cells that are already associated with mycobionts. Friedl (1987) described the exchange of the photobiont in a young developmental stage of a crustose, parasitic lichen. The results of the present study cannot confirm or reject the hypothesis of Ott (1987) and Ahmadjian (1993) and also no exchange of photobionts was detected in the studied Physciaceae, since the ontogeny of Physciaceae species was not studied here. However, at least for foliose Physciaceae, it seems questionable that alga sharing is a common mode of photobiont acquisition. The widespread and abundant sorediate species Physcia adscendens and $P$. tenella were commonly found with ITS-variant I1d. However, the closely related apothecial species $P$. aipolia, $P$. semipinnata and $P$. stellaris were not found with ITS-variant I1d, even if they were growing in close proximity (e.g. specimens of Physcia adscendens (PiaAds1) and Physcia stellaris (PiaSte1), see voucher information in the appendix A.1). Apparently, these apotheciate species did not acquire their 
photobionts from their sorediate relatives. A corresponding example is found in Hypogymnia physodes and Lecanora conizaeoides. Both grow abundantly on bark of Abies sp. and are both associated with algae of clade S (Helms et al. submitted). Both species were found to be associated exclusively with different subclades, which suggests that Lecanora conizaeoides is not taking over algae from the soredia of Hypogymnia physodes.

\subsubsection{Cophylogeny}

\subsubsection{Dependence}

Selectivity is an asymmetric trait in lichen symbiosis. It has been shown here that mycobionts are selective towards particular photobionts (TABLE 5.1), but that the photobionts are not selective towards the mycobiont (TABLE 5.2). Therefore, the mycobiont may be characterized as dependent on its compatible photobiont. In the terminology of cophylogenetic analyses, this would denote the photobiont as the host and the mycobiont as the associate. The two bionts have been treated accordingly in the cophylogenetic analyses below.

\subsubsection{Cophylogenetic analyses}

A heuristic search for cophylogenetic events in 31 host taxa (Trebouxia) and 77 associated Physciaceae species was conducted with TreeMap (Page 1995). This search revealed 19 cospeciation events, 57 duplications, 1 host switch, and 252 sorting events. When performing an exact search and allowing up to 4 host switches no increase of cospeciation events was observed. In order to determine the number of cospeciation events that could be expected from chance alone, randomization tests were conducted (TABLE 5.5, FIG. 5.3). When randomizing host trees 12 cospeciation events were found on average, 16 or more cospeciation events had a probability below 5\% (FIG. 5.3A). When randomizing parasite trees, an average of 20 cospeciation events could be expected and 25 or more cospeciation events had a probability below $5 \%$ (FIG. 5.3B). When both, host and parasite, trees were randomized, an average of 17 cospeciation events was found and 22 or more cospeciation events had a probability below 5\% (FIG. 5.3C). Of the 19 potential cospeciation events found, 11 were assigned to terminal bifurcations in the mycobiont phylogeny, marked with black dots in FIG. 5.4. The remaining eight potential cospeciation events were assigned to internal nodes. The validity of these "internal" cospeciation events appeared ambiguous and could not be tested further. Therefore, these eight potential cospeciation events were not considered further. The mycobiont phylogeny comprised 24 terminal bifurcations in total. In the 13 terminal bifurcations that were not assigned to cospeciation events, the respective sister taxa were associated with the same Trebouxia subclade (corresponding to duplications) or multiple photobionts of one species enclosed the compatible subclade of 
its sister species. These 13 terminal bifurcations are marked with blue dots in FIG. 5.4. This indicates that most speciation events in the Physciaceae are not triggered by Trebouxia speciation events.

\subsubsection{Relative divergence times}

For an identification of cophylogenetic events it is advantageous when relative ages of the two biont groups can be estimated. A plausible estimate for these relative ages might permit an appraisal of simultaneity in speciation events in associated taxa. Simultaneity of speciation events is a premise for the recognition of cospeciation events (Page \& Charleston 1998) and allows a distinction between cospeciation events and coincidental congruencies in the phylogenies of associated taxa. As shown below, this differentiation will have an important impact on the evaluation of the evolutionary dependence of lichen bionts.

All Physciaceae are exclusively associated with Trebouxia (see chapter 4) and apart from clade S, all known Trebouxia clades appear compatible with the Physciaceae. It is therefore the most parsimonious assumption that Trebouxia is the ancestral photobiont of the Physciaceae. Since many other lichen families are also associated with Trebouxia, it might be assumed that the genus Trebouxia could be even older than the family Physciaceae. The mean p-distance found in Trebouxia was 0.16 and the maximal p-distance was 0.29 (I4cG7b). The mean p-distance found in the Physciaceae was 0.18 and the maximal p-distance was 0.32 (Heterodermia leucomela - Buellia elegans / B. zoharyi). This discrepancy of assumed phylogenetic age and sequence divergence might be explained by lower mutation rates in Trebouxia than in the Physciaceae. Therefore, in pairs of cospeciating taxa, the Trebouxia taxa should be separated by a lesser p-distance than the Physciacean sister species. The assumption of lower mutation rates in Trebouxia is concordant with the more general hypothesis that "inhabitants" might exhibit lower mutation rates than "exhabitants" (Law \& Lewis 1983). These authors argued that inhabitants are protected from environmental change by the exhabitants so that the former might experience a more stable environment than the latter. Environmental change, which forces organisms to adapt, was seen as the evolutionary pressure that promotes an increased mutation rate.

Searching for cospeciation events with TreeMap does not take divergence times into account. Therefore cospeciation events revealed by TreeMap had to be analyzed separately with respect to divergence times. Only divergence times of cospeciation events were analyzed that included "terminal" mycobiont sister species. This was done in order to minimize the uncertainty caused by deviating mutation rates in the associated organisms. Analyzing p-distances in Physciacean sister species and their associated Trebouxia photobionts revealed just the opposite of the above assumption about the relation of p-distances in coevolving pairs of sister taxa. In all incidences of potential cospeciation events, the Trebouxia taxa were separated by larger genetic distances than the mycobionts (TABLE 5.6, FIG. 5.4). In many of these instances 
the photobiont p-distance was much larger, indicating that these unequal divergences could not be explained by deviating mutation rates. Therefore, these taxa speciated at different times. This allowed the rejection of the cospeciation hypothesis in most if not all analyzed instances. These findings revealed a pronounced contrast between the apparent ecological dependence of most mycobionts from their photobionts as concluded from the commonly observed high degree of selectivity and the evolutionary independence of the two biont groups as demonstrated by the lack of any significant degree of congruence between the two biont phylogenies.

A)

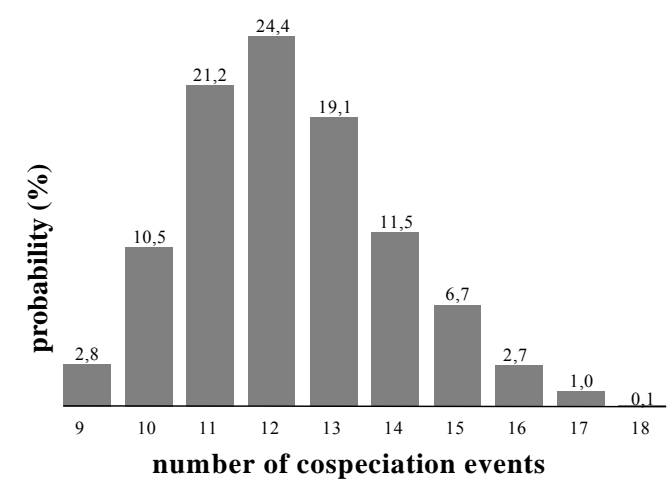

C)

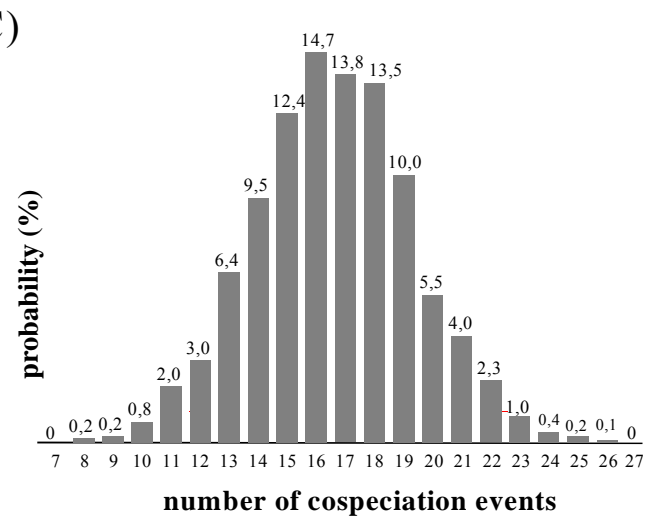

B)

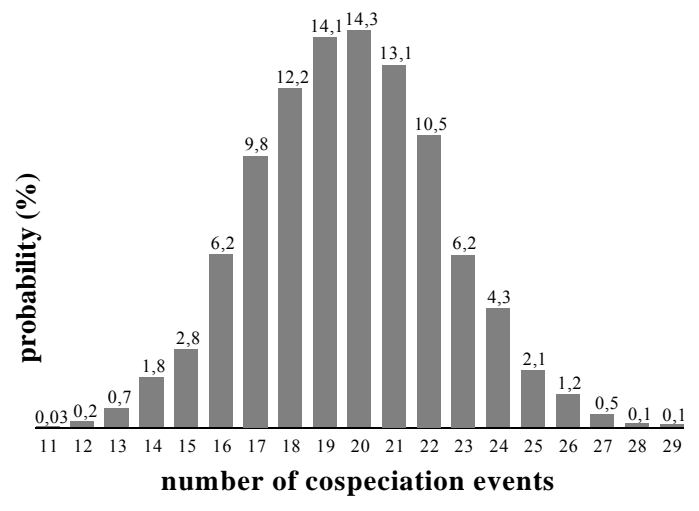

FIG. 5.3: Probabilities (\%) of different numbers of cospeciation events occuring just by chance alone. Histograms produced with TreeMap in randomisation tests of A) photobiont phylogeny (1000 randomisations),
B) mycobiont phylogeny ( 4000 randomisations), or
C) both biont's phylogenies (5000 randomisations).

TABLE 5.5: Number of cospeciation events that could be expected from chance alone, as tested by randomizing host (Trebouxia) and associate (Physciaceae) trees. Ø: average number of cospeciation events, $\mathrm{P}<5 \%$ : minimal number of cospeciation events that had a probability smaller than $5 \%$. Nineteen cospeciation events were detected by TreeMap in the original data.

\begin{tabular}{lll}
\hline \hline & $\varnothing$ & $\mathrm{P}<5 \%$ \\
\hline 1000 random photobiont trees & 12 & 16 or more \\
4000 random mycobiont trees & 20 & 25 or more \\
5000 randomizations of both biont's trees & 17 & 22 or more \\
\hline
\end{tabular}




\section{Trebouxia ITS phylogeny}

\section{Physciaceae ITS phylogeny}

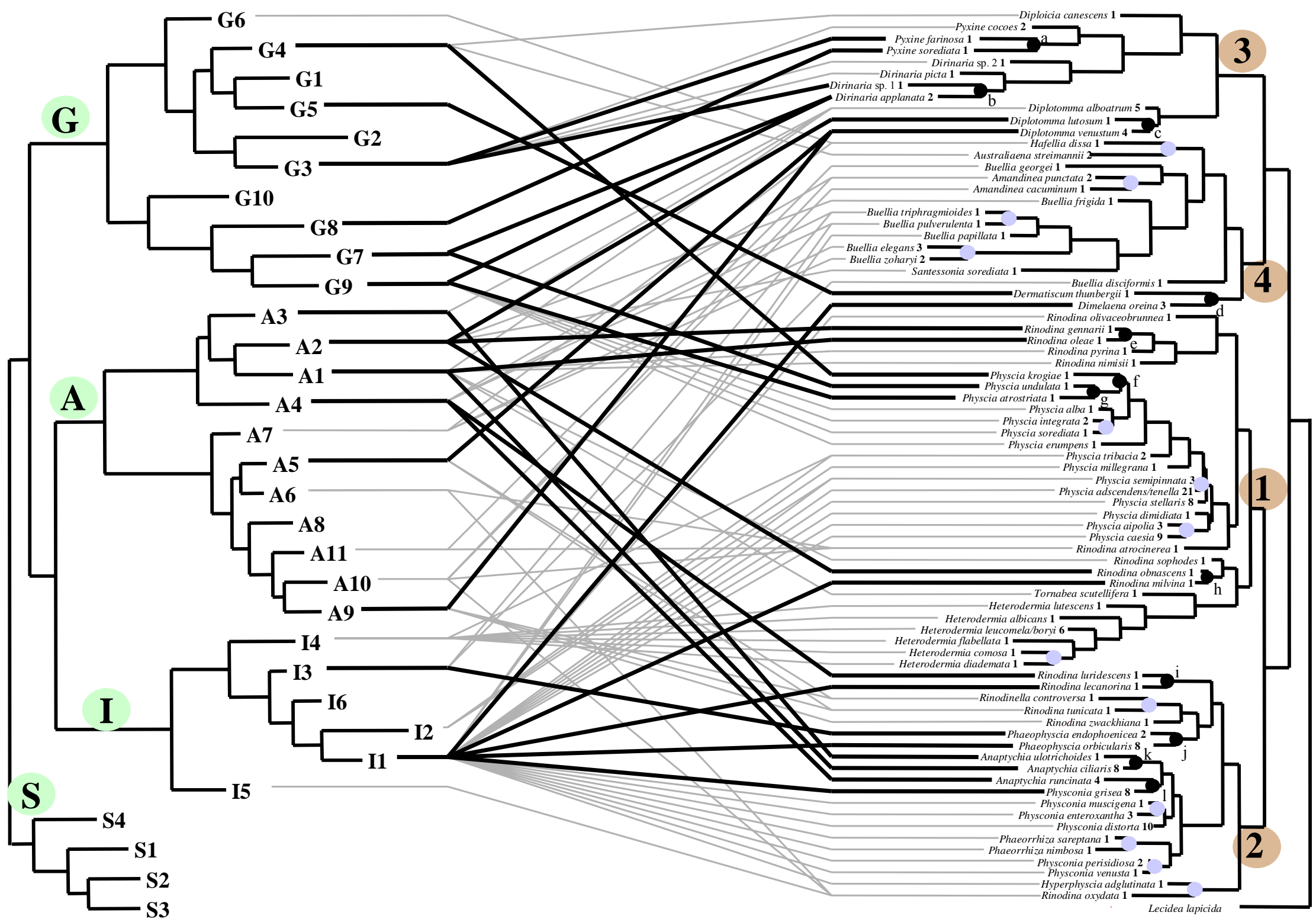

FIG. 5.4:

Potential cospeciation events. The mycobiont phylogeny contains 24 terminal bifurcations of which 11 were identified as potential cospeciation events (marked with black dots, labeled a - 1). Sister species of the remaining 13 terminal bifurcations (marked with blue dots) were either associated with the same subclade or one species was associated with multiple photobiont subclades that "enclosed" the subclade of its sister species. Lines connecting putatively cospeciated taxa are bold. Numbers following the Physciaceae names indicate the number of specimens analyzed in the respective species. 
TABLE 5.6: Comparison of p-distances (Full-length sequences were used in p-distance estimation) between mycobiont sister taxa and their compatible photobionts. These potential cospeciation events are illustrated in FIG. 5.4. Ana: Anaptychia, Der: Dermatiscum, Dim: Dimelaena, Dip: Diplotomma, Dir: Dirinaria, Pco: Physconia, Pha: Phaeophyscia, Pia: Physcia, Pyx: Pyxine, Rin: Rinodina.

\begin{tabular}{lllcc}
\hline \hline node & paired pairs & & $\begin{array}{c}\text { p-distance (\%) } \\
\text { Trebouxia }\end{array}$ & $\begin{array}{c}\text { p-distance (\%) } \\
\text { Physciaceae }\end{array}$ \\
\hline a & G3 / G8 & - Pyx. farinosa / Pyx. sorediata & 24 & 13 \\
b & G3 / (G7/9) & - Dir. sp. 1 / Dir. applanata & $21 / 16$ & 13 \\
c & A2 / (A5/9) & - Dip. lutosum / Dip. venustum & $10 / 8$ & 6 \\
d & G5 / I1 & - Der. thunbergii / Dim. oreina & 20 & 15 \\
e & A2 / A1 & - Rin. gennarii / Rin. oleae & 6 & 3 \\
f & G4 / (G7 / G9) & - Pia. krogiae / (Pia. undulata / Pia. atrostriata) & $21 / 17$ & 11 \\
g & G7 / G9 & - Pia. undulata / Pia. atrostriata & 16 & 6 \\
h & A2 / I1 & - Rin. obnascens / Rin. milvina & 17 & 3 \\
i & A4 / I1 & - Rin. luridescens / Rin. lecanorina & 16 & 6 \\
j & I3 / I1 & - Pha. endophoenicea / Pha. orbicularis & 7 & 6 \\
k & A3 / A1 & - Ana. ulotrichoides / Ana. ciliaris & 6 & 6 \\
l & A4 / I1 & - Ana. runcinata / Pco. grisea & 16 & 6 \\
\hline
\end{tabular}

Most Physciaceae species appeared to be selective at the level of Trebouxia subclades. But not only species were found to be selective, even supraspecific taxa showed a remarkable constancy in photobiont choice. Nine mycobiont lineages ( $\mathrm{a}-\mathrm{i}$ in FIG. 5.5) appeared to be selective for particular Trebouxia subclades. From the 77 species included in this analysis, 50 species were included in these nine mycobiont lineages. In other words, the majority of speciation events in the Physciaceae was not triggered by speciation events in Trebouxia. Twenty-eight duplication events could be counted in the mycobiont phylogeny and are therefore considered to be a common event in Physciaceae evolution. Interestingly, 14 species of these nine lineages switched their photobiont (FIG. 5.5). The phylogenetic steadiness of mycobiont choice on one side (as demonstrated by the frequency of duplication events), the frequent number of alga switches on the other side, as well as the lack of cospeciation events suggests that factors other than mycobiont selectivity determine the evolution of biont association. 


\section{Trebouxia ITS phylogeny}

Physciaceae ITS phylogeny

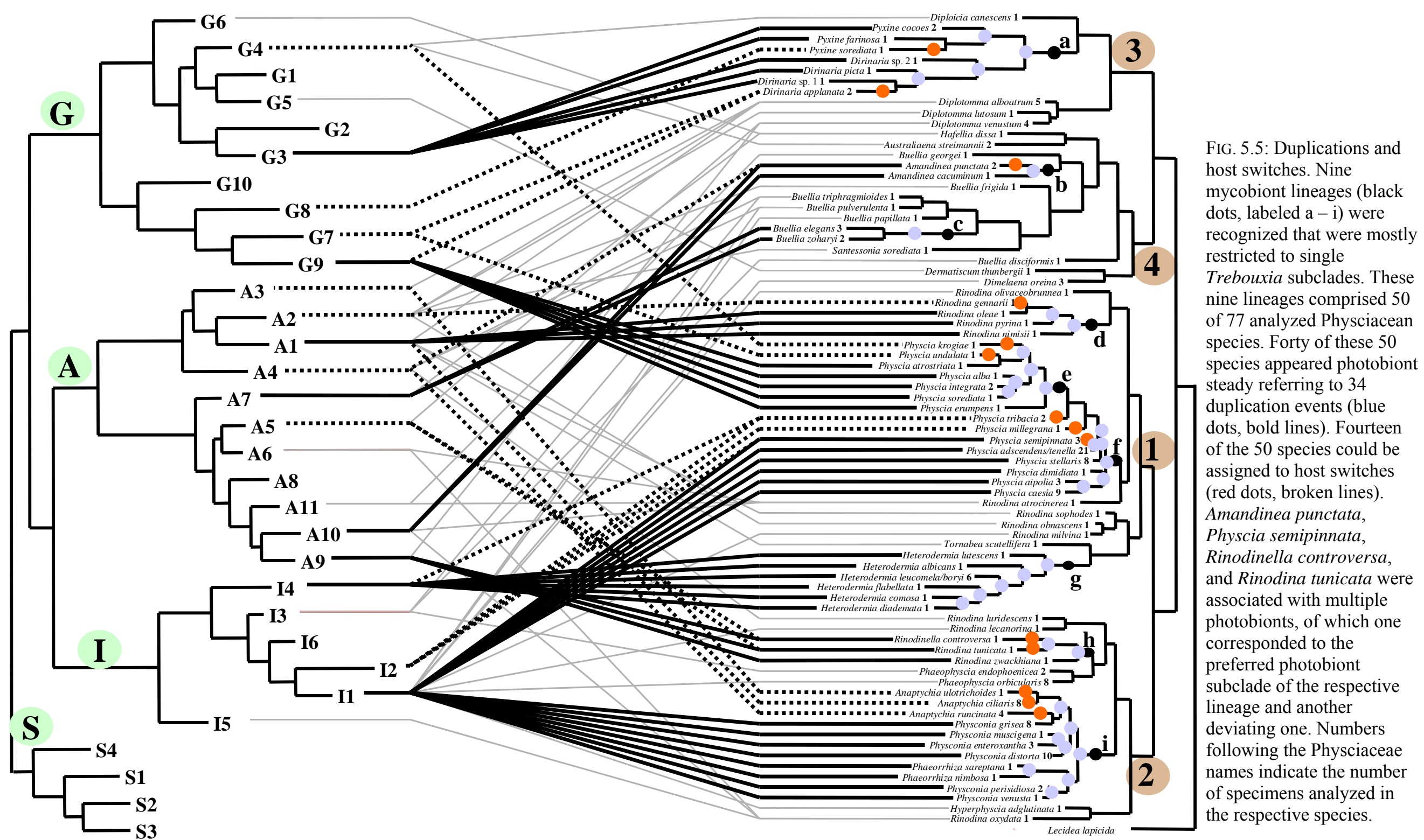




\subsubsection{Environmental aspects}

A notable correlation of the Trebouxia phylogeny with environmental factors was detected. Especially photobionts of asorediate lichens appeared to correlate well with environmental factors such as substrate $\mathrm{pH}$ and macroclimate (see below).

\subsubsection{Trebouxia and $\mathrm{pH}$}

Substrates were assigned to the three $\mathrm{pH}$ categories "acid" (e.g. bark of conifers as well as Betula, $\mathrm{pH}$ below 6), " \pm neutral" (e.g. dust impregnated bark of Acer, Populus, Quercus, etc. and quarzitic rock, pH 6-8), and "basic" (calcareous rock, $\mathrm{pH}$ above 8). Most subclades were found on substrates with \pm neutral $\mathrm{pH}$. Acid and basic substrates delimited monophyletic groups of Trebouxia ITS-variants.

ITS-variants found in asorediate lichens growing on calcareous rock seemed to be restricted to clade A. The only exception observed was ITS-variant S4a. However, not all members of clade A exhibited this substrate affiliation. Only Trebouxia species within the lineage comprising subclades A5 - A11 were found in asorediate lichens growing on calcareous rock. Subclades A1- A4 were preferably found on \pm neutral substrates. These deviating substrate preferences are mirrored in the Trebouxia phylogeny (FIG. 4.5) where subclades A1 - A4 form a distinct, well-supported monophylum.

Clade $\mathrm{S}$ is known from lichens that are common on acid or heavy metal rich substrates (Beck 2002). Except for Cyphelium tigillare, no specimens from acid substrates were analyzed in this study, and correspondingly photobionts of clade S remained exceptional findings. Cyphelium tigillare, a close relative of Buellia species, was collected from acid bark (Betula) and was found with ITS-variant S3b. Amandinea petermannii, collected in Antarctica and possibly growing on heavy metal rich rock was associated with ITS-variant S1b. This ITS-variant was also common in Antarctic Umbilicaria species studied by Romeike et al. (2002). Therefore, it is supposed that Trebouxia spp. of clade $\mathrm{S}$ were usually not found in the Physciaceae studied here, because all other specimens grew on neutral to basic substrates on which members of Trebouxia clade S might not be available.

\subsubsection{Trebouxia and macroclimate}

A conspicuous correlation of the Trebouxia phylogeny with macroclimate could be observed. Trebouxia subclades of tropical and temperate climates appeared almost mutually exclusive. All lichens collected in the tropics were associated with Trebouxia ITS-variants of clade G and subclade I4. Representatives of these two Trebouxia lineages were extremely rare in lichens from Mediterranean to arctic climates (only two exceptions were recognized in Hafellia dissa [South Africa] and Physcia tribacia [Germany]). Another 
correlation of Trebouxia occurrence with environment was revealed on a much finer scale by Beck (2002). He found genetically different taxa of clade $\mathrm{S}$ to be restricted to different altitudes above sea level within the same macroclimatic area.

\subsubsection{Correlating Trebouxia and Physciaceae phylogenies with environmental parameters}

When photobiont and mycobiont phylogenies were correlated with environmental parameters it seemed that the Trebouxia phylogeny was much closer correlated with environmental factors than the mycobiont phylogeny. All Trebouxia subclades found in asorediate lichen species growing on calcareous rock formed a single lineage (subclades A5 - A11; FIG. 4.5), while at least four independent lineages in the Physciaceae were found to thrive on this substrate type (FIG. 5.6). Similarly, all acidophilous ITS-variants formed a single lineage in the Trebouxia phylogeny. Only two Trebouxia lineages were found to occur in the tropics (clade G and subclade I4), where at least six independent lineages of the Physciaceae are adapted to tropical climates (FIG. 5.6).

A close correlation of Trebouxia phylogeny with environmental factors and an apparent incongruence with the mycobiont phylogeny is considered as strong indication for a direct interaction of photobionts with their environment. A strong influence of the mycobiont on the photobiont with respect to habitat preferences may be rejected since otherwise an evolutionary flexibility in habitat choice similar to that of the mycobiont would be prevalent. The ecological independence of the photobiont from the mycobiont might suggest the existence of free-living photobiont populations. However, the existence of such free-living Trebouxia populations has been called into question (e.g. Ahmadjian 1988).

\subsubsection{Photobionts and mycobionts may adapt independently to particular environments}

As a consequence of the incongruent phylogenies of myco- and photobionts as well as the finding that mycobionts are evolutionarily more flexible with regard to their environmental preferences (FIG. 5.6) it may be concluded that both lichen bionts adapt independently to particular environments. This assumption could explain why associated taxa display different ecological amplitudes. For instance, photobiont subclades A1, A2, and I1 are each found in lichens of quite different habitat requirements. Therefore, photobionts belonging to these subclades seem to have a much broader ecological amplitude than most of their compatible mycobionts (FIGS. 5.2, 5.6). For example ITS-variant I1g was found in the corticolous Physconia distorta and the saxicolous Dimelaena oreina, two mycobionts that appear incompatible in their habitat requirements. But also the reverse seems possible. Amandinea punctata seems to tolerate a diversity of substrates not covered by any of the compatible Trebouxia subclades. This mycobiont species is known to occur usually on bark, wood and rarely on siliceous rock. One specimen analyzed in this survey was collected from Tuffite. Since Amandinea is asorediate, and occurs on substrates that are so different that they may bear mutually exclusive 


\section{Trebouxia ITS phylogeny}

\section{Physciaceae ITS phylogeny}

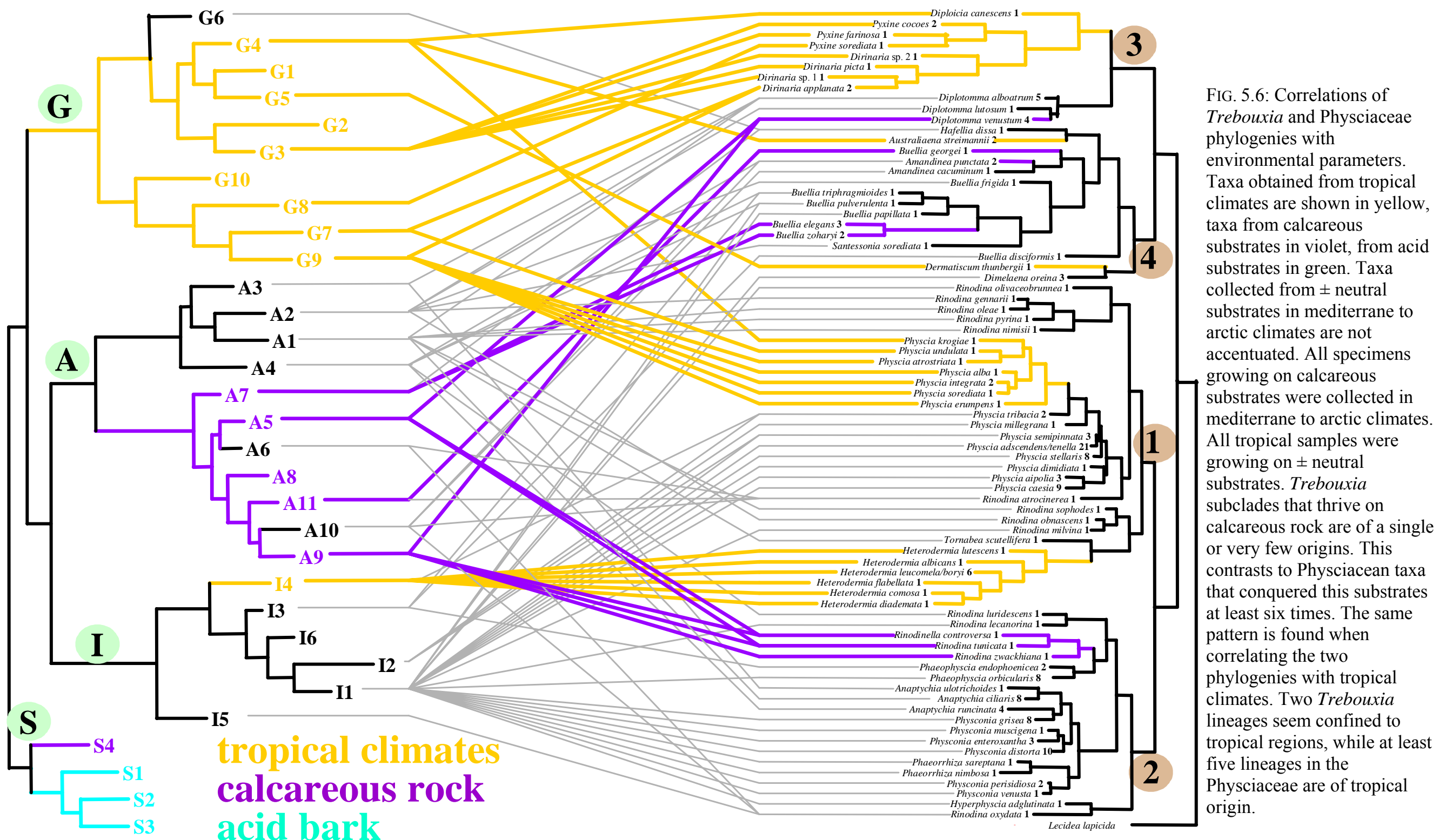


photobiont inventories, it has to be assumed that Amandinea punctata lichenizes with different photobionts on these different substrates. This was exactly what has been observed in this study (TABLE 5.3). A specimen growing on pebbles (Italy) was lichenized with an alga representing ITS-variant A4a, and another specimen collected from Tuffite (Austria) was associated with an alga of ITS-variant A10a. Still other Trebouxia subclades might be expected in corticolous samples.

\subsubsection{Dual propagule formation, a strategy to colonize substrates that are devoid of compatible photobionts}

Incongruent habitat requirements of associated bionts might promote the formation of dual propagules, such as sorediea, isidia, or fragmenting thalli. A corresponding correlation could be observed in several genera of the Physciaceae. Only Trebouxia taxa of subclades A5 - A11 were associated with asorediate Physciaceae growing on calcareous rock. All common, European species of Physcia, Physconia and Phaeophyscia investigated were selective for members of Trebouxia clade I. However, some species, e.g. Phaeophyscia orbicularis, Physcia caesia grow on calcareous rock. These two mycobiont species are also selective for clade I. All other European and North American species of these genera that are described to occur on calcareous rock were also described to be sorediate (Wirth 1995, Brodo et al. 2001). It is assumed that mycobionts are able to neutralize the basic pH of calcareous rock (Schöller 1997) and thereby support their compatible photobiont which alone would not be able to thrive on these substrates and therefore would not be available for germinating ascospores. Among other things, soralia formation might therefore be interpreted as a mycobiont's strategy to colonize substrates that do not bear its compatible algae free living. Or, more generally, deviating substrate preferences of compatible bionts might promote the evolution of dual propagules.

\subsubsection{Single Trebouxia ITS-variants might be ecologically differentiated}

A wider ecological amplitude of Trebouxia subclades when compared to most of the Physciacean mycobionts is obvious from the multitude of phylogenetically and ecologically distinct mycobiont species with which they are lichenized. Even single Trebouxia ITS-variants might not be homogeneous with respect to their ecology and physiology. This assumption was implied by a study of Bačkor \& Váczi (2002), who cultivated strains of "Asterochloris" erici for three years on media with increased copper concentration. These "Asterochloris" strains achieved a significantly increased copper tolerance when compared to clones that were kept on media with low copper concentrations. Since this time span is unlikely to allow the ITS region to change noticeably, physiological plasticity is assumed to be much greater than ITS variability. Therefore distinct ecotypes might be suspected that are characterized by identical ITS sequences. In the case of particular Trebouxia ecotypes that thrive in habitats that are unsuitable for certain mycobionts, it may be 
suspected that a given mycobiont might not be able to lichenize all ITS-variants of its compatible subclade due to an ecological restriction, rather than an instance of physiological incompatibility.

When comparing the frequencies at which certain Trebouxia ITS-variants were found on particular substrates an ecological differentiation as supposed above is supported. Of the 22 Physciacean specimens that were associated with ITS-variant I1a, 20 were collected from bark and two specimens were collected from rock (TABLE 5.7). Those two collected from rock were sorediate. The same correlation was observed in ITSvariant I1d. Twenty-seven specimens were analyzed, of which three were collected from rock and then associated with sorediate mycobiont species. As discussed above, a correlation between Trebouxia and substrate might be obscured in sorediate lichens and therefore both ITS-variants are considered to strongly prefer bark. Although preferring the same substrate, distinct ecological differences between these two ITSvariants were observed. While ITS-variant Ila appeared to occur all over Europe (Austria, Spain, Sweden) and in lichens with sexual and asexual reproduction mode, ITS-variant I1d was not observed in Spain (24 Spanish specimens of Physcia, Physconia, and Phaeophyscia analyzed) and almost exclusively found in sorediate lichens. Physconia distorta was the only asorediate lichen species in which ITS-variant I1d was found. In contrast to the two previous two ITS-variants, ITS-variant I1b was detected more often in lichens growing on rock. This ITS-variant was detected four times in asorediate, crustose specimens of the species Dimelaena oreina (three specimens) and Diplotomma alboatrum (one specimen) and once in a corticol specimen of Phaeophyscia orbicularis, a sorediate and foliose species (TABLE 5.7). 
TABLE 5.7: Sources from which particular Trebouxia ITS-variants of subclade I1 were obtained. *: Samples of Dahlkild et al. (2001) were included. Dual propagules are soredia or isidia that serve as propagation units.

\begin{tabular}{|c|c|c|c|c|c|}
\hline $\begin{array}{l}\text { Trebouxia } \\
\text { ITS variant }\end{array}$ & $\begin{array}{l}\text { source } \\
\text { lichen species }\end{array}$ & $\begin{array}{l}\text { sample } \\
\text { number }\end{array}$ & $\begin{array}{c}\text { dual } \\
\text { propagules }\end{array}$ & origin & substrate \\
\hline \multirow[t]{11}{*}{ I1a } & $\begin{array}{l}\text { Phaeophyscia } \\
\text { orbicularis* }\end{array}$ & 5 & yes & $\begin{array}{l}\text { Finland, Spain, } \\
\text { Sweden }\end{array}$ & $\begin{array}{l}\text { Fraxinus excelsior, Populus } \\
\text { tremula, Ulmus glabra }\end{array}$ \\
\hline & Physcia adscendens & 3 & yes & Germany, Spain & $\begin{array}{l}\text { Acer sp., Malus domestica, } \\
\text { Populus sp. }\end{array}$ \\
\hline & Physcia aipolia & 2 & no & Germany, Spain & Juglans regia, Populus nigra \\
\hline & Physcia dimidiata & 1 & yes & Austria & Tuffit \\
\hline & Physcia semipinnata & 1 & no & Spain & bark \\
\hline & Physcia stellaris & 3 & no & Germany, Spain & $\begin{array}{l}\text { Juglans regia, Populus sp., } \\
\text { Quercus pyrinaicus }\end{array}$ \\
\hline & Physcia tenella & 1 & yes & Spain & Ailanthus sp. \\
\hline & Physconia distorta & 3 & no & Spain & Populus sp., Quercus pyrinaicus \\
\hline & $\begin{array}{l}\text { Physconia } \\
\text { enteroxantha }\end{array}$ & 1 & yes & Spain & rock \\
\hline & Physconia grisea & 1 & yes & Spain & bark \\
\hline & Physconia venusta & 1 & no & Spain & Quercus pyrinaicus \\
\hline \multirow[t]{3}{*}{$\mathrm{I} 1 \mathrm{~b}$} & $\begin{array}{l}\text { Diplotomma } \\
\text { alboatrum }\end{array}$ & 1 & no & Sweden & On mortar \\
\hline & Dimelaena oreina & 3 & no & Austria, Spain & siliceous rock \\
\hline & $\begin{array}{l}\text { Phaeophyscia } \\
\text { orbicularis }\end{array}$ & 1 & yes & Spain & Populus nigra \\
\hline \multirow[t]{8}{*}{ I1d } & Buellia pulverulenta & 1 & yes & Sweden & calcareous rock \\
\hline & $\begin{array}{r}\text { Hyperphyscia } \\
\text { adglutinata }\end{array}$ & 1 & yes & Germany & Aesculus hyppocastanea. \\
\hline & Physcia adscendens & 4 & yes & Germany & $\begin{array}{l}\text { Acer pseudoplatanus, Fraxinus } \\
\text { sp., Malus domestica }\end{array}$ \\
\hline & Physcia tenella* & 8 & yes & $\begin{array}{l}\text { Finland, Germany, } \\
\text { Sweden }\end{array}$ & $\begin{array}{l}\text { Acer pseudoplatanus, Fraxinus } \\
\text { excelsior, Populus tremula, } \\
\text { Quercus robur, Salix sp., Tilia } \\
\text { cordata }\end{array}$ \\
\hline & Physconia distorta* & 4 & no & Germany, Sweden & $\begin{array}{l}\text { Acer platanoides, Fraxinus } \\
\text { excelsior, Quercus robur, Tilia } \\
\text { cordata }\end{array}$ \\
\hline & $\begin{array}{l}\text { Physconia } \\
\text { enteroxantha }\end{array}$ & 1 & yes & Germany & Populus $x$ canadensis \\
\hline & Physconia grisea & 7 & yes & $\begin{array}{l}\text { Austria, Germany, } \\
\text { Italy }\end{array}$ & $\begin{array}{l}\text { Acer pseudoplatanus, Catalpa } \\
\text { bignonioides, Cupressus } \\
\text { semervirens, Juglans regia, Tilia } \\
\text { sp., mossy slate wall, Tuffit }\end{array}$ \\
\hline & $\begin{array}{l}\text { Physconia } \\
\text { perisidiosa }\end{array}$ & 1 & yes & Germany & Acer pseudoplatanus \\
\hline
\end{tabular}




\section{Symbiosis in Associations of Physciaceae* and Trebouxia}

\subsection{Introduction}

In 1877, Frank introduced the term "Symbiotismus" for the instance of spatial proximity (the living together) of different organisms. He subdivided such associations into three levels, according to the degree of their mutual dependence. Random, i.e. facultative, associations that do not involve nutrition flux from one to the other organism he termed "Pseudoparasitismus". An obligatory, unilateral dependence and thus often antagonistic association he interpreted as an instance of "Parasitismus". An association in which both bionts depend on each other, he called a "Homobium". However, the terms "Symbiotismus", "Pseudoparasitismus", and "Homobium" introduced by Frank (1877) did not enter scientific language. In 1879, DeBary introduced the term "symbiosis", very much in the sense of Frank's symbiotismus, however, without giving any reference to Frank's work. He also explicitly included parasitic systems in symbiotic associations and also referred to lichens as an example of symbiosis. In lichens, he clearly saw parallels to parasites, but also appreciated the accelerated growth rate of lichenized algae and considered this as a deviation from the typical concept of parasitism. Therefore, he used the term "Lichenismus" as an alternative to mutualism and parasitism. In correspondence to Frank (1877), DeBary also considered transient associations as instances of symbiosis. Therefore, Frank as well as DeBary used the term "symbiosis" to denote a possibly unspecific but always obligatory interaction, i.e. flowers and their pollinators were seen as examples of symbiosis.

Since the introduction of the term "symbiosis" by DeBary in 1879, the understanding of this term has "diversified" (Lewis 1985, Douglas \& Smith 1989, Saffo 1992, Sapp 1994). In concordance with its original definition, "symbiosis" can be understood as simply referring to the physical contact of two dissimilar organisms. Hence, it does not imply any assumption about costs and benefits of the associated taxa. However, some authors (e.g. Lewin 1995) use the term "symbiosis" synonymous to mutualism. Mutualism, in turn, does not necessarily imply a physical contact of interacting organisms (Begon, Harper \& Townsend 1996). Furthermore, the term "parasitism", generally used with respect to the "cost and benefit" aspect, is often used in cophylogenetic analyses for an organism depending on and selecting another organism, not considering "costs and benefits" (Page 2002). The term "host" is used in symbiotic relationships of quite different nature. Sometimes it is used for "large" organisms that harbor "small" symbionts (often considered as mutualists) such as bacteria and protozoa living inside the host or on its surface, sometimes as the victim of parasites and last but not least as the "resource-entity" (see below) in cophylogenetic studies.

Here "symbiosis" is understood similar to its original meaning (Frank 1877, DeBary 1879). However, it is restricted to associations where at least one of the involved bionts depends on a prolonged physical contact

* "Physciaceae" also includes the analyzed species denoted as Caliciaceae in chapter 3. 
with a host individual, in order to complete its life cycle. For a less ambiguous usage of the terms implying organismic interactions, it is suggested to confine these terms to particular aspects of interaction (e.g. the continua described by Starr 1975). For example, mutualism and parasitism may only refer to the "cost and benefit" aspect but do not necessarily imply a symbiosis as defined here (Begon, Harper \& Townsend 1996). The aspects of dependence and selectivity are integral traits in symbiotic associations and not synonymous with the "costs and benefit" aspect (Starr 1975, Douglas \& Smith 1989). Page and Charlston (1998) used the terms "host" and "associate" for associations considered under the aspect of dependence.

\subsection{Systems of coevolving organisms are characterized by highly efficient mechanisms of isolation}

Coevolutionary studies in other symbiotic systems revealed the importance of isolation with respect to an occurrence of cophylogeny. Vertical inheritance of symbionts alone is not regarded as sufficient to prevent host switches (Herre et al. 1999). In addition, highly efficient mechanisms of isolation need to be established to prevent host switches (Clayton et al. 2003). These mechanisms may be caused by behavior or physiology. In the system of pocket gophers and their chewing lice (Hafner \& Nadler 1988), isolation is assured through the solitary behavior of the host and the parasite's inability to survive for prolonged time without its host. This behavior ensures vertical transmission of parasites and prevents horizontal transfer. In the system of mycorrhizae and the parasitic Monotropoideae (Ericaceae; Bidartondo \& Bruns 2002), efficient isolation is effectuated by a species specific induction of cell to cell contacts. Although parasite transfer between hosts seems extremely unlikely in these systems, it nevertheless did rarely occur. Even drastic host switches such as the switch from insects to truffle were reported from the entomoparasitic ascomycete genus Cordyceps (Clavicipitaceae; Nikoh \& Fukatsu 2000). This switch demonstrates the incredible potential of overcoming inter host barriers especially in ascomycetes. In systems that lack such mechanisms of isolation, frequent host switches are supposed (Ronquist 1997). Sparidae (Teleostei) and their parasitic Lamellodiscus (Monogenea) may serve as an example, as reported by Desdevises et al. (2002). Different hosts of this symbiosis occur in sympatry and the parasite develops free-living stages. Although Lamellodiscus was also found to be host specific (as are most of the investigated lichens) no obvious instance of cospeciation could be shown. In fact, the tanglegram obtained for Sparidae and Lamellodiscus and the tanglegram presented in this study appeared quite similar in nature. Both symbiotic systems seem to be characterized by similar ecological features such as the sympatry of numerous host species as well as aposymbiotic stages in the associates. Accordingly, it is concluded that efficient mechanisms of isolation are not in effect in lichens, despite a high degree of selectivity in most lichen mycobionts. 


\subsection{The Lichen symbiosis: Mutualism or Parasitism?}

All lichen mycobionts live on carbohydrates which they receive from their photobionts (Richardson et al. 1967). The benefit of the latter, however, is not as obvious, since no matter flow towards the photobiont could be detected. Except for Asterochloris and Trebouxia, most other photobiont genera are as abundant or even more abundant in the non-lichenized state than in the lichenized state and might not benefit from the mycobiont in any respect. The symbioses in these lichens that are not associated with Asterochloris or Trebouxia might adequately be understood as a form of parasitism. Ahmadjian \& Jacobs (1981) further showed that mycobionts kill and feed on incompatible algae, demonstrating their potentially parasitic nature. However, Trebouxia, the most common photobiont in lichens, is much rarer in the aposymbiotic than in the lichenized state. Lichen symbioses with this photobiont might therefore not readily be understood as parasitism. Ahmadjian (1993) used the metaphor of human civilization raising cattle for this case. Traditionally, parasitism is distinguished from mutualism by the distribution pattern of costs and benefits in the associated organisms. However, analyzing costs and benefits often results in ambiguous findings. The amount of costs and benefits often depends on the developmental stage of the associated organisms and the environment the symbionts live in. Rarely are all parameters known that influence outcomes of interaction. Estimates of costs and benefits are often restricted to the immediate interactions of the associated bionts and do not consider the influence of additional organisms. In lichens this aspect might be dramatic: Trebouxia was never observed to establish dense and stable populations in the free-living state although it can be easily cultivated on inorganic media for unlimited time. Therefore, free-living photobionts (especially Trebouxia), might be weak competitors outside the lichen thallus, when compared to other subaerial algae (Frey 1932, Douglas 1995, Honegger 1998). This points to the important role of competitors and consumers outside the lichen thallus that interact with aposymbiotic photobionts. An increase in population size when lichenized might be explained by a relief from competition rather than by any direct benefit that the alga obtains from the mycobiont. This is certainly a different situation than a situation in which the algae would receive a direct benefit from their mycobiont comparable to nutrition uptake. A flow of minerals from the mycobiont to the photobiont has been frequently suggested but doubted by Smith (1975). Therefore, the nature of interactions in lichens is considered fundamentally different from other mutually beneficial associations, such as flowers and their pollinators or plants and their fruit propagators where the ecologically dominant effect is mediated directly between the interacting organisms. 


\subsubsection{Indirect Mutualism}

When designating an organismic interaction as mutualism, a statement is made that net benefits are exchanged between the involved organisms. However, the term "mutualism" does not specify if the interaction is direct or indirect. Therefore, two forms of mutualism may be distinguished. A relationship of reciprocal, direct benefit (direct mutualism) and an indirect relationship, in which reciprocal benefit is mediated by a third taxon (indirect mutualism; Vandermeer 1980, Vandermeer et al. 1985). The two concepts of mutualism have different implications: Organisms involved in direct mutualism are expected to be more common in the symbiotic state than in the aposymbiotic state, irrespective of the presence of other organisms. Thus, the symbiotic state may have a similar relevance for the fitness of both bionts. Indirect mutualism is thought to consist of at least three components (bionts A, B, and C). In tripartite systems, each component affects any of the other two components on two ways: directly, and indirectly via the third component. If all interactions between the three components are antagonistic, the indirect effects (e.g. effect of $\mathrm{A}$ on $\mathrm{C}$ via $\mathrm{B}$ ) are positive. Depending on the intensity of the interactions, it is possible that the indirect, positive effects are stronger than the direct negative effects (Jordan 2001). Although, in such a case, each direct interaction would be qualified as an antagonism, the whole system might give the impression of reciprocal benefit and thus a form of mutualism. A particular difficulty in assigning costs and benefits in tripartite systems might be that one taxon of the system might be only facultatively associated with the other two. The outcome of the interaction between the two permanently associated taxa might switch from mutualism to antagonism depending on the presence / absence of the third taxon. This dilemma seems inherently prevalent in lichens. Here, the distinction between direct and indirect effects has not been made. When considering the ecological advantage that Trebouxia receives from lichenization, the symbiosis was frequently denoted a mutualism (e.g. Hawksworth 1988). Focusing on direct interactions as are observable in resynthesis experiments, the symbiosis appeared as a form of parasitism (Ahmadjian \& Jacobs 1981). For an adequate understanding and evaluation of ecological interactions in lichens, it is supposed that the ecology of free-living Trebouxia cells and their interactions with other organisms than their compatible mycobionts might be of great importance. Unfortunately, nothing is known about this aspect, which admittedly might be difficult to investigate. Therefore, it appears premature to speculate about costs and benefits in lichen symbioses and classify them as mutualism or parasitism. With respect to lichens, therefore, the term "symbiosis" in its original meaning might still be the most appropriate to use.

\subsubsection{Analogies to Parasitism}

Although caution seems called for when classifying lichen symbioses as parasitism or mutualism, a number of principal analogies to parasitic systems can be detected (Ahmadjian 1995). 1.) While most parasites are rare in the aposymbiotic state (often only in form of dispersal propagules), their hosts usually perform better in the aposymbiotic state (as measured by any aspect of vitality). 2.) As long as parasites are exposed to the 
environment, their distribution range might be environmentally limited and not entirely congruent with the range of their hosts, i.e. the parasites range might be only a fraction of the host's range. 3.) The distribution pattern of selectivity may differ between mutualistic and parasitic systems. In mutualistic systems, both bionts might develop a certain degree of selectivity for each other, while in parasitic systems it is only the parasite that specializes. 4.) A differential influence of the symbiotic state on the phenotypic differentiation of both bionts might be assumed. In mutualistic systems, the symbiotic state might promote an increased proliferation in both partners, while in host/parasite systems only the parasite's development is enhanced. 5.) Saffo (1992) suggested that the criterion of prevalence (the percentage of "infected" hosts) could be used to distinguish between mutualistic and parasitic systems. In parasitic systems she always found symbiont-free hosts (prevalence $<100 \%$ ), while in truly mutualistc systems symbiont-free hosts were not observed (prevalence $=100 \%$ ).

1.) This aspect might not be especially significant in lichens that are associated with Trebouxia or Asterochloris, since both genera are obviously more common in the symbiotic state. However, also these photobionts were found free-living (Famintzin \& Baranietzky 1867, Tschermak-Woess 1978, 1988, Bubrick et al. 1984, Ahmadjian 1988, Garty \& Delarea 1988, Mukhtar et al. 1994), while mycobionts were never seen to reproduce in the aposymbiotic state.

2.) This instance applies particularly to lichens, since mycobionts are fully exposed to the environment and not like endoparasites protected from the environment. As could be shown in this study, particular photobionts were found in distantly related lichens that had quite different habitat requirements. This suggests that the distribution range of these photobionts was much larger than that of any of the mycobionts that were associated with them. Therefore this aspect supports a parasitic kind of relationship.

3.) As has been shown here, the asymmetry in selectivity between mycobionts and photobionts clearly depicts lichens to be more similar to parasitic systems than to mutualism.

4.) Also the effect of the symbiotic state on individual differentiation depicts the asymmetry in most lichens, which is typical for parasitic systems. Mycobionts are more highly differentiated in the symbiotic state while photobionts behave just the opposite way.

5.) When denoting the photobiont as the lichen host, the aspect of prevalence depicts lichens as parasites, since all lichen photobionts are also known free-living (Tschermak - Woess 1988).

All five aspects mentioned here, the relation between abundance in the symbiotic state compared to the aposymbiotic state in both bionts, incongruence of habitats, the obvious discrepancy in selectivity in the two 
lichen bionts, the differential influence of the symbiotic state on the phenotypic differentiation of the bionts as well as a fungal prevalence of less than $100 \%$ in the photobionts clearly favor the concept of an antagonistic relationship even in lichens that are associated with Trebouxia, rather than that of a mutualistic symbiosis. An interesting implication of this qualification is that in analogy to parasitic systems, the "parasite" might be a useful indicator for the "host" taxonomy (Mitter \& Brooks 1983, Barrett 1986). Therefore, mycobionts might be valuable indicators for the taxonomy of photobionts in general and particularly for the taxonomy of Trebouxia and not vice versa as considered by Rambold (1998).

\subsubsection{Certain aspects of lichen ecology appear as adaptations to nutrition deficient habitats}

In a theoretical survey Hochberg et al. (2000) investigated the influence of habitat productivity on resistance and virulence of symbionts. Habitats with low productivity were predicted to promote a reduced resistance in hosts as well as a reduced virulence in parasites. Both effects favor the evolution of mutualistic associations. Furthermore, such habitats promote the tendency towards asexuality in the host. A reduced geneflow between populations promotes geographical diversity. Also, the chance of hyperparasite evolution increases under these conditions (corresponding to lichenicolous fungi). All these effects can be recognized in lichens which appear only persistent in environments with low productivity (Schöller 1997). Transferring lichen thalli on nutritionally rich media causes the associated bionts to disintegrate (Ahmadjian 1962). The congruence of lichen ecology with the predictions made by Hochberg et al. (2000) is considered as additional support for the qualification of photobionts as hosts and mycobionts as parasites.

\subsection{The significance of competition for lichen ecology and evolution}

When characterizing photobionts as hosts and mycobionts as parasites, the question remains what causes Trebouxia to adapt to the symbiotic life style. It is suggested here that it is the strong competitive stress it experiences in the aposymbiotic state. Free-living Trebouxia cells are exposed to competition with a variety of subaerial algae and probably also suffer from consumers. A model of interactions between lichen bionts that depicts such interactions is shown in FIG. 5.7. This model incorporates two distinct life stages of the photobiont as well as its exposure to competitive stress in its free-living phase. This concept assumes an antagonistic relationship between lichen bionts while supporting the evolutionary stability of the symbiosis. Interestingly, it agrees with the very earliest concepts of the lichen symbioses as described by Schwendener (1873) and DeBary (1879) who both considered lichens to be parasites. An antagonistic concept, which includes free-living stages of the photobiont, stresses the importance of the environmental requirements of the photobiont for lichen existence. Maybe it is the fitness of the free-living photobiont populations available for lichenization that determines occurrence and abundance of lichens, especially for the asorediate species as already suggested by Wirth (1983). 
Assuming low densities of free-living photobiont populations as well as a dependency of asorediate lichens on these free-living photobionts, the availability of compatible photobionts for relichenization might be a limiting resource for lichen populations. This assumption receives support when comparing the ecological success of sorediate with their asorediate sister species (Bowler \& Rundel 1975). Hence, competition for accessible and compatible photobionts might be suspected in asorediate lichens. Therefore, evolutionary forces might be in effect that minimize competition. Several options can be postulated. Development of dual propagules, change or restriction of the mycobiont's ecological niche within the ecological range of the compatible photobiont, switch to another photobiont of the same environment, or a switch to another photobiont in another environment. All these strategies have apparently been realized in lichens and contribute to their diversity. Competition for a common set of photobionts might therefore promote an increase of selectivity as a strategy to minimize resource overlap (analoguous to the principle of resource partitioning, Futuyma \& Slatkin 1983 and citations therein, Roughgarden 1983, Buckling \& Rainey 2002). In case sympatric mycobionts are selective for the same photobiont, competition might have just the opposite effect on the degree of selectivity. In such situations an alga switch might be promoted (van Baalen et al. 2001). Therefore, competition for photobionts is suspected to be a major cause for the apparently contradictory findings of ecological dependence (i.e. selectivity) and evolutionary independence.

When considering competition for photobionts as an evolutionary force that promotes diversification in lichens, an interesting correlation emerges. The lower the density of free-living compatible photobionts, the more diverse are the mycobionts that depend on it. To illustrate this correlation the diversity of lichen taxa that are associated with the three most common photobionts Trebouxia, Trentepohlia, and Nostoc might be compared to the abundance of these photobionts in the aposymbiotic state. Trentepohlia as well as Nostoc are frequently observed in the free-living state but Trebouxia is not. Accordingly, the diversity of lichens that depend on Trebouxia is greatest. Further, the order of fungi that includes the highest percentage of lichens depending on Trebouxia, the Lecanorales, is also the most diverse order. Therefore, the general finding that most lichens adopt Trebouxia as their photobiont, might be explained by an accelerated rate of diversification caused by an especial strong competition in those fungi that become dependent on Trebouxia. Also the fact that sorediate lichens often do not continue to speciate might be interpreted under the aspect of a "diversifying competition" for compatible photobionts. Sorediate lichens escape this competition and so "lose" their motor of diversification. 


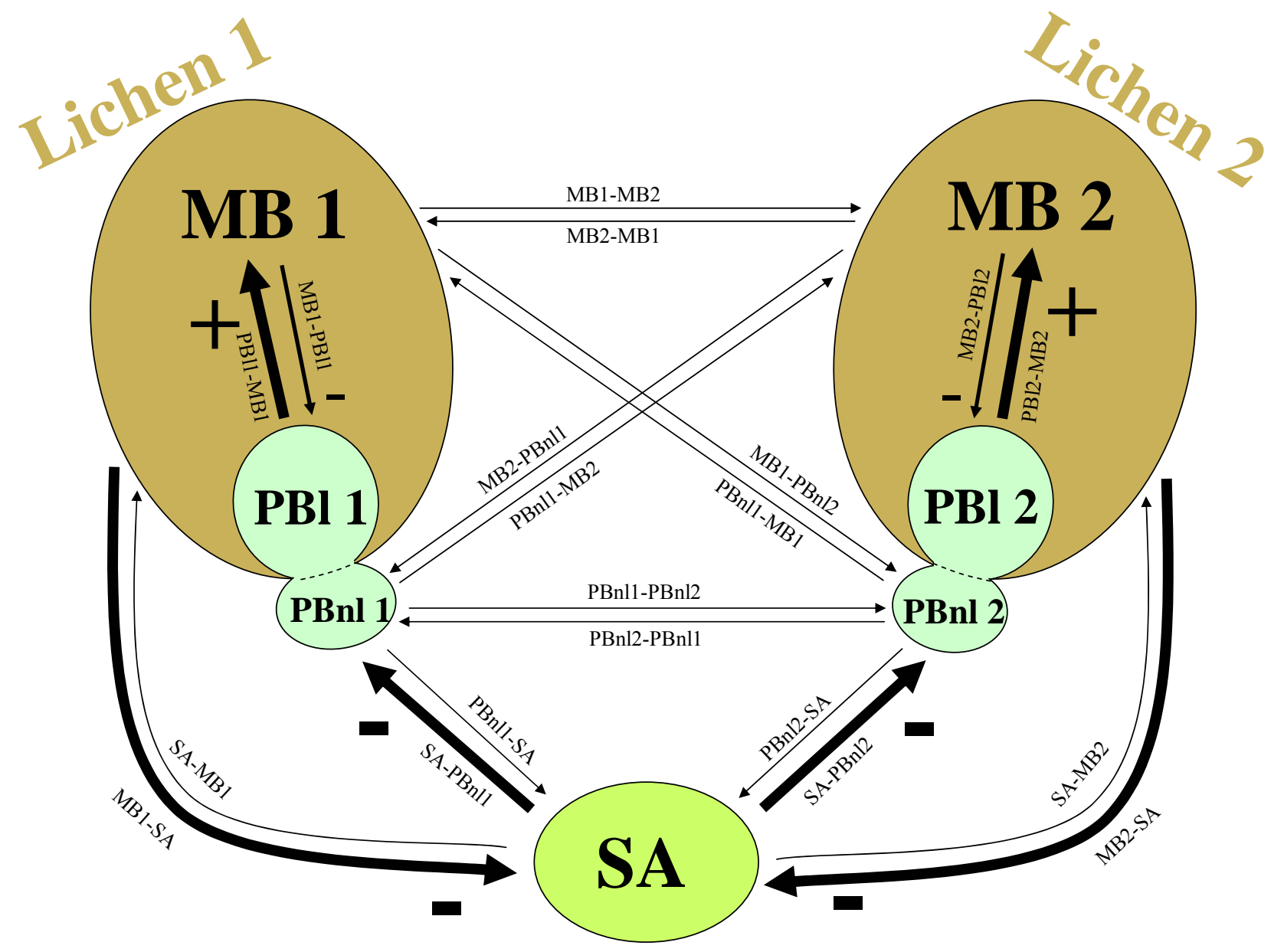

\section{Fig. 6.1: Flow diagram of hypothetical interactions between lichen bionts and subaerial algae}

It is assumed that photobionts (PB) occur in two distinct stages: lichenized (PBl) and non-lichenized (PBnl). The lichenized stage is symbolized by the area enclosed by the mycobiont (MB); the aposymbiotic stage is symbolized by the area outside the mycobiont. The close proximity of the two distinct photobiont areas depicts the genetic connection between the two stages but not necessarily any spatial or temporal proximity. Lichenized photobionts are supposed to interact only with the mycobiont while photobionts in the aposymbiotic stage are supposed to interact with a variety of organisms, such as subaerial algae (SA). Thin arrows are of purely hypothetical nature and may have variable intensities in different taxa. Further, interactions symbolized with these thin arrows might even not be realized in many cases (e.g. PBnl1-PBnl2 / PBnl2-PBnl1 or PBnl-SA). Thick arrows indicate intensive interactions which are observed in all lichens and are either beneficial or detrimental (indicated by "+” and “_“ signs). PBl1-MB1 / PBI2-MB2: Beneficial and intensive effect of the photobiont on the mycobiont. The transfer of carbohydrates from the photobiont to the mycobiont is a long established fact (Richardson et al. 1967). MB1-PBI1 / MB2-PBI2: A direct beneficial effect of the mycobiont on the photobiont has not been proven. The loss of carbohydrates is the only effect that has been ascertained. Therefore, this effect is suspected to be negative although not lethal. MB1-SA / MB2-SA: Lichens overgrow subaerial algae and are therefore superior when competing for space. Intensity and nature of effects of SA on MB is not known but might be suspected to be weak or even absent in many cases. SA-PBnl1 / SA-PBnl2: The fact that most Trebouxia strains seem readily cultivable, i.e. grow well although slowly in the absence of competition suggests that the rarity of Trebouxia in the free-living state is due to competition with faster growing subaerial algae. Therefore, subaerial algae are suspected to have an intense and negative effect on growth rates of free-living photobionts. In the case of Trebouxia, free-living photobionts might possibly have no effect on other subaerial algae. 


\section{Introns of the Physciaceae* nrSSU}

\subsection{Summary}

In this study, the Physciaceae were found to harbor an extraordinary number of group I and spliceosomal introns in their nrSSU genes. Most introns were found at known intron insertion sites (Cannone et al. 2002). Four new insertion sites could be added that have not been reported in any other organism yet. Using intron binding primers for PCR amplification it could be shown that nrSSU repeats are heterogeneous with respect to the presence of their introns. Furthermore, a high rate of horizontal transmission of group I introns was suggested by comparing intron phylogenies with the nrITS phylogeny of the respective species. Physciacean group I introns appear as highly mobile genetic elements. The proportion of invaded ribosomal repeats was found to vary between individuals of the same species as well as between species. Incidences were shown, where the presence of a particular intron was only detectable when using intron-specific primers for amplification.

\subsection{Introduction}

\subsubsection{Introns in general}

Introns are optional sequence insertions in coding DNA and occur in some bacteria and most if not all eukaryotes (Gargas et al. 1995, Johansen et al 1996). In eukaryotes they are found in the nuclear and mitochondrial DNA and in the case of photosynthetic taxa also in the plastid DNA. Their characteristic properties are expressed after transcription on the RNA level. Referring to their primary and secondary structure as well as the mechanisms of their excision from the primary transcript, four groups of introns are distinguished: Group I and group II introns, archaeal and spliceosomal introns. Self splicing introns such as group I and II introns may be found in cells and cell compartments where transcription and translation is not separated, e.g. in prokaryotes, mitochondria and chloroplasts. Here they are most common in genes coding for structural RNA such as rRNA or tRNA where non-spliced introns are not translated (Mattick 1994). Spliceosomal introns ( $\cong$ nuclear introns) rely on the spliceosome to be spliced out (mRNA processing) and are common in nuclear genes of eukaryotes. Archaeal introns appear to be restricted to Archaea and reside in their tRNA and rRNA genes (Lykke-Andersen et al. 1997). Due to the ubiquity of ribosomal genes and their frequent sequencing in phylogenetic studies, a particularly rich amount of data on ribosomal introns is available. Comparative analyses of these rDNA introns revealed that introns are not distributed randomly but restricted to particular insertion sites. Introns of the same insertion site from different organisms are more 
similar to each other than introns of different insertion sites in the same organism. Therefore introns of the same insertion site are thought to be homologous and vertically transmitted through evolutionary time (Belfort \& Perlman 1995, Hibbett 1996, Bhattacharya et al. 1996, 2002). In order to specify the particular insertion sites of introns the rDNA of E. coli is used as a reference sequence (Gargas et al. 1995).

\subsubsection{Group I introns}

Group I introns have been observed in the organellar genomes of ciliates, fungi, green algae, and higher plants as well as in cyanobacteria, bacteriophages, and Chlorella viruses. In nuclear genomes this type of intron has been found less commonly (e.g. ciliates, green algae, fungi) and appears to be restricted to the ribosomal genes in this cell compartment (Van Oppen et al. 1993). Group I introns vary in size from ca. 180 to 3000 nucleotides, depending on the presence / absence of open reading frames (ORFs). Although group I introns vary considerably in their primary sequence, their secondary and tertiary structure as well as single nucleotide positions are strongly conserved (Cech 1988, Saldanha et al.1993). The 5'-flanking exon almost universally ends with an uridine and the intron ends with a guanosine. Michel and Westhof (1990) distinguish 11 types of group I introns, according to structural characteristics. A remarkable property of many group I introns (and group II introns) is their capability to catalyze their own excision independent from protein activity. This self-splicing capability is mediated by the secondary and tertiary structure. The secondary structure typically consists of ten double strand helices, denoted as P1 through P10 (FIG. 7.1, Cech et al. 1994, Damberger \& Gutell 1994). Splice-site recognition relies on pairings of an internal guide sequence (IGS) at the $5^{\prime}$ end of the intron with exon sequences flanking the intron. The IGS pairs with the 5'exon sequences to form helices P1 and the 3'-exon sequences to form P10. Elements P5-P4-P6 and P9-P7P3-P8 form two stacks of coaxially assembled helices that form a cleft containing the intron's active site (Michel \& Westhof 1990). The splicing reaction consists of two transesterfication steps. In the first step, the $3^{\prime}-\mathrm{OH}$ of a free guanosine attacks the phosphodiester bond at the $5^{\prime}$ splice site and replaces the $5^{\prime}$ exon, thereby cleaving the exon-intron junction. The 5'-exon's conserved terminal uridine then attacks the 3' splice site in the second step. Through a second transesterfication reaction similar to the first step the 5' exon's terminal uridine replaces the intron's 3' terminus. In this step the flanking exons are ligated and the intron is set free. Although some group I introns self-splice in vitro, many require proteins for efficient splicing in vivo (Lambowitz \& Perlman 1990). Some proteins required for splicing mitochondrial group I introns are either encoded by nuclear genes or by the introns themselves (Lambowitz \& Belfort 1993). 


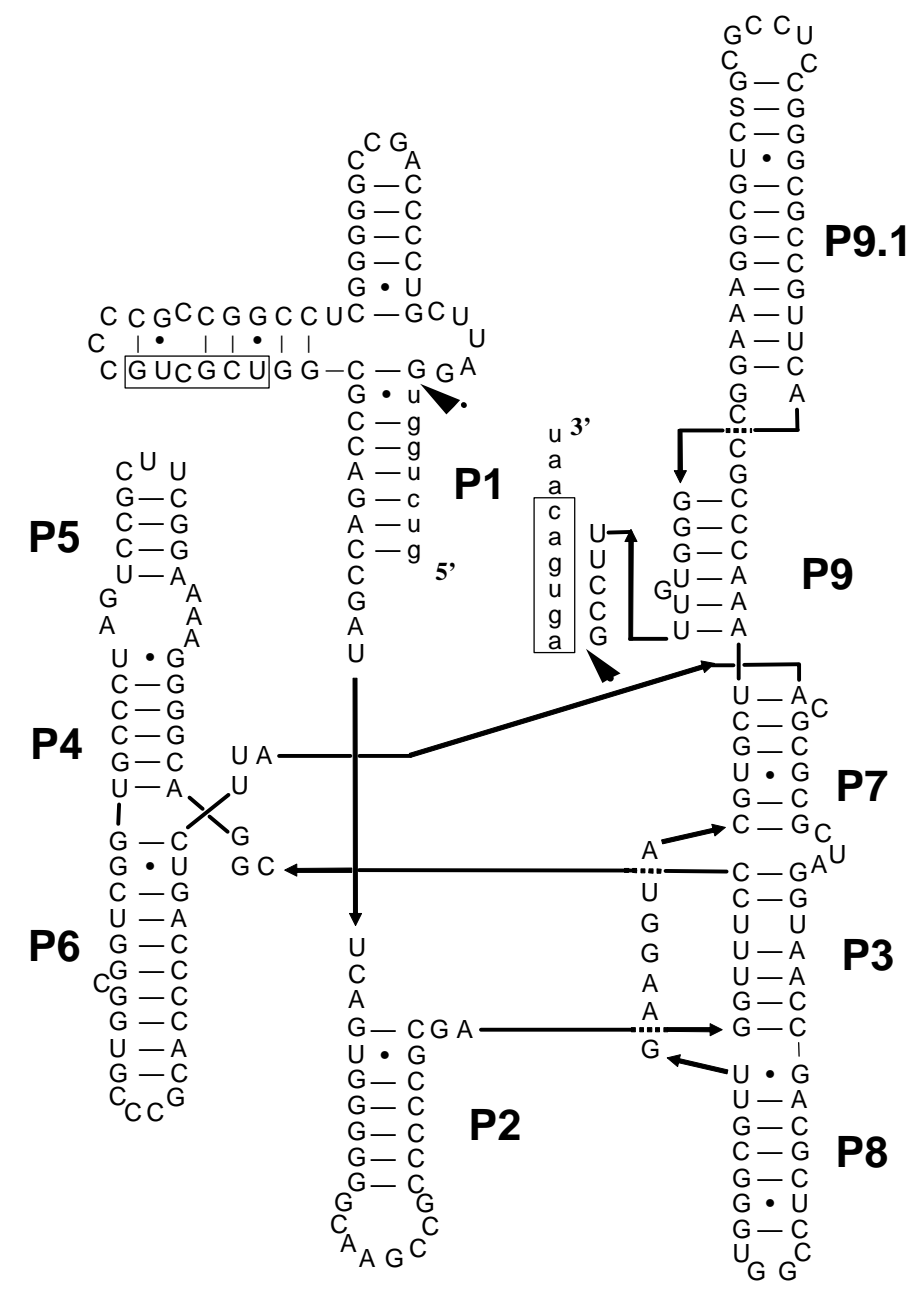

FIG. 7.1: Secondary structure of the group I intron of Anaptychia runcinata inserted at E. coli position 516. Secondary structure drawn according to Cech et al. (1994) and Damberger \& Gutell (1994). Upper case letters represent intron sequence, lower case letters represent exon sequence, arrows indicate splice junctions, boxed motives mark P10. Intron positions involved in P1 and P10 are denoted the internal guide sequence (IGS).

\subsubsection{Spliceosomal introns}

Spliceosomal introns usually occur in the nuclear genes of eukaryotes and are incapable of self-splicing. Their removal is catalyzed by the spliceosome. They may reach lengths of several thousand nucleotides although most reported were less than 100 nucleotides (nt) long, often only around $50 \mathrm{nt}$. They are not characterized by a conserved secondary structure and can be recognized by three conserved sequence motives. The $5^{\prime}$ terminus starts with GU usually followed by WHG $(\mathrm{W}=\mathrm{A}$ or $\mathrm{T} ; \mathrm{H}=\mathrm{A}, \mathrm{T}$ or $\mathrm{C})$ and the $3^{\prime}$ terminus ends with YAG ( $\mathrm{Y}=\mathrm{C}$ or $\mathrm{T})$. Close to the $3^{\prime}$ terminus the strongly conserved branch point is located with the sequence motive CTAAC (Cubero et al. 2000, Bhattacharya et al. 2000).

\subsubsection{Horizontal transfer}

A remarkable finding about introns is that their genealogies often differ significantly from those of the organisms that harbor them. Instances have been reported where closely related introns were discovered in distantly related organisms such as Chlorella viruses and green algae (Yamada et al 1994, Bhattacharya et al. 
1996) or in different compartments of different organisms (Nishida \& Sugiyama 1995, Turmel et al. 1995). In these instances a horizontal transfer of the intron has been postulated. A further unexpected observation has been the irregular distribution of these introns. Not only different species of the same genus may differ in the presence/absence of particular introns, even different strains of the same species have been found to differ in this respect (Friedl et al. 2000). Several authors even reported instances where different copies of the nuclear ribosomal RNA genes within one genome differed in intron presence/absence (DePriest 1993, Gargas et al. 1995, Hibbett 1996, Perotto et al. 2000). Therefore, it seemes that introns are highly mobile elements that might be transmitted not only sexually but also by other mechanisms that are capable of surpassing species boundaries.

\subsubsection{Intron encoded endonucleases}

Group I and group II introns are known to occasionally include open reading frames (ORFs) that encode proteins with site specific endonuclease activity. Notably, the endonucleases recognition sites were congruent with the intron insertion site (Dujon 1989, Lambowitz \& Belfort 1993). This congruency suggests a specific mode of intron insertion. After introduction of an intron with an endonuclease gene into a cell with an intron deficient allele, the endonuclease may be expressed and the native intron-free allele might be cut at the homing site. A cell inherent double strand break repair mechanism then may use the donor allele as a template to repair the double strand break and the intron is synthesized into the native allele. Once the intron is inserted into its homing site, the recognition sequence for the endonuclease is disrupted and cannot be cleaved again. Therefore, intron homing is an unidirectional process that efficiently propagates endonuclease encoding introns (Dujon 1989, Lambowitz \& Belfort 1993). Once all insertion sites are occupied by the intron, functionality of the endonuclease is no more selected for and the gene may degenerate. After loss of endonuclease activity, the intron itself might be lost, thus exposing the allele to a new round of intron invasion (Loizos et al. 1994, Goddard \& Burt 1999).

\subsubsection{Reverse splicing}

The majority of group I and II introns lack ORFs (Johansen et al. 1996, this study). Several instances were reported where the distribution of such ORF-less introns also contradicted the assumption of vertical inheritance (Hibbett 1996, Cho \& Palmer 1999, Holst-Jensen 1999, Friedl et al. 2000, Palmer et al. 2000). Two alternatives have been postulated to explain the mode of their dispersion. The first alternative assumed that these ORF lacking introns once possessed an endonuclease gene at the time of their transmission and lost it subsequently. The second alternative assumes the reversal of the splicing reaction. Excised introns may reinsert into intron free (processed) RNA which subsequently may be reverse transcribed by transacting reverse transcriptase. The presence and activity of such reverse transcriptase can be assumed from the ubiquity of retroviruses, retrotransposons and introns coding for reverse transcriptases (Li 1997). The cDNA 
may recombine with the genomic DNA and the intron may insert into the genome trough crossover (Dujon 1989, Lambowitz \& Belfort 1993, Belfort \& Perlman 1995, Roman \& Woodson 1998). Alternatively, the intron RNA may insert directly into ssDNA and may subsequently be reverse transcribed (Yang et al. 1996, Dickson et al. 2001). Simultaneously, these two mechanisms also suggest how introns might get lost. Processed RNA might be reverse transcribed and "replace" an intron containing copy (Merlos-Lange et al. 1987, Levra-Juillet et al. 1989).

\subsubsection{The intron early - intron late debate}

Prior to the discovery of introns, the two vital functions of information storage and katalytic activity (as well as structure forming function) were thought to be represented by distinct molecule classes, nucleic acids and proteins respectively. With the discovery of the catalytic activity of intron RNA molecules, this view was disproven. The union of information storage and catalytic activity within one molecule inspired numerous authors to propose catalytic RNA molecules as the precursors of life (The RNA world, e.g. Cech 1993). In subsequent protein evolution, introns were suspected of having facilitated exon shuffling, thereby increasing genetic complexity and accelerating protein evolution. This scenario is also termed the exon theory of genes (Gilbert 1978), or the intron early hypothesis. However, this theory is called into question by an overwhelming amount of data. Most bacteria are devoid of introns in their protein coding genes and functional domains of protein genes in eukaryotes often do not coincide with intron insertion sites. Furthermore, many introns have been shown to be mobile elements that are capable of crossing species boundaries. All these observations stand in favor of an intron spread after prokaryote radiation and after eukaryote origin, pointing to the intron - late hypothesis. An extensive review of this subject is provided by Mattick (1994).

\subsection{Materials and Methods}

\subsubsection{Alignment and phylogenetic analyses}

The nrSSUs of 41 specimens of the Physciaceae were sequenced and introns identified as optional sequence insertions. Intron - exon boundaries were determined according to conserved sequence motives as reviewed in the introduction. Introns of particular insertion sites were aligned with ClustalW (Thompson et al. 1994) using a gap opening penalty of 2 and a gap extension penalty of 1. Prior to phylogenetic analyses, all gap containing positions were excluded. Intron phylogenies were estimated as described in chapter 2, paragraphs 2.2.3 and 2.2.4). Under the maximum-likelihood criterion only Bayesian analyses were performed. 


\subsubsection{Primer design and primer constellations}

Conserved sequence motives within the analyzed introns were identified for which primers could be designed that were complementary to all introns of a particular insertion site. In order to investigate if introns are reliably detected by amplifying nrDNA with exon binding primers (as done for rDNA sequencing), taxa in which no introns had been sequenced were screened with these intron-specific primers. As a control also those taxa were included in the PCR screening that were already shown to possess the respective introns. Intron insertion sites at E. coli positions 516, 788, and 1199 were screened with different primer combinations. Primer constellations were chosen as in Hibbett (1996). FIG. 7.2 gives a graphical overview of the primer binding sites and resulting amplicons for each primer combination. TABLE 2.1 (p. 9, 10) shows the primer sequences and TABLE 7.2 gives the actual primer combinations used. With respect to PCR screens it is important to note that the absence of a PCR product cannot be regarded as evidence for the absence of the target. Mutated or disrupted annealing sites may prevent amplicon formation. Also long insertions between the primer annealing sites might hinder product formation when extension times are not sufficiently long.

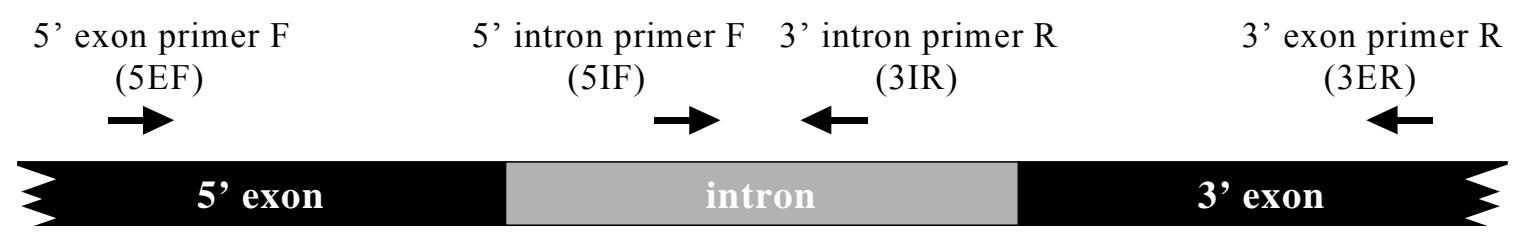

primer combinations and their resulting PCR products

$$
\begin{aligned}
& 5 E F-3 E R \\
& 5 E F-3 I R \\
& 5 I F-3 E R \\
& 5 I F-3 I R
\end{aligned}
$$

FIG. 7.2: Primer combinations used to screen presence / absence of introns. Primer combination 5EF-3ER results in a PCR product independent of intron presence/absence but with respective length differences, 5EF-3IR and 5IF-3ER result in PCR products only when the intron is present in the specific gene, 5IF-3IR results in a PCR product when the intron is present, irrespective of the intron's location. 


\subsection{Results}

\subsubsection{Distribution of spliceosomal and group I introns}

Forty-one Physciacean nrSSU sequences were obtained, representing 40 species and 19 genera. A total of 180 introns was detected, of which 28 were identified as spliceosomal introns and 152 as group I introns (TABLE 7.1). No other intron types were recognized. Thirty-two insertion sites were revealed, of which 16 were occupied by group I introns and 16 by spliceosomal introns. No insertion site was found that harbored both group I and spliceosomal introns (FIG. 7.3). Insertion sites 302, 471, 1049, and 1385 were not reported in Gutell's webpage (Cannone et al. 2002) and are therefore only known from the Physciaceae. Group I introns at positions 1211 and 1390 are denoted with insertion sites 1210 and 1389 in Gutell's webpage. However, positions 1210 and 1389 are preceded by a cytosine, whereas positions 1211 and 1390 are preceded by a thymidine. Therefore the latter two positions are in accordance with the general rule that group I introns are preceded by a thymidine (Cech 1988). Also the alignment confirmed these latter insertion sites. Position 1224 is occupied by a spliceosomal intron here, whereas in Gutell's webpage only group I introns are noted in this position. The number of introns found by nrSSU sequencing varied considerably between species and insertion sites. In several species no introns were detected by nrSSU sequencing (i.e. using exon specific primers only) while Phaeophyscia orbicularis and Physconia perisidiosa comprised 13 introns. The most frequently found group I introns were at E. coli insertion sites 1516 (25 introns sequenced), 1199 (18), 788 (15), and 516 (14, see TABLE 7.1). In Rinodina gennarii, the two specimens analyzed differed at several insertion sites with respect to the presence / absence of introns (TABLE 7.1). An extraordinary group I intron was found at position 1199 in Physcia dimidiata. This intron encompassed two open reading frames of 717 and $630 \mathrm{bp}$ length respectively. Altogether this intron was $1585 \mathrm{bp}$ long. 
TABLE 7.1: Distribution of nrSSU introns across the 40 Physciaceae species and 32 insertion sites as amplified and sequenced with nrSSU specific primers. Numbers behind species names indicate specific specimens (see appendix A.1). Insertion sites of group I introns are labeled red, insertion sites of spliceosomal introns (s) in black.

*: data already published in Bhattacharya et al. (2002), however spliceosomal introns were not reported there.

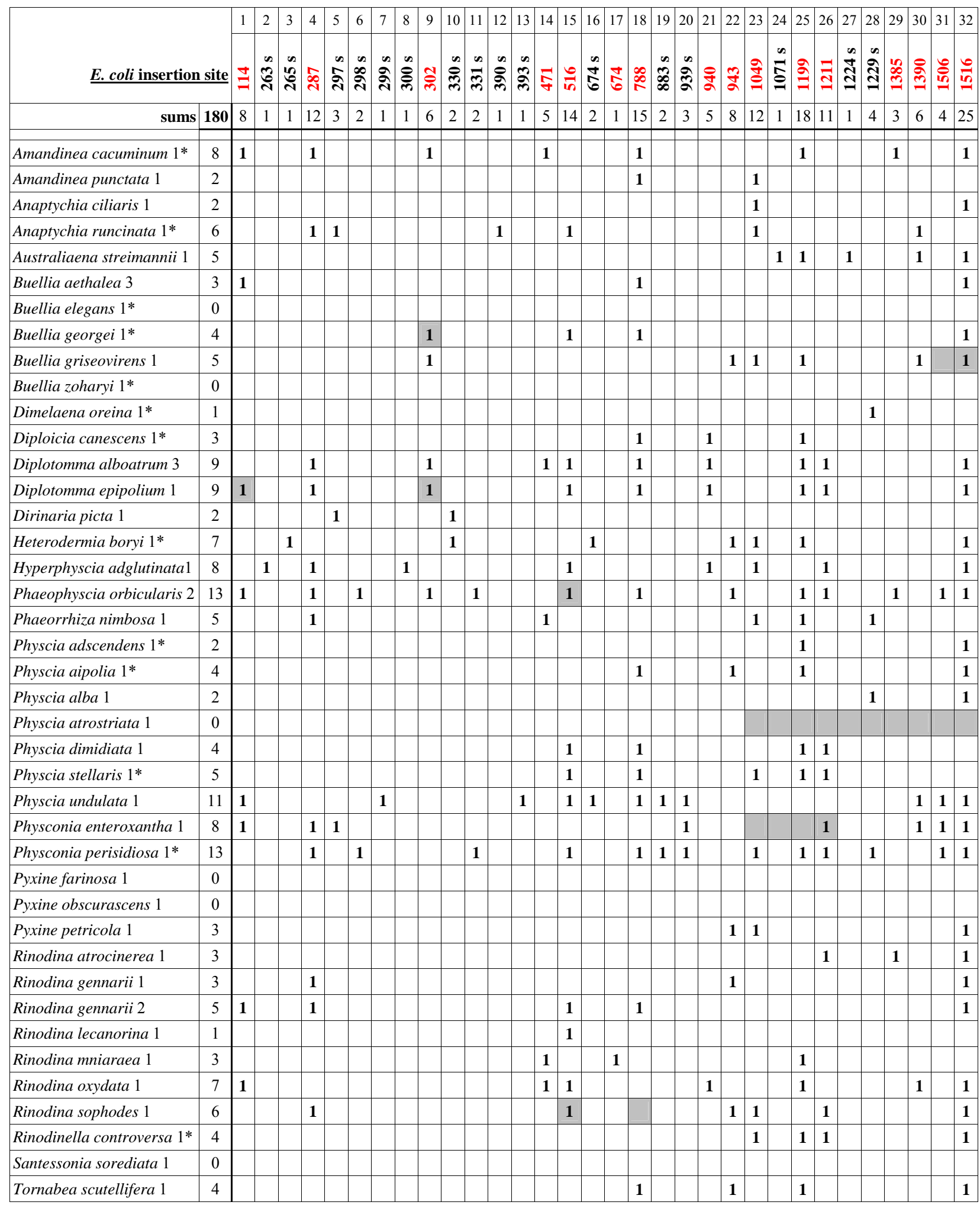




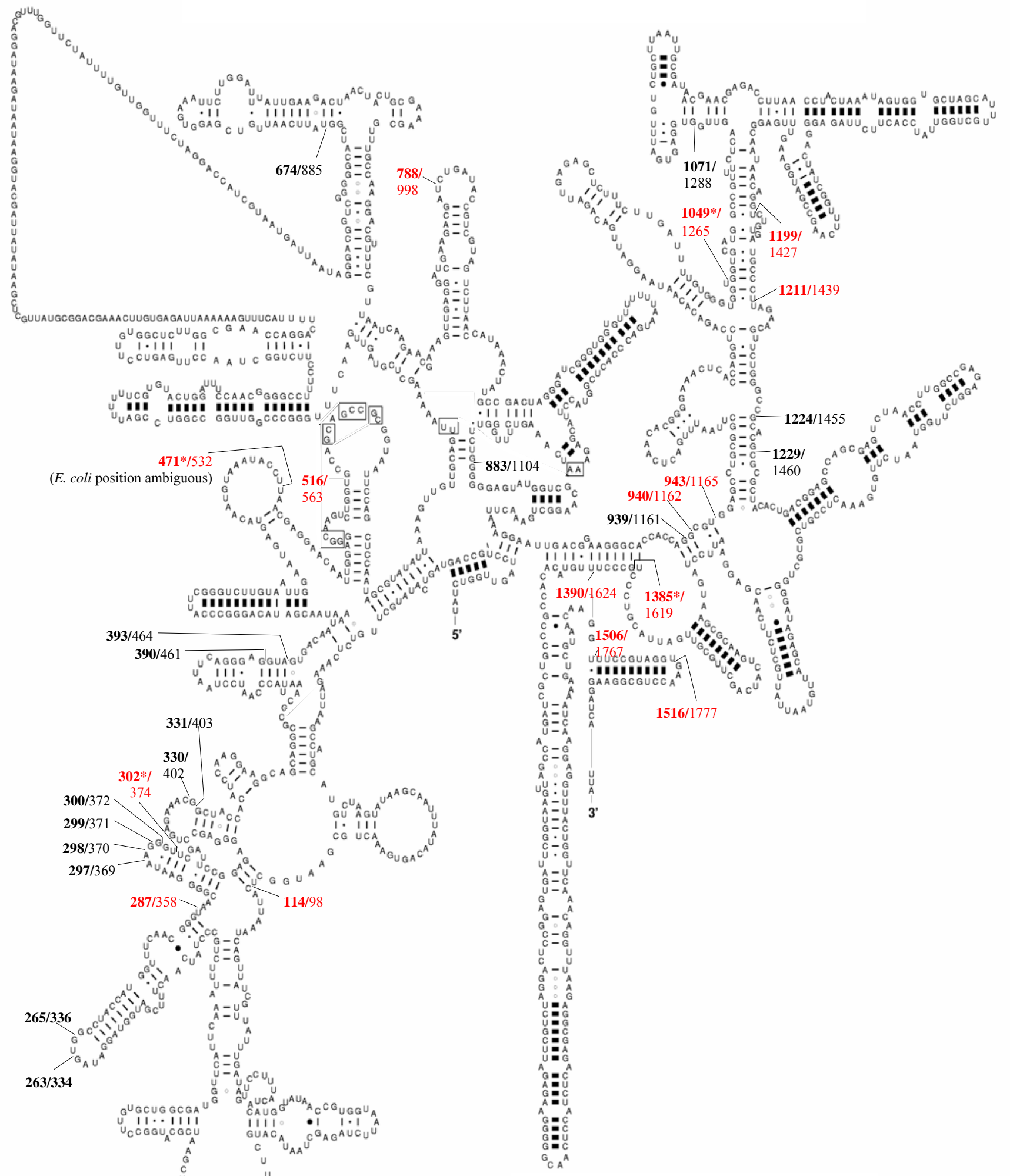

FIG. 7.3: Secondary structure of the nrSSU of Sacharomyces cerevisiae (Cannone et al. 2002) with Physciaceae intron insertion sites. The first number (bold) indicates $E$. coli insertion site, the second number indicates $S$. cerevisiae insertion site. Positions at which group I introns were found are labelled red, positions at which spliceosomal intron were detected are labelled black. *: Intron insertion sites that are not reported in Gutell's webpage (Cannone et al. 2002) 


\subsubsection{Screening for the presence of introns}

Twenty-two specimens were screened for the presence of introns at E. coli insertion sites 516, 788 and 1199. These insertion sites were especially intron-rich as shown by nrSSU sequencing (TABLE 7.1) and conserved regions in these introns could be found for which primers could be designed that were compatible with all sequenced introns of the respective insertion sites. With these primers introns could be detected that were not amplified with exon binding primers and therefore remained undetected by nrSSU sequencing (TABLE 7.2)

\subsubsection{Intron presence at $E$. coli insertion site 516}

In eight of the 22 taxa the 516 intron had been sequenced, i.e. was amplified with exon binding primers (TABLE 7.1). In all of these taxa, primer combinations including intron binding primers yielded amplicons of the expected sizes, confirming the effectivity of intron binding primers as well as the respective primer combinations (TABLE 7.2). In Australiaena streimannii, Rinodina gennarii (specimen 1), and Santessonia sorediata, primer combination 516-5IF / 516-3ER yielded an amplicon where no intron had been sequenced. However, another primer combination including the second intron-specific primer did not result in an amplicon. Possibly the binding site for primer 516-3IR was mutated in these three taxa, since the functionality of this primer combination could be affirmed in the other taxa. No intron-internal amplicon was generated where combinations of intron and nrSSU binding primers also failed to do so. This supports the assumption that 516 introns do not reside in other genes than the nrSSU.

\subsubsection{Intron presence at $E$. coli insertion site 788}

In eight of the 22 taxa the 788 intron had been sequenced (TABLE 7.1). In all of these taxa, primer combinations including intron binding primers yielded amplicons of the expected sizes, thus confirming the effectivity of intron binding primers as well as the respective primer combination (TABLE 7.2). Interestingly, in further eight specimens an amplicon was obtained using an intron specific primer (788-5IF) where no intron had been sequenced. This means that in more than half of the taxa in which the introns were not detected by nrSSU sequencing, the intron presence could be demonstrated with intron-specific primers. These were specimens of Australiaena streimannii 1, Dirinaria picta 1, Hyperphyscia adglutinata 1, Phaeorrhiza nimbosa 1, Physconia enteroxantha 1, Rinodina gennarii 1, R. sophodes 1, and Santessonia sorediata 1 . The finding suggests that only a minority of nrSSU repeats in these taxa contained the 788 intron. It further demonstrates how misleading nrSSU sequence data can misrepresent the distribution of introns among taxa. 


\subsubsection{Intron presence at $E$. coli insertion site 1199}

In eight of the 22 taxa, the 1199 intron was sequenced (TABLE 7.1). However, in one of these taxa, Australiaena streimannii 1, amplification with an intron internal primer did not result in an amplicon. In Hyperphyscia adglutinata 1 an amplicon was obtained with an intron internal primer although no 1199 intron was detected by sequencing. In six specimens intron-internal amplicons were obtained with the predicted size, but neither nrSSU sequencing nor amplification with an exon / intron primer combination yielded a product. This constellation was found in Amandinea punctata 1, Buellia aethalea 1, Physcia undulata 1, Pyxine petricola 1, Rinodina lecanorina 1, and Rinodina sophodes 1 (TABLE 7.2).
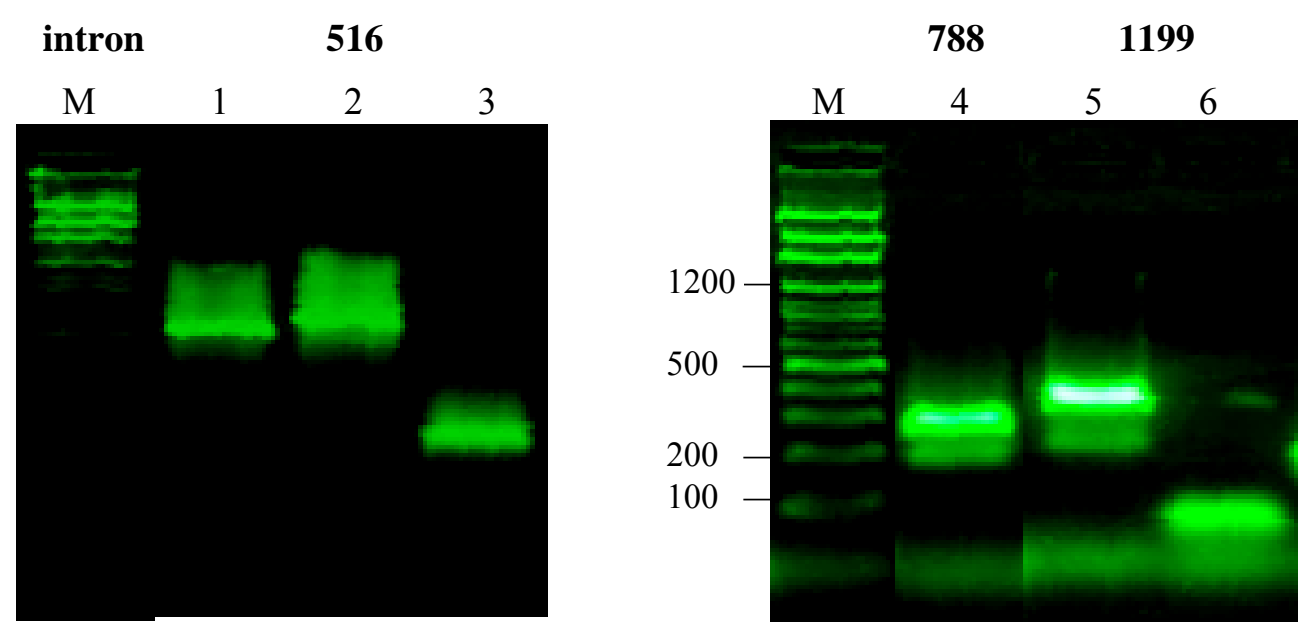

FIG. 7.4: Results of PCR screens for the detection of introns at E. coli insertion sites 516 (lanes 1 -3), 788 (lane 4), and 1199 (lanes 5, 6) in the nrSSU genes of Dirinaria picta 1. Primer combinations are given in TABLE 7.2.

M: DNA fragment length marker "GeneRuler 100 bp DNA Ladder Plus" (Fermentas). 
TABLE 7.2: PCR screening for the presence of introns at E. coli insertion sites 516, 788, and 1199 in the nrSSU of 22 species of Physciaceae. For primer terminology see FIG. 7.2 and TABLE 2.1 (p. 9, 10). PCR assays that yielded strong products are marked with a large dot, those that yielded a weak product with a circle and those where no product was visible are marked with a dash. Uncertain PCR products are denoted with "?". Due to considerable length variability of the introns, values for the expected lengths of amplicons are only approximations. Further, some primer combinations might span multiple intron insertion sites and when multiple introns were present amplicon size might exceed the expected size by several $100 \mathrm{bp}$.

\begin{tabular}{|c|c|c|c|c|c|c|c|c|c|}
\hline & & 516 in & on & & 788 int & ron & 119 & 9 intron & \\
\hline amplified region & intron detected & intron & nrSSU & intron & intron detected & intron in & $\begin{array}{l}\text { intron detected } \\
\text { by sequencing }\end{array}$ & $\begin{array}{l}\text { intron in } \\
\text { nrSSU }\end{array}$ & $\begin{array}{c}\text { intron } \\
\text { anywhere }\end{array}$ \\
\hline $\begin{array}{c}\text { forward primer } \\
\text { reverse primer } \\
\text { app. expected amplicon length }\end{array}$ & $\begin{array}{c}\text { MY } 60 \mathrm{~F} \\
\text { MY } 1200 \mathrm{R}\end{array}$ & $\begin{array}{c}\text { 516-5IF } \\
516-3 \mathrm{ER} \\
\text { ca. } 440\end{array}$ & $\begin{array}{l}\text { SR11R } \\
\text { 516-3IR } \\
\text { ca. } 390\end{array}$ & $\begin{array}{c}516-5 \mathrm{IF} \\
516-3 \mathrm{IR} \\
\text { ca. } 140\end{array}$ & $\begin{array}{c}\text { MY } 60 \mathrm{~F} \\
\text { MY } 1200 \mathrm{R}\end{array}$ & $\begin{array}{c}788-5 \mathrm{IF} \\
788-3 \mathrm{ER} \\
\text { ca. } 265\end{array}$ & $\begin{array}{l}\text { MY } 1200 \mathrm{~F} \\
\text { ITS4 }\end{array}$ & $\begin{array}{l}1199-5 \mathrm{EF} \\
1199-3 \mathrm{IR} \\
\text { ca. } 340\end{array}$ & $\begin{array}{l}1199-5 \mathrm{IF} \\
1199-3 \mathrm{IR} \\
\text { ca. } 60\end{array}$ \\
\hline PCR assay number & & 1 & 2 & 3 & & 4 & & 5 & 6 \\
\hline Amandinea punctata 1 & - & - & - & - & ○ & ○ & - & - & 0 \\
\hline Australiaena streimannii 1 & - & 0 & - & - & - & 0 & 0 & - & $?$ \\
\hline Buellia aethalea 1 & - & - & - & - & 0 & 0 & - & - & $\dot{0}$ \\
\hline Buellia griseovirens 1 & - & - & - & - & - & - & 0 & 0 & 0 \\
\hline Diplotomma alboatrum 3 & 0 & 0 & 0 & 0 & 0 & 0 & 0 & 0 & 0 \\
\hline Dirinaria picta 1 & - & - & - & - & - & 0 & - & - & 0 \\
\hline Hyperphyscia adglutinata 1 & O & $\bullet$ & 0 & 0 & - & 0 & - & $\mathbf{0}$ & $\mathbf{0}$ \\
\hline Phaeophyscia orbicularis 2 & 0 & 0 & 0 & 0 & 0 & 0 & 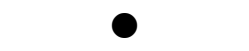 & 0 & 0 \\
\hline Phaeorrhiza nimbosa 1 & - & - & - & - & - & $\mathbf{0}$ & 0 & 0 & 0 \\
\hline Physcia dimidiata 1 & $\bullet$ & 0 & & 0 & 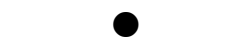 & 0 & 0 & $\bullet$ & $\bullet$ \\
\hline Physcia undulata 1 & ○ & 0 & $\bullet$ & 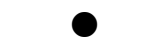 & 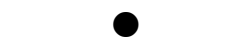 & 0 & - & - & $\mathbf{0}$ \\
\hline Physconia enteroxantha 1 & - & - & - & - & - & $\mathbf{0}$ & - & 0 & 0 \\
\hline Pyxine farinosa 1 & - & - & - & - & - & - & - & - & $?$ \\
\hline Pyxine obscurascens 1 & - & - & - & - & - & - & - & - & ? \\
\hline Pyxine petricola 1 & - & - & - & - & - & - & - & - & 0 \\
\hline Rinodina gennarii 1 & - & 0 & 0 & 0 & - & 0 & - & - & $?$ \\
\hline Rinodina gennarii 2 & 0 & 0 & 0 & 0 & 0 & 0 & - & - & ? \\
\hline Rinodina lecanorina 1 & 0 & 0 & 0 & 0 & - & - & - & - & $\dot{0}$ \\
\hline Rinodina mniaraea 1 & - & - & - & - & - & - & 0 & 0 & 0 \\
\hline Rinodina sophodes 1 & 0 & ○ & 0 & 0 & - & $\mathbf{0}$ & - & - & 0 \\
\hline Santessonia sorediata 1 & - & $\bullet$ & - & - & - & $\mathbf{0}$ & - & - & $?$ \\
\hline Tornabea scutellifera 1 & - & - & - & - & 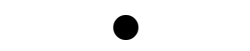 & 0 & 0 & 0 & $?$ \\
\hline
\end{tabular}




\subsubsection{Comparing nrSSU intron genealogies with the nrITS phylogeny}

Genealogies of the four most common group I introns found in the Physciacean nrSSU were established and compared to the nrITS phylogeny already discussed in chapter 3. Putative candidates were detected that likely acquired their intron by horizontal transfer. FIG. 7.5 shows the ITS phylogeny of Physciaceae species from which nrSSU sequences were obtained that harbored introns. This phylogeny corresponds to the phylogeny discussed in chapter 3 .

\section{Physciaceae ITS phylogeny}

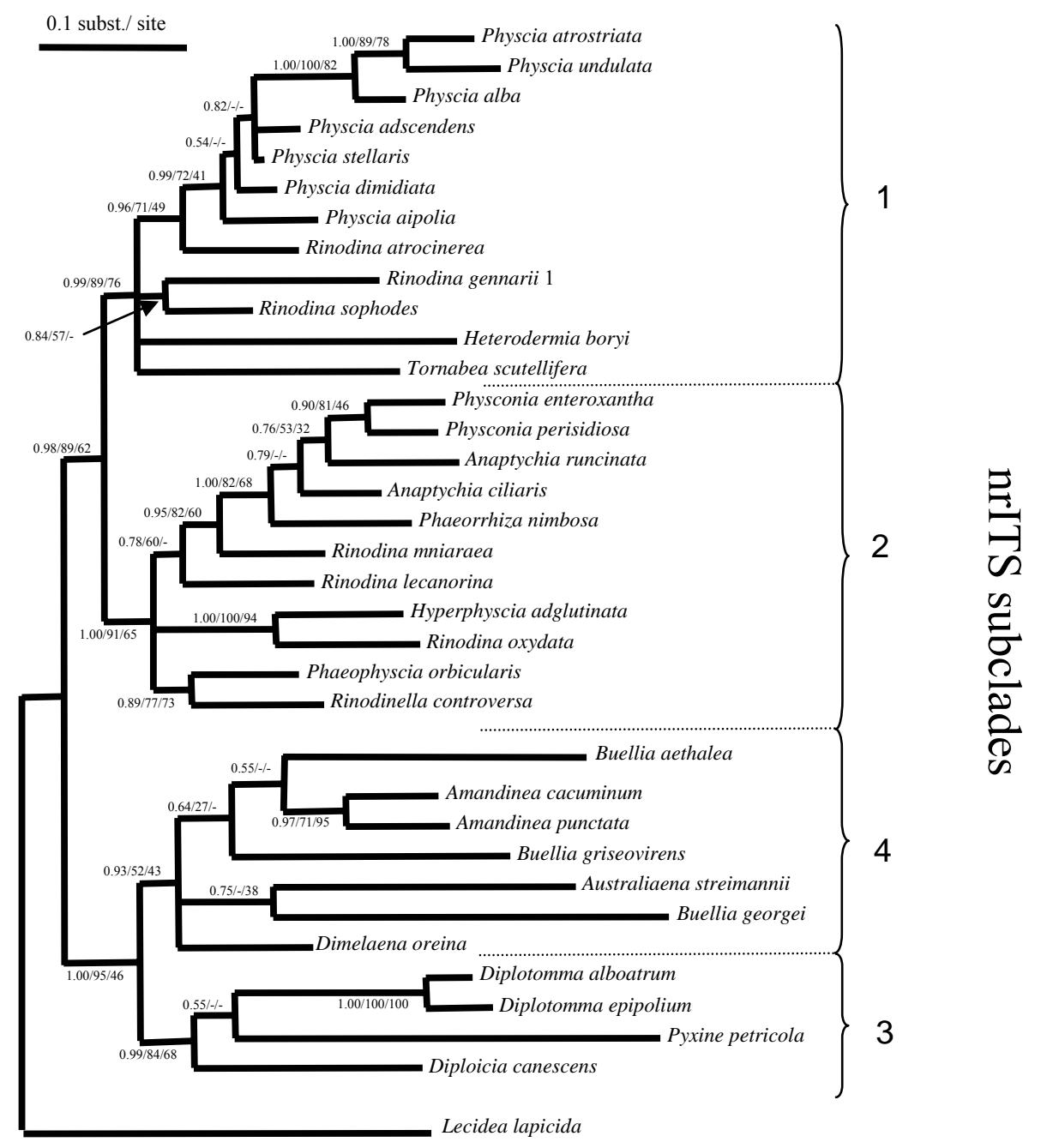

FIG. 7.5: ITS phylogeny of Physciaceae species that were found to harbor introns in their nrSSU sequences. The topology is based on Bayesian analysis. First branch support value is obtained by Bayesian analysis, second value by bootstrap analysis (1000 replicates) under the maximum-parsimony optimality criterion and third value by bootstrap analysis (1000 replicates) under the minimum evolution optimality criterion (neighbor-joining analysis employing the Jukes-Cantor model). The alignment from which this phylogeny was inferred was 271 positions long of which 207 were variable and 156 were parsimony-informative. Numbers $1-4$ on the right side indicate subclades as assigned in chapter 3. 


\subsubsection{Genealogy of introns at $E$. coli insertion site 287}

Twelve 287 group I introns were sequenced. After removing all positions that contained indels, the alignment was 154 positions long and comprised 99 variable and 75 parsimony-informative sites. The topology of these intron's genealogy is quite different from the ITS phylogeny. In Hyperphyscia adglutinata and Phaeorrhiza nimbosa, the phylogenetic positions of the 287 introns and the ITS sequences are discordant, although not significantly supported. The 287 intron of Hyperphyscia adglutinata clustered with the respective introns of subclade 1, while this species has been shown to be a member of subclade 2 (chapter 3, FIG. 7.5). Phaeorrhiza nimbosa, closely related to Physconia and Anaptychia species, revealed a 287 intron that appeared more closely related to Phaeophyscia orbicularis. The 287 intron of Amandinea cacuminum assumes a strongly supported position that deviates from the position of A. cacuminum in the ITS phylogeny. Its 287 intron clusters together with taxa of subclade 1 in the ITS phylogeny while A. cacuminum was shown to be a member of subclade 4 (FIG. 7.6).
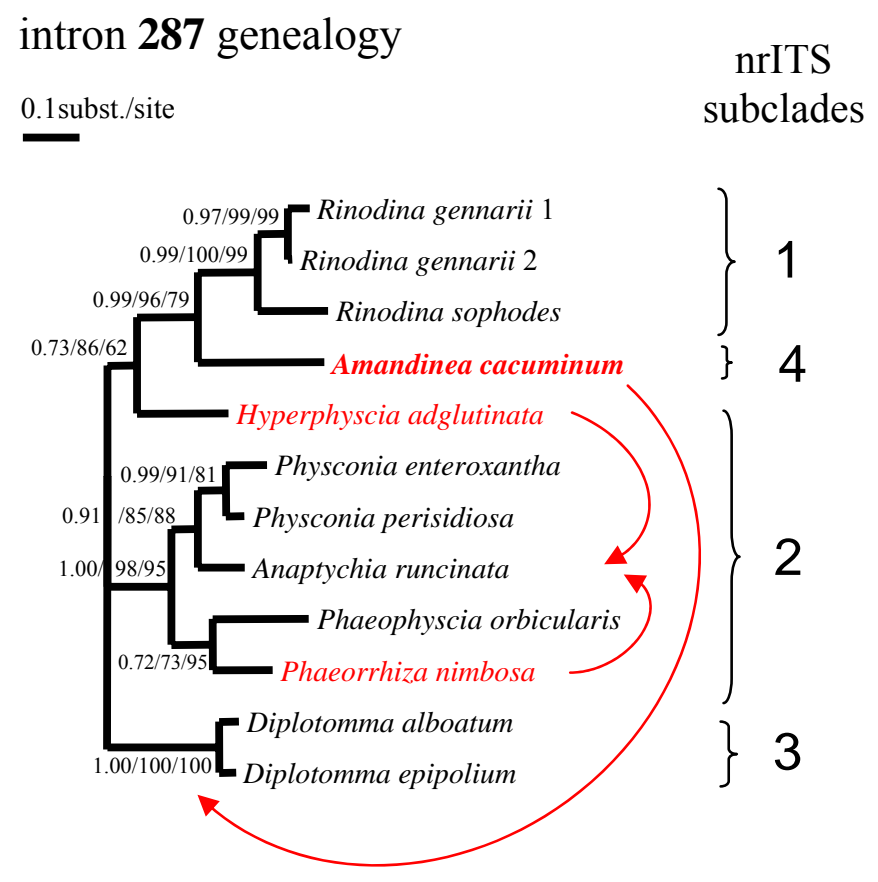

FIG. 7.6: Genealogy of Physciacean nrSSU group I introns inserted at E. coli positions 287. Red colored taxa assume a significantly different position than in the ITS phylogeny. The arrows indicate putative horizontal transfers and point to the taxon's respective position in the ITS phylogeny. Numbers on the right side indicate the respective subclades to which the taxa were assigned (chapter 3). The topology is based on Bayesian analysis. First branch support value is obtained in Bayesian analysis, second value in bootstrap analysis (1000 replicates) under the maximum-parsimony optimality criterion and third value in bootstrap analysis (1000 replicates) under the minimum evolution optimality criterion (neighbor-joining analysis employing the Jukes-Cantor model). Topologies are unrooted. 


\subsubsection{Genealogy of introns at $E$. coli insertion site $\mathbf{7 8 8}$}

Fifteen 788 group I introns were sequenced. After removing all positions with indels, the alignment was 174 positions long and comprised 78 variable and 62 parsimony-informative sites. Topologies of the two main lower branches in the 788 intron genealogy shown in FIG. 7.7 were entirely conform with the ITS phylogeny. However, the upper main branch in the intron's genealogy comprised three presumptive horizontal transfers. The 788 introns of Tornabea scutellifera and Physcia undulata appeared among 788 introns of the Caliciaceae (see chapter 3) and the introns of the two related Amandinea species were separated by long distances and highly significant support values.

intron 788 genealogy

nrITS

0.1 subst./site

subclades

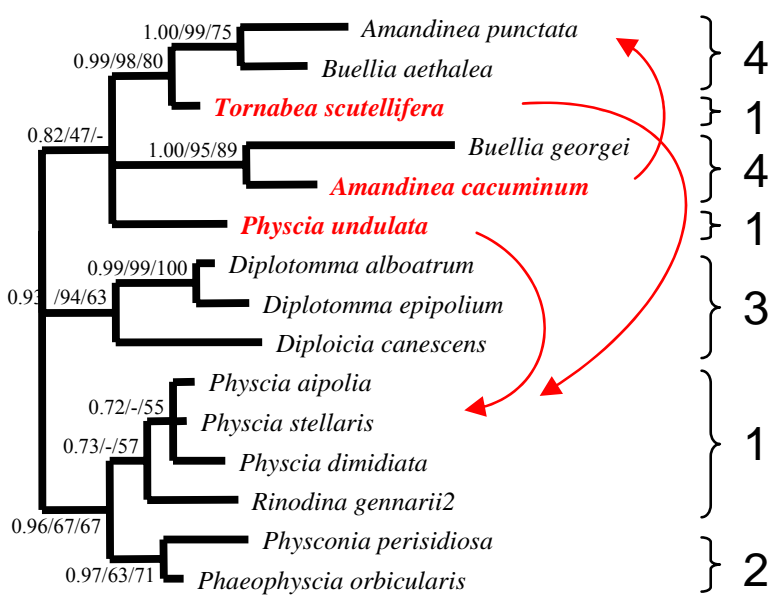

FIG. 7.7: Genealogy of Physciacean nrSSU group I introns inserted at E. coli positions 788. Red colored taxa assume a significantly different position than in the ITS phylogeny. The arrows indicate putative horizontal transfers and point to the taxon's respective position in the ITS phylogeny. Numbers on the right side indicate the respective subclades to which the taxa were assigned (chapter 3). The topology is based on Bayesian analysis. First branch support value is obtained in Bayesian analysis, second value in bootstrap analysis (1000 replicates) under the maximum-parsimony optimality criterion and third value in bootstrap analysis (1000 replicates) under the minimum evolution optimality criterion (neighbor-joining analysis employing the Jukes-Cantor model). Topologies are unrooted. 


\subsubsection{Genealogy of introns at $E$. coli insertion site 1199}

Eighteen 1199 group I introns were sequenced. After removing all positions that contained indels the alignment was 133 positions long and comprised 80 variable and 63 parsimony-informative sites. The intron's genealogy differed extensively from the ITS phylogeny, however, many of the differences did not receive significant support. Four potential horizontal transfers received strong support. The 1199 introns of Tornabea scutellifera and Phaeorrhiza nimbosa were very closely related whereas their ITS sequences assigned them to different lineages of the Physciaceae (FIG. 7.5). The 1199 introns of Buellia griseovirens and Amandinea cacuminum were found among those of distantly related Physciaceae and the 1199 intron of Australiaena streimannii was closer related to the intron of Diploicia canescens than the latter to the two Diplotomma introns (FIG. 7.8).

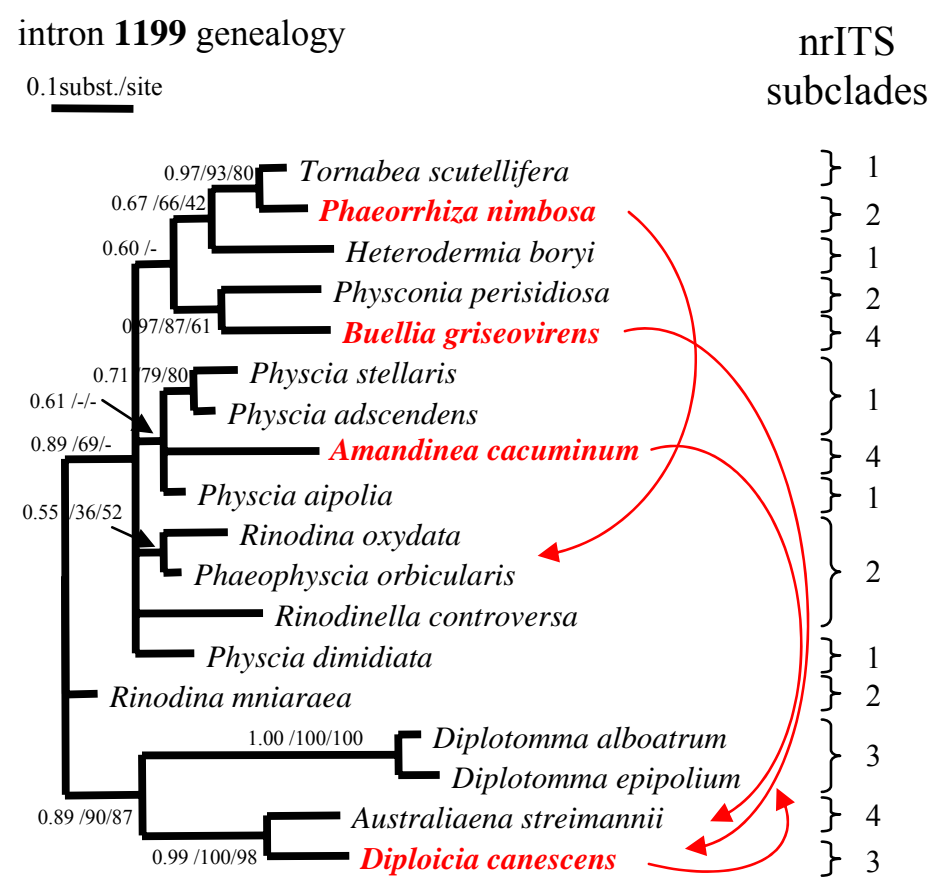

FIG. 7.8: Genealogy of Physciacean nrSSU group I introns inserted at E. coli positions 1199. Red colored taxa assume a significantly different position than in the ITS phylogeny. The arrows indicate putative horizontal transfers and point to the taxon's respective position in the ITS phylogeny. Numbers on the right side indicate the respective subclades to which the taxa were assigned (chapter 3). The topology is based on Bayesian analysis. First branch support value is obtained in Bayesian analysis, second value in bootstrap analysis (1000 replicates) under the maximum-parsimony optimality criterion and third value in bootstrap analysis (1000 replicates) under the minimum evolution optimality criterion (neighbor-joining analysis employing the Jukes-Cantor model). Topologies are unrooted. 


\subsubsection{Genealogy of introns at $E$. coli insertion site 1516}

Twenty-five 1516 group I introns were sequenced. After removing all positions that contained indels, the alignment was 134 positions long and comprised 91 variable and 74 parsimony-informative sites. The overall topology reflected the ITS phylogeny but at least six instances of horizontal transmission of group I introns could be assumed. The 1516 intron of Tornabea scutellifera was closer related to the intron of Physcia aipolia than the introns of Physcia adscendens and Rinodina atrocinerea. The 1516 introns of Physcia undulata and Heterodermia boryi were closely related and separated from the rest of the subclade I taxa (FIG. 7.5). Introns of Physcia alba, Rinodina oxydata and Hyperphyscia adglutinata were found among introns of the subclade 4 (FIG. 7.9).

intron 1516 genealogy

0.1 subst./site
nrITS

subclades

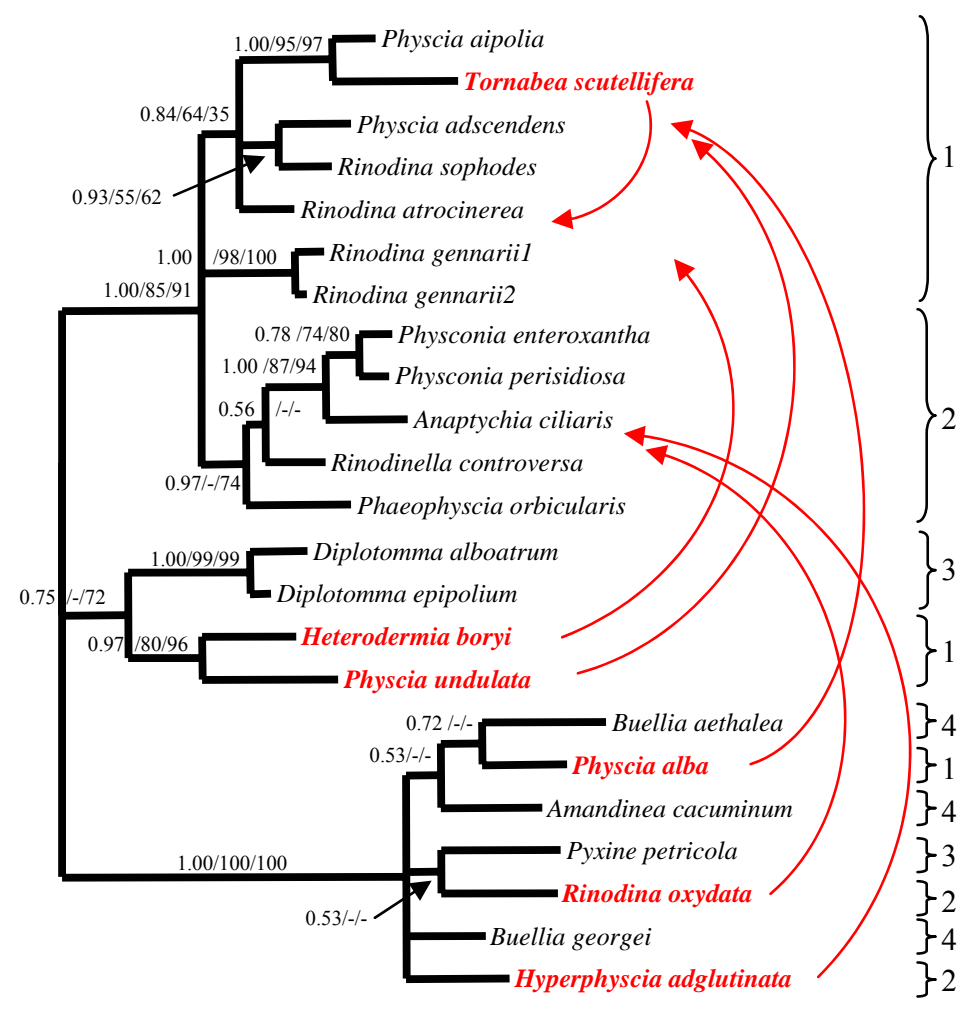

FIG. 7.9: Genealogy of Physciacean nrSSU group I introns inserted at E. coli positions 1516. Red colored taxa assume a significantly different position than in the ITS phylogeny. The arrows indicate putative horizontal transfers and point to the taxon's respective position in the ITS phylogeny. Numbers on the right side indicate the respective subclades to which the taxa were assigned (chapter 3). The topology is based on Bayesian analysis. First branch support value is obtained in Bayesian analysis, second value in bootstrap analysis (1000 replicates) under the maximum-parsimony optimality criterion and third value in bootstrap analysis (1000 replicates) under the minimum evolution optimality criterion (neighbor-joining analysis employing the Jukes-Cantor model). Topologies are unrooted. 


\subsection{Discussion}

\subsubsection{Intron abundance}

The Physciaceae were found to be exceptionally rich in nrSSU introns. However, the number of described introns might still be underestimated. In numerous instances where no introns had been detected by sequencing (using exon binding primers only), PCR assays yielded amplicons when using intron binding primers. In circa half of the taxa in which 788 and 1199 introns were not observed in nrSSU sequences, the introns could be detected with intron specific primers. Corresponding observations that point to a heterogeneity in intron absence / presence in rDNA repeats have already been reported by various authors (DePriest 1993, Gargas et al. 1995, Hibbett 1996, Perotto et al. 2000). These authors observed PCR amplicons of different sizes obtained with one primer combination only. The heterogeneity of these amplicons was explained by the optional presence of introns in rDNA repeats. In these cases, the numbers of intron-containing and intron-free rDNA repeats might have been similar as they revealed bands of similar intensity. However, in many instances no side products were recognized that indicated intron presence in the amplified target. Still, the introns could be detected using intron binding primers. This suggests that the tested introns were present only in a minority of the nrDNA repeats (ca. 150 nuclear tandem repeats in Saccharomyces cerevisiae, Nomura 1999). This situation was apparent in two specimens of Rinodina gennarii. Their nrSSU sequences deviated in the presence / absence of four introns (at E. coli positions 114, 516, 788, and 943; TABLE 7.1). Successful amplification with primers that annealed at introns 516 and 788 showed that the introns were present also in the specimen in which the introns were not detected by nrSSU sequencing (TABLE 7.2), although only single bands were observed when amplifying their nrSSU with two exon binding primers. A similar situation might have also been present in the Cladoniaceae as reported by DePriest \& Been (1992).

The absence of introns in amplicons obtained with two exon binding primers may be explained with a differential amplification of intron-less targets. Shorter fragments are amplified more efficiently than longer fragments. Further, PCR byproducts of low concentrations as might have been produced in cases where only few nrSSU repeats contained introns, might have gone undetected. Background noise in sequences obtained from crude PCR products is quite common and may reach intensities greater than $10 \%$ of the proper signal. Therefore, it is doubted that strongly underrepresented introns are reliably detected by rDNA sequencing. From the different intensities of intron-containing amplicons obtained from samples that were apparently heterogeneous with respect to the presence / absence of rDNA introns, it is concluded that the fraction of intron-containing rDNA repeats is variable. Notably, loss or gain of introns at different insertion sites appeared unlinked, as observed in the example of Rinodina gennarii (TABLE 7.1). Instability of intron 
presence might lead to complete intron loss and corresponds well with the irregular pattern of intron spread in organismic phylogenies.

Testing the presence of the 1199 intron provided an interesting instance where intron-internal amplicons were obtained and simultaneously no amplicons could be generated using intron - exon primer combinations. This suggests that the intron might have been present in another location than the 1199 insertion site. Indeed, the 287 intron is closely related to the 1199 intron (Bhattacharya et al. 2002) and might also serve as template for the two 1199 intron binding primers. However, only in one instance of the 22 specimens tested had the 287 intron been sequenced. Since the presence of the 287 intron was not tested more rigorously, the suspicion that the 1199 intron might reside in loci other than the nrSSU genes remains to be proven.

Mechanisms of reverse splicing that can account for intron acquisition and intron loss have received thorough experimental support (Dujon 1989, Lambowitz \& Belfort 1993, Roman \& Woodson 1998, Yang et al. 1996, Dickson et al. 2001). In addition to the dynamics that emerge from the intron inherent catalytic activity, mechanisms described for the phenomena of gene conversion (Li 1997) might contribute to a dynamic turn over of nrDNA introns. Intron fluctuation in nrDNA might be closely correlated with the phenomenon of concerted evolution of multi-copy genes, such as the ribosomal RNA genes. Therefore studying the dynamics of rDNA intron fluctuation in the Physciaceae might be of general interest also with respect to the subject of gene conversion, a ubiquitous and not yet fully understood phenomenon.

\subsubsection{Horizontal transfers}

In a more general study on the vertical evolution and intragenic spread of rDNA group I introns, it has been shown that major lineages of group I introns appear to be vertically inherited (Bhattacharya et al. 2002). A closer look at Physciacean group I intron genealogies, however, revealed considerable incongruencies with the previously established nrITS phylogeny of this ascomycete family. Numerous instances were detected where nrITS phylogeny and intron genealogy were incongruent, suggesting instances of such horizontal transfers (Thell 1999, FIGS. 7.5 - 7.9). Genealogies of introns 287, 788, 1199, and 1516 all comprised branches that were incongruent with the ITS phylogeny. As shown in chapter 3, the ITS phylogeny receives strong support also from phenotypic characters and fits overall genus concepts. Therefore, it is assumed that deviating topologies in the intron genealogies originate from horizontal transfers of introns. Not only are these introns transferred within the Physciaceae, but also among a wider taxonomic range. Bhattacharya et al. (2002) showed the 1516 introns of Buellia georgei and Amandinea cacuminum (formerly Rinodina cacuminum) to be more closely related to introns of Lecanora and Cladonia species than to those of other Physciaceae species. This finding suggests that this lineage of the 1516 intron might not have evolved within 
the Physciaceae, but invaded multiple Physciaceae taxa independently. This interpretation is supported by the long and highly supported branch leading to the group that includes Buellia georgei and Amandinea cacuminum as well as Buellia aethalea, Physcia alba, Pyxine petricola, Rinodina oxydata, and Hyperphyscia adglutinata. Although these taxa are separated by long branches in the ITS phylogeny, suggesting long periods of evolutionary time had passed since their divergence, the introns could not be resolved with significant support in these analyses and branch lengths within this intron lineage were short. Therefore, all members of this lineage might have obtained their 1516 introns through independent horizontal transfers. A second instance where an intron of a non-Physciacean taxon was found among Physciacean introns was the 1199 intron of Cladonia merochlorophaea (Bhattacharya et al. 2002). These observations suggest that introns may be dispersed across large taxonomic distances. These transfers might be mediated by viruses. The mechanism of self-splicing requires only short recognition motives of four to six nucleotides for excision and insertion (Roman et al. 1999). Therefore, statistically there are numerous protosplice sites even in small genomes such as viruses that could serve as vectors (Yamada et al. 1994, Bhattacharya et al. 1996, Nishida et al. 1998). Concentric bodies known from lichen-forming ascomycetes are suspected to represent dormant stages of viruses (Ahmadjian 1993). The possibility of virus-mediated intron transfer in green algae has already been discussed by Bhattacharya et al. (1996). Here a close relationship of introns detected in green algal viruses and Trebouxia could be shown. Notably, no nrDNA introns were detected that could be suspected of being transferred between lichen fungi and lichen algae (Bhattacharya et al. 2002).

Considerable parts of the intron trees also resembled the ITS phylogeny, suggesting long periods of vertical transmission as well. In another ascomycete group, the genus Cordyceps, vertical transmission appeared to be the typical case (Nikoh \& Fukatsu 2001). In none of the taxa where a recent acquisition of an intron was suspected was the intron enclosed by aberrant flanking regions as is often observed in the case of homing endonuclease-mediated intron transfers (Cho et al. 1998). The lack of co-converted flanking regions supports the assumption that horizontal transfer was not mediated by a homing endonuclease but by reverse splicing. However, the evidence for this assumption might be weak, since introns are typically inserted in highly conserved regions that might be identical in donor and recipient organism. The observation of an intron with ORFs, the 1199 intron in Physcia dimidiata, is not considered a typical case. If ORFs would have been present in the other Physciacean group I introns at the time of transmission, it may have taken long evolutionary time to remove them from the introns (Goddard \& Burt 1999), and therefore a larger number of degenerated ORFs should have been observed in the multitude of introns found, especially in the recently acquired 1516 introns, such as those of the taxa constituting the lower branch in FIG. 7.9. 


\section{Literature cited}

Ahmadjian V. 1962. Investigation on Lichen Synthesis. Amer. J. Bot. 49: 277 - 283.

Ahmadjian V. 1982. Algal / fungal symbiosis. Progress in Phycological Research 1: 181 - 233.

Ahmadjian V. 1987. Coevolution in lichens. Annals of the New York Academy of Sciences 503: 307 - 315.

Ahmadjian V. 1988. The lichen alga Trebouxia: does it occur free - living? Plant Systematics and Evolution 158: $243-247$.

Ahmadjian V. 1993. The lichen photobiont - what can it tell us about lichen systematics?. The Bryologist 96: $310-313$.

Ahmadjian V. 1993. The lichen symbiosis. John Wiley \& Sons, Inc., New York. 250 pp.

Ahmadjian V. 1995. Lichens - Specialized Groups of Parasitic Fungi. In: Kohmoto K., Singh U.S., Singh RP. (eds): Pathogenesis and Host selectivity in plant diseases. Vol. II Eukaryotes

Ahmadjian V, Henriksson E. 1959. Parasitic relationship between two culturally isolated and unrelated lichen components. Science 130: 1251.

Ahmadjian V, Jacobs JB. 1981. Relationship between fungus and alga in the lichen Cladonia cristatella Tuck. Nature 289: 169 - 172.

Ahmadjian V, Jacobs JB. 1983. Algal - fungal relationships in lichens: recognition, synthesis, and development. In: Goff LJ (ed.): Algal Symbiosis. Cambridge University Press, Cambridge, pp. 147 - 172.

Akaike H. 1974. A new look at the statistical model identification. IEEE Trans. Autom. Contr. 19: $716-723$.

Alfaro ME, Zoller S, Lutzoni F. 2003. Bayes or Bootstrap? A Simulation Study Comparing the Performance of Bayesian Markov Chain Monte Carlo Sampling and Bootstrapping in Assessing Phylogenetic Confidence. Mol. Biol. Evol. 20:255 - 266.

Archibald PA. 1975. Trebouxia de Puymaly (Chlorophyceae, Chlorococcales) and Pseudotrebouxia gen. nov. (Chlorophyceae, Chlorosarcinales). Phycologia 14: 125 - 137.

Awasthi DD. 1975. A monograph of the lichen genus Dirinaria. Bibl. Lichenol. 2: $1-108$.

Baalen van M, Kriivan V, van Rijn PCJ, Sabelis MW. 2001. Alternative Food, Switching Predators, and the Persistence of Predator - Prey Systems. Am. Nat. 157: 13 pp.

Bačkor M, Váczi P. (2002). Copper tolerance in the lichen photobiont Trebouxia erici (Chlorophyta). Environmental and Experimental Botany 48: 11 - 20.

Barrett JA. 1983. Plant - Fungus Symbioses. In Futuyma DJ and Slatkin M (eds.): Coevolution. Sinauer Associations Inc. Sunderland, Massachusetts.

Barrett JA. 1986. Host - parasite interactions and systematics. In: Coevolution and Systematics (eds. Stone AR \& Hawksworth DL) The Systematics Association, Clarendon Press, Oxford.

Beck A. 1999. Photobiont inventory of a lichen community growing on heavy-metal-rich rock. Lichenologist 31: $501-510$.

Beck A. 2002. Selektivität der Symbionten schwermetalltoleranter Flechten. Dissertation, Ludwig Maximilians - Universität München.

Beck A, Friedl T, Rambold G. 1998. Selectivity of photobiont choice in a defined lichen community: inferences from cultural and molecular studies. New Phytologist 139: 709 - 720.

Beck A, Kasalicky T, Rambold G. 2002. Myco - photobiontal selection in a Mediterranean cryptogam community with Fulgensia fulgida. New Phytologist 153: 317 - 326.

Beekley PK, Hoffman GR. 1981. Effects of sulfur dioxide fumigation on photosynthesis, respiration, and chlorophyll content of selected lichens. The Bryologist 84: 379 - 390.

Begon M, Harper JL, Townsend C. 1996. Ecology. Blackwell, Oxford.

Belfort M, Perlman PS. 1995. Mechanisms of intron mobility. J. Biol. Chem. 270: 30237 - 30240.

Bellemère A, Letrouit - Galinou M-A. 1987. Differentiation of lichen asci including dehiscence and sporogenesis: an ultrastructural survey. In: E. Peveling (ed.): Progress and Problems in Lichenology in the eighties. Bibl. Lichenol. 25: 137 - 161.

Bhattacharya D, Friedl T, Damberger S. 1996. Nuclear - encoded rDNA group I introns: origin and phylogenetic relationships of insertion site lineages in the green algae. Mol Biol Evol. 13: 978 - 989.

Bhattacharya D, Friedl T, Helms G. 2002.Vertical Evolution and Intragenic Spread of Lichen - Fungal Group I Introns. J. Mol. Evol. 55: 74 - 84. 
Bhattacharya D, Lutzoni F, Reeb V, Simon D, Nason J, Fernandez F. 2000. Widespread occurrence of spliceosomal introns in the rDNA genes of ascomycetes. Mol Biol Evol. 17:1971 - 84.

Bhattacharya D, Medlin LK 1995. The phylogeny of plastids: A review based on comparisons of small subunit ribosomal RNA coding regions. J. Phycol. 31: 489 - 498.

Bidartondo MI, Bruns TD. 2002. Fine - level mycorrhizal selectivity in the Monotropoideae (Ericaceae): selectivity for fungal species groups. Molecular Ecology 11: 557 - 569.

Bowler PA, Rundel PW. 1975. Reproductive strategies in lichens. Bot. J. Linn. Soc. 70: 325 - 340.

Brodo IM, Sharnoff SD, Sharnoff S. 2001. The lichens of North America. Published by Yale University Press.

Bubrick P, Frensdorff A, Galun M. 1985. Selectivity in the lichen symbiosis. In: D. H. Brown (ed.): Lichen Physiology and Cell Biology. Plenum Press, New York and London, pp. 319 - 334.

Bubrick P, Galun M, Frensdorff A. 1984. Observations on free - living Trebouxia DePuymaly and Pseudotrebouxia Archibald, and evidence that both symbionts from Xanthoria parietina (L.) Th. Fr. can be found free - living in nature. New Phytologist 97: 455 - 462.

Buckling A, Rainey PB. 2002. The role of parasites in sympatric and allopatric host diversification. Nature 420: 496 - 498.

Cannone JJ, Subramanian S, Schnare MN, Collett JR, D'Souza LM, Du Y, Feng B, Lin N, Madabusi LV, Muller KM, Pande N, Shang Z, Yu N, Gutell RR. 2002. The Comparative RNA Web (CRW) Site: an online database of comparative sequence and structure information for ribosomal, intron, and other RNAs: Correction. BMC Bioinformatics 31; 15. [http://www.rna.icmb.utexas.edu/].

Cech TR. 1988. Conserved sequences and structures of group I introns: Building an active site for RNA catalysis. Gene 73: 259 - 271.

Cech TR. 1993. The efficiency and versatility of catalytic RNA: implications for an RNA world. Gene 15:33 - 36.

Cech TR, Damberger SH, Gutell RR. 1994. Representation of the secondary and tertiary structure of group I introns. Nat Struct Biol. 1:273 - 80.

Cho Y, Palmer JD. 1999. Multiple acquisitions via horizontal transfer of a group I intron in the mitochondrial coxl gene during evolution of the Araceae family. Mol. Biol. Evol. 16:1155 - 1165.

Cho Y, Qiu YL, Kuhlman P, Palmer JD. 1998. Explosive invasion of plant mitochondria by a group I intron. Proc Natl Acad Sci U S A. 95:14244 - 9.

Clayton DH, Al-Tamimi S, Johnson KP. 2003. The ecological basis of coevolutionary history. In: Tangled Trees: phylogeny, cospeciation and coevolution. Ed. Page RDM.

Cubero OF, Bridge PD, Crespo A. 2000. Terminal - sequence conservation identifies spliceosomal introns in ascomycete 18S RNA genes. Mol Biol Evol. 17:751 - 6.

Dahlkild Å, Källersjö M, Lohtander K, Tehler A. 2001. Photobiont diversity in Physciaceae (Lecanorales). The Bryologist 104: 527 - 536.

Damberger SH, Gutell RR. 1994. A comparative database of group I intron structures. Nucleic Acids Res. 22:3508 - 10.

De Bary A. 1866. Morphologie und Physiologie der Pilze, Flechten und Myxomyceten. In: Handbuch der physiologischen Botanik. Ed. Wilh.Hofmeister. Leipzig: Engelmann, 1866 XII, 316 pp.

De Bary A. 1879. Die Erscheinung der Symbiose. Verlag Karl J. Trübner, Straßburg, 30 pp.

DePriest PT. 1993. Small subunit rDNA variation in a population of lichen fungi due to optional group I introns. Gene 134: 67 - 74.

DePriest PT, Been M. 1992. Numerous group I introns with variable distribution in the ribosomal DNA of a lichen fungus. Journal of Molecular Biology 228: 315 - 321.

Desdevises Y, Morand S, Jousson O, Legendre P. 2002. Coevolution between Lamellodiscus (Monogenea) and Sparidae (Teleostei): the study of a complex host - parasite system. Evolution 56 (12): 2459 - 2471.

Dickson L, Huang H - R, Liu L, Matsuura M, Lambowitz AM, Perlman PS. 2001. Retrotransposition of a yeast group II intron occurs by reverse splicing directly into ectopic DNA sites. PNAS 98: 13207 - 13212.

Douglas AE. 1995. The Ecology of Symbiotic Micro - organisms. Advances in ecological research 26: 60 - 103.

Douglas AE, Smith DC. 1989. Are endosymbioses mutualistic? Trends in Ecology and Evolution, 4, 350 - 352.

Dujon B. 1989. Group I introns as mobile genetic elements: facts and mechanistic speculations - a review. Gene 82:91 - 114.

Eichler W. 1941a. Wirtsspezifität und stammesgeschichtliche Gleichläufigkeit (Fahrenholz Regel) bei Parasiten im Allgemeinen und bei Mallophagen im Besonderen. Zool. Anzeiger 132: 254 - 292. 
Eichler W. 1941b. Korrelation in der Stammesentwicklung von Wirten und Parasiten. Zeitschr. Parasiten 19: 24.

Eichler W. 1948. Some rules in ectoparasitism. Ann. Mag. Nat. Hist. 12: 588 - 598.

Ekman S. 1996. The corticolous and lignicolous species of Bacidia and Bacidina in North America. Opera Botanica 127: 1 - 148.

Eriksson OE, Baral HO, Currah RS, Hansen K, Kurtzman CP, Rambold G, Laesøe T (eds). 2001. Outline of Ascomycota. Myconet 7: 1 - 88.

Eriksson OE, Baral H - O, Currah RS, Hansen K, Kurtzman CP, Rambold G, Laessøe T (eds). 2003. Outline of Ascomycota - 2003. Myconet 9: 1 - 89.

Esslinger TL. 1986. Studies in the lichen family Physciaceae VII. The new genus Physciella. Mycologia 78: $92-97$.

Ettl H, Gärtner G. 1995. Syllabus der Boden - , Luft - und Flechtenalgen. Gustav Fischer Verlag, Stuttgart, 721 pp.

Fahselt D. 1995. Lichen sexuality from the perspective of multiple enzyme forms. Crypt. Bot. 5: 137 - 143.

Fahselt D. 1996. Individuals, populations and population ecology. In: Nash III TH (ed.), Lichen Biology, 303 pp. Cambridge University Press.

Famintzin A, Baranietzky J. 1867. Beitrag zur Entwickelungsgeschichte und der Gonidien und Zoosporenbildung bei Physcia parietina. Vorläufige Mitteilung. Botanische Zeitung 25: 189 - 190.

Felsenstein J. 1985. Confidence limits on phylogenies: an approach using the bootstrap. Evolution 39: 783 - 791.

Frank AB. 1877. Ueber die biologischen Verhältnisse des Thallus einiger Krustenflechten. Beiträge zur Biologie der Pflanzen 2: 123 - 200.

Frey E. 1932. Die Spezifizität der Flechtengonidien. Alte und neue Probleme. Berichte der schweizerischen botanischen Gesellschaft|Ber. Schweiz. Bot. Ges. 41: 180 - 198.

Frey E. 1963. Beiträge zu einer Flechtenflora der Schweiz II. III. Die Familie Physciaceae. Berichte der Schweizerischen Botanischen Gesellschaft 73: 389 - 503.

Friedl T. 1987. Thallus development and phycobionts of the parasitic lichen Diploschistes muscorum. Lichenologist 19: 183 - 191.

Friedl T. 1989a. Comparative ultrastructure of pyrenoids in Trebouxia (Microthamniales, Chlorophyta). Plant Systematics and Evolution 164: 145 - 159.

Friedl T. 1989b. Systematik und Biologie von Trebouxia (Microthamniales, Chlorophyta) als Phycobiont der Parmeliaceae (lichenisierte Ascomyceten). Universität Bayreuth, Bayreuth. 218 pp.

Friedl T. 1993. New aspects of the reproduction by autospores in the lichen alga Trebouxia (Microthamniales, Chlorophyta). Archiv für Protistenkunde 143: 153 - 161.

Friedl T. 1996. Evolution of the polyphyletic genus Pleurastrum (Chlorophyta): inference from nuclear encoded ribosomal DNA sequences and motile cell ultrastructure. Phycologia 35: 456 - 469.

Friedl T, Besendahl A, Pfeiffer P, Bhattacharya D. 2000. The distribution of group I introns in lichen algae suggests that lichenization facilitates intron lateral transfer. Mol. Phylogenet. Evol. 14: 342 - 352.

Friedl T, Rokitta C. 1997. Species relationships in the lichen alga Trebouxia (Chlorophyta, Trebouxiophyceae): molecular phylogenetic analyses of nuclear - encoded large subunit rRNA gene sequences. Symbiosis 23: 125 - 148.

Friedl T, Zeltner C. 1994. Assessing the relationships of some coccoid green lichen algae and the Microthamniales (Chlorophyta) with $18 \mathrm{~S}$ ribosomal RNA gene sequence comparisons. Journal of Phycology 30: 500 - 506.

Futuyma DJ, Slatkin M. 1983. Introduction. In: Futuyma DJ, Slatkin M (eds). Coevolution. Sinauer Assoc. Inc. Sunderland, Massachusetts.

Gargas A, DePriest PT, Grube M, Tehler A. 1995. Multiple origins of lichen symbioses in fungi suggested by nrSSU phylogeny. Science 268(5216): 1492 - 1495.

Gargas A, DePriest PT, Taylor JW. 1995. Positions of multiple insertions in SSU rDNA of lichen - forming fungi. Mol Biol Evol 12: 208 - 218.

Gärtner G. 1985a. Die Gattung Trebouxia Puymaly (Chlorellales, Chlorophyceae). Archiv für Hydrobiologie, Supplement. Algological Studies 41: 495 - 548.

Gärtner G. 1985b. Taxonomische Probleme bei den Flechtenalgengattungen Trebouxia und Pseudotrebouxia (Chlorophyceae, Chlorellales). Phyton (Austria) 25: 101 - 111.

Garty J, Delarea J. 1988. Evidence of liberation of lichen ascospores in clusters and reports on contact between freeliving algal cells and germinating lichen ascospores under natural conditions. Can. J. Bot. 66: $2171-7$. 
Gauslaa Y, Kopperud C, Solhaug KA. 1996. Optimal quantum yield of photosystem II and chlorophyll degradation of Lobaria pulmonaria in relation to $\mathrm{pH}$. Lichenologist 28: 267 - 278.

Gilbert W. 1978. Why genes in pieces? Nature 271: 501.

Giralt M. 2001. The lichen genera Rinodina and Rinodinella (lichenized Ascomycetes, Physciaceae) in the Iberian Peninsula. Biblioth. Lich. 79: 1 - 160.

Giralt M, Etayo J, Boom v.d. P. 2002. Buellia laurocanariensis, a new species from Canary Islands. Lichenologist 34: 203 - 206.

Goddard MR and Burt A. 1999. Recurrent invasion and extinction of a selfish gene. PNAS 23: 13880 - 13885.

Greuter WJ, McNeill FR, Barrie HM, Burdet V, Demoulin TS, Filgueiras DH, Nicolson PC, Silva JE, Skog P, Trehane NJ, Turland DL, Hawksworth DL (eds). 1999. International Code of Botanical Nomenclature (Saint Louis Code) adopted by the Sixteenth International Botanical Congress St Louis Missouri July - August 1999 [http://www.gbm.rg/iapt/nomenclature/code/default.tm].

Grube M, Arup U. 2001. Molecular and morphological evolution in the Physciaceae (Lecanorales, lichenized Ascomycetes), with special emphasis on the genus Rinodina. Lichenologist 33: 63 - 72.

Grube M, Kroken S. 2000. Molecular approaches and the concept of species and species complexes in lichenized fungi. Mycol. Res. 104: 1284 - 1294.

Hafellner J. 1984. Studien in Richtung einer natürlicheren Gliederung der Sammelfamilien Lecanoraceae und Lecideaceae. In: Hertel H, Oberwinkler F (eds.) Festschrift J. Poelt. Beiheft zur Nova Hedwigia 79: $241-372$.

Hafellner J, Mayrhofer H, Poelt J. 1979. Die Gattungen der Flechtenfamilie Physciaceae. Herzogia 5: 39 - 79.

Hafner MS, Nadler SA. 1988. Phylogenetic trees support the coevolution of parasites and their hosts. Nature, $332,258-259$.

Hale ME, Vobis G. 1978. Santessonia, a new lichen genus from South West Africa. Botanisca Notiser 131:1 - 5.

Hall TA. 1999. BioEdit: a user - friendly biological sequence alignment editor and analysis program for Windows 95/98/NT. Nucl. Acids. Symp. Ser. 41: 95 - 98. [http://www.bio.csu.du/BioEdit/bioedit.tml].

Hansen K, Læssøe T, Pfister D. 2001. Phylogenetics of the Pezizaceae, with an emphasis on Peziza. Mycologia 93: 958 - 990.

Hawksworth DL. 1994. The recent evolution of lichenology: a science for our times. Crypt. Bot., 4: 117 - 129.

Hawksworth DL.1988: Coevolution of Fungi with Algae and Cyanobacteria in lichen symbioses. In: Pirozynski, KA/Hawksworth, DL (eds.): Coevolution of Fungi with Plants and Animals. Academic Press, London, San Diego, pp. 125 - 148.

Hawksworth DL, Honegger R. 1994. The lichen thallus: a symbiotic phenotype of nutritionally specialized fungi and its response to gall producers. In: Williams M.A.J. (ed.) Plant Galls. Systematics Association Special Volume No. 49 pp. 77 - 98; Claredon Press Oxford

Helms G, Friedl T, Rambold G, Mayrhofer H. 2001. Identification of photobionts from the lichen family Physciaceae using algal - specific nrITS sequencing. Lichenologist 33: 73 - 86.

Helms G, Friedl T, Rambold G. 2003. Phylogenetic Relationships of the Physciaceae inferred from rDNA sequence data and selected phenotypic Characters. Mycologia 95(6) (in press).

Helms G, Hauck M, Friedl F. submitted. Photobiont selectivity in the epiphytic lichens Hypogymnia physodes and Lecanora conizaeoides. Plant Biology. submitted.

Henssen A, Jahns HM. 1974. Lichenes - Eine Einführung in die Flechtenkunde. Thieme Verlag, Stuttgart.

Hepperle D. 2000. Multicolor Sequence Alignment Editor. [http://domix0.tripod.com].

Herre EA, Knowlton N, Mueller UG, Rehner SA. 1999. The evolution of mutualisms: exploring the paths between conflict and cooperation. Tree 14: 49 - 53.

Hibbett DS. 1996. Phylogenetic Evidence for Horizontal Transmission of Group I Introns in the Nuclear Ribosomal DNA of Mushroom - Forming Fungi. Mol. Biol. Evol. I3:903 - 917.

Hildreth KC, Ahmadjian V. 1981. A study of Trebouxia and Pseudotrebouxia isolates from different lichens. Lichenologist 13: 65 - 86.

Hill DJ. 1994. The nature of the symbiotic relationship in lichens. Endeavour 18: 96 - 103.

Hillis DM, Bull JJ 1993. An empirical test of bootstrapping as a method for assessing the confidence in phylogenetic analysis. Syst. Biol. 42:182 - 192.

Hochberg ME, Gomulkiewicz R, Holt RD, Thompson JN. 2000. Weak sinks could cradle mutualistic symbioses - strong sources should harbor parasitic symbioses. J. Evol. Biol. 13: 213 - 222. 
Holst-Jensen A, Vaage M, Schumacher T, Johansen S. 1999. Structural characteristics and possible horizontal transfer of group I introns between closely related plant pathogenic fungi. Molecular Biology and Evolution 16: 114 - 126.

Honegger R. 1978. The ascus apex in lichenized fungi I. The Lecanora - , Peltigera - and Teloschistes types. Lichenologist 10: 47 - 67.

Honegger R. 1982. Ascus structure and function, ascospore delimitation, and phycobiont cell wall types associated with the Lecanorales (Lichenized Ascomycetes). J. Hattori Bot. Lab. 52: 417 - 429.

Honegger R. 1991. Fungal evolution: Symbiosis and Morphogenesis. In: Margulis L., Fester R. (eds) Symbiosis as a source of evolutionary innovation. The MIT Press, Cambridge, Massachusetts, London, pp. 320 - 340.

Honegger R. 1993. Developmental biology of lichens. New Phytologist 125: 659 - 677.

Honegger R. 1996. Morphogenesis. In: Nash TH (ed.). Lichen Biology. Cambridge University Press.

Honegger R. 1998. The lichen symbiosis - what is so spectacular about it?. Lichenologist 30: 193 - 212.

Huelsenbeck J, Ronquist F. 2001. MRBAYES: Bayesian inference of phylogeny. Bioinformatics 17:754 - 755.

Jahns HM. 1988. The lichen thallus. In: M. Galun (ed.): CRC Handbook of Lichenology. Volume I. CRC Press, Inc., Boca Raton, pp. 95 - 143.

Janzen DH. 1985. The natural history of mutualism. In: Boucher DH (ed.): The Biology of Mutualism. Croom Helm, London \& Sydney.

Johansen S, Muscarella DE, Vogt VM. (1996). "Insertion elements in ribosomal DNA", Chapter 5 (pp 89 108) in Zimmermann RA and Dahlberg AE (eds): Ribosomal RNA: Structure, Evolution, Gene Expression, and Function in Protein Synthesis. CRC Press.

Jordan F. 2001. Strong threads and weak chains? - a graph theoretical estimation of the power of indirect effects. Community Ecology 2: 17 - 20.

Kalb K. 1987. Brasilianische Flechten 1: Die Gattung Pyxine. Bibl. Lichenol. 24:1 - 89.

Kappen L. 1994. The lichen, a mutualistic system - some mainly ecophysiological aspects. Crypt. Bot. 4: 193 - 202.

Kashiwadani H. 1975. The Genera Physcia, Physconia, and Dirinaria (Lichens) of Japan. Ginkgoana 3: 1 - 77.

Kishino H, Hasegawa M. 1989. Evaluation of maximum likelihood estimate of the evolutionary tree topologies from DNA sequence data, and the branching order of the Hominoideae. J. Mol. Evol. 29: $170-179$.

Kroken S, Taylor JW. 2000: Phylogenetic species, reproductive mode, and specificity of Trebouxia forming lichens with the fungal genus Letharia. The Bryologist 103: 645 - 660.

Kumar S, Tamura K, Jakobsen IB, Nei M. 2001. MEGA2: Molecular Evolutionary Genetics Analysis software, Arizona State University, Tempe, Arizona, USA. [http://www.megasoftware.net/].

Kurokawa S. 1973. Supplementary notes on the genus Anaptychia. J. Hattori Bot. Lab. 37: 563 - 607.

Lambowitz AM, Belfort M. 1993. Introns as mobile genetic elements. Annu Rev Biochem. 62:587 - 622.

Lambowitz AM, Perlman PS. 1990. Involvement of aminoacyl - tRNA synthetases and other proteins in group I and group II intron splicing. Trends Biochem. Sci., 15: 440 - 444.

Larget B, Simon DL. 1999. Markov Chain Monte Carlo algorithms for the Bayesian analysis of phylogenetic trees. Mol. Biol. Evol. 16:750 - 759.

Law R, Lewis DH. 1983. Biotic environments and the maintenance of sex - some evidence from mutualistic symbioses. Biol. J. Lin. Soc. 20: 249 - 276.

Levra-Juillet E, Boulet A, Seraphin B, Simon M, Faye G. 1989. Mitochondrial introns aI1 and/or aI2 are needed for the in vivo deletion of intervening sequences. Mol. Gen. Genet 217: 168 - 171.

Lewin RA. 1995. Symbiotic algae: definitions, quantification and evolution. Symbiosis 19: 31 - 51.

Lewis DH. 1985. Symbiosis and Mutualism: Crisp Concepts and soggy semantics. In The biology of mutualism: ecology and evolution (ed. D. H. Boucher), pp. 29 - 39. London: Croom Helm.

Li H - W. 1997. Molecular Evolution. Sinauer Associates, Inc.

Lohtander K, Kallersjö M, Moberg R, Tehler A. 2000. The family Physciaceae in Fennoscandia: phylogeny inferred from ITS sequences. Mycologia 92: 728 - 735.

Loizos N, Tillier ERM, Belfort M. 1994. Evolution of Mobile Group I Introns: Recognition of Intron Sequences by an Intron - Encoded Endonuclease. Proc. Natl. Acad. Sci. USA. 91: 11983 - 11987.

Lumbsch HT, Schmitt I, Döring H, Wedin M. 2001. ITS sequence data suggest variability of ascus types and support ontogenetic characters as phylogenetic discriminators in the Agyriales (Ascomycota). Mycol. Res. 105: 265 - 274. 
Lutzoni F, Pagel M, Reeb V. 2001. Major fungal lineages are derived from lichen symbiotic ancestors. Nature 411: 937 - 940.

Lutzoni FM, Pagel M. 1997. Accelerated evolution as a consequence of transitions to mutualism. Proceedings of the National Academy of Sciences, USA 94: 11422 - 11427.

Lykke - Andersen J, Aagaard C, Semionenkov M, Garrett A. 1997. Archaela introns: splicing, intercelular mobility and evolution. TIBS 22: 326 - 331.

Lyons - Weiler J, Hoelzer GA, Tausch RJ. 1996. Relative apparent synapomorphy analysis (RASA) I: The statistical measurement of phylogenetic signal. Mol. Biol. Evol. 13: 749 - 757.

Marbach B. 2000. Corticole und lignicole Arten der Flechtengattung Buellia sensu lato in den Subtropen und Tropen. Biblioth. Lich. 74: 1 - 384.

Marti J. 1985. Die Toxizität von Zink, Schwefel - und Stickstoffverbindugen auf Flechten - Symbionten. Biblioth. Lichenol. 21: 1 - 129.

Mattick JS. 1994. Introns: evolution and function. Curr Opin Genet Dev 4:823 - 31.

Mattsson J - E, Wedin M. 1999. A re - assessment of the family Alectoriaceae. Lichenologist 31: 431 - 440.

Matzer M, Mayrhofer H, Elix JA. 1997. Australiaena streimannii, a new genus and species in the Physciaceae from tropical Australasia. Lichenologist 29: 35 - 44.

Matzer M, Mayrhofer H, Scheidegger C. 1994. Notes on Amandinea petermannii comb. nov. (Physciaceae) from Antarctica. Lichenologist 26: 39 - 46.

Matzer M, Mayrhofer H. 1996. Saxicolous species of the genus Rinodina (lichenized Ascomycetes, Physciaceae) in southern Africa. Bothalia 26: 11 - 30.

Mayrhofer H. 1982. Ascosporen und die Evolution der Flechtenfamilie Physciaceae. J. Hattori Bot. Lab. 52: $313-321$.

Mayrhofer H. 1984. Die saxicolen Arten der Flechtengattung Rinodina und Rinodinella in der Alten Welt. Journ. Hattori Bot. Lab. 55: 327 - 493.

Mayrhofer H, Poelt J. 1978a. Phaeorrhiza, eine neue Gattung der Physciaceae (Lichenes). Nova Hedwigia 30: $781-798$.

Mayrhofer H, Poelt J. 1978b. Rinodinella - eine neue Gattung der Flechtenfamilie Physciaceae. Hoppea 37: $89-105$.

Mayrhofer H, Sheard JW, Matzer M. 1992. Mobergia (Physciaceae, Lichenized Ascomycetes), a new genus endemic to Western North America. The Bryologist 95: 439 - 442.

Mayrhofer H, Sheard JW. 2002. Amandinea cacuminum: a new combination (Physciaceae, lichenized Ascomycetes). Mycotaxon 82: 437 - 441.

Merlos - Lange AM, Kanbay F, Zimmer M, Wolf K. 1987. DNA splicing of mitochondrial group I and II introns in Schizosaccharomyces pompe. Mol. Gen. Genet. 206: 273 - 278.

Mitter C, Brooks DR. 1983. Phylogenetic aspects of coevolution. In: Futuyma DJ and Slatkin M (eds.): Coevolution. Sinauer Associations Inc. Sunderland, Massachusetts.

Moberg R. 1977. The lichen genus Physcia and allied genera in Fennoscandia. Acta Univ. Ups. Symb. Bot. Ups. 22: $1-108$.

Moberg R. 1987. The Genera Hyperphyscia and Physconia in East Africa. Nord. J. Bot. 7: 719 - 728.

Moberg R, Nash TH. 1999. The genus Heterodermia in the Sonoran desert area. The Bryologist 102: 1 - 14.

Moberg R, Purvis W. 1997. Studies on lichens of the Azores. Part 4. The genus Heterodermia. Acta Univ. Ups. Symb. Bot. Ups. 32: 187 - 194.

Molina MC, Crespo A, Blanco O, Hladun N, Hawksworth DL. 2002. Molecular phylogeny and status of Diploicia and Diplotomma, with observations on Diploicia subcanescens and Diplotomma rivas martinezii. Lichenologist 34: 509 - 519.

Mukhtar A, Garty J, Galun M. 1994. Does the lichen alga Trebouxia occur free-living in nature: further immunological evidence. Symbiosis 17(2 - 3): 247 - 253.

Nägeli C. 1849. Gattungen einzelliger Algen, physiologisch und systematisch bearbeitet. 139 pp., Schultheß, Zürich.

Nash III TH. 1996. Introduction. In: Nash III TH (ed.), Lichen Biology, 303 pp. Cambridge University Press.

Nikoh N, Fukatsu T. 2000. Interkingdom host jumping underground: phylogenetic analysis of entomoparasitic fungi of the genus Cordyceps. Mol. Biol. Evol. 17: 629 - 38.

Nikoh N, Fukatsu T. 2001. Evolutionary Dynamics of Multiple Group I Introns in Nuclear Ribosomal RNA Genes of Endoparasitic Fungi of the Genus Cordyceps. Mol. Biol. Evol. 18: 1631 - 1642. 
Nimis PL, Tretiach M. 1997. A revision of Tornabea, a genus of fruticose lichens new to North America. The Bryologist 100: 217 - 225.

Nishida H, Sugiyama J. 1995. A Common Group I Intron between a Plant Parasitic Fungus and Its Host. Mol. Biol. Evol. 12:883 - 886.

Nishida K, Suzuki S, Kimura Y, Nomura N, Fujie M, Yamada T. 1998. Group I introns found in Chlorella viruses: biological implications. Virology. 242:319 - 26.

Niu Y - C, Wei J - C. 1993. Variations in ITS2 sequences of nuclear rDNA from two Lasallia species and their systematic significance. Mycosystema 6: 25 - 29.

Nomura M.1999. Regulation of Ribosome Biosynthesis in Escherichia coli and Saccharomyces cerevisiae: Diversity and Common Principles. Journal of Bacteriology 181: 6857 - 6864.

Nordin A. 1996. Buellia species (Physciaceae) with pluriseptate spores in Norden. Acta Univ. Ups. Symb. Bot. Ups. 31: $327-354$.

Nordin A. 1997. Ascospore characters in Physciaceae: an ultrastructural study. Acta Univ. Ups. Symb. Bot. Ups. 32: 195 - 208.

Nordin A. 1999. Buellia species with pluriseptate spores: new and unrecorded species in North America. The Bryologist 102: 249 - 264.

Nordin A. 2000. Taxonomy and phylogeny of Buellia species with pluriseptate spores (Lecanorales, Ascomycotina). Acta Univ. Ups. Symb. Bot. Ups. 33: 1 - 117.

Nordin A, Mattsson J - E. 2001. Phylogenetic reconstruction of characteristic development in Physciaceae. Lichenologist 33: 3 - 23.

Ott S. 1987. Reproductive strategies in lichens. In: E. Peveling (ed.): Progress and Problems in Lichenology in the Eighties. Bibliotheca Lichenologica No. 25. J. Cramer, Berlin - Stuttgart, pp. 81 - 93.

Page RDM (ed.). 2003. Tangled trees: phylogeny, cospeciation and coevolution. 378 pp.

Page RDM. 1995. Parallel phylogenies: reconstructing the history of host - parasite assemblages. Cladistics $10,155-173$.

Page RDM. 1996. TREEVIEW: An application to display phylogenetic trees on personal computers. Computer Applications in the Biosciences 12: 357 - 358.

Page RDM and Charleston MA. 1998. Trees within trees: Phylogeny and historical associations. Trends in Ecology and Evolution 13:356 - 359.

Palmer JD, Adams KL, Cho Y, Parkinson CL, Qiu Y - L, Song K. 2000. Colloquium. Dynamic evolution of plant mitochondrial genomes: Mobile genes and introns and highly variable mutation rates Proc. Natl. Acad. Sci. USA. 97: 6960 - 6966.

Palmqvist K, Samuelsson G, Badger MR. 1994. Photobiont - related differences in carbon acquisition among green - algal lichens. Planta 195: 70 - 79.

Paterson AM, Banks J. 2001. Analytical approaches to measuring cospeciation of host and parasites: through a glass, darkly. Int. J. Parasitol., 31, 1012 - 1022.

Paulsrud P. 2001. The Nostoc Symbiont of Lichens. Diversity, Specificity, and Cellular Modifications. Acta Universitatis Upsaliensis, Uppsala.

Perotto S, Nepote - Fus P, Saletta L, Bandi C, and. Young JPW. 2000. A Diverse Population of Introns in the Nuclear Ribosomal Genes of Ericoid Mycorrhizal Fungi Includes Elements with Sequence Similarity to Endonuclease - Coding Genes. Mol. Biol. Evol., 17: 44 - 59.

Peveling E. 1988. Beziehungen zwischen den Symbiosepartnern in Flechten. Naturwissensch. 75: 77 - 86.

Piercey - Normore MD, DePriest PT. 2001. Algal switching among lichen symbioses. Am. J. Bot. 88: 1490 - 1498.

Poelt J. 1965. Zur Systematik der Flechtenfamilie Physciaceae. Nova Hedwigia 9: 21 - 32.

Poelt J. 1973. Classification. In: Ahmadjian V, Hale M (eds.): The Lichens: 599 - 632. New York: Academic Press.

Posada D, Crandall KA. 1998. MODELTEST: testing the model of DNA substitution. Bioinformatics 14: $817-818$.

Purvis WO, Coppins BJ, Hawksworth DL, James WP, Moore MD (eds). 1992. The Lichen Flora of Great Britain and Ireland. The Natural History Museum, London.

Puymaly A. 1924. Recherches sur les algues vertes aeriénnes. Thès. Fac. Sci. Univ. de Paris, Ser. A No. 991, 274 pp., Bordeaux.

Rambold G. 1995. Observation on hyphal, ascus and ascospore wall characters in Lecanorales s. 1. Crypt. Bot 5: $111-119$.

Rambold G, Friedl T, Beck A. 1998. Photobionts in lichens: possible indicators of phylogenetic 
relationships? The Bryologist 101: 392 - 397.

Rambold G, Hagedorn G. 1998. The distribution of selected diagnostic characters in the Lecanorales. Lichenologist 30: 473 - 487.

Rambold G, Mayrhofer H, Matzer M. 1994. On the ascus types in the Physciaceae (Lecanorales). Pl. Syst. Evol. 192: 31 - 40.

Rambold G, Meier C, Thamerus M. 1998. A comparative study on structure and functionality of asci in species of Rhizocarpon (Lecanorales, Ascomycetes). Cryptogamie, Bryol. Lichénol. 19: 247 - 255.

Rambold G, Triebel D. 1992. The Inter - lecanoralean Associations. Biblioth. Lich. 48: 1 - 201.

Rambold G, Triebel D. 1995 - 2002. Genera of lichenized and lichenicolous ascomycetes. In: LIAS: a global information system for lichenized and non - lichenized ascomycetes. Botanische Staatssammlung München. [http://www.lias.net/forms/genera/index.html].

Richardson DHS, Smith DC, Lewis DH. 1967. Carbohydrate movement between the symbionts of lichens. Nature 214: 879 - 882.

Rodríguez F, Oliver JF, Marín A, Medina JR. 1990. The general stochastic model of nucleotide substitution. J. Theor. Biol. 142: 485 - 501.

Roman J, Rubin MN, Woodson SA. 1998. Sequence specificity of in vivo reverse splicing of the Tetrahymena group I intron. RNA 5: 1 - 13.

Roman J, Woodson SA. 1998. Integration of the Tetrahymena group I intron into bacterial rRNA by reverse splicing in vivo. Proc. Natl. Acad. Sci. USA 95: 2134 - 2139.

Romeike J, Friedl T, Helms G, Ott S. 2002. Genetic diversity of algal and fungal partners in four species of Umbilicaria (lichenized ascomycetes) along a transect of the Antarctic Peninsula. Mol. Biol. Evol. 19: 1209 - 1217.

Ronquist F. 1997. Phylogenetic approaches in coevolution and biogeography. Zoologica Scripta 26: 313 - 322.

Rosen DE. 1978. Vicariant patterns and historical explanation in biogeography. Systematic Zoology 27: 159 - 188.

Roughgarden J. 1983. The Theory of Coevolution / Coevolution between Competitors. In: Futuyma DJ, Slatkin M (eds). Coevolution. Sinauer Assoc. Inc. Sunderland, Massachusetts.

Saffo MB. 1992. Coming to Terms with a Field: Words and Concepts in Symbiosis. Symbiosis, 14: 17 - 31.

Saitou N, Nei M 1987. The neighbor - joining method: a new method for reconstructing phylogenetic trees. Mol. Biol. Evol. 4: 406 - 425.

Saldanha R, Mohr G, Belfort M, Lambowitz AM. 1993. Group I and group II introns. FASEB J. 7: 15 - 24.

Sambrook J, Fritsch EF, Maniatis T. 1989. Molecular Cloning - a laboratory manual. Cold Spring Harbor Laboratory Press.

Sanger F, Micklen S, and Coulson AR. 1977. DNA sequencing and chain terminating inhibitors. Proc. Natl. Acad. Sci. USA, 74, 5463 - 5467.

Sanz MJ, Gries C, Nash TH III. 1992: Dose - response relationships for $\mathrm{SO}_{2}$ fumigations in the lichens Evernia prunastri (L.) Ach. and Ramalina fraxinea (L.) Ach. New Phytologist 122: 313 - 319.

Sapp J. 1994. Evolution by Association - A History of Symbiosis. Oxford University Press.

Scheidegger C. 1985. Systematische Studien zur Krustenflechte Anzina carneonivea (Trapeliaceae, Lecanorales). Nova Hedwigia 41: 191 - 218.

Scheidegger C. 1993. A revision of European saxicolous species of the genus Buellia de Not. and formerly included genera. Lichenologist 25: 315 - 364.

Scheidegger C, Mayrhofer H, Moberg R and Tehler A. 2001. Evolutionary trends in the Physciaceae. Lichenologist 33: 25 - 45.

Schöller H. 1997. Ökologie und Verbreitung. In: Schöller H (ed.). Flechten. Geschichte, Biologie, Systematic, Ökologie, Naturschutz und kulturelle Bedeutung. Kleine Senckenberg - Reihe Nr. 27. pp. 247.

Schwendener S. 1873. Die Flechten als Parasiten der Algen. Verh. Naturforsch. Ges. Basel 5: 527 - 557.

Schwendener. 1869. Die Algentypen der Flechtengonidien. Programm für die Rectoratsfeier der Universität. Universitätsbuchdruckerei von C. Schultze, Basel. 42 pp.

Sérusiaux E, Wessels D. 1984. Santessonia (Lecanorales, Buelliaceae) In the Namib Desert (South West Africa). Mycotaxon 19: 479 - 502.

Sheard JW. 1992. The lichenized ascomycete genus Hafellia in North America. The Bryologist 95: 79 - 87.

Shimodaira H, Hasegawa M. 2001. CONSEL: for assessing the confidence of phylogenetic tree selection. Bioinformatics. 17(12): 1246 - 1247. 
Smith DC. 1975. Symbiosis and the biology of lichenized Fungi. In: Jennings DH \& Lee DL (eds.) Symbiosis. Society for Experimental Biology, Symposia of the Society for Experimental Biology 29: $373-405$.

Smith DC, Douglas A. 1987. The Biology of Symbiosis. London: Edward Arnold.

Spatafora, J. W., T. G. Mitchell, and R. Vilgalys. 1995. Analysis of genes coding for small - subunit rRNA sequences in studying phylogenetics of dematiaceous fungal pathogens. J. Clin. Microbiol. 33:1322 - 1326.

Starr MP. 1975. A generalized scheme for classifying organismic associations. Symposia for the Society of Experimental Biology 29: 1 - 20.

Stenroos S, DePriest PT. 1998. nrSSU phylogeny of cladoniiform lichens. American Journal of Botany 85(11): 1548 - 1559.

Swinscow TD, Krog H. 1976. The Genera Anaptychia and Heterodermia in East Africa. Lichenologist 8: $103-138$.

Swinscow TD, Krog H. 1988. Macrolichens of East Africa. British Museum (Natural History) London.

Swofford DL. 2000. PAUP*. Phylogenetic Analysis Using Parsimony (*and Other Methods). Version 4. Sinauer Associates, Sunderland, Massachusetts.

Tamura K, Nei M. 1993. Estimation of the number of nucleotide substitutions in the control region of mitochondrial DNA in humans and chimpanzees. Mol. Biol. Evol. 10: 512 - 526.

Taylor JW, Jacobson DJ, Kroken S, Kasuga T, Geiser DM, Hibbett DS, Fisher MC. 2000. Phylogenetic Species Recognition and Species Concepts in Fungi. Fungal Genetics and Biology 31: 21 - 32.

Tehler A. 1996. Systematics, phylogeny and classification. In: Nash III TH (ed.), Lichen Biology, 303 pp. Cambridge University Press.

Thell A. 1999. Group I intron versus ITS sequences in phylogeny of cetrarioid lichens. Lichenologist 31: 441 - 449.

Thell A, Mattsson J - E, Kärnefelt I. 1995. Lecanoralean ascus types in the lichenized families Alectoriaceae and Parmeliaceae. Cryptogamic Botany 5: 120 - 127.

Thompson JD, Higgins DG, Gibson TJ. 1994. CLUSTAL W: improving the sensitivity of progressive multiple sequence alignment through sequence weighting, position specific gap penalties and weight matrix choice. Nucleic Acids Research 22: 4673 - 4680.

Thompson JN. 1982. Interaction and Coevolution. John Wiley \& Sons. 179 pp.

Tibell L, Wedin M. 2000. Mycocaliciales - a new order for non - lichenized calicioid fungi. Mycologia 92 $577-581$.

Treboux O. 1912. Die freilebende Alge und die Gonidie Cystococcus humicola in bezug auf die Flechtensymbiose. Ber. Dt. bot. Ges. 30: 69 - 80.

Tschermak - Woess E. 1978. Myrmecia reticulata as a phycobiont and free-living Trebouxia - The problem of Stenocybe septata. Lichenologist 10: 69 - 79.

Tschermak - Woess E. 1980. Asterochloris phycobiontica, gen. et. spec. nov., der Phycobiont der Flechte Varicellaria carneonivea. Pl. Syst. Evol. 135: 279 - 294.

Tschermak - Woess E. 1988. The algal partner. In: M. Galun (ed.): CRC Handbook of Lichenology. Volume I. CRC Press, Inc., Boca Raton, pp. 39 - 92.

Tschermak - Woess E. 1989. Developmental studies in trebouxioid algae and taxonomical consequences. P1. Syst. Evol. 164: $161-195$.

Turmel M, Cote V, Otis C, Mercier JP, Gray MW, Lonergan KM, Lemieux C. 1995. Evolutionary transfer of ORF - containing group I introns between different subcellular compartments (chloroplast and mitochondrion). Mol Biol Evol.12:533 - 45.

Van Oppen MJH, Olsen JL, Stam WT 1993. Evidence for independent acquisition of group I introns in green algae. Molecular Biology and Evolution 10: 1317 - 1326.

Vandermeer J. 1980. Notes and Comments. Indirect Mutualism: Variations on a Theme by Steven Levine. The American Naturalist 116: 441 - 448.

Vandermeer J, Hazlet B, Rathcke B. 1985. Indirect facilitation and mutualism. In: The Biology of Mutualism. (ed. Boucher D), pp. 326 - 343. Croom Helm, London \& Sydney.

Vilgalys R, Hester M (1990) Rapid genetic identification and mapping of enzymatically amplified ribosomal DNA from several Cryptococcus species. Journal of Bacteriology, 172, 4238 - 4246.

Wang Yang JR, Ahmadjian V. 1972. A morphological study of the algal symbionts of Cladonia rangiferina (L.) Web. and Parmelia caperata (L.) Ach.. Taiwania 17: 170 - 181.

Watson W. 1929. The classification of lichens I. New Phytol. 28: 1 - 36. 
Wedin M, Baloch E, Grube M. 2002. Parsimony analyses of mtSSU and nnrITS sequences reveal the natural relationships of the lichen families Physciaceae and Caliciaceae. Taxon 51: 655 - 660.

Wedin M, Döring H, Ekman S. 2000. Molecular phylogeny of the lichen families Cladoniaceae, Sphaerophoraceae, and Stereocaulaceae (Lecanorales, Ascomycota). Lichenologist 32: 171 - 187.

Wedin M, Döring H, Nordin A, Tibell L. 2000. Small subunit rDNA phylogeny shows the lichen families Caliciaceae and Physciaceae (Lecanorales, Ascomycotina) to form a monophyletic group. Can. J. Bot. 78: 246 - 254.

Wedin M, Grube M. 2002. Proposal to conserve the name Physciaceae against Caliciaceae (Lecanorales, Ascomycota). Taxon 51: 802.

White TJ, Bruns T, Lee S, Taylor J. 1990. Amplification and direct sequencing of fungal ribosomal RNA genes for phylogenetics. In: Innis M, Gelfand D, Snisky J, and White T (eds.), PCR protocols, a guide to methods and applications: 315 - 322. Academic Press, New York.

Wirth V. 1983. Phytosoziologie, Okologie und Systematik bei Flechten. Berichte der Deutschen Botanischen Gesellschaft 96: 103 - 115.

Wirth V. 1995. Die Flechten Baden- Württembergs. Ulmer (Eugen).

Wuyts J, Van de Peer Y, Winkelmans T, De Wachter R. 2002. The European database on small subunit ribosomal RNA. Nucleic Acids Res. 30: 183 - 185.

Yamada T, Tamura K, Aimi T and Songsri P. 1994. Self - splicing group I introns in eukaryotic viruses. Nucleic Acids Research 22: 2532 - 2537.

Yang J, Zimmerly S, Perlman PS, Lambowitz AM. 1996. Efficient integration of an intron RNA into double - stranded DNA by reverse splicing. Nature 381:332 - 5 .

Yang Z. 1994. Maximum likelihood phylogenetic estimation from DNA sequences with variable rates over sites: Approximate methods. J. Mol. Evol. 39: 306 - 314.

Zahlbruckner A. 1898. In: Engler A (ed.), Syllabus der Pflanzenfamilien 2: 46.

Zahlbruckner, A. 1907. Lichenes (Flechten). B. Spezieller Teil: Ascolichenes (Schlauchflechten); Hymenolichenes (Basidiomycetenflechten); Nachträge zu Teil 1, Abtheilung 1 bis Ende 1906. In: Engler, A. (ed.), Die natürlichen Pflanzenfamilien. Erste Auflage. I(1): 193 - 249.

Zahlbruckner, A. 1926. Lichenes (Flechten). B. Spezieller Teil: Ascolichenes (Schlauchflechten); Hymenolichenes (Basidiomycetenflechten). In: Engler, A. (ed.), Die natürlichen Pflanzenfamilien. Zweite Auflage. 8: 61 - 263.

Zharkikh A. 1994. Estimation of evolutionary distances between nucleotide sequences. J. Mol. Evol. 39: 315 - 329.

Zharkikh A, Li W - H 1992. Statistical properties of bootstrap estimation of phylogenetic variability from nucleotide sequences: I. four taxa with a molecular clock. Mol Biol Evol 9: 1119 - 1147. 


\section{Appendix}

\section{A.1 Voucher Information}

Specimens are listed in alphabetical order. In addition to the voucher information a six letter code is given which in connection with a one or two digit extension specifies particular specimens. Also the obtained sequence data are indicated: MB: mycobiont derived sequences, SSU: small subunit of the nuclear ribosomal DNA, ITS: internal transcribed spacer of the nuclear ribosomal DNA, PB: photobiont derived DNA. Only the nrITS region was sequenced in the photobionts and instead of specifying the region, the ITS-variant is given.

Amandinea cacuminum (Th. Fr.) H. Mayrhofer \& Sheard. RinCac1. MB: SSU, ITS; PB: A1a, A10a. FINNLAND, Nylandia, Perna / Pernaja, Bathstrand SW of Perna/ Pernaja, boulders near the shore, granite. Leg: H. Mayrhofer 2.8.97 \# 13.706 (GZU).

Amandinea petermannii (Hue) Matzer, H. Mayrhofer \& Scheidegger. AmaPet1. MB: -; PB: S1b. PENINSULA ANTARCTICA, Caleta Brialmont,

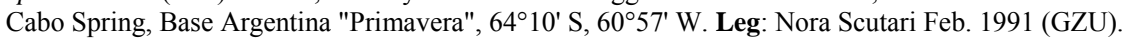

Amandinea punctata (Hoffm.) Coppins \& Scheid. AmaPun1. MB: ITS; PB: A4a. ITALY: Prov. di Livorno: Isola d'Elba, 1 km E of Morcone, Monte Calamita mountain, walking trail on western slope. $42^{\circ} 44^{\prime} \mathrm{N}, 10^{\circ} 23^{\prime}$ E, 400m. On pebbles. Leg: 15.4.1998, D. Triebel \& G. Rambold \# 6146 (M). - AmaPun2. MB: SSU, ITS; PB: A10a. AUSTRIA, Steiermark: Oststeirisches Hügelland, Riegersburg N Feldbach, nordwestl. u. westseitige Abbrüche der Burgfelsen, am Eselsteig, 420-450 m, Tuffit. Leg: 27.2.00 Mayrhofer \& Litterski \# 13.931 (GZU).

Anaptychia ciliaris (L.) Körb. AnaCil1. MB: SSU, ITS; PB: A1a. GERMANY, Lk München, Pullach (Grünwalderstr.). Spitzahorn, Straßenallee. 580 m, Tk25: 7935/13. Leg: T. Friedl \# 94/8, 10.10.1994.

— AnaCilN. MB: ITS; PB: A1a. SPAIN, Madrid, Nava del Rayo, Quercus pyrinaicus- Wäldchen. Am Stamm junger Q. pyrinaicus. Ca 1000m. Leg: V. Souza-Egipsy, Daniela, Libertat, G. Helms, 13.4.01 (GOET).

- AnaCilT. MB: -; PB: A1e. SPAIN, Madrid, El Tiemblo, El Castanar del Tiemblo. Kastanienwald mit Quercus pyrinaicus, z. T. sehr alte Bäume. ca. 1200m, N 40²0.906', W 4³0.868'. Leg: Libertat, Daniela, V. Souza-Egipsy, G. Helms, 14.4.01 (GOET).

Anaptychia runcinata (With.) J.R.Laundon. AnaRun1. MB: SSU, ITS; PB: A4a. ITALY: Prov. di Livorno: Isola d'Elba, 3 km E of Capoliveri, Colle di Calagrande. $42^{\circ} 44^{\prime} \mathrm{N}, 10^{\circ} 25^{\prime} \mathrm{E}, 2-5 \mathrm{~m}$. NE-exposed coastal rocks, on horizontal and inclined surface. Leg: 17.4.1998, D. Triebel \& G. Rambold \# 6162 (M).

— AnaRun2. MB: ITS; PB: A4a. SPAIN, Barcelona, St. Coloma de Farnes, Rocky peak next to the Castillo de Farnes, On vertical rock, sunexposed, ca $450 \mathrm{~m}$. Leg: G. Helms \& P. Dornes 8.9.00 (GOET).

— AnaRun3. MB: ITS; PB: A4a. SPAIN, Barcelona, St. Coloma de Farnes, between St. Coloma and the castillo, ca. $250 \mathrm{~m}$. On mossy rock below Quercus ilex (shadow). Leg: G. Helms \& P. Dornes 8.9.00 (GOET).

- AnaRun4. MB: ITS; PB: A4a. SCOTLAND, Moray District: Lighthouse between Lossiemouth and Hopeman, S Covesea Skerries, costal rocks. Leg: E. \& H. Mayrhofer \# 13.978, 8.8.1995 (GZU).

Anaptychia ulotrichoides (Vain.) Vain. AnaUlo1. MB: ITS; PB: A3a. KYRGUSTAN, W of Turishan, Tschitschkan-Tal, Unterlauf, N Toktogil, an Populus, ca 1700 m. Leg: B. Litterski 30.7.1999 \# 4994 (GZU).

Australiaena streimannii Matzer, H. Mayrhofer \& Elix. AusStr1. MB: SSU, ITS; PB: G4c. AUSTRALIA, Northern Territory: Robin Falls, 13 km SSE of Adelaide river township. $13^{\circ} 21^{\prime} \mathrm{S}, 131^{\circ} 08^{\prime} \mathrm{E}$, ca. $120 \mathrm{~m}$. Dense vegetation on creek flats surrounded by Eukalyptus savannah. On shaded rock face near falls. Leg: H. Streimann, 14.4.1989 \# 42136 (B).

- AusStr2. MB: -; PB: G4c. AUSTRALIA, Northern Territory: Roper Bar Road, near Mt Price, $66 \mathrm{~km}$ E of Mataranka. 1455'S, $133^{\circ} 41^{\prime} \mathrm{E}, 90 \mathrm{~m}$. Short dense scrub along edge of escarpment, Acacia and Owenia dominated. On shaded boulder. Leg: H. Streimann, 8.4.1989 \# 41950 (B).

Buellia aeruginosa A. Nordin, Owe-Larss. \& Elix. BulAer1. MB: -; PB: A2a. AUSTRALIA. NEW SOUTH WALES: Near Melville Point, 13 km SSE of Batemans Bay. alt. 1-5 m. Lat/long: 35:50 S, 152:12 E. Steep seashore cliffs facing E. Leg: 15.III.1992. R. Moberg \& B. OweLarsson 69: 17 (UPS).

Buellia aethalea (Ach.) Th. Fr. BulAet1. MB: SSU, ITS; PB: -. SWEDEN. Narke: Götlunda Island Valen. Alt. 25 m. Lat/long: 59:14 N, 15:45 E. On siliceous rock in stone wall. Leg: 16.V.1993. Anders Nordin 3256 (UPS).

Buellia capitis-regum W. A. Weber. BulCap1. MB: ITS; PB: -. USA. CALIFORNIA: Santa Barbara, Santa Rosa Island, upper part of Cherry Canyon. Alt. 75 m. Lat/long: 33:59 N, 120:01 W. Mixed oak-chaparral and pasture, on sandstone. Leg: 5.I. 1994. T. H. Nash 33113 (UPS).

Buellia disciformis (Fr.) Mudd. BulDis21. MB: ITS; PB: -. JAPAN. TESHIO: Hokkaido, $23 \mathrm{~km}$ NNW of the small town Teshio at the coast, the Wakasakanai area, $\mathrm{S}$ of the road from the coast to the Toyotomi Town, Toyotomi-cho, Teshio-gun. On Abies sachalinensis. Leg: $30 . \mathrm{V}$. 1995. G. Thor 13622 (Kashiwadani, Lich. minus cogn. exs. 56) (UPS).

- BulDis22. MB: ITS; PB: -. RUSSIA. KOMI REPUBLIC: Syktyvdinskii, Ib, W brink of Sysola, $48 \mathrm{~km}$ S of Syktyvkar railway station. Alt. 120 m. Lat/long: 61:15 N, 50:51 E. On Alnus incana in young-growth deciduous forest, slope of the brink. Leg: 24.IX.1994. Janolof Hermansson 4538 (UPS).

— BulDis23. MB: ITS; PB: I3b. SWEDEN. UPPLAND: Rådmansö Riddersholm, Kvarnudden, västra delen, 6 km SO Rådmansö kyrka. Alt. .Lat/long: 59:45 N, 19:00 E. Grid: RN 1681950 6626200. On ash, Fraxinus excelsior, in meadow with broad-leaved forest. X.1997. Leg: Per Johansson 5 (UPS).

Buellia elegans Poelt. BulEle1. MB: SSU, ITS; PB: A7a. AUSTRIA, Osttirol. On moor, over S-exposed limestone slope, limestone slate. Leg: 30.9.96, U. Trinkaus, J. Prügger \& H. Mayrhofer \# 439 (GZU). 
— BulEle2. MB: ITS; PB: A5a, A7c. TIBET, Prov. Xizang, Himalaya Range, $210 \mathrm{~km}$ SE of Lhasa, $15 \mathrm{~km}$ ESE of Lhüntse, way to Qayü, dry valey of Subansiri; $28^{\circ} 24^{\prime}$ N / 92 $37^{\prime}$ E, 4100-4200 m. Leg: 31.07.1994, W. Obermayer 5147 (GZU).

— BulEle3. MB: ITS; PB: A7a. USA, IDAHO, Idaho Co., S of Lucile at Lucile Csves, T25N, R1E, Sec. 11, $1700 \mathrm{ft}$, on calcareous soil in mountain mahogany habitat. Leg: 11.05.1984, R. Rosentreter 4081 (GZU).

Buellia frigida Darb. BulFri1. MB: ITS; PB: A2c. ANTARCTICA, Lagoon Island, close to coast, on rock. Leg: S. Ott Jan. 2001, Det: H. Mayrhofer (GOET).

Buellia geophila (Flörke ex Sommerf.) Lynge. BulGph1. MB: ITS; PB: -. SWEDEN. TORNE LAPPMARK: Jukkasjärvi On the shore of lake Torneträsk ca. $3 \mathrm{~km} \mathrm{NW}$ of Abisko. Alt. $350 \mathrm{~m}$. Lat/long: 68: 22N 18: 46E. On calcareous ground. Leg: 23.VIII.1996. Anders Nordin 4429 (UPS).

Buellia georgei Trinkaus, H. Mayrhofer \& Elix. BulGrg1. MB: SSU, ITS; PB: A11a. AUSTRALIA, Wheatbelt Region of Western Australia: Lancelin, northside of Lancelin. On soil over limestone plates. Leg: U. Trinkaus 2.12.1996 \# 356a (GZU).

Buellia griseovirens (Turner \& Borrer ex Sm.) Almb. BulGris1. MB: SSU, ITS; PB: -. SWEDEN. UPPLAND: Gräsö Lönnholmen. Alt. 5 m. Lat/long: 60: 19N 18: 32E. On trunk of Populus tremula in shaded situation. Leg: 8.V.1997. Anders Nordin 4734 (UPS).

Buellia muriformis A. Nordin \& Tønsberg. BulMur1. MB: ITS; PB: -. USA. OREGON: Coos Co. Oregon Dunes National Recreation Area, just NE of Bluebill Lake. Alt. 15m. Lat/long: 43:26 N, 124:15 W. On branches of Chamaecyparis lawsoniana. Leg: 16.VI.1998. Anders Nordin 5336a. (UPS).

Buellia ocellata (Flot.) Körb. BulOce1. MB: ITS; PB: -. THE FAROES. SKOVOY: N of the village. Alt. 30 m. Lat/long: 61:46 N, 6:48 W. On stone wall at track. Leg: 7.VIII.1995. Anders Nordin 4284 (UPS).

Buellia papillata (Sommerf.) Tuck. BulPap34. MB: ITS; PB: I1r. NEW ZEALAND. OTAGO: Potters, W slopes of Old Man Range. Alt. $1200 \mathrm{~m}$. Overgrowing detritus, grass, dead bryophytes etc. Leg: 26.II. 1998. David Galloway 0239 (UPS).

Buellia penichra (Tuck.) Hasse. BulPen1. MB: ITS; PB: -. USA. OREGON: Deschutes Co. Three Sisters Wilderness, along Fall Creek below the falls, S of South Sister Mt. Alt. 1800 m. Lat/long: 44: 03N 121: 44W. On dead, decorticated Tsuga mertensiana. Leg: 15.VI.1998. Anders Nordin 5322 (UPS).

Buellia pulverulenta (Anzi) Jatta. BulPulv1. MB: ITS; PB: A4a, I1d. SWEDEN. TORNE LAPPMARK: Jukkasjärvi. On the shore of lake Torneträsk c. $3 \mathrm{~km} \mathrm{NW}$ of Abisko. Alt. $350 \mathrm{~m}$. Lat/long: 68: 22N 18: 46E. On calcareous rock. Leg: 22.VIII.1996. Anders Nordin 4427 (UPS).

Buellia sequax (Nyl.) Zahlbr. BulSqx1. MB: -; PB: A11a. ITALY: Prov. di Livorno: Isola d'Elba, $5 \mathrm{~km}$ W of Portoferraio, Capo d'Enfola, eastern slope of Monte Envola. 42 ${ }^{\circ} 49^{\prime} \mathrm{N}, 10^{\circ} 16^{\prime}$ E, 20 - 50 m. Rock beside gravel road. Leg: 23.4.1998, D. Triebel \& G. Rambold \# 6209 (M).

Buellia sp. BulSp2. MB: -; PB: A7a. NAMIBIA: Namib Desert, Namib Naukluft Park near Swakopmund, Moonlandscape, valley of river Swakop, about $18 \mathrm{~km}$ E Swakopmund. $200 \mathrm{~m}$ alt. 22 $2^{\circ}$ ' $\mathrm{S}, 14^{\circ} 40^{\prime}$ E. Lichen field with Xanthomaculina convoluta in deprression; on the ground. Leg: C. Kainz, 4.9.98 \# 304 (M).

Buellia submuriformis Aptroot \& Diederich. BulSum1. MB: ITS; PB: -. INDIA. UTTAR PRADESH: $23 \mathrm{~km}$ NNE of Uttarkashi, $1 \mathrm{~km}$ NW of Dharwa Pass. Alt. 4000 m. Lat. /long: 30:54 N, 78:31 E. On bark of young Picea on ridge with Abies pindrow close to tree limit. Leg: 22.V.1999. Leif Tibell 21897 (UPS).

Buellia triphragmioides Anzi. BulTrip1. MB: ITS; PB: A4b, I3b. SWEDEN. TORNE LAPPMARK: Jukkasjärvi. At the path to Björkliden ca. 4 km NW of Abisko. Alt. 380 m. Lat/long: 68:22 N, 18:44 E. On trunk of Salix caprea. Leg: 22.VIII.1996. Anders Nordin 4425 (UPS).

Buellia triseptata A. Nordin. BulTris1. MB: ITS; PB: -. USA. ARIZONA: Apache Co. White Mts, Apache National Forest, Mt Baldy Wilderness, E fork of Little Colorado River, along trail 95 from Phelb's Cabin to Mt Baldy, montane forest and meadows with granite boulders. Alt. 2960 m. Lat/long: 33:56 N, 109:30 W. On basal branches of Picea engelmannii. Leg: 8.VI.1998. Anders Nordin 5229 (UPS).

Buellia zoharyi Galun. BulZoh1. MB: SSU, ITS; PB: A7b. CANARY ISLANDS, Provinicia de Las Palmas de Gran Canaria. On soil. Leg: 12.8.96, U. Trinkaus \& M. Grube Ex GZU 356a (GZU).

— BulZoh2. MB: ITS; PB: A7a. SPAIN, Madrid, Aranjues, Gipsiferous hills at Mar de Otigola, on soil, ca. 450 m. Leg: P. Dornes, V. Souza-Egipsy \& G. Helms 16.9.00 (GOET).

Calicium adspersum Pers. CalAds1. MB: ITS; PB: -. GERMANY, Brandenburg, Landkr. Uckermark. N of Buchholz, in the forest beyond the forest house. Alt. ca. 75 m. MTB 2748/4. On trunk of thick oak along road in deciduous forest. Leg: H. Sipman, 24.4.2001; \# 47502.

Calicium salicinum Pers. CalAds1. MB: ITS; PB: -. GERMANY, Harz, Siebertal, auf Weide. Leg: V. Souza-Egipsy \& G. Helms, Aug. 2000 (GOET).

Calicium viride Pers. CalVir1. MB: ITS; PB: -. GERMANY, Brandenburg, Landkr. Uckermark. N of Buchholz, in the forest beyond the forest house. Alt. ca. 75 m. MTB 2748/4. On trunk of thick oak along road in deciduous forest. Leg: H. Sipman, 24.4.2001; \# 47503.

Cyphelium tigillare (Ach.) Ach. CypTig2. MB: ITS; PB: S3b. NORWAY, Oppland, Sel: Horgesetrene, W above Rosten, towards Mt. Horgenosi. $61^{\circ} 52^{\prime} \mathrm{N}, 9^{\circ} 22^{\prime} \mathrm{E}$, ca. $1000 \mathrm{~m}$. Betula nana - Cladina-heath, on hill ridge just above tree limit. On isolated Betula tree trunk. Leg: H. Sipman, 12.7.1999 \# 44159 (B).

Dermatiscum thunbergii (Ach.) Nyl. DerThu1. MB: ITS; PB: G5a. SOUTH AFRICA, Prov. Transvaal, Distr. Pilgrims rest. Treur River near Bourkes Luck. Ca. 1400m. Sandstone outcrops in steep grassland slope. On rock. Leg: H. Sipman, 14.1.1986 \# 19.908 (B).

Dimelaena oreina (Ach.) Norman. DimOre1. MB: SSU, ITS; PB: I1b. AUSTRIA, Steiermark, Teigitschgraben S Voitsberg, ca. 2, 5 km NE der Langmannsperre, ca. 560-600 m. Leg: H. Mayrhofer \& U. Arup 16.11.98 \# 13.737 (GZU).

— DimOre2. MB: ITS; PB: I1g. USA, Idaho, Lemhi County: Lemhi Valley, Mollie Gulch S of Little Eightmile Creek, NW of Leadore; ca. 1800 m, quartzitic boulders close to the ground. Leg: H. Mayrhofer \& R. Rosentreter 30.7.99 \# 13.879 (GZU).

— DimOre3. MB: ITS; PB: I1b. SPAIN, Cerro del Castillo, S-slope, S-exp., ca 1100 m, on wayside, on Granite rock. Leg: G. Helms \& V. Souza-Egipsy 18.4.00 (GOET).

- DimOre4. MB: ITS; PB: I1b. AUSTRIA, Steiermark, Wölzer Tauern, Lachtal, Rücken zw. der Roßalpe und dem Knappenstein S des Großen Lachtals; SW-exp. Flächen eines freistehenden Silikatblockes; ca. 1870 m; 47'13'54"N, 1420'18"E; MTB 8752/3. Leg: H. Mayrhofer \& E. Sterner \# 13.970 \# 11.8.00 (GZU).

Dimelaena tenuis (Müll. Arg.) H. Mayrhofer \& Wippel. DimTen1. MB: -; PB: I1m. QUEENSLAND: Peninsula Development, 56 km NW of Coen (5 km SE of Archer River Crossing) $13^{\circ} 28^{\prime} \mathrm{S}, 142^{\circ} 58^{\prime} \mathrm{E}, 140 \mathrm{~m}$. Dry sclerophyll forest on flats with boulders. On semishaded boulder. Leg: Streimann, 10.10.95 \# 56309 Det: H. Sipman 1998 (B).

Diploicia canescens (Dickson) A. Massal. DipCan1. MB: SSU, ITS; PB: -. ITALY: Prov. di Livorno: Isola d'Elba, 2 km SE of Cavo, Cala del Telegrapho. N 4251', E 10²6', ca. 3 m. NE facing, vertical cliffs of rock at beach. Leg: 22.4.1998, D. Triebel \& G. Rambold \# 6188 (M). - DipCan2. MB: ITS; PB: -. GERMANY, Rheinland-Pfalz, Nordpfälzer Bergland: ND Schöne Aussicht north of Winnweiler. On silicate rock at the bottom of a cliff. rather common. Leg: P. Dornes 24.1.1999 \# 9901.050 Herbar P. Dornes (Ex: Herbarium Bayreuth). — BulSp1. MB: ITS; PB: G4a. NAMIBIA: Namib Desert, National West Coast Tourist Recreation Area, beside coastal road, route C34, junction to Cape Cross. $50 \mathrm{~m}$ alt. $21^{\circ} 46^{\prime} \mathrm{S}, 1^{\circ} 00^{\prime}$ E. Lichen field beside road, gravel and crustose soil; on the ground. Leg: C. Kainz, 3.9 .98 \# $250(\mathrm{M})$.

Diplotomma alboatrum (Hoffm.) Flot. BulAlb3. MB: SSU, ITS; PB: -. ENGLAND. DEVON: Pudcombe Cove, Coleton Fishacre. 0001 m; Grid: UTM SX 20/912 505. On sheltered Lower Devonian shale above HWM. (contains norstictic acid). Leg: 2.IV. 2000.Barbara Benfield \# 04973 (UPS). — BulAlb6. MB: ITS; PB: -. SWEDEN. ÖSTERGÖTLAND: V. Tollstad Mt Omberg, Alvastra, beech forest N of the ruins. Alt. $150 \mathrm{~m}$. Lat/long: 58: 17N 14: 39E. On overhanging rock. Leg: 9.V.1998. Anders Nordin 5055 (UPS). 
— BulAlb7. MB: ITS; PB: A1a. NORWAY. HORDALAND: Bömlo Kvernavika, ca. 2 km W of Kalavåg. Alt. 5 m. Lat/long: 59:34 N, 05:10 E. On overhanging sea-shore rocks in the upper Verrucaria maura zone. Leg: 20.VII.1995. Anders Nordin 4265 (UPS).

— BulAlb9. MB: ITS; PB: I1b. SWEDEN. JÄMTLAND: Brunflo Brunflo church. Alt. 360 m. Lat/long: 63:05 N, 14:49 E. On mortar on the castal. Leg: 3.IX.1993. Anders Nordin 3347 (UPS).

— BulAlb11. MB: ITS; PB: -. SWEDEN. BOHUSLÄN: Tjärnö Saltö, Kattholmen. Alt. 2 m. Lat/long: 58:51 N, 11:08 E. On vertical seashore rock, in the Verrucaria maura zone. Leg: 20.III.1996. Anders Nordin 4372 (UPS).

— BulAlb12. MB: -; PB: A1a. SWEDEN. UPPLAND: Ed Lövsta. Alt. 2 m. Lat/long: 59:32 N, 17:53 E. On trunk of Acer platanoides in avenue. Leg: 8.IV.1996. Anders Nordin 4382 (UPS).

— BulAlb15. MB: ITS; PB: A2a. SWEDEN. SÖDERMANLAND: Ornö Huvudskär archipelago, Ålandsskär. Alt. 1 m. Lat/long: 58:57 N, 18:34 E. On N- exposed sea-shore rocks in Verrucaria maura zone. Leg: 13.IX.1997. Anders Nordin 4961 (UPS).

— BulAlb17. MB: ITS; PB: A3a. USA. ARIZONA: Apache Co. White Mts, Apache National Forest, Mt Baldy Wilderness, E fork of Little Colorado River, along trail 95 from Phelb's Cabin to Mt Baldy, base of huge open rock cliffs in Pseudotsuga menziesii-Abies lasiocarpa forest. Alt. $3020 \mathrm{~m}$. Lat/long: 33: 56N 109: 30W. On overhanging rock. Leg: 8.VI.1998. Anders Nordin 5234 (UPS).

Diplotomma lutosum A. Massal. BulSud1. MB: ITS; PB: A2d. SWEDEN. UPPLAND: Väddö Nothamn, SE of the lime-stone quarry. Alt. $5 \mathrm{~m}$. Lat/long: 60:01 N, 18:51 E. On S-exposed rock surface. Leg: 23.IX.1996. Anders Nordin 4449 (UPS).

Diplotomma epipolium (Ach.) Arnold $=$ D. venustum (Körb.) Körb. DipEpi1. MB: SSU, ITS; PB: A9a. AUSTRIA, Steiermark: Oststeirisches Hügelland, Riegersburg N Feldbach, nordwestl. u. westseitige Abbrüche der Burgfelsen, am Eselsteig, 420-450 m, Tuffit. Leg: 27.2.00 Mayrhofer \& Litterski \# 13.933 (GZU).

Diplotomma pharcidium (Ach.) M. Choisy. BulPha1. MB: ITS; PB: A1c, A1d. SWEDEN. UPPLAND: Husby-Ärlinghundra Steninge. Alt. 5 m. Lat/long: 59:36 N, 17:48 E. On trunk of Acer platanoides in avenue. Leg: 30.IV.1993. Anders Nordin 3204 (UPS).

Diplotomma venustum (Körb.) Körb. BulVen45. MB: ITS; PB: A5a. GREECE. CRETE: Chania, Omalos plain. Alt. 1160 m. Lat/long: 35:19 N, 23:54 E. On calcareous rock. Leg: 2.IV.1993. Anders Nordin 3180 (UPS).

— BulVen46. MB: ITS; PB: A5a. HUNGARY. BORSOD-ABAUJ-ZEMPLÉN: Aggtelek National Park, 3-4 km NNE of Josvafö, Nagyoldal. Alt. 480 m. Lat/long: 48:31 N, 20:36 E. On limestone rocks in open area. Leg: 14.IV. 1994. Leif Tibell 20012 (UPS).

— BulVen48. MB: ITS; PB: A5a. SWEDEN. GOTLAND: Rute Husken, ca. 3 km SE of Valleviken. Alt. 15 m. Lat/long: 57:46 N, 18:58 E. On S-exposed calcareous rock. Leg: 18.V.1993. Anders Nordin 3260 (UPS).

- BulVen49. MB: ITS; PB: S4a. USA. ARIZONA: Gila Co., Tonto National Forest, vicinity of Whispering Pines, along the Houston Mesa Rd and $1 \mathrm{~km} \mathrm{~S}$ of the Control Rd (ca. $16 \mathrm{~km}$ NNE of Payson), N-slope of hill. Alt. $1570 \mathrm{~m}$. Lat/long: 34:22 N, 111:17 W. On calcareous rock. Leg: 10.VI.1998. Anders Nordin 5276 (UPS).

Dirinaria applanata (Fée) D. D. Awasthi. DirApp1. MB: ITS; PB: G9c. BOLIVIA, Alto Beni: Nueva Israel. 67²15.91'W, $15^{\circ} 34.77^{\prime} \mathrm{S}$; alt. $540 \mathrm{~m}$. Plantation 30 years, owner V. Calderon; on Theobroma cacao bark. Leg: N. Derakashani, 25.6.1999 \# 14 (B).

— DirApp2. MB: ITS; PB: G7a. Singapore, southern islands, Kusu Island. $1^{\circ} 13^{\prime} \mathrm{N}, 103^{\circ} 52^{\prime} \mathrm{E}$; alt. $1 \mathrm{~m}$. Cleared beach forest with scattered Casuarina, Terminalia and planted trees. On Terminalia catappea tree trunk within reach from the ground. Leg: H. Sipman, 14.11.2000 \# 46067 (B)

Dirinaria confluens (Fr.) D. D. Awasthi. DirCon2. MB: ITS; PB: -. THE PHILIPPINES, Benguet: Mt Santo Tomas, 4500-5000 ft. On bark of Alnus tree. Leg: P. A. Bawingan, May 2000 \# 59 Det: H. Sipman, Oct. 2000 TLC \# 13009 (B).

— DirCon4. MB: ITS; PB: -. THE PHILIPPINES, Benguet: Mt. Santo Tomas, 4500-5000 ft. On bark of Alnus tree. Leg: P. A. Bawingan, \# 60, May 2000 (B).

Dirinaria picta (Sw.) Clem. \& Shear. DirPic1. MB: ITS; PB: G3b. SINGAPORE, Campus of National University of Singapore, around Kent Ridge. $1^{\circ} 18^{\prime} \mathrm{N}, 103^{\circ} 45,5^{\prime} \mathrm{E}$; alt. 50 m. Parkland with scattred buildings and roads, Kent Ridge Road. On Roystonea regia trunk. Leg: H. Sipman, 5.11 .2000 \# 45628 (B).

Dirinaria sp. DirSp1. MB: ITS; PB: G3d. BRAZIL, Pernambuco, Estacao Experimental do IPA (Instituto de Pesquisas Agropecuarias), municipio de Caruaru, 15 km NE de Caruaru; 500-600 m; vegetacao semiaberta da Caatinga, sobre cortex de árvores pequenos. Leg: M. Cáceres \& R. Lücking, Okt. 2000 \# 00-954 (GOET).

Dirinaria sp. DirSp2. MB: ITS; PB: G3a. BRAZIL, Pernambuco, Estacao Experimental do IPA (Instituto de Pesquisas Agropecuarias), municipio de Caruaru, $15 \mathrm{~km}$ NE de Caruaru; 500-600 m; vegetacao semiaberta da Caatinga, sobre cortex de árvores pequenos. Leg: M. Cáceres \& R. Lücking, Okt. 2000 \# 00-951 (GOET).

Dirinaria sp. DirSp3. MB: ITS; PB: -. BRAZIL, Pernambuco, Reserva Ecológica de Gurjaú, municípios do Cabo, Moreno e Jaboatao dos Guararapes, propriedade da Companhia Pernambucana de Saneamento (COMPESA); $8^{\circ} 16{ }^{\prime} \mathrm{S}, 35^{\circ} 00^{\prime} \mathrm{E}, 80-150 \mathrm{~m}$; remanescente da Mata Atlantica sobre rochas cristalinas, com floresta perenifolia primaria alternando com vegetacao secundaria; sobre cortex de árvores pequenos. Leg: M. Caceres \& R. Lücking, Okt. 2000 \# 00-956 (GOET).

Hafellia dissa (Stirt.) H. Mayrhofer \& Sheard. HafDis1. MB: ITS; PB: G6b, A7a. SOUTH AFRICA. WESTERN CAPE. Heather Hill, ca. 11 km W of Knysna. Alt. 175 m. Lat/long: 33:59 S, 22:58 E. On trunk of Pinus radiata. 11.XII.1996.Leg: Anders Nordin 4632 (GZU).

Heterodermia albicans (Pers.) Swinscow \& Krog. HetAlb1. MB: ITS; PB: I4a. EL SALVADOR, Depto. Ahuachapán: P. N. El Imposible, sector La Fincona; Bosque del Tanque, near La Fincona; $13^{\circ} 51^{\prime} \mathrm{N}, 89^{\circ} 59^{\prime} \mathrm{W}, 800 \mathrm{~m}$. On old Manilkara chicle (Nispero, \# 4C) tree, ca. $25 \mathrm{~m}$ tall, in semi-evergreen, dry, primary forest, on fallen canopy branches. Leg: R. Welz, \# 894, 12.12.98 (B).

Heterodermia barbifera (Nyl.) J. C. Wei. HetBar2. MB: -; PB: I4b. BOLIVIA, Depto. Cochabamba, prov. Chapare, Parque National Carrasco, 1339 $\mathrm{km}$ del camino antiguo de Cochabamba a Villa Tunari. $17^{\circ} 07^{\prime} \mathrm{S}, 65^{\circ} 34^{\prime} \mathrm{W}, 1450 \mathrm{~m}$. Bosque siempre-verde; epifita. Leg: K. Bach \& M. Kessler \& E. Rapp, 12.10.1997 (B).

Heterodermia boryi (Fée) K. P. Singh \& S. R. Singh. HetBor1. MB: SSU, ITS; PB: I4b. CANARY ISLANDS, Tenerife, Teno-Gebirge, an der Forststraße zw. Erjos u. Las Poetelas, ca. 950 m, Lorbeerwald. Leg: H. Mayrhofer \& J. Hafellner, 17.12.98 \# 13.773 (GZU).

— HetBor2. MB: ITS; PB: I4c. TANSANIA, Arusha Nationalpark, Ngurdoto Krater. Leg: Juli 2000, Monika Düsing det: P. Dornes, Juli 2000 (GOET)

Heterodermia casarettiana (A. Massal.) Trevis. HetCas2. MB: ITS; PB: I4b. VENEZUELA, Sierra Nevada, Edo. Merida, Mun. Libertador. 2135 m, Weg Barinitas - La Montana (Nebelwald); Boden humusreich - frisch; eher schattig, üppige Vegetation; W-exp., Inkl ca. $3^{\circ}$; Mittelhang; an Baumrinde. Leg: K. Wiegleb, 6.1.1995 det: H. Sipman, 1998 \# 227.

Heterodermia comosa (Eschw.) Follm. \& Redon. HetCom1. MB: ITS; PB: I4a. BOLIVIA, Depto. Cochabamba, prov. Ayopaya, 20 km de Cocapata hacia Cotacajes. $16^{\circ} 46^{\prime} \mathrm{S}, 66^{\circ} 44^{\prime} \mathrm{W}, 2000 \mathrm{~m}$. Bosque semideciduo disturbado de $5 \mathrm{~m}$ de altura en una quebrada; epifita. Leg: K. Bach \& M. Kessler, J, Gonzales, A. Acebey, 15.5.1997 \# 92 (B).

Heterodermia diademata (Taylor) D. D. Awasthi. HetDia1. MB: ITS; PB: I4b. BOLIVIA, Depto. Beni, Prov. Ballivan, 20 km por carretera maderera al SW del km 12 Yucumo - Rurrenabaque. $1^{\circ} 07^{\prime} \mathrm{S}, 67^{\circ} 08^{\prime} \mathrm{W}, 900-950 \mathrm{~m}$. Bosque siempreverde de $25 \mathrm{~m}$ de altura; epifita. Leg: Bach, Kesseler \& Portugal, \# 389, 6.8.97 (B).

Heterodermia flabellata (Fée) D. D. Awasthi. HetFla1. MB: ITS; PB: I4b. THE PHILIPPINES, Benguet: Mt. Santo Tomas, $4500-5000 \mathrm{ft}$. On bark of Alnus tree. Leg: P. A. Bawingan, \# 61, May 2000 (B). 
Heterodermia leucomela (L.) Poelt. HetLeu1. MB: ITS; PB: I4b. CANARY ISLANDS, Lorbeerwald Las Mercedes, Streu, ca 200 m Leg: P. Dornes, 22.3.99 Herb. P. Dornes.

— HetLeu2. MB: ITS; PB: I4b. VENEZUELA, Caracas, IVIC Parkplatz. On Pinus-Stumpf. Leg: H. Thues, ca. Ostern 2001 (GOET).

- HetLeu3. MB: ITS; PB: I4b. BOLIVIA, Depto. Cochabamba, prov. Ayopaya, $20 \mathrm{~km}$ de Cocapata hacia Cotacajes. $16^{\circ} 46^{\prime} \mathrm{S}, 66^{\circ} 44^{\prime} \mathrm{W}$, 2000 m. W-exp.; bosque semideciduo disturbado de $5 \mathrm{~m}$ de altura; terrestre. Leg: Bach, Kessler, Gonzales, Acebey, \# 106, 15.5.97 (B).

— HetLeu4. MB: ITS; PB: I4a. EL SALVADOR, Depto. Ahuachapán: P. N. El Imposible, sector La Campana; Cafetal Las Piedrones; $13^{\circ} 51^{\prime} \mathrm{N}, 89^{\circ} 55^{\prime} \mathrm{W}, 1300 \mathrm{~m}$. Road bank in Citrus plantation. On dead branch of isolated tree. Leg: Sipman \& Welz, \# 44833, 10.11 .98 (B).

Hetrodermia lutescens (Kurok.) Follm. HetLut1. MB: ITS; PB: -. El Salvador, Depto. Ahuachapán: P. N. El Imposible, sector La Fincona; between La Fincona and Paso El Imposible, along road near Paso El imposible; $13^{\circ} 52^{\prime} \mathrm{N}, 89^{\circ} 58^{\prime} \mathrm{W}, 800 \mathrm{~m}$. Mossy road bank at Paso. Leg: Sipman \& Welz, \# 44716, 8.11.98 (B).

Hyperphyscia adglunitata (Flörke) Mayrhofer \& Poelt. HypAdg1. MB: SSU, ITS; PB: I1d. GERMANY, Baden-Württemberg, Markgräflerland, Südlliche Oberrheinebene: Müllheim, Gasthof zum Bad. On bark of the stem of an old, solitary Aesculus hyppocastanea. rare. Leg: P. Dornes 27.12.1998 \#: 411b Herb. P. Dornes.

Phaeophyscia endophoenicea (Harm.) Moberg. PhaEnd1. MB: ITS; PB: I3a. AUSTRIA, Steiermark, Niedere Tauern, Schladminger Tauern, Naturpark Sölktäler, Kleinsölktal Unterste Abhänge der Großen Kesselspitze unweit der ZaunrinneW-exp. Fichten-Tannenwald mit Bergahorn, ca. 1100-1200 m. über corticolen Moosen von Acer pseudoplatanus. Leg: P. Bilovitz \& H. Mayrhofer 10.8.98 \# 1187 (GZU).

— PhaEnd2. MB: ITS; PB: I3a. S-GERMANY, Garmisch, Leutaschtal unterhalb der Klamm. Am Stamm solitärer Bäume am Weg. Leg: G. Helms (Algen-Exkursion) 8.10.00 (GOET).

Phaeophyscia kairamoi (Vain.) Moberg. PhaKai1. MB: -; PB: I3b. NORWAY, Oppland, Dovre: Jonndalen, ca. 5 km SW of Dovre, S-side of Mt. Nonshaugen. $62^{\circ} 57^{\prime} \mathrm{N}, 9^{\circ} 13^{\prime} \mathrm{E}$, ca. $700 \mathrm{~m}$. Populus tremula and Alnus incana - forest on steep, S-facing slope in narrow mountain valley. On Populus tremula. Leg: H. Sipman, 16.7.99 \# 44266 (B).

Phaeophyscia orbicularis (Neck.) Moberg. PhaOrb1. MB: SSU, ITS; PB: I1a. SPAIN, Madrid, Alfredos Garten. Leg: G. Helms \& V. Souza-Egipsy April 2000 (GOET).

— PhaOrb2. MB: ITS; PB: I1b. SPAIN, Navacerada, road to Barranca, on Populus nigra,. Leg: G. Helms \& Alfredo 17.4.00 (GOET).

Phaeorrhiza nimbosa (Fr.) H. Mayrhofer \& Poelt. PhrNim1. MB: SSU, ITS; PB: I1j. ITALIEN, Südtirol, Dolomiten. Hochalpe westl. Innerprags, Lapadures Joch über den Hochalpenhütten. $46^{\circ} 43^{\prime} \mathrm{N} / 12^{\circ} \mathrm{E}$, ca. $2250 \mathrm{~m}$. alpine Rasen. Leg: H. Mayrhofer \# 13.775 \& H. Teppner (GZU).

Phaeorrhiza sareptana (Tomin) H. Mayrhofer \& Poelt. PhrSar1. MB: ITS; PB: I1g. SW GREENLAND: Head of Sondre Stromfjord, Mt Hassel, south facing slope. $67^{\circ} 01^{\prime} \mathrm{N}, 50^{\circ} 42^{\prime} \mathrm{W}$. On loess in steppe-like community together with Physconia muscigena, Cladonia pocillum, Fulgensia bracteata and Caloplaca tominii. Leg: E. S. Hansen, 29.7.1998 \# 106519 (B).

Physcia adscendens(Fr.) H. Olivier. PiaAds1. MB: SSU, ITS; PB: I1d. GERMANY, München, Franz-Schrank-Str. am Stamm einer Jungen Fraxinus sp. Leg: G. Helms \& A. Beck 13.4.99 (GOET).

- PiaAds2. MB: ITS; PB: I1d. GERMANY, Baden-Württemberg, Südliche Oberrheinebene, Markgräfler Land: Müllheim, Werderstraße 79.Am Stamm eines jungen Malus domestica. Am Fundort gesellig. Leg: Tanja Dornes Juni 1998 \#: 9806.005 Herb. P. Dornes.

— PiaAds3. MB: ITS; PB: I1a. GERMANY, Baden-Württemberg, Südliche Oberrheinebene, Markgräfler Land: Müllheim, Werderstraße 79. Auf der flachrissigen Borke am Stamm eines jungen Malus domestica. Leg: P. Dornes 14.4.1996 \#: 40g Herb. P. Dornes.

— PiaAds4. MB: ITS; PB: -. SPAIN, Madrid, Cercedilla, Platanen am Wanderweg westl. des Bahnhofes, ca. 1150m. Leg: G. Helms \& V. Souza-Egipsy 30.April 2000 (GOET).

— PiaAds5. MB: ITS; PB: I1a. SPAIN, Cercedilla, Las Dehesas, roadside bfore P, on Populus, 1400 m. Leg: G. Helms \& V. SouzaEgipsy 30.4.00 (GOET)

— PiaAdsMi. MB: -; PB: I1d. S-GERMANY, Mittenwald, Bergahorn vor der Araltankstelle. Leg: G. Helms (Voralpenexkursion), 13.10.00 (GOET).

— PiaAdsW. MB: -; PB: I1a. GERMANY, München. Pullach, Wolfratshäuserstrasse, alte Straßenbäume (Acer sp., Tilia sp.). Leg: G. Helms (Voralpenexkursion), Oktober 2000 (GOET).

Physcia aipolia (Ehrh. ex Humb.) Fürnr. PiaAip1. MB: SSU, ITS; PB: I1e. Germany, Lk München, Pullach (Grünwalderstr.). Spitzahorn, Straßenallee. 580 m, Tk25: 7935/13. Leg: T. Friedl, \# 94/10, 10.10.1994 (GOET).

— PiaAipII. MB: ITS; PB: I1a. GERMANY, Baden-Württemberg, Markgräfler Land, Südschwarzwald: In der Nähe des Waldes südwestlich von Lipburg, am Rand eines Weges. An dicken Kronenästen einer halbabgestorbenen, alten, freistehenden Juglans regia. Vom Wind umgeworfen. Am Fundort gesellig. Leg: P. Dornes 2.4.1995 \#: 37b Herb. P. Dornes.

— PiaAip3. MB: ITS; PB: I1a. SPAIN, Navacerada, road to Barranca, on Populus nigra,. Leg: G. Helms \& A. Espinosa 17.4.00 (GOET).

Physcia alba (Feé) Müll. Arg. PiaAlb1. MB: SSU, ITS; PB: G9a. EL SALVADOR, Depto. Ahuachapán: P. N. El Imposible, sector La Fincona; Bosque del Tanque, near La Fincona; $13^{\circ} 51^{\prime} \mathrm{N}, 89^{\circ} 59^{\prime} \mathrm{W}, 800 \mathrm{~m}$. On old Manilkara chicle (Nispero, \# 4A) tree, ca. $25 \mathrm{~m}$ tall, in semievergreen, dry, primary forest, on fallen canopy branches. Leg: R. Welz, \# 738, 25.11.98 (B).

Physcia atrostriata Moberg. PiaAtr1. MB: SSU, ITS; PB: -. GUYANA, Region 7 (Upper Mazaruni Distr.) Paruima Mission, Warik-ma Tepu, hill N of the village, across Kamarang river. $61^{\circ} 04^{\prime} \mathrm{W}, 5^{\circ} 50^{\prime} \mathrm{N}, 60 \mathrm{~m}$. Abandoned field at foot. On rock. Leg: H. Sipman, \# 39628, 2.5.97 (B).

- PiaAtr2. MB: ITS; PB: G9b. EL SALVADOR, Depto. Ahuachapán: P. N. El Imposible, sector La Campana; Cafetal Las Piedrones; $13^{\circ} 51^{\prime} \mathrm{N}, 89^{\circ} 55^{\prime} \mathrm{W}, 1300 \mathrm{~m}$. Coffee plantation, on trunks of shade trees. Leg: H. Sipman, \# 44971, 19.11 .99 (B).

Physcia caesia (Hoffm.) Fürnr. PiaCae1. MB: ITS; PB: I1c. SPAIN, N of Collado Mediano, on Granit (Wegböschung), S-exp. in pinus forest;. Leg: G. Helms \& V. Souza-Egipsy 16.4.00 (GOET).

- PiaCae2. MB: ITS; PB: I1s, I1t. Germany, Bayern, Spessart: Wiesen. Auf waagrechten Flächen einer niedrigen Betonmauer an der Hauptstraße. zerstreut,. Leg: P. Dornes, 22.7.1998 \#: 9807.004 Herb. P. Dornes.

— PiaCae3. MB: ITS; PB: I1c. SPAIN, Madrid, Collado Mediano, Höhenweg oberhalb Collado Mediano, ca 1100 m, on rock, S-exp. Leg: V. Souza-Egipsy, P. Dornes \& G. Helms. 10.9.00 (GOET).

- PiaCae4. MB: ITS; PB: I1j. ANTARCTIS: High Flat Iron Valley, 515 m, NW-exp. Scree slope, dry water channel. Leg: C. M. Harris, 6.2.01 FIH-1 (GOET).

Physcia dimidiata (Arnold) Nyl. PiaDim1. MB: SSU, ITS; PB: I1a. AUSTRIA, Steiermark: Oststeirisches Hügelland, Riegersburg N Feldbach, nordwestl. u. westseitige Abbrüche der Burgfelsen, am Eselsteig, 420-450 m, Tuffit. Leg: 27.2.00 Mayrhofer \& Litterski \# 13.932 (GZU).

— PiaDim2. MB: -; PB: I1a. FRANKREICH, Elsaß, Nordvogesen: Chateau. Auf vertikalen Parteien einer Buntsandsteinmauer bei der Burgkapelle. an Fundort gesellig. Leg: P. Dornes 1.7.1998 \#: 502a Herb. P. Dornes.

Physcia erumpens Moberg. PiaEru1. MB: ITS; PB: G9a. EL SALVADOR, Depto. Ahuachapán: P. N. El Imposible, sector La Fincona; Bosque del Tanque, near La Fincona; $13^{\circ} 51^{\prime} \mathrm{N}, 89^{\circ} 59^{\prime} \mathrm{W}, 800 \mathrm{~m}$. Semi-evergreen, dry, secondary forest in abandoned coffee plantation; on mature Amate (\# 1C, Ficus sp.) tree, ca. $25 \mathrm{~m}$ tall, on bark of trunk, ca. $8 \mathrm{~m}$ above the ground. Leg: R. Welz, \# 182, 11.12 .98 (B).

Physcia integrata Nyl. PiaInt1. MB: ITS; PB: G9a. EL SALVADOR, Depto. Ahuachapán: P. N. El Imposible, sector San Benito; Cerro El León; $13^{\circ} 50^{\prime} \mathrm{N}, 89^{\circ} 57^{\prime} \mathrm{W}, 1100 \mathrm{~m}$. Stunted primary forest with exposed rock outcrops on summit. Leg: Sipman \& Welz, \# 44890, 13.11 .98 (B). 
— PiaInt2. MB: ITS; PB: G9b. EL SALVADOR, Depto. Ahuachapán: P. N. El Imposible, sector La Campana; Cafetal Las Piedrones; $13^{\circ} 51^{\prime} \mathrm{N}, 89^{\circ} 55^{\prime} \mathrm{W}, 1300 \mathrm{~m}$. Coffee plantation, on trunks of shade trees. Leg: H. Sipman, \# 44975, 19.11.99 (B).

Physcia krogiae Moberg. PiaKro1. MB: ITS; PB: G4b. EL SALVADOR, Depto. Ahuachapán: P. N. El Imposible, sector La Fincona; valley of Rio Nixtepe, near La Fincona, below Cueva de Cal; $13^{\circ} 51^{\prime} \mathrm{N}, 89^{\circ} 59^{\prime} \mathrm{W}, 400 \mathrm{~m}$. Primary forest remnant on valley bottom. On fallen Mulo (Licania retifolia) tree trunk (tree 2). Leg: Sipman \& Welz, \# 44672, 7.11 .98 (B).

Physcia lobulata Moberg. PiaLob1. MB: -; PB: I4a. EL SALVADOR, Depto. Ahuachapán: P. N. El Imposible, sector La Campana; Cafetal Las Piedrones; $13^{\circ} 51^{\prime} \mathrm{N}, 89^{\circ} 55^{\prime} \mathrm{W}, 1300 \mathrm{~m}$. Coffee plantation, on trunks of shade trees. Leg: Sipman \& Bohnke, \# 44972, 19.11 .99 (B).

Physcia millegrana Degel. PiaMil1. MB: ITS; PB: I2b. USA, Iowa, Iowa City. Am Fundort gesellig. Leg: T. Friedl, August.1998 det.: P.Dornes 25.8.1998, \# x80 Herb. P.Dornes.

Physcia semipinnata (Gmelin) Moberg. PiaSem1. MB: ITS; PB: I2b. SPANIEN, Prov. Murcia, Sierra de la Pila: Nebengipfel am Nordosthang des Pila, in ca. $900 \mathrm{~m} \mathrm{NN}$. An dürren Zweigen eines jungen Quercus ilex in einem lichten, montanen Pinus halepensis - Wald. Am Fundort gesellig. Leg: P. Dornes 23.11.1996 \#: 133b Herb. P. Dornes.

— PiaSem2. MB: ITS; PB: I1a. SPAIN, Madrid, Collado Mediano, O slope of the Castillo, ca 1100 m. Leg: G. Helms \& P. Dornes. 10.9.00 (GOET).

- PiaSemN. MB: -; PB: I1m. SPAIN, Madrid, Nava del Rayo, Quercus pyrinaicus- Wäldchen. Am Stamm junger Q. pyrinaicus. Ca 1000m. Leg: V. Souza-Egipsy, Daniela, Libertat, G. Helms, 13.4.01 (GOET).

Physcia sorediosa (Vain.) Lynge. PiaSor1. MB: ITS; PB: G9a. EL SALVADOR, Depto. Ahuachapán: P. N. El Imposible, sector La Campana; Cafetal Las Piedrones; $13^{\circ} 51^{\prime} \mathrm{N}, 89^{\circ} 55^{\prime} \mathrm{W}, 1300 \mathrm{~m}$. Coffee plantation, on trunks of shade trees. Leg: Sipman \& Bohnke, \# 44971a, 19.11 .99 (B).

Physcia sp. PiaSp4. MB: -; PB: I4a. NAMIBIA: Otjiwarongo, Groot Waterberg, Waterberg Plateau, near Bernabe de la Bat Camp. $1650 \mathrm{~m}$ alt. $20^{\circ} 25^{\prime}$ S, $17^{\circ} 15^{\prime}$ E. On the plateau; on twigs of a shrub, at southern side. Leg: C. Kainz, 30.8 .98 \# 234 (M).

Physcia stellaris (L.) Nyl. PiaSte1. MB: SSU, ITS; PB: I1h. GERMANY, München, Franz-Schrank-Str. am Stamm einer Jungen Fraxinus sp. Leg: G. Helms \& A. Beck 13.4.99 (GOET).

— PiaSte2. MB: -; PB: I1e. GERMANY, Baden-Württemberg, Südliche Oberrheinebene, Markgräfler Land: Nordöstlich von Müllheim. An Ästen von Juglans regia in einer Streuobstwiese. Am Fundort zerstreut. Leg: P. Dornes 31.12.1993 \#: 36a Herb. P. Dornes.

- PiaSte3. MB: ITS; PB: I1a. GERMANY, Baden-Württemberg, Südliche Oberrheinebene, Markgräfler Land: Westlicher Ortrand von Niederweiler. An einem Kronenast Ast einer alten, gefällten Juglans regia. Leg: P. Dornes 11.4.1996 \#: 9604.006 Herb. P. Dornes.

— PiaSte4. MB: ITS; PB: I1c. SPAIN, Madrid, Collado Mediano, Alfredos Garten. Leg: G. Helms \& V. Souza-Egipsy 4. 2000 (GOET).

— PiaSte5. MB: ITS; PB: I1a. SPAIN, Villalba, Populuspark, ca. 950 m, on Populus.,. Leg: G. Helms, V. Souza-Egipsy, Alfredo, Anchilles, Paco 25.4.00 (GOET).

— PiaSte6. MB: ITS; PB: I1v. SPAIN, Madrid, Aranjues, Gipsiferous hills at Mar de Otigola, on branch, ca. 450 m. Leg: V. SouzaEgipsy, P. Dornes \& G. Helms 16.9.00 (GOET).

_ PiaSteT. MB: -; PB: I1a. SPAIN, Madrid, El Tiemblo, El Castanar del Tiemblo. Kastanienwald mit Quercus pyrinaicus, z. T. sehr alte Bäume. Ca. 1200m, N 40²0.906', W 4³0.868'. Leg: Libertat, Daniela, V. Souza-Egipsy, G. Helms, 14.4.01 (GOET).

Physcia tenella (Scop.) DC. PiaTen1. MB: ITS; PB: I1d. GERMANY, Hessen, Hessisches Bergland, Burgwald: Südöstlich bei Mellnau. Auf der tiefrissigen Borke am Stamm einer alten Fraxinus excelsior am Rand einer Straße. Leg: P. Dornes 24.7.1995 \#: 45g Herb. P. Dornes.

— PiaTen2. MB: -; PB: I1d. GERMANY, Hessen, Hessisches Bergland, Amöneburger Becken: Schweinsberg, nordwestlich bei der Burg. Auf den glatten Borkenpartien am Stamm alter, freistehender Acer pseudoplatanus. Leg: P. Dornes 14.4.1995 \#: 45e Herb. P. Dornes.

— PiaTen3. MB: ITS; PB: I1h. SPAIN, Madrid, Navacerrada. Leg: G. Helms \& V. Souza-Egipsy April 2000 (GOET).

— PiaTen4. MB: ITS; PB: I1a. SPAIN, Navacerada, Ortsrand Richtung „old hospital“, On bark of Ailanthus sp., O-exp. Leg: G. Helms \& A. Espinosa 17.4.00 (GOET).

- PiaTenJ. MB: -; PB: I1j. SPAIN, Sierra de Gredos, an der Straße zw. Jerte und Harvas. Nahe der Baumgrenze, ca. 1370 m, am Stamm alter Q. pyrinaicus. N $40^{\circ} 13.862^{\prime}$, W 552.710'. Leg: V. Souza-Egipsy, G. Helms, 18.4.01 (GOET).

— PiaTenM. MB: -; PB: I1d. GERMANY, Hessen, Meißner, Salix sp. Leg: G. Helms (Praktikumsexkursion zum GP2 2001) (GOET).

- PiaTenMi. MB: -; PB: I1d. S-GERMANY, Mittenwald, Bergahorn vor der Araltankstelle. Leg: G. Helms (Voralpenexkursion), 13.10.00 (GOET).

Physcia tribacia (Ach.) Nyl. PiaTri1. MB: ITS; PB: I4a. GERMANY, Rheinland-Pfalz, Rheinhessen, Nahetal: Bad Münster am Stein, Burgberg der Ruine Rheingrafenstein. Auf einem mäßig besonnten, vertikalen Quarzporphyr - Felsen am Rand des Weges in ca. $220 \mathrm{~m}$ NN. gesellig. Leg: \& det: P. Dornes \& Tanja Dornes 9.8.1998 \#: 504a Herbar P. Dornes.

- PiaTri2. MB: ITS; PB: I2d. SPAIN, Barcelona, St. Coloma de Farnes, Rocky peak next to the Castillo de Farnes, On ground rock, ca 450 m. Leg: G. Helms \& P. Dornes. 8.9.00 (GOET).

Physcia undulata Moberg. PiaUnd1. MB: SSU, ITS; PB: G7b. SINGAPORE: Sembawan Park, on N-coast. $1^{\circ} 28^{\prime}$ N, $103^{\circ} 51^{\prime}$ E, ca. 2 m. Grassland with scatteres trees and shrubs. On tree trunk within reach from the ground. Leg: H. Sipman, 25.11.00 \# 46400 (B).

Physconia distorta (With.) J. R. Laundon. PcoDis1 (II). MB: ITS; PB: I1a. SPAIN, Madrid, Cercedilla, Las Dehesas, roadside before parking lot, on Populus sp. 1400 m. Leg: G. Helms \& V. Souza-Egipsy 30.April 2000.

— PcoDis2. MB: ITS; PB: I1a. SPAIN, Cercedilla, Las Dehesas, roadside bfore P, on Populus, 1400 m. Leg: G. Helms \& V. SouzaEgipsy 30.4.00 (GOET).

- PcoDis3/ PcoPulv1. MB: -; PB: I1d. GERMANY, Lk München, Pullach (Grünwalderstr.). Spitzahorn, Straßenallee. 580 m, Tk25: 7935/13.Leg: T. Friedl \# 94/1, 10.10.1994 (GOET).

- PcoDisHT. MB: -; PB: I1a. SPAIN, Madrid, Nava del Rayo, Quercus pyrinaicus- Wäldchen. Am Stamm junger Q. pyrinaicus. Ca 1000m. Thallus "hypertroph". Leg: V. Souza-Egipsy, Daniela, Libertat, G. Helms, 13.4.01 (GOET).

- PcoDisN. MB: -; PB: I1m. SPAIN, Madrid, Nava del Rayo, Quercus pyrinaicus- Wäldchen. Am Stamm junger Q. pyrinaicus. Ca 1000m. Thallus "normal". Leg: V. Souza-Egipsy, Daniela, Libertat, G. Helms, 13.4.01 (GOET).

Physconia enteroxantha (Nyl.) Poelt. PcoEnt1. MB: SSU, ITS; PB: I1a. SPAIN, Puerto de Valdemorillo, on soil/rock SW-exp. Leg: V. SouzaEgipsy, A. Espinosa, G. Helms 20.4.00 (GOET).

— PcoEnt2. MB: ITS; PB: I1c. SPAIN, Cercedilla, Las Dehesas, roadside before P, on Populus, 1400m. Leg: V. Souza-Egipsy \& G. Helms 30.4.00 (GOET).

— PcoEnt3. MB: ITS; PB: I1d. GERMANY, Rheinland-Pfalz, Pfälzerwald: Entersweilerhof östlich von Kaiserslautern. Am Stamm einer freistehenden, alten Populus $x$ canadensis am Ufer der Lauter. Leg: P. Dornes 30.8.1998 \#: 240d Herbar P. Dornes.

Physconia grisea (Lam.) Poelt. PcoGri1. MB: ITS; PB: I1d. GERMANY, Baden-Württemberg, Bodenseebecken: In der Nähe der Schiffsanlegestelle von Kressbronn. Am Stamm eines alten, solitären Acer pseudoplatanus. Leg: P. Dornes 7.9.1995 \#: 112e Herb. P. Dornes.

— PcoGri2. MB: ITS; PB: I1d. GERMANY, Baden-Württemberg, Neckarland, Schönbuch: Hof des Klosters von Bebenhausen. Am Stamm einer sehr alten, freistehenden Tilia sp. Am Fundort ziemlich selten. Leg: P. Dornes 1.9.1995 \#: 112c Herb. P. Dornes. 
— PcoGri3. MB: ITS; PB: I1d. GERMANY, Baden-Württemberg, Markgräfler Land, Südschwarzwald: Westlicher Eichwald in der Nähe von Müllheim. Am Stamm eines alten, gefällten Laubbaumes (vermutlich Juglans regia). Am Fundort gesellig. Leg: P. Dornes 30.12.1997 \#: 112h Herb. P. Dornes.

- PcoGri4. MB: ITS; PB: I1d. GERMANY, Hessen, Mittleres Lahntal: Wetzlar, Schiefer-Bruchsteinmauer neben dem Dom. Über Moosen und direkt auf Gestein. am Fundort gesellig. Leg: P. Dornes 10.12.1995 \#: 112f Herb. P. Dornes.

— PcoGri5. MB: ITS; PB: I1d. GERMANY, Rheinland-Pfalz, "Rheinhessen": Kurpark von Bad Dürkheim. An der Stammbasis eines freistehenden Catalpa bignonioides. am Fundort gesellig. Leg: P. +T. Dornes Mai 1998 \#: 112k Herb. P. Dornes.

— PcoGri6. MB: ITS; PB: I1d. AUSTRIA, Steiermark: Oststeirisches Hügelland, Riegersburg N Feldbach, nordwestl. u. westseitige Abbrüche der Burgfelsen, am Eselsteig, 420-450 m, Tuffit. Leg: 27.2.00 Mayrhofer \& Litterski \# 13.929 (GZU).

- PcoGri7. MB: ITS; PB: I1a. SPAIN, Madrid, El Escorial, Allee trees O of monastry, ca 900 m. Leg: G. H., P. D., Alfredo \& Isabell 11.9.00 (GOET).

- PcoGri8. MB: ITS; PB: I1d. ITAly, Toscana, Firenze: Chianti: San Donato in Pogio ca. $30 \mathrm{~km}$ SE of Firenze, ca. $400 \mathrm{~m}$; $43^{\circ} 32^{\prime} \mathrm{N} / 11^{\circ} 14^{\prime} \mathrm{E}$; On road side Cupressus semervirens close to the cemetry. Leg: H. Mayrhofer \# 13.888 30.4.99 (GZU).

Physconia muscigena (Ach.) Poelt. PcoMus2. MB: ITS; PB: I1u. S. W. GREENLAND: Head of S $\varnothing$ ndre Str $\varnothing$ mfjord, Ravneklippen. 6700' N, $50^{\circ} 41^{\prime} \mathrm{W}$. On mosses in a thin layer of loess gneissic boulder. Leg: E. S. Hansen, 28.7.98 (B).

Physconia perisidiosa (Erichsen) Moberg. PcoPer1. MB: SSU, ITS; PB: I1k. GERMANY, Lk München, Pullach (Grünwalderstr.). Straßenallee. 580 m, Tk25: 7935/13 Beleg\#. Leg: T. Friedl, 10.10.1994 \# 94/12 (GOET).

— PcoPer2. MB: ITS; PB: I1d. GERMANY, Hessen, Lahntal: Weilburg, Minigolfplatz in der Nähe des Lahnufers. An dem Stamm eines Acer pseudoplatanus, in einem älteren, relativ dichten Bestand am Fundort gesellig. Leg: \& det: P. T. Dornes Juli 1997 \#: $393 \mathrm{~b}$ Herbar P. Dornes.

Physconia sp. PcoSp1. MB: ITS; PB: I1d. FRANCE, Dépt. Var, c. 3, $5 \mathrm{~km} \mathrm{~S}$ of Fayence, 1, $5 \mathrm{~km} \mathrm{~N}$ of village St-Paul-en-forêt, camping site „le

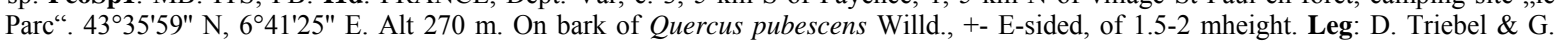
Rambold, 22.4.2000 \# 6387 (M).

Physconia venusta (Ach.) Poelt. PcoVen1. MB: ITS; PB: I1a. SPAIN, Madrid, El Escorial, La Herreria, ca. 1000 m on Quercus pyrinaicus (forest). Leg: G. Helms \& P. Dornes 14.9.00 (GOET).

Pyxine cocoes (Sw.) Nyl. PyxCoc1. MB: ITS; PB: G3a. SINGAPORE, Fort Canning Park, in town centre. $1^{\circ} 17.5^{\prime} \mathrm{N}, 103^{\circ} 51^{\prime} \mathrm{E}$; alt. $30 \mathrm{~m}$. On tree trunks in park on hilltop. Leg \& det: H. Sipman, 18.11.2000 \# 46259 (B).

— PyxCoc2. MB: ITS; PB: G3a. VENEZUELA, Caracas DF. Parque National El Avila, Altamira, 1000 m. Sobre rama de Eurthrina poeppigiana. Leg: B. Manara 21.6.97 det: H. Sipman 1999 \# 767a (B).

Pyxine farinosa Kashiw. PyxFar1. MB: SSU, ITS; PB: G3b. SINGAPORE, southern islands, Kusu Island. $1^{\circ} 13^{\prime} \mathrm{N}, 1_{100^{\circ}} 52^{\prime} \mathrm{E}$; alt. $1 \mathrm{~m}$. Cleared beach forest with scattered Casuarina, Terminalia and planted trees. On tree trunk within reach from the ground. Leg: H. Sipman, 14.11.2000 \# 46068 (B).

Pyxine obscurascens Malme. PyxObs1. MB: SSU, ITS; PB: G10.VENEZUELA, Edo. Amazonas, Alto Orinoco, Savanna of la Esmeralda, near Humbodt-station, $65^{\circ} 33^{\prime} \mathrm{W}, 3^{\circ} 11^{\prime} \mathrm{N}$, alt. $150 \mathrm{~m}$. Non-flooded tree- and shrub-savanna on slopes of small hills. Leg: A. Jentzsch det: H. Sipman März 1996 \# 15 (B).

Pyxine petricola Nyl. PyxPed1. MB: SSU, ITS; PB: -. VENEZUELA, Caracas DF. Parque National El Avila, Altamira, 1000 m. Sobre rame de Erythina poeppigiana. Leg: B. Manara det: H. Sipman 21.6.199 \# 767 (B).

Pyxine sorediata (Ach.) Mont. PyxSor2. MB: ITS; PB: G8a. KAMBODSCHA, Siem Riap, Bayon, 9, 2 km N Siem Reap; ca. 100 m, auf Sandstein; N 13²2'20", E 101³3'18". Leg: U. Schwarz 14.2.1998 det: H. Sipman 1999 \# 541 (B).

Pyxine sp. PyxSp1. MB: -; PB: G3c. BRAZIL, Pernambuco, Reserva Ecológica de Gurjaú, municípios do Cabo, Moreno e Jaboatao dos Guararapes, propriedade da Companhia Pernambucana de Saneamento (COMPESA); $8^{\circ} 16^{\prime} \mathrm{S}, 35^{\circ} 00^{\prime} \mathrm{E}, 80-150 \mathrm{~m}$; remanescente da Mata Atlantica sobre rochas cristalinas, com floresta perenifolia primaria alternando com vegetacao secundaria; sobre cortex de árvores pequenos. Leg: M. Cáceres \& R. Lücking, Okt. 2000 \# 00-957 (GOET).

Rinodina atrocinerea (Hook.) Körb. RinAtro1. MB: SSU, ITS; PB: A10a, A11a, A6a. AUSTRIA, Steiermark, Teigitschgraben S Voitsberg, ca. 2,5 km NE der Langmannsperre, ca. 560-600 m. Leg: H. Mayrhofer \& U. Arup 16.11.98 \# 13.740 (GZU).

Rinodina capensis Hampe. RinCap1. MB: SSU, ITS; PB: I1g. AUSTRIA, Kärnten: Gailtaler Alpen, Gemeinde Paternion, zwischen Boden und Farchtensee; ca. 995 m; 46² 1 'N / 13²9'E; auf Tilia cordata. Leg: 09.11.1998, H. Mayrhofer 13.723 \& B. Pichorner (GZU). .

Rinodina gennarii Bagl. RinGen1. MB: SSU, ITS; PB: -. GREECE, Cyclades Archipelago, Paros. Along road from Lefkes to Aspro Chorio, in Kavouropotamos valley. $37^{\circ} 01^{\prime} \mathrm{N}, 25^{\circ} 12^{\prime} \mathrm{E}$, ca. 350-400 m. Gneissic rock outcrops in S facing slope with low scrub. Leg: H. Sipman \& T. Raus 22 June 1998 \# 43369 (B).

— RinGen2. MB: SSU, ITS; PB: A2c. THE NETHERLANDS, prov. Utecht: Soest, along Kastanjelaan near railway station Soest-Zuid. Coord. 149.0-463.8; km-block 32.32.25. On roadside Aesculus trunk ca. 25 cm diam. Leg: H. Sipman 6 June 2000 \# 44435 (B).

Rinodina lecanorina (A. Massal.) A. Massal. RinLec1. MB: SSU, ITS; PB: I1g, I1p. AUSTRIA, Steiermark, Grazer Bergland, Jungfernsprung bei der Ruine Gösting; ca. 565 m; $15^{\circ} 23^{\prime} \mathrm{E} / 47^{\circ} 06^{\prime} \mathrm{N}$; MTB: 8858/3. Leg: H. Mayrhofer \# 13.120 22.9.96 (GZU).

Rinodina milvina (Wahlenb.) Th. Fr. RinMil1. MB: ITS; PB: I1n. FINNLAND, Nylandia, Sibbo/Sipoo: Kalkstrand, coastal rocks, $60^{\circ} 15^{\prime} \mathrm{N} / 25^{\circ} 24^{\prime} \mathrm{E}$, 02.08.1997. Leg: H. Mayrhofer 13.702 (GZU).

Rinodina mniaraea var. mniaraeiza (Nyl.) H. Magn. BulIns1. MB: SSU, ITS; PB: -. SWEDEN. TORNE LAPPMARK: Jukkasjärvi Below Paddos, ca. 4 km NE of Abisko. Alt. 600 m. Lat/long: 68:19 N, 18:51 E. On the ground. Leg: 21.VIII.1996. Anders Nordin 4417 (UPS).

Rinodina nimisii Giralt \& H. Mayrhofer. RinNim1. MB: ITS; PB: G8a. GREECE, Cyclades Archipelago, Paros. Santa Maria, Ormos Alikis. $37^{\circ} 08.5^{\prime}$ $\mathrm{N}, 25^{\circ} 17^{\prime}$ E, $1 \mathrm{~m}$. Coastal sand dunes with Juniperus macrocarpa dominated scrub. On Juniperus macrocarpa shrub. Leg: H. Sipman \& T. Raus 14.June 1998 \# 42685 (B).

Rinodina obnascens (Nyl.) H. Olivier. RinObn1. MB: ITS; PB: A2c. GREECE, Cyclades Archipelago, Paros. Kolymbithres, ca. 2 km W of Naoussa, S-side of Mt. Vigla. $37^{\circ} 07.5^{\prime} \mathrm{N}, 25^{\circ} 13^{\prime} \mathrm{E}$, ca. $25 \mathrm{~m}$. Largely barren granite slope with little valleys. On granite rock. Leg: H. Sipman \& T. Raus 12 June 1998 \# 42477 (B).

Rinodina oleae Bagl. RinOle1. MB: ITS; PB: A1b. GREECE, Cyclades Archipelago, Paeos. Ormos Molos, E of Marmara. 37 $03.5^{\prime} \mathrm{N}, 25^{\circ} 16^{\prime} \mathrm{E}, 1 \mathrm{~m}$. On $15 \mathrm{~cm}$ diam. Trunk of Juniperus macrocarpa tree near the beach. Leg: H. Sipman \& T. Raus 14.June 1998 \# 42740a (B).

Rinodina olivaceobrunnea Dodge \& Baker. RinOli1. MB: ITS; PB: I1g. ANTARCTICA: Lagoon Island, 15m, 68 $15^{\prime} \mathrm{W}, 67^{\circ} 35^{\prime} \mathrm{S}$ on moss. Leg: J. Romeike, 20.1.99 (GOET).

Rinodina oxydata (A. Massal.) A. Massal. RinOxy1. MB: SSU, ITS; PB: A10a, A6a, I5a. AUSTRIA, Steiermark: Oststeirisches Hügelland, Riegersburg N Feldbach, nordwestl. u. westseitige Abbrüche der Burgfelsen, am Eselsteig, 420-450 m,. Leg: 27.2.00 Mayrhofer \& Litterski \# 13.930 (GZU).

Rinodina pyrina (Ach.) Arnold. RinPyr1. MB: ITS; PB: A1a. AUSTRIA, Steiermark, Niedere Tauern, Schladminger Tauern, Naturpark Sölktäler, Kleinsölktal Forsthaus Kohlung, auf Ribes rubrum, ca. 1000m. Leg: P. Bilovitz \& H. Mayrhofer 18.5.99 \# 483 (GZU). 
Rinodina sophodes (Ach.) A. Massal. RinSop1. MB: SSU, ITS; PB: A1a. AUSTRIA, Steiermark, Niedere Tauern, Schladminger Tauern, Naturpark Sölktäler, Großsölktal entlang des Bräualmbaches, bachbegleitende Gehölze, ca. $1130 \mathrm{~m}$, auf Ästen von Salix sp. Leg \& det: P. Bilovitz 7.8.98 \# 968 (GZU).

Rinodina sp. RinSp1. MB: -; PB: G4a. COSTA RICA, Prov. Guanacaste, Pazifikküste bei Puerto Vieja w Brasilito, Felsen im Trockenwald nahe der Küste, ca. 40m. Leg: H. Mayrhofer \& E. Hierzer 8.4.91 \# 9943 (GZU).

Rinodina tunicata H. Mayrhofer \& Poelt. RinTun1. MB: ITS; PB: A5b, A9a. GRIECHENLAND, Kreta, Nomós Chaníon, ca. 1 km S Imbros an der Straße nach Hora Sfakion, E-exp. Kalkschrofen über dem Einstieg zur Imbros-Schlucht, ca 800m. Leg: H. Mayrhofer\& R. Ertl 13.5.97 \# 13.749 (GZU).

Rinodina zwackhiana (Kremp.) Körb. RinZwa1. MB: ITS; PB: A9a. SLOWENIEN, Kras SW-exp. Felsabbrüche über Crni Kal, ca 380m, Kalk. Leg: H. Mayrhofer 9.4.99 \# 13.848 (GZU).

Rinodinella controversa (A. Massal.) H. Mayrhofer \& Poelt. RilCon1. MB: SSU, ITS; PB: A5a, A9a. GRIECHENLAND, Kreta, Nomós Chaníon, ca. $1 \mathrm{~km} \mathrm{~S}$ Imbros an der Straße nach Hora Sfakion, E-exp. Kalkschrofen über dem Einstieg zur Imbros-Schlucht, ca 800m-. Leg: H. Mayrhofer \& R. Ertl 13.5.97 \# 13.747 (GZU).

Santessonia sorediata Sérus. \& Wessels. SanSor1. MB: SSU, ITS; PB: A2b. NAMIBIA: Namib Desert, Namib Naukluft Park near Swakopmund, Moonlandscape, valley of river Swakop. $200 \mathrm{~m}$ alt. $22^{\circ} 45^{\prime} \mathrm{S}, 14^{\circ} 45^{\prime} \mathrm{E}$. SE slope, about $100 \mathrm{~m}$ in length, densly lichen covered; on granite stones. Leg: C. Kainz, 4.9.98 \# 275 (M).

Thelomma santessonii L. Tibell. TheSan1. MB: ITS; PB: -. MEXICO, Baja Calfornia. Cabo San Quintin, Cerro Kenton between Bahia Falsa and Bahia de San Quintin. $30^{\circ} 28^{\prime} \mathrm{N}, 116^{\circ} 00^{\prime} \mathrm{W}$, ca. $20 \mathrm{~m} .1 \mathrm{~m}$ tal desert scrub on E-side of low volcano: coastal scrub community (Aesculus californica, Ambroisia, Euphorbia misera, Jatropha, Lycium, etc.) with basalt rocks. On rock. Leg: H.Sipman, 4.1 .1989 \#24826 (B).

Thelomma siliceum (Fée) Tibell . TheSil1. MB: ITS; PB: -. GREECE, East Aegean Islands, Nomos Dodekanisou: Kos Island, Kefalos peninsula. Ca. $4 \mathrm{~km} \mathrm{~S}$ of Kefalos, along road to Aigos Ioannis. $36^{\circ} 435^{\prime} \mathrm{N}, 26^{\circ} 574^{\prime} \mathrm{E}$, ca. $200 \mathrm{~m}$. Phrygana dwarfshrub vegetation on hilltop with siliceous rock outcrops. Accomp: Xanthoria calcicola Oxner, Diploicia canescens. Leg: H. Sipman, 23.9.2000 \# 47029 (B)

Tornabea scutellifera (With.) J. R. Laundon. TorScu1. MB: SSU, ITS; PB: A1b. OMAN, Dhofar: plateau of Jabal Samhan, near radio station. $17^{\circ} 07^{\prime}$ $\mathrm{N}, 54^{\circ} 43^{\prime} \mathrm{E}, 1150-1250 \mathrm{~m}$. Monsoon affected rocky hillslopes with Euphorbia balsamifera shrubland; epiphyte on E. balsamifera and Carissa edulis. Leg: P. Hein, 4.10.98 \# 5323 Det: H. Sipman, 2000 (B). 


\section{A.2 Trebouxia nrITS alignments}

Alignments of Trebouxia nrITS segments are shown that include unique sequence insertions in particular Trebouxia taxa. T. arboricola SAG 219-1a (Z68705, ITS-variant A2a) was chosen as a reference sequence for indicating insertion positions in FIGS. 1 - 4. The 18S portion of this reference sequence was stripped, and numbering of sequence positions starts with the first position of the ITS 1 region. In FIG. 5, T. impressa UTEX 893 (AF345890) was chosen as reference sequence.

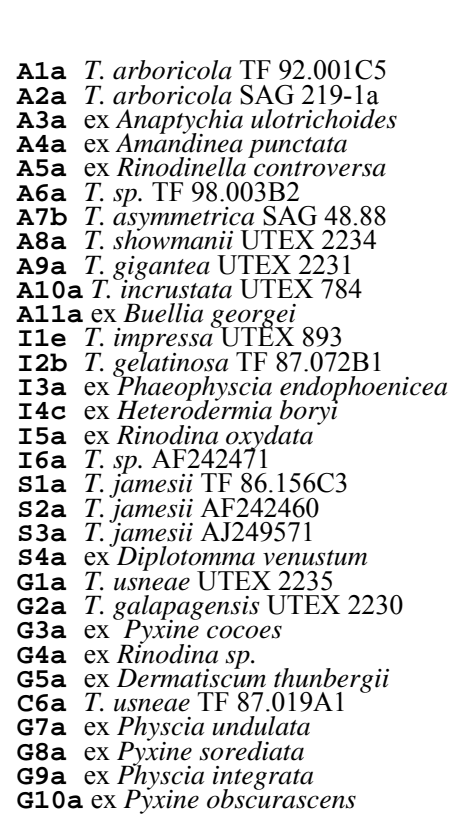

FIG.A.1: Segment of the Trebouxia nrITS 1 region. The alignment includes representatives of all subclades distinguished in this study. All ITS-variants of clade A are distinct from all other subclades by the lack of an AG rich stretch of $4-9$ bp after positions 59 .

Dots in sequence I2b of T. gelatinosa TF 87.072B1 indicate a sequence insertion shown in FIG. A.5. 
A 1a T. arboricola TF $92.001 \mathrm{C} 5$

A 1b ex Tornabea scutellifera

A 1c ex Buellia pharcidia

A 1d ex Buellia pharcidia

A 1e ex Anaptychia ciliaris

A 2a T. arboricola SAG 219-1a

A $\mathbf{2 b}$ ex Santessonia sorediata

A 2c ex Buellia frigida

A 2d ex Diplotomma lutosum

A 3a ex Anaptychia ulotrichoides

A 4a ex Anaptychia runcinata

A 4b ex Buellia triphragmioides

A 5a ex Diplotomma venustum

A $5 \mathbf{b}$ ex Rinodina tunicata

A $6 \mathbf{6}$ ex Rinodina oxydata

A 7a ex Buellia elegans

A 7b T. asymmetrica SAG 48.88

A 7c ex Buellia elegans

A 8a T. showmanii UTEX 2234

A 9a T. gigantea UTEX 2231

A10a T. incrustata UTEX 784

A11a ex Buellia georgei

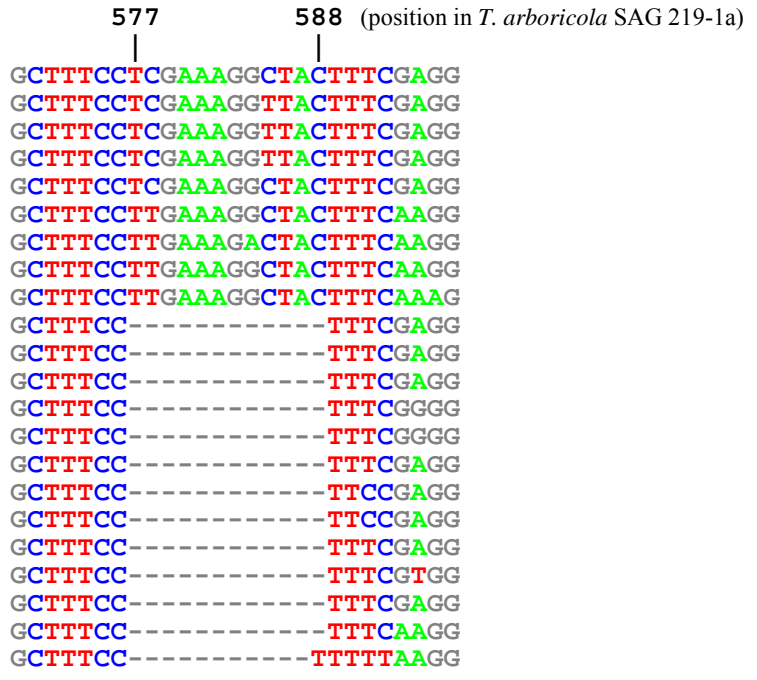

FIG. A.2: Segment of the Trebouxia nrITS 2 region. The alignment includes representatives of all subclades. distinguished in this study. A sequence insertion between positions 577 and 588 supprts a single origin of subclade A1 and $\mathrm{A} 2$.

A 1a T. arboricola TF $92.001 \mathrm{C} 5$

A $\mathbf{1 b}$ ex Tornabea scutellifera

A 1d ex Buellia pharcidia

A 1e ex Anaptychia ciliaris

A 2a T. arboricola SAG 219-1a

A $\mathbf{2 b}$ ex Santessonia sorediata

A 2c ex Buellia frigida

A 2d ex Diplotomma lutosum

A 3a ex Anaptychia ulotrichoides

A 4a ex Anaptychia runcinata

A $\mathbf{4 b}$ ex Buellia triphragmioides

A $5 \mathbf{a}$ ex Diplotomma venustum

A $5 \mathbf{b}$ ex Rinodina tunicata

A 6a ex Rinodina oxydata

A 7a ex Buellia elegans

A 7c ex Buellia elegans

A 8a T. showmanii UTEX 2234

A 9a T. gigantea UTEX 2231

A10a T. incrustata UTEX 784

A11a ex Buellia georgei
A 1c ex Buellia pharcidia

A 7 b T. asymmetrica SAG 48.88

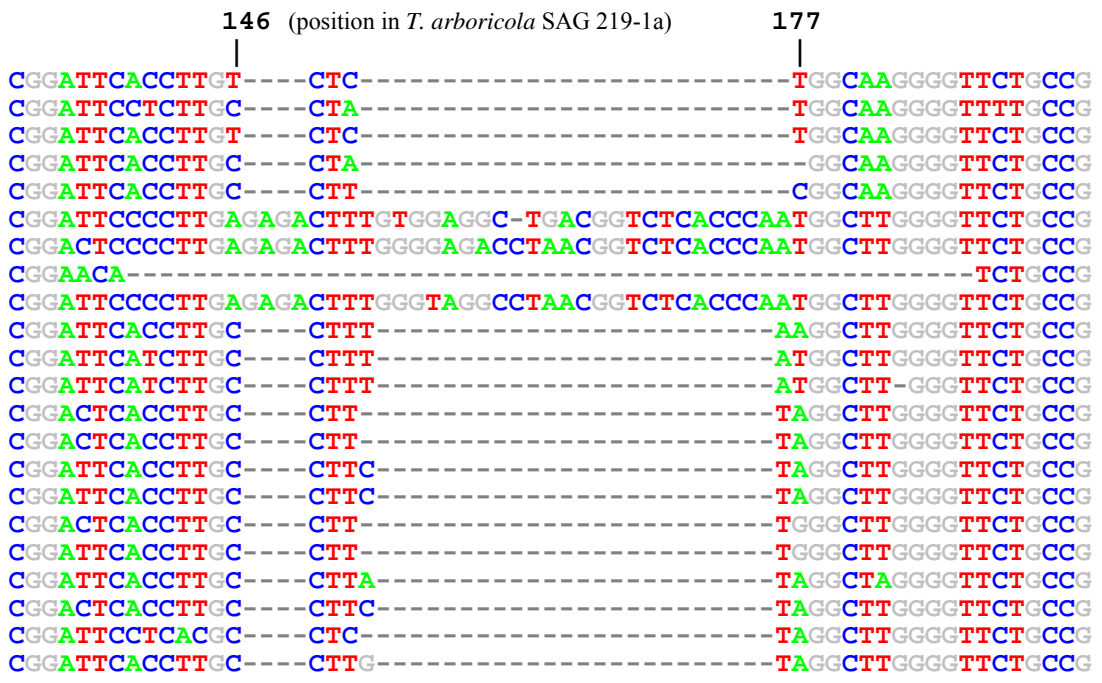

Fig. A.3: Segment of the Trebouxia nrITS 1 region. The alignment includes representatives of all ITS-variants of clade A. Subclade A2 was delimited from A1 and all other subclades by an additional sequence insertion at positions $146-$ 177. Notably this insertion plus flanking positions is absent in ITS-variant A2c. 
A $1 \mathbf{a}$ T. arboricola TF 92.001C5

A 1b ex Tornabea scutellifera

A $1 c$ ex Buellia pharcidia
A $1 \mathbf{d}$ ex Buellia pharcidia
A 1 ex Anaptychia ciliaris

A 1e ex Anaptychia ciliaris

2b ex Santessonia sorediata

A $2 \mathbf{c}$ ex Buellia frigida

A $\mathbf{3}$ ex Anaptychia ulotrichoides

4a ex Anaptychia runcinata

A b ex Buellia triphragmioides

5a ex Diplotomma venustum

$\mathbf{5 b}$ ex Rinodina tunicate
$\mathbf{6 a}$ ex Rinodina oxydata

6a ex Rinodina oxydata

A 7b T. asymmetrica SAG 48.88

A 8a T. showmanii UTEX 223

A 9a T. gigantea UTEX 2231
$7 \mathrm{c}$ ex Buellia elegans

A11a ex Buellia georgei

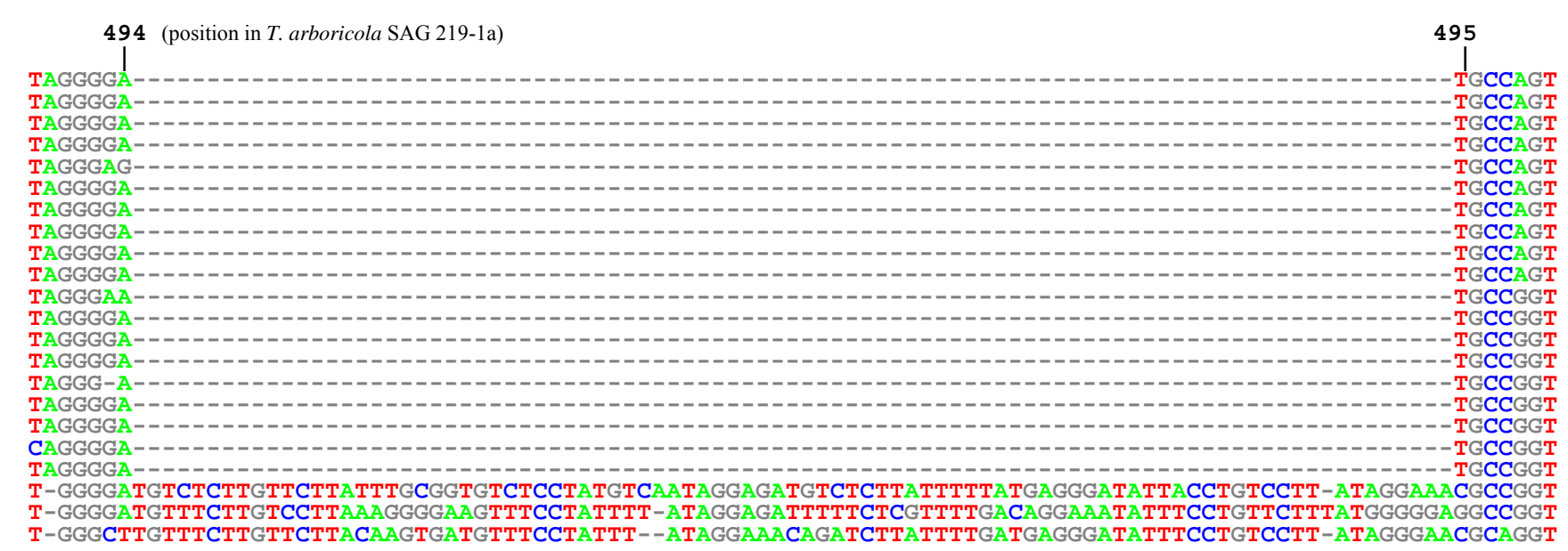

FIG. A.4: Segment of the Trebouxia nrITS 2 region. The alignment includes representatives of all ITS-variants of clade A. Subclades A9, A10, and the new ITS-variant A11a formed one lineage that was characterized by the presence of a sequence insertion of $85-87$ bp length at position 494 in the ITS-2 region 


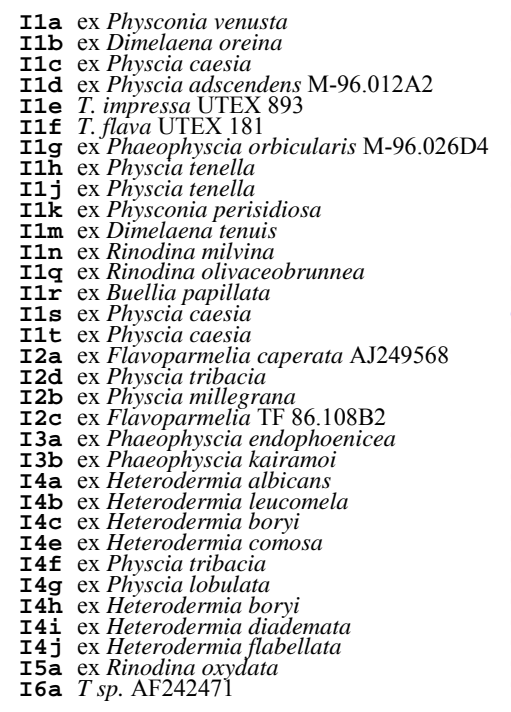

continued

I1a ex Physconia venusta

I1c ex Physcia caesia
I1d ex Physcia adscendens M-96.012A2

I1e T. impressa UTEX 893
I1f $T$. flava UTEX 181

I1g ex Phaeophyscia orbicularis M-96.026D

I1h ex Physcia tenella

I1je ex Physcia tenella

I1k ex Physconia perisidiosa
I1m ex Dimelaena tenuis
I1n ex Rinodina milvina

I1n ex Rinodina milvina
I1q ex Rinodina olivaceobrunnea

I1q ex Rinodina olivaceo
I1r ex Buellia papillata
I1s ex Physcia caesia

I2a ex Flavoparmelia caperata AJ249568

I2d ex Physcia tribacia2

I2b ex Physcia cf. millegrana1
I2c ex Flavoparmelia TF $86.108 \mathrm{~B} 2$

I3a ex Phaeophyscia endophoenice

I3b ex Phaeophyscia kairamoi

I4b ex Heterodermia leucomela

I4c ex Heterodermia boryi

14e ex Heterodermia con

49 ex Physcia lobulata

14h ex Heterodermia boryi

I4j ex Heterodermia flabellata

I5a ex Rinodina oxyda beginning of the ITS-1 region. The position of this insertion cannot be unambiguously identified since its flanking regions are not alignable with other taxa of this clade. This insertion consists of a repeated motif, which is 34 to $40 \mathrm{bp}$ long and repeated three (I2b, c), four (I2d) or five (I2a) times.

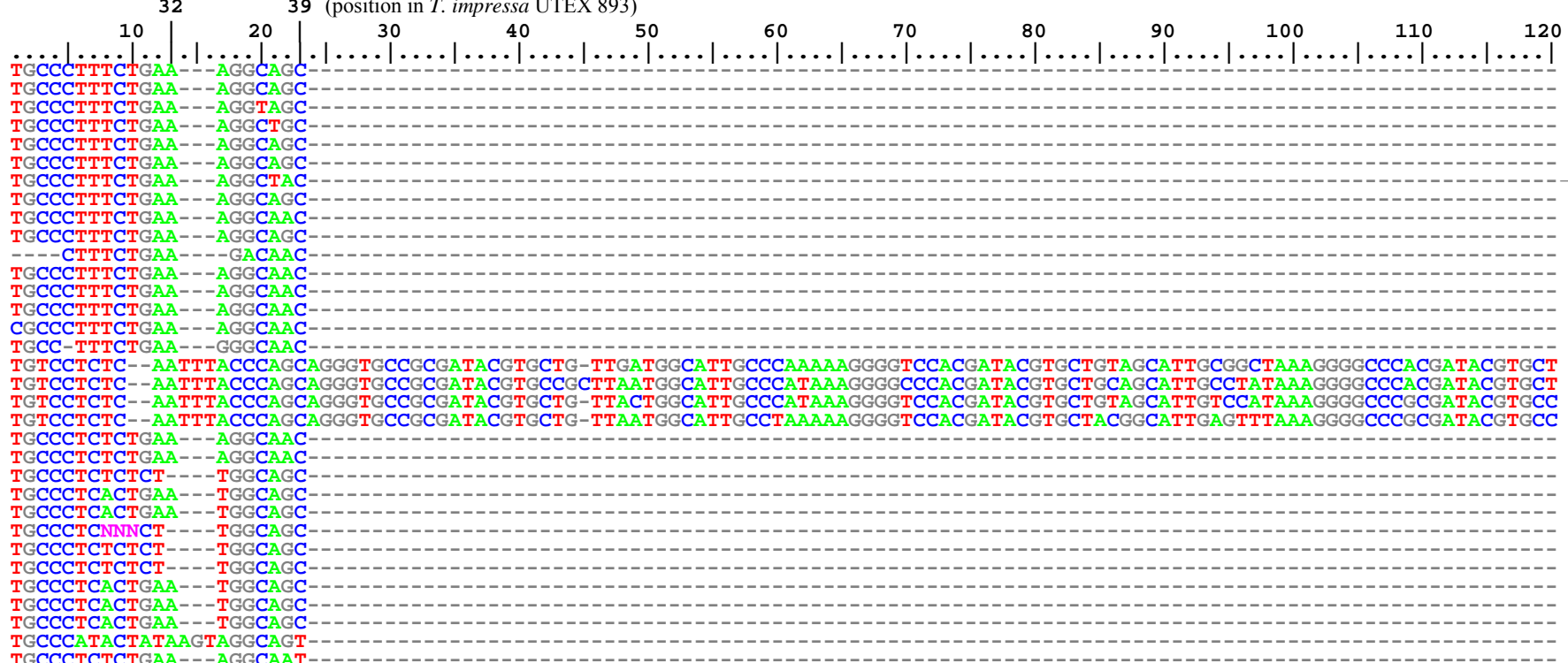

\begin{tabular}{|l|l|l|l|l|l|l|l|l|l|l|l|l|l|l|}
130 & 140 & 150 & 160 & 170 & 180 & 190 & 200 & 210 & 220 & 230 & 240
\end{tabular}

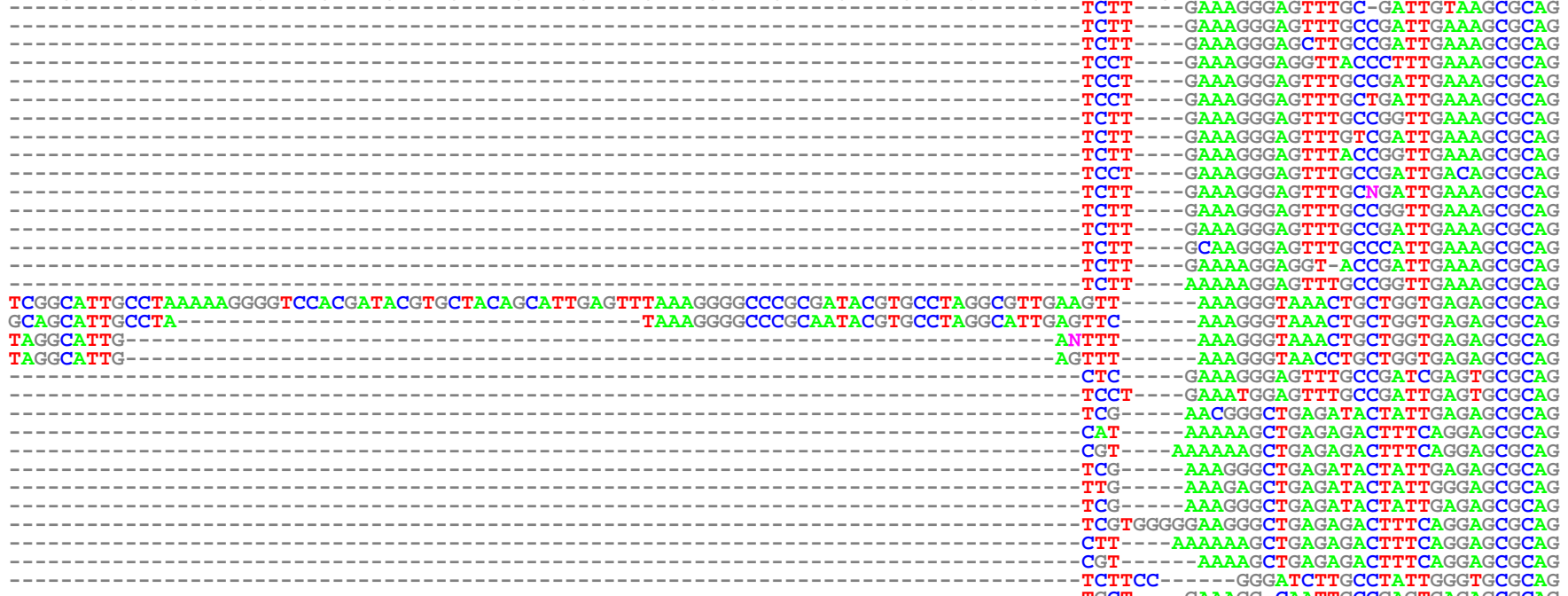




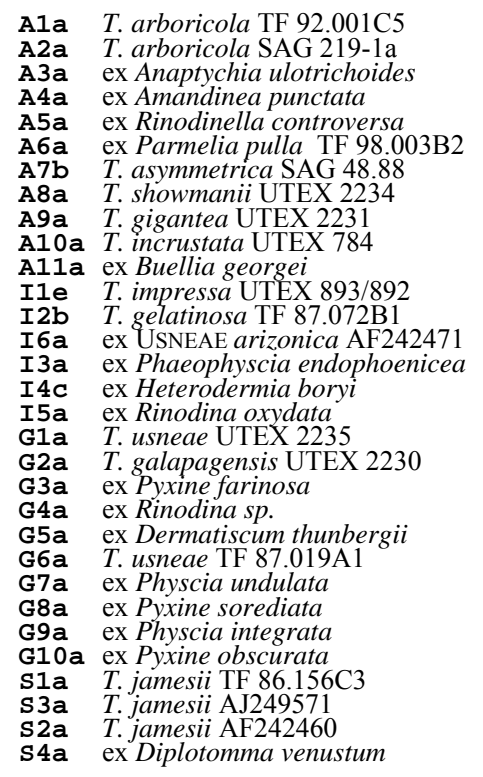

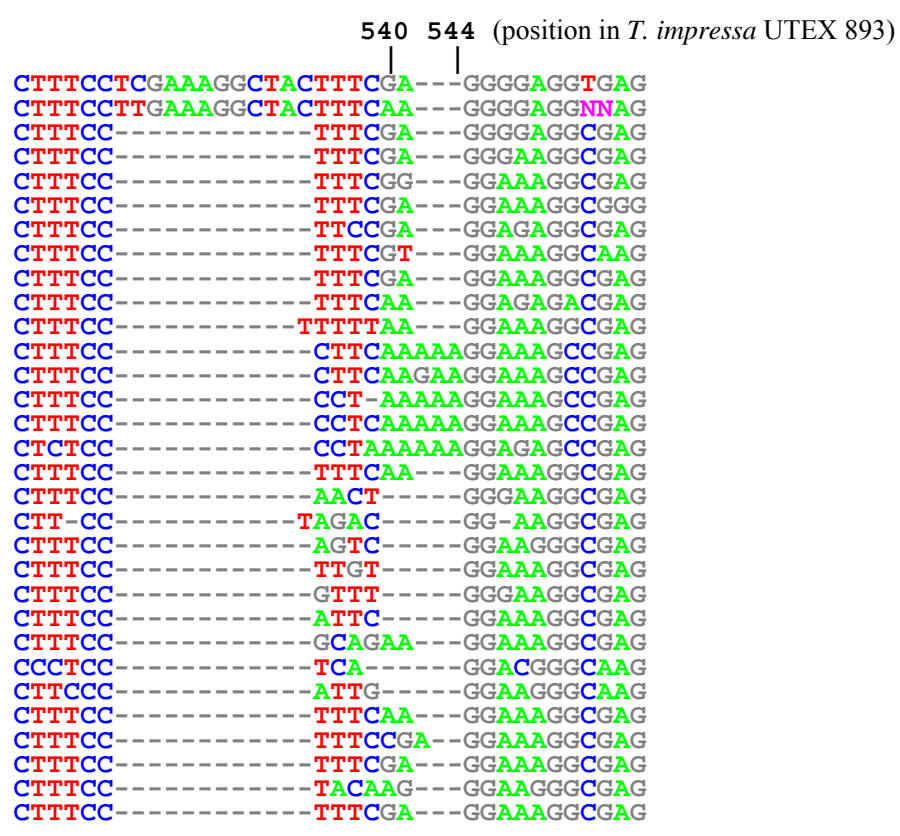

FIG. A.6: Segment of the Trebouxia nrITS 2 region. The alignment includes representatives of all subclades distinguished in this study. Except for subclade I5, all other subclades of clade I have a run of four to six adenosines corresponding to positions 540 to 544 of $T$. impressa UTEX 893.

$\begin{array}{ll}\text { A1a } & \text { T. arboricola TF 92.001C5 } \\ \text { A2a } & \text { T. arboricola SAG 219-1a } \\ \text { A3a } & \text { ex Anaptychia ulotrichoides } \\ \text { A4a } & \text { ex Amandinea punctata } \\ \text { A5a } & \text { ex Rinodinella controversa } \\ \text { A6a } & \text { ex Parmelia pulla TF 98.003B2 } \\ \text { A7b } & \text { T. asymmetrica SAG 48.88 } \\ \text { A8a } & \text { T. showmanii UTEX 2234 } \\ \text { A9a } & \text { T. gigantea UTEX 2231 } \\ \text { A10a } & \text { T. incrustata UTEX 784 } \\ \text { A11a } & \text { ex Buellia georgei } \\ \text { I6a } & \text { ex Usnea arizonica AF242471 } \\ \text { I1e } & \text { T. impressa UTEX 893/892 } \\ \text { I2b } & \text { T. gelatinosa TF 87.072B1 } \\ \text { I3a } & \text { ex Phaeophyscia endophoenicea } \\ \text { I4c } & \text { ex Heterodermia boryi } \\ \text { I5a } & \text { ex Rinodina oxydata } \\ \text { S1a } & \text { ex Parmelia saxatilis TF } 86.156 \mathrm{C} 3 \\ \text { S3a } & \text { T. simplex TW-1A2 } \\ \text { S2a } & \text { ex Letharia gracilis AF242460 } \\ \text { S4a } & \text { ex Diplotomma venustum } \\ \text { G1a } & \text { T. usneae UTEX 2235 } \\ \text { G2a } & \text { T. galapagensis UTEX } 2230 \\ \text { G3a } & \text { ex Pyxine farinosa } \\ \text { G4a } & \text { ex Rinodina sp. } \\ \text { G10a } & \text { ex Pyxine obscurata } \\ \text { G6a } & \text { T. usneae TF 87.019A1 } \\ \text { G5a } & \text { ex Dermatiscum thunbergii } \\ \text { G7a } & \text { ex Physcia undulata } \\ \text { G8a } & \text { ex Pyxine sorediata } \\ \text { G9a } & \text { ex Physcia integrata }\end{array}$

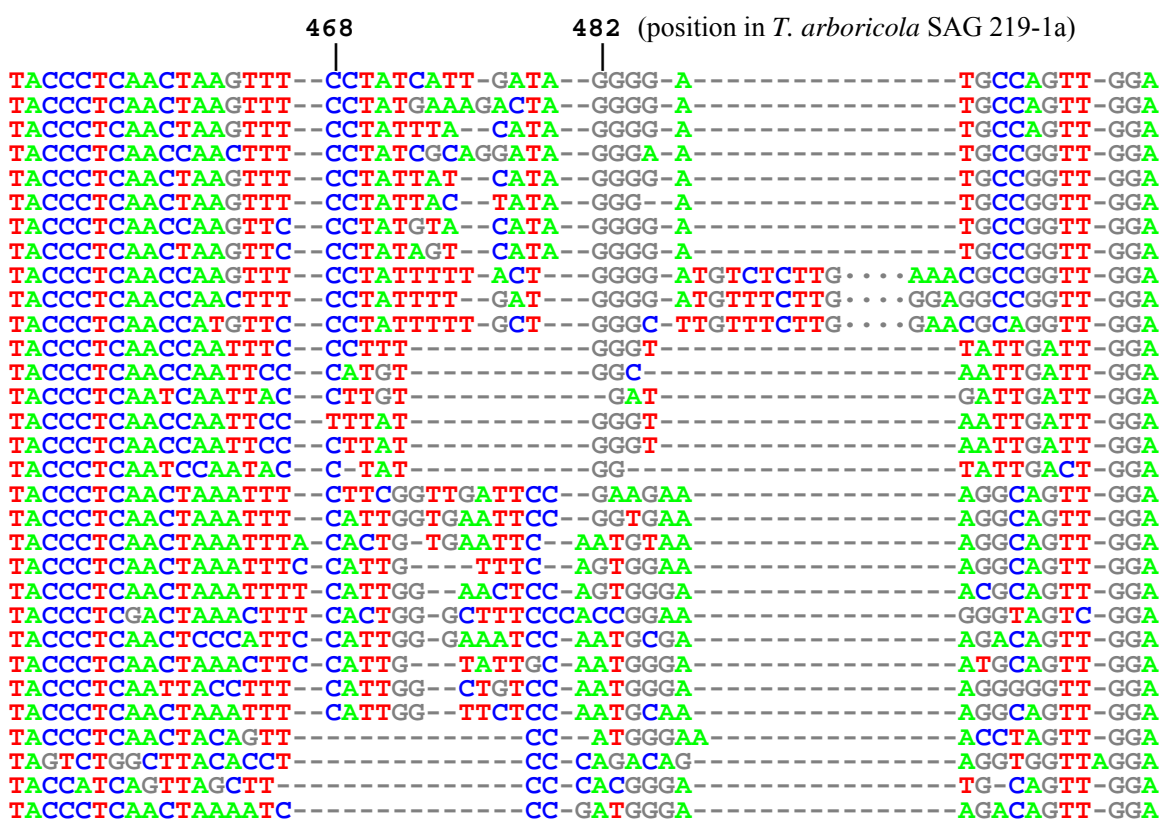

FIG. A.7: Segment of the Trebouxia nrITS 2 region. The alignment includes representatives of all subclades distinguished in this study. A closer relation between clades $\mathrm{G}$ and $\mathrm{S}$ is supported by similarities in a highly variable domain between positions 468 - 482 of T. arboricola SAG 219-1a. All members of clade S as well as subclades G1G4, G6, and G10 have a region in common that is different or absent in all other Trebouxia subclades. This may support a single origin of clades $\mathrm{S}$ and $\mathrm{G}$ if two independent losses of this sequence segment in clade $\mathrm{G}$ were assumed, once in subclade G5 and once in the common ancestor of subclades G7 - G9 (see Fig. 4.9). Dots in sequence A9a, A10a, and A11a indicate sequence insertions shown in FIG. A.4. 


\section{A.3 PAUP}

The program PAUP works with files that are written in the NEXUS format. The NEXUS format is organized in blocks. The TAXA-, CHARACTERS- (these two blocks may be linked in a DATA block), ASSUMPTIONS-, SET-, TREES-, CODON-, and DISTANCE blocks are normally placed in input files (i.e. together with the alignment). Commands available in the PAUP block can be used to specify tree searches. These commands can be written in batch files, facilitating tree search. Within most commands various options are available that allow a refined phylogenetic analysis. The order of commands needs to be in an appropriate order. The order of options assigned to a command is arbitrary. Each command begins with a command-name and ends with a semicolon. Otherwise, the commands are completely free-format. A command may span any number of lines (returns) and whitespace (tabs and blanks) may be inserted will. Anything enclosed in square brackets is ignored when executing the runfile. Square brackets may be nested. Input of PAUP commands is case-insensitive, so command names, option keywords, etc. may be entered in any combination of upper- and lower-case characters (the only exception pertains to the MATRIX command). In addition, PAUP allows abbreviation of command names and keywords to the shortest unambiguous truncation. Note that other NEXUSconforming programs may not accept these abbreviations (David L. Swofford, Beta Documentation Cmd_ref_v2.pdf). For a better understanding, the runfile shown below is annotated with explanations available in the PAUP manual (David L. Swofford, Beta Documentation Cmd_ref_v2.pdf). For all tree searches conducted with PAUP in the course of this study the following DATA block and runfile (PAUP block) was used. Commands are capitalized and in bold, options are only capitalized. This routine can be obtained from the author and used as is, when saved in text format.

\section{A.3.1 The DATA block:}

\#NEXUS

BEGIN DATA;

DIMENSIONS

NTAX $=X$

NCHAR $=Y$;

\section{FORMAT}

DATATYPE $=$ DNA

INTERLEAVE

MISSING $=\mathrm{N}$

$\mathrm{GAP}=-$;

\section{MATRIX}

taxon_1 ACGT.....

taxon 2 ACCT.....

taxon_3 ACCC..... ;

END； [specifies the NEXUS format]

[The DATA block contains the data matrix and other associated information. All options of the TAXA and CHARACTERS blocks are permitted under the DATA block.]

[The DIMENSIONS command specifies the size of the data matrix.]

[number of taxa]

[number of characters]

[The FORMAT command is used to specify information pertaining to the format of the data file.]

[This subcommand specifies the class of data. If present, it must be the first subcommand in the FORMAT command.]

[specifies that the data matrix is written in interleaved format (in contrast to the sequential format)]

[ $\mathrm{N}$ is specified to represent missing data. If MISSING is not specified, it defaults to '?'.]

[Assigns the hyphen as the gap character. Whitespace is illegal as a MISSING DATA or GAP symbol, as are the following: ( ) [] \{\}$\left./ \backslash, ;:=*^{\prime} "^{\prime}<>^{\wedge} \quad\right]$

[In its standard format, the MATRIX command contains a sequence of taxon names, each] [followed by a space and sequence. Taxon names must not include blanks, hyphens or any of] [the following: ( ) [] \{\}$/ \backslash, ;: *^{\prime} "^{\prime}<>\wedge$. The matrix itself may appear in a variety of forms.]

[terminates the DATA block] 
A.3.2 The PAUP block:

\#NEXUS

$[C D$

C: \path\folder; ]

LOG

FILE = Alignment_name_NJJC.log

START = YES

REPLACE = YES;

FACTORY;

[ \#\#\# replace: Alignment_name

$\begin{array}{lll}\# \# \# & \text { replace: } & {[\mathrm{NJ}] 1000} \\ \# \# \# \text { replace: } & {[\mathrm{MP}] 1000} \\ \# \# \# \text { replace: } & {[\mathrm{ML}] 100}\end{array}$

]

OUTGROUP taxon taxa IONLY;

SET

$\begin{array}{ll}\text { INCREASE } & =\text { AUTO } \\ \text { ROOT } & =\text { OUTGROUP } \\ \text { OUTROOT } & =\text { MONOPHYL; }\end{array}$

$[* *$ doing NJJC $* * *]$

SET

CRITERION = DISTANCE;

DSET

DISTANCE $\quad=\mathrm{JC}$

OBJECTIVE = ME

SUBST $\quad=A L L$

NEGBRLEN = SETZERO;

NJ

$\begin{array}{ll}\text { SHOWTREE } & =\text { NO } \\ \text { BREAKTIES } & =\text { RANDOM; }\end{array}$

SAVETREES

FILE = Alignment_name_NJJC.tre

BRLENS $=$ YES

ROOT $=$ NO

REPLACE = YES; [specifies the NEXUS format]

[specifies the directory to which files are saved]

[saves output to the specified file]

[logging to the specified file is initiated]

[A preexisting file with this name is replaced without warning]

[restores default settings. There is a bug report for this function, however, it is believed that this bug does not affect this routine]

Ten files are generated by this routine. Use the editor's replacement function to replace preexisting alignment names with the current one

You may adjust the number of bootstrap replicates for each phylogenetic method separately with the editor's replace function ML bootstrapping requires extensive computing time and may be excluded by parenthesizing the respective commands. Support values based on the ML criterion might be obtained in Bayesian analyses.

[transfers specified taxa to the outgroup]

[no other taxa than those specified are kept as outgroup]

[The SET command is used to set a variety of options whose scope extends beyond single commands.]

[When maximal number of trees that can be stored is reached during a search, this setting allows the automatic increase of this limit.]

[The ROOT option is used to specify how unrooted trees are to be rooted prior to output]

[Shows the outgroup monophyletic to the ingroup]

[NJ = neighbor-joining, $\mathrm{JC}=$ Jukes-Cantor model of evolution $]$

[Sets the optimality criterion to distance]

[Under the DSET command options for distance analysis can be set] [Sets the model of evolution to the Jukes-Cantor model] [Sets minimum evolution (ME) as the objective function] [counts or estimates substitutions of all types (default)]

[Negative branch lengths are allowed but set to zero when computing the value of the objective function (default)]

[ The NJ command specifies neighbor-joining method]

[Trees are not output to the display buffer]

[ties encountered during tree construction are broken randomly and not according to the input order of the taxa]

[saves trees currently in memory to the specified file]

[saves branch lengths]

[roots trees using the rooting options currently in effect before they are saved]

[A preexisting file with this name is replaced without warning] 


\section{BOOTSTRAP}

$\begin{array}{ll}\text { NREPS } & =[\mathrm{NJ}] 1000 \\ \text { CUTOFFPCT } & =0 \\ \text { KEEPALL } & =\text { YES } \\ & \\ \text { SEARCH } & =\mathrm{NJ} ;\end{array}$

\section{SAVETREES}

FILE = Alignment_name_NJJCboo.tre

FROM $=1$ TO $=1$

$\begin{array}{ll}\text { SAVEBOOTP } & =\text { NODELABELS } \\ \text { MAXDECIMALS } & =\odot \\ \text { ROOT } & =\text { YES } \\ \text { REPLACE } & =\text { YES }\end{array}$

LOG STOP;

$[* *$ doing MPn $* * *]$

LOG

FILE = Alignment_name_MPn.log

START = YES REPLACE = YES;

\section{SET}

CRITERION = PARSIMONY

MAXTREES $=10000$

increase $=\mathrm{NO}$;

\section{PSET GAPMODE = NEWSTATE;}

\section{HSEARCH}

START = STEPWISE

ADDSEQ $=$ RANDOM

NREPS $=100$

SWAP $=$ TBR

STATUS $=$ NO;
[Bootstrap analysis is initiated]

[specifies the number of bootstrap replicates, see headlines]

[specify the minimum bootstrap partition frequency to be displayed in the partition frequency table. Partitions occurring at a frequency below this value are not shown]

[Groups occurring at frequencies less than CONLEVEL will also be retained in the bootstrap consensus as long as they are compatible with all groups that are already included in the consensus. Effectively, this forces CONLEVEL $=50$, which is also the default value]

[uses the NJ method for tree calculation from each bootstrap replicate]

[Saves Bootstrap consensus tree to the specified file] [due to a bug in the program the tree number of the bootstrap consensus tree has to be specified]

[Saves bootstrap proportions as internal node labels] [rounds bootstrap proportions to integer values] [see above]

[see above]

[stops saving output to file]

$[\mathrm{MPn}=\mathrm{MP}$ with gap characters treated as fifth character state $]$

[see above]

[Sets the optimality criterion to parsimony]

[limits the maximum number of trees kept in memory to 10000] [prevents MAXTREES to be increased automatically, this mode is chosen because of the endless number of trees that can be generated when almost identical sequences are included in the alignment, which would require extensive computing time]

[treats gap characters as a fifth base. This option is only available under the parsimony optimality criterion in PAUP version $4.0 \mathrm{~b} 10]$

[employs heuristic algorithms for tree search] [sequences are added stepwise to obtain the] [the order of added sequences is random] [Specifies the number of random-addition-sequence replications to be performed for finding the starting tree for branch swapping]

[Specifies the algorithm used by branch-swapping (=default)] [number of trees examined is not output to a status window ]

SAVETREES

FILE = Alignment_name_MPn.tre

[see above]

ROOT $=$ YES BRLENS $=$ YES REPLACE = YES; 
PSCORES

$\begin{array}{ll}\mathrm{CI} & =\text { YES } \\ \mathrm{RI} & =\mathrm{YES} \\ \mathrm{RC} & =\mathrm{YES} \\ \mathrm{HI} & =\text { YES }\end{array}$

$[* *$ doing WMPn ***]

REWEIGHT

INDEX $=\mathrm{RC}$

BASEWT $=1000$

FIT = MEAN;

HSEARCH

START = STEPWISE

ADDSEQ $=$ RANDOM

NREPS $=100$

SWAP $=$ TBR

STATUS $=$ NO; [requests a listing of tree lengths and/or fit measures for one or more trees]

[consistency index]

[retention index]

[rescaled consistency index]

[homoplasy indices]

[wMPn $=$ weighted MP with gap characters treated as fifth character state $]$

[Use the REWEIGHT command to assign weights to the characters based on their fit to the trees currently in memory]

[Specifies the fit measure to use when calculating the new character weights $(\mathrm{RC}=$ rescaled consistency index $(=$ default $)]$

[Specifies the maximum possible weight that a character can be assigned, corresponding to an index. Weights are scaled from 0 to this value]

[Specify whether the new weights are based on the mean of the fit values for each character over all of the trees in memory]

[The same heuristic search is executed as the previous one except that alignment positions are weighted]

\section{SAVETREES}

[see above]

FILE = Alignment_name_wMPn.tre

ROOT $=$ YES BRLENS $=$ YES REPLACE = YES;

PSCORES/

$\mathrm{CI} \quad=$ YES

[see above]

RI = YES

RC $=$ YES

$\mathrm{HI} \quad=$ YES;

$\left[{ }^{* *}\right.$ doing WMPn bootstrapping $\left.{ }^{* * *}\right]$ [bootstrapping is based on current settings, which are weighted parsimony and gaps treated as fifth character state]

SET

MAXTREES $=100 \quad$ increase $=$ no; $\quad$ [see above $]$

BOOTSTRAP

$=[\mathrm{MP}] 1000$

[see above]

CUTOFFPCT

KEEPALL

$=0$

SEARCH

= HEURISTIC;

\section{SAVETREES}

FILE

$=A 1$

FROM $=1 \quad$ TO $=1$

SAVEBOOTP $=$ NODELABELS

MAXDECIMALS $=0$

ROOT $=$ YES

REPLACE $\quad=$ YES; 
SET

MAXTREES $=100$

INCREASE = AUTO;

\section{PSET}

GAPMODE

= MISSING;

LOG STOP; [resets the autoincrease function]

[resets gap characters as missing data]

[see above]

$[* *$ doing MLNJ ***] $\quad[\mathrm{MLNJ}=\mathrm{ML}$ with ML scores as estimated by ModelTest and starting tree search with a NJ tree]

LOG

FILE = Alignment_name_ML.log

START = YES REPLACE = YES;

SET

CRITERION = LIKELIHOOD;

\section{LSET}

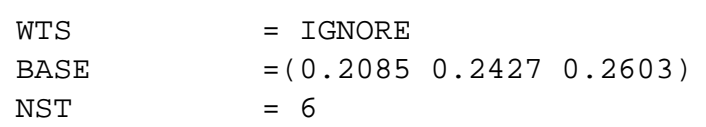

RMAT $=(1.2330$

$\begin{array}{ll}\text { RATES } & =\text { GAMMA } \\ \text { SHAPE } & =0.3516\end{array}$

NCAT $\quad=4$

PINVAR $=0 ;$

\section{HSEARCH}

START $=\mathrm{NJ}$

SWAP $=$ TBR

STATUS $=$ NO;

[see above]

[Sets the optimality criterion to maximum-likelihood]

[Sets options for maximum likelihood analysis. All options specified here can be approximated by ModelTest]

[Ignores the weights calculated during the MP tree search (if in doubt]

[Explicitly specifies base frequencies (frqA frqC frqG)]

[Specifies the number of substitution types]

) [Specifies the values for a six-parameter instantaneous rate matrix if NST $=6$ ]

[Uses a gamma distribution to compensate for among site rate variation] [specifies the $\alpha$ - (or shape-) parameter of the gamma distribution, which determines the shape of the gamma distribution.]

[Specifies the number of categories to divide the discrete approximation of the gamma distribution. This value is not provided by ModelTest but the given setting (4) corresponds to the default setting of PAUP] [specify the proportion of sites unable to accept substitutions; the remaining sites are assumed to vary at the same rate]

[Starts the heuristic search with a NJ-tree]

[see above]

[see above]

[see above]

FILE = Alignment_name_MLNJ.tre
ROOT $=$ YES BRLENS $=$ YES REPLACE = YES;

$$
\begin{array}{ll}
\text { NREPS } & =[M L] 100 \\
\text { CUTOFFPCT } & =0 \\
\text { KEEPALL } & =\text { YES } \\
\text { SEARCH } & =\text { HEURISTIC; }
\end{array}
$$

\section{SAVETREES}
FILE = Alignment_name_MLboo.tre FROM $=1$ TO $=1$ SAVEBOOTP $=$ NODELABELS
MAXDECIMALS $=0$
ROOT $=$ YES
REPLACE $\quad=$ YES;

LOG STOP; [see above]

[see above]

[see above] 


\section{A.4 MrBayes}

The program MrBayes reads the NEXUS format. Therefore, data can be entered with the DATA block described above. The command block for MrBayes is written just below the DATA block. Annotations for each command and option are taken from the program's manual.

\section{A.4.1 The MrBayes command block:}

BEGIN MRBAYES;

\section{SET}

AUTOCLOSE = YES

NOWARNINGS = YES;

OUTGROUP 1;

$\begin{array}{ll}\text { LSET } & =6 \\ \text { NST } & =\text { GAMMA } \\ \text { RATES } & \\ \text { NGAMMACAT } & =6 ;\end{array}$

MCMC

$\begin{array}{ll}\text { NGEN } & =1000000 \\ \text { PRINTFREQ } & =50 \odot \\ \text { SAMPLEFREQ } & =50 \\ \text { NCHAINS } & =4 \\ \text { STARTINGTREE } & =\text { RANDOM } \\ \text { SAVEBRLENS } & =\text { YES; }\end{array}$

[starts the MrBayes block]

[Sets run conditions and defines active data partition]

[The program will not prompt you during the course of executing the file.]

[If nowarnings is set to yes, then the program will not prompt you when overwriting an output file that is already present.]

[This command assigns the first taxon of the DATA block to the outgroup. Only a single taxon can be assigned to be the outgroup.]

[Sets the parameters of the likelihood model]

[Sets the number of substitution types. "6" allows all rates to be different, subject to the constraint of time-reversibility (e.g., a GTR model).]

[Sets the model for among-site rate variation. Gamma specifies Gamma- distributed rates across sites. The rate at a site is drawn from a gamma distribution. The gamma distribution has a single parameter that describes how much rates vary.]

[Sets the number of rate categories for the gamma distribution. The gamma distribution is continuous. However, it is virtually impossible to calculate likelihoods under the continuous gamma distribution. Hence, an approximation to the continuous gamma is used; the gamma distribution is broken into ncat categories of equal weight ( $1 /$ ncat). The mean rate for each category represents the rate for the entire category. This option allows you to specify how many rate categories to use when approximating the gamma.]

[This command starts the Markov chain Monte Carlo (MCMC) analysis. The posterior probability of phylogenetic trees (and other parameters of the substitution model) cannot be determined analytically. Instead, MCMC is used to approximate the posterior probabilities of trees by drawing (dependent) samples from the posterior distribution. This program can implement a variant of MCMC called "Metropolis-coupled Markov chain Monte Carlo", or MCMCMC for short. Basically, "Nchains" are run, with Nchains - 1 of them heated. The chains are labeled $1,2, \ldots$, Nchains. The heat that is applied to the $\mathrm{i}$-th chain is $\mathrm{B}=1 /(1+$ temp $\mathrm{X}$ i). $\mathrm{B}$ is the power to which the posterior probability is raised. When $\mathrm{B}=0$, all trees have equal probability and the chain freely visits trees. $\mathrm{B}=1$ is the "cold" chain (or the distribution of interest). MCMCMC can mix better than ordinary MCMC; after all of the chains have gone through one cycle, two chains are chosen at random and an attempt is made to swap the states (with the probability of a swap being determined by the Metropolis et al. equation). This allows the chain to potentially jump a valley in a single bound.]

[This option sets the number of cycles for the MCMC algorithm. This should be a big number as you want the chain to first reach stationarity, and then remain there for enough time to take lots of samples.]

[This specifies how often information about the chain is printed to the screen.]

[This specifies how often the Markov chain is sampled. You can sample the chain every cycle, but this results in very large output files. Thinning the chain is a way of making these files smaller and making the samples more independent. ]

[Specifies how many chains are run for the MCMCMC variant.]

[The starting tree for the chain can either be randomly selected or user-defined. It might be a good idea to start from randomly chosen trees; convergence seems likely if independently run chains, each of which started from different random trees, converge to the same answer.] [This specifies whether branch length information is saved with the trees.] 
SUMT

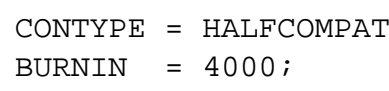

END;

QUIT;
[This command summarizes the trees in a file named "<filename $>$ ". All of the trees are read from the file and the proportion of the time any single taxon bipartition is found is counted. The proportion of the time that the bipartition is found is an approximation of the posterior probability of the bipartition. (Remember that a taxon bipartition is defined by removing a branch on the tree, dividing the tree into those taxa to the left and right of the removed branch. This set is called a taxon bipartition.) The branch length of the bipartition is also recorded. The result is a list of the taxon bipartitions found, the frequency with which they were found, the posterior probability of the bipartition and, if the branch lengths were recorded, the mean and variance of the length of the branch. ]

[creates a consensus tree equivalent to a $50 \%$ Majority rule consensus tree]

[Specifies the number of initial, saved trees that are ignored when calculating the consensus tree. It may take a while for the chain to reach stationarity. Samples taken when the chain is not at stationarity (the early phase of the chain) should be discarded. The default is 0 , but you may want to discard those trees that were sampled while the chain was not at stationarity.]

[Denotes end of a block in file]

[Quits the program]

\section{The MrBayes command block without annotations:}

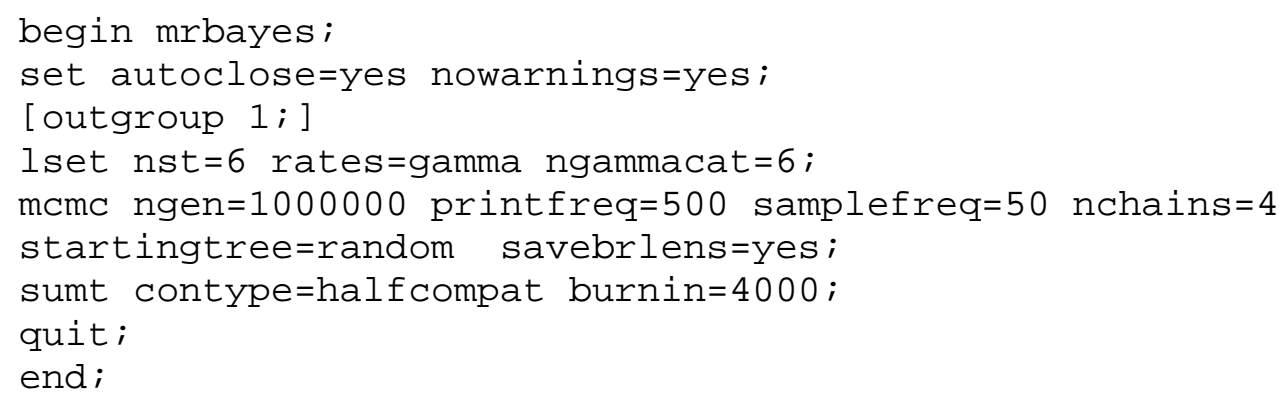




\section{Acknowledgements}

First of all, I'd like to express my gratitude to Prof. T. Friedl and Prof. G. Rambold, who initiated this project. Further, especial acknowledgement is due to Prof. T. Friedl who provided supreme lab facilities without which this work could not have succeeded as far as it did. Many thanks are also due for his invitation to access his collection of literature.

For an initial introduction to lichenes, I am much indepted to Patrick Dornes, who most patiently shared his competence and enthusiasm about lichens with me and certainly provided a valuable stimulus to me. Special thanks are due to PD H. Mayrhofer, who wisely selected Physciaceae species of particular interest. Also his recommendations for initial readings on Physciaceae are heartily appreciated.

I am grateful to Patrick Dornes, Anders Nordin and the herbarium curators Walter Obermayer, Harrie Sipman and Dagmar Triebel for providing valuable sample vouchers and helping in sample determination. Many thanks to Virginia Souza-Egypsi, Alfredo Espinosa and Patrick Dornes for excellent guidance on various excursions where fresh material had been collected.

Thanks are due to Andreas Beck, who gave an initial introduction to DNA extraction and PCR amplification. I would like to thank Elke Zufall-Roth for excellent assistance in the lab as well as Dominik Hepperle and Frank Kauff for valuable advice in phylogenetic analyses. Thanks are due to Jana Fredersdorf, Claudia Kamcke, Thomas Lehmann und Boris Rewald for their cooperation in the student lab 2001 in which numerous seqeunce data had been generated.

I'm especially indepted to Prof. T. Friedl for an extensive review of the complete manuscript of this thesis. Without his comments many of the results and much of the discussion wouldn't have been presented as pointed and structured. I further would like to thank Helmut Mayrhofer, David Hewitt, Toby Spribille, Jochen Heinrichs, Maren Huck and Patrick Dornes for helpful comments on various parts of the manuscript.

Many thanks are due to Prof. D. Bhattacharya (Iowa, USA) for his invitation to his lab to work on secondary structure and self-splicing activity in group I introns in Oct. 1999 and Prof. F. Lutzoni for his invitation to continue the work on introns at his fabulous lab at Duke University (Durham NC, USA) Oct. - Dec. 2002. Thanks are due to the Universitätsbund Göttingen, who financially supported visits to various conferences.

Special thanks to the EPSAG crew (Elke Zufall-Roth, Ilse Kunkel, Marlis Heinemann, Dr. D. Mende and all the others) for the friendly atmosphere which made lab work so much more enjoyable. Special thanks are expressed to Dr. D. Mende for his patience and competence in maintainig computers and software.

Last not least I thank my parents for their extensive support throughout the years. 


\section{Erklärung}

Hiermit erkläre ich, daß ich die Arbeit selbständig verfaßt und keine anderen als die von mir angegebenen Quellen und Hilfsmittel benutzt habe. Ferner erkläre ich, daß ich nicht anderweitig mit oder ohne Erfolg versuche t habe, eine Dissertation einzureichen oder mich der Doktorprüfung zu unterziehen.

Göttingen, 


\section{Lebenslauf}

Name:

Gert Helms

Adresse:

Lange Str. 29

Geburtstag:

27.05 .1968

Geburtsort:

Tübingen

Nationalität:

deutsch

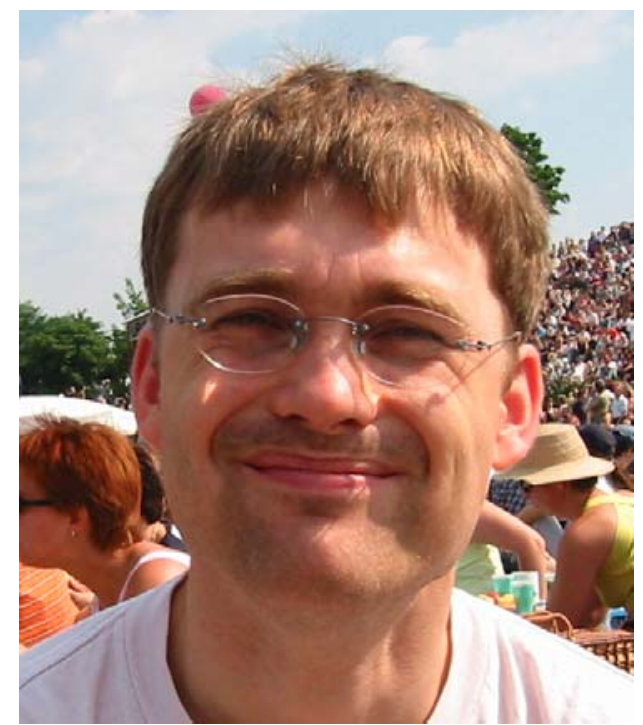

Bildung: $\quad$ Gymnasium Mainz-Gons. $\quad 1978$ - 1987

Abitur

23.06.1987

Zivildienst: $\quad$ Rettungshelfer in Würzburg $01.10 .1987-31.05 .1989$

Studium:

Biologie in Kaiserslautern Okt.1989 - Feb. 1996

Diplom

29.02 .1996

Beginn der Promotion an der Universität Göttingen: 1.4.1999

Voraussichtliches Ende der Promotion: 7.11.2003 